Florida International University FIU Digital Commons

$4-1-2011$

\title{
Managing for Resilience: Practical Applications of Marine Science to Improve Natural Resource Management: A Case Study in the Puerto Morelos Marine Protected Area
}

Mark Ladd

Florida International University, mladd001@fiu.edu

DOI: $10.25148 /$ etd.FI1 1050603

Follow this and additional works at: https://digitalcommons.fiu.edu/etd

\section{Recommended Citation}

Ladd, Mark, "Managing for Resilience: Practical Applications of Marine Science to Improve Natural Resource Management: A Case Study in the Puerto Morelos Marine Protected Area" (2011). FIU Electronic Theses and Dissertations. 388.

https://digitalcommons.fiu.edu/etd/388 


\title{
FLORIDA INTERNATIONAL UNIVERSITY \\ Miami, Florida
}

\begin{abstract}
MANAGING FOR RESILIENCE: PRACTICAL APPLICATIONS OF MARINE
SCIENCE TO IMPROVE NATURAL RESOURCE MANAGEMENT: A CASE STUDY IN THE PUERTO MORELOS MARINE PROTECTED AREA IN THE

MEXICAN CARIBBEAN
\end{abstract}

A thesis submitted in partial fulfillment of the

requirements for the degree of

MASTER OF SCIENCE

in

ENVIRONMENTAL STUDIES

by

Mark C. Ladd

2011 
To: Dean Kenneth G. Furton

College of Arts and Sciences

This thesis, written by Mark C. Ladd, and entitled Managing for Resilience: Practical Applications of Marine Science to Improve Natural Resource Management: A Case Study in the Puerto Morelos Marine Protected Area in the Mexican Caribbean, having been approved in respect to style and intellectual content, is referred to you for judgment.

We have read this thesis and recommend that it will be approved.

Joel Heinen

Deron Burkepile

\section{Ligia Collado-Vides, Major Professor}

Date of Defense: April 1, 2011

The thesis of Mark C. Ladd is approved.

\begin{tabular}{r}
\hline $\begin{array}{r}\text { Dean Kenneth G. Furton } \\
\text { College of Arts and Sciences }\end{array}$ \\
\hline Interim Dean Kevin O'Shea \\
University Graduate School
\end{tabular}

Florida International University, 2011 


\section{DEDICATION}

I dedicate this thesis to my family, beginning with my grandmother Ruth Ladd and the late Wayne Ladd, my mother, and my father, to whom I am eternally indebted for the love, support, and encouragement they have never stopped providing throughout my lifetime. The values and lessons that I learned growing up with your influences and following your examples have shaped the person that I am today. I would also like to dedicate this thesis to my sister and brother-in-law for their unwavering love and support that has allowed me to pursue my dreams and complete this project. Lastly, I would like to dedicate this thesis to my niece, Camile Erika de Souza Rodrigues, with the hope that coral reefs will persist long into the future so that she and her children can be as fortunate as I have been and experience their magic and beauty. 


\section{ACKNOWLEDGMENTS}

I wish to thank the members of my committee Dr. Heinen and Dr. Burkepile for their support and guidance throughout the course of my time at Florida International University. I would especially like to thank my principal advisor Dr. Ligia ColladoVides for opening my eyes to the world of marine protected areas, for her constant support and encouragement throughout the duration of this project, and for the invaluable lessons that I have learned from her over the past two years. I thank the Parque Nacional Arrecife de Puerto Morelos (PNAPM) and the Comisión Nacional de Areas Naturales Protegidas (CONANP) for their collaboration and support that made this project possible. I acknowledge the Department of Earth and Environment for providing me with a teaching assistantship during my time at FIU. I also thank Latin American Caribbean Center at FIU and the Tinker Foundation for travel funding and the Centro Regional de Investigación Pesquera (CRIP) for providing housing for my fieldwork during the summer. I would like to thank Paulette Johnson of FIU Statistical Consulting for her guidance and assistance in calculating the statistics for this research and the Seagrass Ecosystems Research Lab and Stable Isotope Laboratory at FIU for their assistance in sample processing. Lastly I would like to thank the Marine Macroalgae Research lab and all if its members for their support. 
ABSTRACT OF THE THESIS

MANAGING FOR RESILIENCE: PRACTICAL APPLICATIONS OF MARINE

SCIENCE TO IMPROVE NATURAL RESOURCE MANAGEMENT: A CASE

STUDY IN THE PUERTO MORELOS MARINE PROTECTED AREA IN THE

MEXICAN CARIBBEAN

by

Mark C. Ladd

Florida International University, 2011

Miami, Florida

Professor Ligia Collado-Vides, Major Professor

Coral reefs and the ecological, social, and economic benefits that they provide are seriously endangered by a colossal number of threats. This study was conducted in marine protected area (MPA) in the Mexican Caribbean. The purpose of this study was to provide results that can be directly applied by MPA managers to improve coral reef conservation and management. Characterization of four coral reef sites and stressors described in a proxy map were integrated into a comparative resilience assessment. Sites ranged from $16.5 \%$ to $3.5 \%$ coral cover and $47.5 \%$ to $12 \%$ macroalgal cover. Stressor distribution and intensity was highest near the Puerto Morelos town center and followed general water current patterns. Fishing, tourism, and pollution were identified as major stressors on which management can positively influence. The results of this study provide managers throughout the Caribbean a managerial tool chest to improve management efficacy and bolster conservation initiatives. 


\section{TABLE OF CONTENTS}

CHAPTER

PAGE

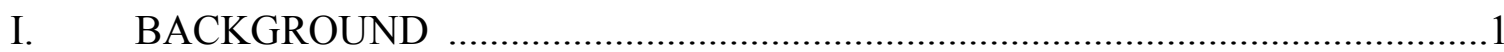

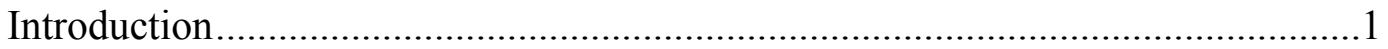

Study Site Description ...............................................................................6

II. ECOLOGICAL CHARACTERIZATION OF FIVE SITES WITHIN THE

PARQUE NACIONAL ARRECIFE DE PUERTO MORELOS ..........................11

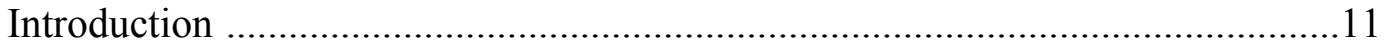

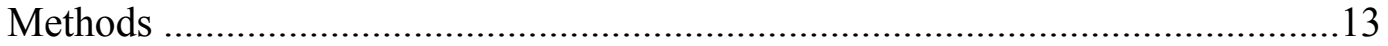

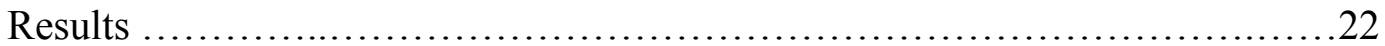

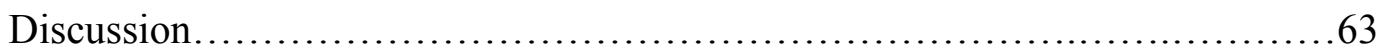

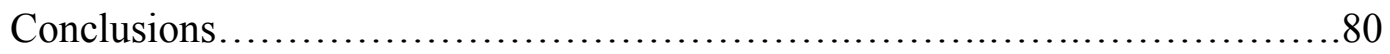

III. STRESSOR PROXY MAP

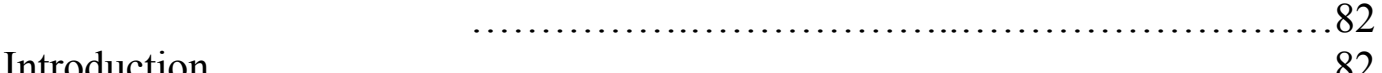

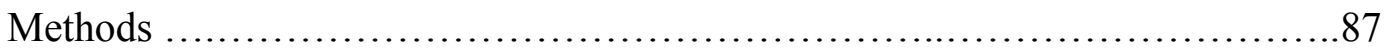

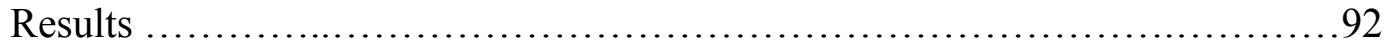

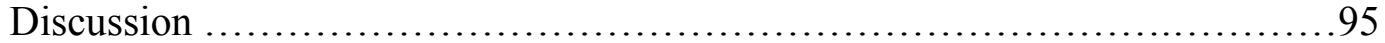

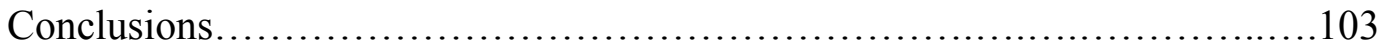

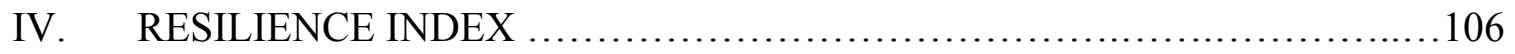

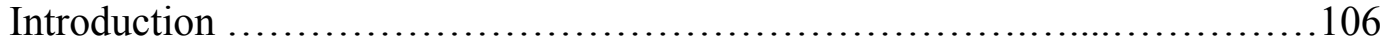

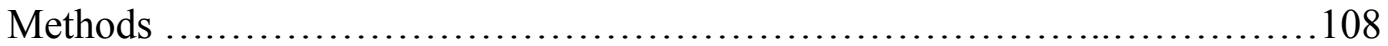

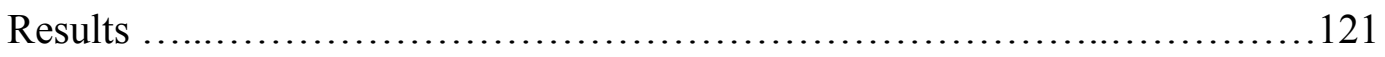

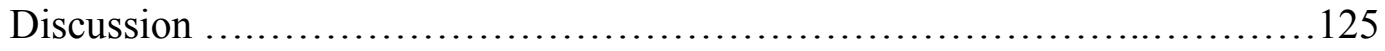

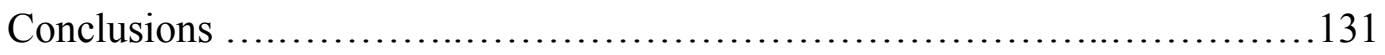

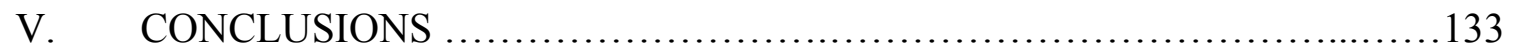

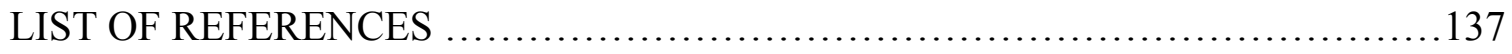

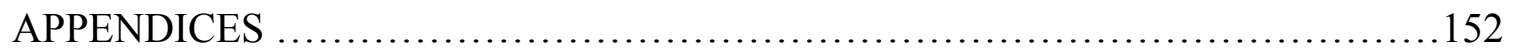




\section{LIST OF TABLES}

TABLE

PAGE

1. Definition of substrate categories utilized in benthic community transects ............... 17

2. Percent nutrient content results for macroalgae nutrient analyses in Limones............ 25

3. Total number $(\mathrm{N})$, density $\left(\right.$ per $\mathrm{m}^{2}$ ), and percentage of the total site population for the five most abundant fishes observed in Limones.............................................. 25

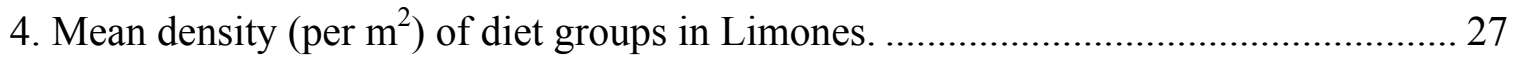

5. Mean density $\left(\right.$ per $\mathrm{m}^{2}$ ) of size classes within Limones.......................................... 28

6. Nutrient content results for macroalgae nutrient analyses in La Bonanza.................. 29

7. Total number $(\mathrm{N})$, density $\left(\right.$ per $\mathrm{m}^{2}$ ), and percentage of the total site population for the five most abundant fishes observed in La Bonanza...................................... 30

8. Mean percentage and density $\left(\right.$ per $\left.\mathrm{m}^{2}\right)$ of diet groups in La Bonanza........................ 31

9. Mean density $\left(\right.$ per $\mathrm{m}^{2}$ ) of size classes within La Bonanza....................................... 32

10. Percent nutrient content results for macroalgae nutrient analyses in Tanchacte....... 33

11. Total number $(\mathrm{N})$, density $\left(\right.$ per $\mathrm{m}^{2}$ ), and percentage of the total site population for the five most abundant fishes observed in Tanchacte............................................ 34

12. Mean percentage and density $\left(\right.$ per $\mathrm{m}^{2}$ ) of diet groups in Tanchacte.......................... 35

13. Mean percentage and density $\left(\right.$ per $\mathrm{m}^{2}$ ) of size classes within Tanchacte.................. 36

14. Percent nutrient content results for macroalgae nutrient analyses in Radio Pirata..... 36

15. Total number $(\mathrm{N})$, density $\left(\right.$ per $\mathrm{m}^{2}$ ), and percentage of total site population for the five most abundant fishes observed in Radio Pirata..

16. Mean density $\left(\right.$ per $\mathrm{m}^{2}$ ) of diet groups in Radio Pirata.. .......................................... 38

17. Mean density $\left(\right.$ per $\mathrm{m}^{2}$ ) of size classes within Radio Pirata..................................... 39

18. Percent nutrient content results for macroalgae nutrient analyses in Jardines........... 41 
19. Total number $(\mathrm{N})$, density $\left(\right.$ per $\mathrm{m}^{2}$ ), and percentage of total site population for the five most abundant fishes observed in Jardines.

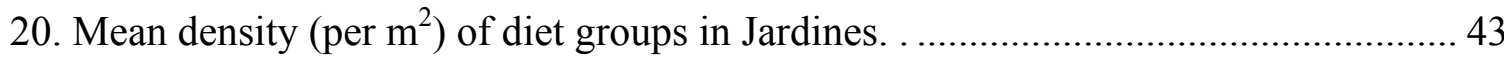

21. Mean density $\left(\right.$ per $\mathrm{m}^{2}$ ) of size classes within Jardines........................................... 44

22. Mean percent cover values for each substrate category by site............................. 45

23. ANOVA results for differences in percent cover of different substrate types........... 45

24. N:P, C:N, and C:P tissue nutrient content ratios by site................................... 51

25. Abundance and percentage of total for the five most common families of fishes

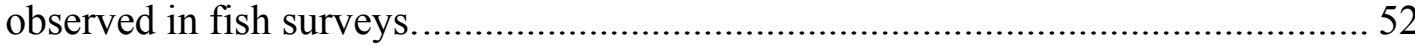

26. Abundance and percent of total for the ten most abundant species observed in belt transect surveys of PNAPM fish communities. ................................................... 52

27. Abundance of the five most abundant species by size category.............................. 53

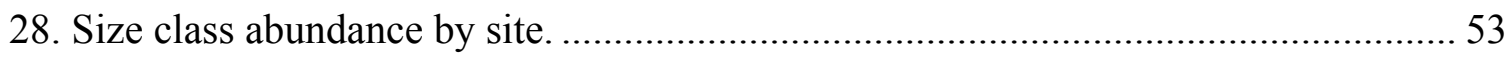

29. Percent of total site populations represented by each size class. ............................. 53

30. Kruskal-Wallis test of significance for differences in size class densities between sites.

31. MANOVA results for differences in the percent of fish in each size class relative to the total number of fish observed in each site.................................................. 57

32. Percent of site populations represented by each size class. ................................ 57

33. Kruskal-Wallis test of significance for differences in diet group densities between sites.

34. ANOVA test of significance for differences in diet group percentages between sites. .

35. Percent of site populations represented by each diet group. 61

36. Sample resilience score calculation results. 109

37. Resilience and resistance values for each coral species encountered with 
supporting references from which these values were derived.

112

\section{LIST OF FIGURES}

FIGURE

PAGE

1. Study site location within the Mexican Caribbean. .............................................. 7

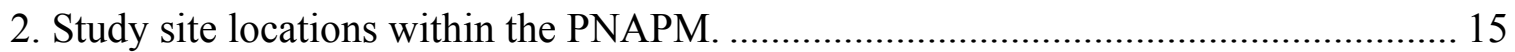

3. Mean percentage cover of substrate in Limones................................................ 24

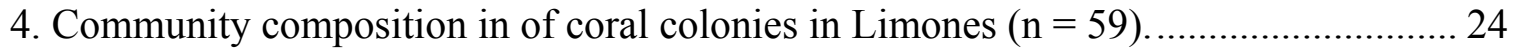

5. Percentage of fish population by diet group in Limones...................................... 26

6. Percentage of fish population by size class in Limones. ....................................... 27

7. Mean percentage cover of substrate in La Bonanza.. ........................................... 28

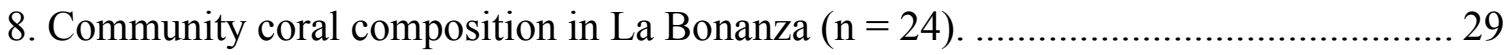

9. Percentage of fish population by diet group in La Bonanza.................................... 30

10. Percentage of fish population by size class in La Bonanza. ................................. 31

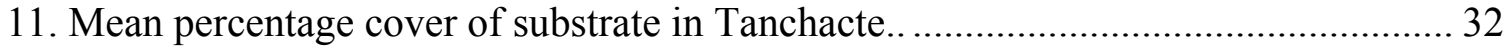

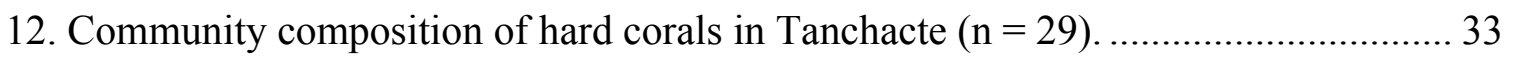

13. Percentage of fish population by diet group in Tanchacte...................................... 35

14. Percentage of fish population by size class in Tanchacte..................................... 36

15. Percentage of fish population by diet group in Radio Pirata. .................................. 38

16. Percentage of fish population by size class in Radio Pirata..................................... 39

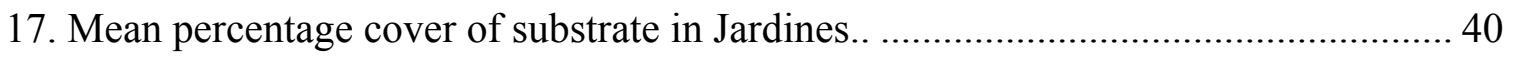

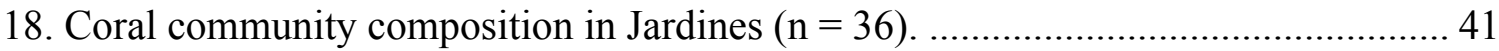

19. Percentage of fish population by diet group in Jardines...................................... 42

20. Percentage of fish population by size class in Jardines. ...................................... 43 
21. Mean coral colony size by site. 46

22. Mean percent of dead coral tissue and live coral tissue for all coral colonies surveyed by site.

23. Mean architectural index scores by site. No significant differences were detected.. 48

24. Mean rugosity scores by site. No significant differences were detected between sites.

25. Tissue phosphorous content results $(\% \mathrm{P})$ in Dictyota menstrualis/cervicornis complex.

26. Tissue nitrogen content results (\% N) in Dictyota menstrualis/cervicornis complex

27. Tissue carbon content results (\%C) in Dictyota menstrualis/cervicornis complex. 51

28. Overall fish community densities by site. 54

29. Size class densities by site. Significantly different values are denoted with different letters.

30. Diet group densities by site. 59

31. Diet group densities by site. 60

32. Mean total biomass by site 61

33. Mean herbivore biomass by site.. 62

34. Mean number of visitors per month by site. 63

35. Modified version of the Relative Dominance Model (RDM) proposed by Littler and Littler (2007)..

36. Mean $\delta^{15} \mathrm{~N}$ and $\% \mathrm{~N}$ values by site. 93

37. Resilience rankings (un-weighted and weighted) and scores for all resilience indicators for each study site using the original Maynard et al. (2010a) framework.

38. Management influence potential rankings based on the total score for each site for indicators identified as having the potential to be influenced by management activities based on the original Maynard et al. (2010a) framework. 
39. Resilience rankings (un-weighted and weighted) and scores for all resilience indicators for each study site using the refined index (from this study)................. 124

40. Management influence potential rankings based on the total score for each site for indicators identified as having the potential to be influenced by management activities based on the refined index. 


\section{CHAPTER I - BACKGROUND}

\section{INTRODUCTION}

Coral reefs ecosystems provide a multitude of invaluable services that generate ecological, social, and economic benefits (Moberg and Folke, 1999; Harborne et al., 2006; Brander et al., 2007). Coral reefs comprise critical spawning, nursery, refuge, and feeding habitats for an enormous number of marine species, including both resident and transient inhabitants (Nagelkerken et al., 2000; Harborne et al., 2006). In 2004, an estimated 116 million people inhabited areas within $100 \mathrm{~km}$ of coastal areas in the Caribbean region, where coral reefs provide protection from wave damage, hurricanes, beach erosion, and events that can seriously damage tourist infrastructure and socialwellbeing (Reaka-Kudla, 1996; Moberg \& Folke, 1999; Burke \& Maidens, 2004). Lagoons created by coral reefs provide areas for fishing, recreation, and tourism, as well as essential nursery habitats for commercially important fishery species (Reaka-Kudla, 1996; WRI, 2008).

Coral reefs and the host of ecological, social, and economic benefits that they provide and sustain are seriously endangered by a colossal number of threats. Globally, live coral cover has declined more than $30 \%$ since the 1980 's, while the Caribbean region has been characterized by an average decline of coral cover over $40 \%$ (Gardner, et al., 2003; Côte et al., 2005; Bruno \& Selig, 2007). The observed degradation has been largely accredited to the loss or serious decline of resilience in coral reefs ecosystems, defined by Bellwood et al. (2004) as a "systems ability to absorb shocks, resist phase shifts, and regenerate after natural and human-induced disturbances" (Holling, 1973; Nyström et al. 2000; Hughes et al., 2003). A phase shift is the transition from community 
assemblage (e.g., coral-dominated) to a different community assemblage (e.g., algaedominated) with environmental change, and occurs when specific thresholds in the resilience of an ecosystem are crossed (Bellwood et al., 2004; McManus and Polsenberg, 2004; Mumby \& Hastings, 2007; Dudgeon et al., 2010). A multitude of stressors contribute to the erosion of resilience, ranging from global factors such as climate change and ocean acidification (Hughes et al., 2003; Hoegh-Guldberg et al., 2007) to local threats such as coastal development (Cortes \& Risk, 1985; Babcock \& Smith, 2002; Laponte et al., 2010), overfishing (Jennings \& Polunin, 1997; Bryant et al., 1998; Hawkins \& Roberts, 2004), eutrophication (Harrison \& Ward, 2001; Bruno et al., 2003; Loya, 2004; McManus \& Polsenberg, 2004), and direct physical impacts (Rouphael \& Inglis, 1997; 2001; Plathong et al., 2000), among others. The persistence of coral reef ecosystem function depends upon the protection of key ecosystem processes such as herbivory and recruitment, critical components of coral reef ecosystems (e.g., fish and corals), and the major factors impacting them (Bellwood et al, 2004; Mumby, 2006; Maynard et al., 2010).

Marine protected areas (MPAs) have become an increasingly popular approach for marine resource management and conservation. These protected areas can bolster conservation initiatives, in several cases have demonstrated improved fishery stocks in surrounding areas (Lester \& Halpern, 2008; McCook et al., 2010), and are a crucial aspect of coral reef conservation efforts. However, a 2004 study identified that only $6 \%$ of the 285 MPAs present in the Caribbean region were defined as "effectively managed" (based on management activity and plan in place, resource availability, and regulation 
enforcement), clearly demonstrating the need for increased MPA management efficiency (Burke \& Maidens, 2004).

The Parque Nacional Arrecife de Puerto Morelos (PNAPM), classified as a category II National Park by the International Union for Conservation of Nature (IUCN), which implies the "protection of large-scale ecological processes along with the complement of species and ecosystems characteristic of the area" (IUCN, 2009), is located in the town of Puerto Morelos on the northeastern coast of the Yucatan Peninsula in Quintana Roo. The PNAPM was created in 1998 at the insistence of community members concerned with increasing environmental threats and a desire to conserve and sustainably manage marine resources (INE-SEMARNAP, 2000; Rodríguez-Martínez, 2008). The coral reef ecosystem present within the PNAPM comprises the ecological, social, and economic foundation of the Puerto Morelos community. In 2009 approximately 124,000 people visited the PNAPM, generating nearly USD \$232,000 in tourism revenue (http://cobro.conanp.gob.mx/concentrados.php? anio=2009). A local fishing cooperative relies upon fishing concessions within the PNAPM, which depend on the well-being of the coral reef ecosystem and its biotic community (Rodríguez-Martínez, 2008). The livelihood and survival of the beachfront town of Puerto Morelos, comprised of hotels, restaurants, and boutique shops, relies upon the revenue generated from national and international tourists drawn to visit the beach and coral reef. The PNAPM management plan was implemented in the year 2000, and clearly specifies areas for fishing, tourism, public use, and scientific "no-take" areas, each with specific permitted and prohibited activities. The zoning strategy has produced a spectrum of activity and resource-use levels that may have variable impacts on the coral reef ecosystem. 
The coral reef within the PNAPM is arguably one of the best-studied coral reefs in the region as a result of the presence of multiple research entities near the Puerto Morelos town center, including the Instituto de Ciencias del Mar y Limnología (IMcYLUNAM) and the Centro Regional de Investigación Pesquera. Paradoxically, very few studies have been conducted since the inception of the PNAPM in 1998 that assess the effectiveness of current management strategies in achieving MPA objectives and goals (but see Maldonado Cuevas, 2008; Reyes Bonilla, 2009). Evaluation of management effectiveness through assessments and monitoring is a critical component of a successful adaptive management strategy (NRC, 2001; Sobel \& Dahlgren, 2004; Wilson et al., 2010). Although monitoring has been conducted in the PNAPM since 2003, assessments have been sporadic, infrequent, and do not directly address management goals.

Coral reef assessments in 1981 and 1993 demonstrated an overall decline in cover and species richness in all Puerto Morelos reef zones (Jordán-Dahlgren et al., 1981; Rodriguez-Martinez, 1993 in Rentería et al., 1999). The most recent coral reef assessment conducted in the PNAPM, which compiles data from 1993 to 2005, reports the Puerto Morelos reef as having a low $(<3 \%)$ coral cover and high macroalgal cover (Rodríguez-Martínez et al., 2010). Recreational activities such as S.C.U.B.A. and snorkel tours, involving approximately 150,000 tourists annually, generate direct threats to the coral reef via diver damage, boat groundings, and pollution generation (RodríguezMartínez, 2008). There is no sewer system in Puerto Morelos, resulting in possible groundwater contamination, which could eventually reach and negatively impact the coral reef environment (Rentería et al., 1999; Rodríguez-Martínez et al., 2010). Recent exponential coastal development and population growth in Puerto Morelos and nearby 
tourist destinations has generated a wealth of potentially devastating threats to the PNAPM (Burke and Maidens, 2004; Rodríguez-Martínez, 2008; Rodríguez-Martínez et al., 2010). Regional threats combined with global stressors such as climate change, ocean acidification, and increasing sea temperatures (Aronson et al., 2002; Hughes et al., 2003; Côte et al., 2005; Aronson and Precht, 2006; Hoegh-Guldberg et al., 2007) pose very real threats to the integrity and longevity of the Puerto Morelos coral reef ecosystem structure and dynamics, which unmistakably comprise the ecological, economic, and social backbone of the Puerto Morelos community.

My study examines the relationship between ecological characteristics, major stressors, and coral reef ecosystem resilience at four sites within the PNAPM. This research was conducted in three parts; 1) ecological characterizations, 2) the development of an interactive map determining the distribution and intensity of multiple stressors present within the PNAPM, and 3) the implementation of a pre-defined resilience index in order to rank sites within the PNAPM based on information from the first two parts of the study. Each component of the study is presented as a separate chapter to clarify results and avoid overlooking important findings, and therefore contains a brief introduction specific to the focus of that chapter. The final chapter integrates findings from the previous three chapters in order to draw overall study conclusions and make recommendations based on the findings. 


\section{STUDY SITE DESCRIPTION}

This research was conducted in a marine protected area (MPA) within the Mesoamerican Barrier Reef System located in the Mexican Caribbean. All data collection occurred within the Parque Nacional Arrecife de Puerto Morelos (PNAPM) $\left(21^{\circ} 00^{\prime} 00^{\prime \prime} \mathrm{N}\right.$ and $20^{\circ} 48^{\prime} 33^{\prime \prime} \mathrm{N}, 86^{\circ} 53^{\prime} 14.40^{\prime \prime} \mathrm{W}$ and $86^{\circ} 46^{\prime} 38.94$ 'W) located in the waters directly offshore of Puerto Morelos, Quintana Roo, Mexico (See Figure 1). The PNAPM is located approximately $35 \mathrm{~km}$ south of Cancún, on the northeastern coast of the Yucatan Peninsula (INE-SEMARNAP, 2000; Rodríguez-Martínez, 2008). The PNAPM consists of 9,066 ha of shoreline, lagoon, seagrass beds, marine springs, and a semi-continuous coral reef tract with several distinct zones adjacent to a $21 \mathrm{~km}$ stretch of coastline (Jordán et al., 1981; Rentería et al., 1999; Rodríguez-Martínez, 2008). Inshore lagoons dominated by red mangrove (Rhizophora mangle) are located 100-200m inland and are physically isolated from the marine environment (Ruíz-Rentería et al., 1998). 


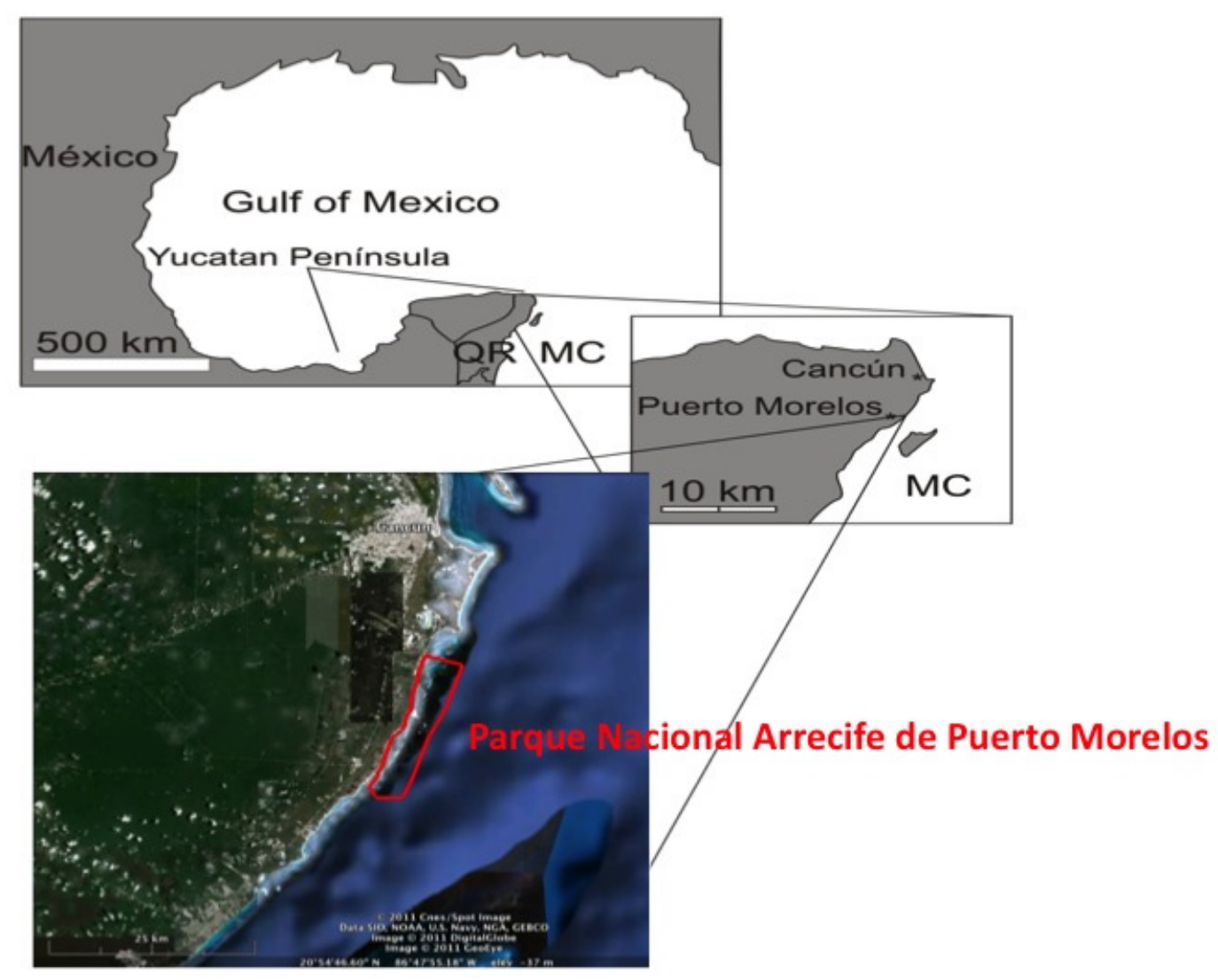

Figure 1. Study site location within the Mexican Caribbean.

Coral Reef

The coral reef environment contained within the PNAPM is part of the northernmost section of the Mesoamerican Barrier Reef tract, the second largest barrier reef in the world, which extends from Honduras north to the Yucatan Channel (Coronado et al., 2007). The coral reef ecosystem located within the PNAPM is characterized as a semi-continuous barrier reef system, composed of several kilometer-long continuous tracts of coral reef habitat separated by small and large sections of calcareous sand (Jordán-Dahlgren \& Rodríguez-Martínez, 1998; Núñez-Lara et al., 2005; Coronado et al., 2007). The coral reef habitat within the PNAPM has been described as highly heterogeneous, and can be separated into three distinct zones: 1) a backreef zone, 2) reef crest or "breaker” zone, and 3) a forereef zone (Jordán et al., 1981, Ruíz-Rentería et al., 
1998). Although no recent data has been published on coral coverage for these three distinct zones, studies in 1981 by Jordán et al. (1981) recorded the backreef and reef crest containing higher percent coral cover ( $28.4 \%$ and $27.1 \%$ respectively) in comparison to the shallow $(5 \mathrm{~m})$ forereef zone (7.4\%). These figures are significantly higher than found in coral reef assessments conducted in 1993, which reported an overall decline in cover (backreef: $4.6 \%$, reef crest: $6.4 \%$, and forereef: $2.2 \%$ ) and species richness in all Puerto Morelos reef zones compared to the 1981 assessment (Jordán-Dahlgren et al., 1981; Rodriguez-Martinez, 1993 in Rentería et al., 1998). The CARICOMP monitoring data from 1993 to 1999 recorded a trend of increasing macroalgal abundance (44.8\% to 92.8\%) at their Puerto Morelos sampling station (CARICOMP, 2000). The PNAPM coral reef environment has been seriously impacted by numerous storms that have influenced the coral reef community composition (Jordán-Dahlgren \& RodríguezMartínez, 1998). The most influential storms to affect the Puerto Morelos reef environment were hurricane Gilbert in 1988 and hurricane Wilma in 2005, both of which passed directly over the PNAPM coral reef and produced significant impacts on coral cover (Jordán-Dahlgren \& Rodríguez-Martínez, 1998; Maldonado Cuevas, 2008).

\section{Lagoon}

The reef lagoon ranges in width from just over one hundred meters in the southern region of the park, gradually widening to nearly 2.5 kilometers towards the northern region of the park, with depths ranging from 2-8m (INE-SEMARNAP, 2000). RuízRentería et al. (1998) separate the lagoon into three zones defined by the dominant vegetation: a "narrow coastal fringe" dominated by either the seagrass Thalassia 
testudinum or Syringodium filiforme with associated algae, a "mid-lagoon zone" comprises the largest area of the lagoon habitat and is characterized by large patches of sand interspersed with developed T. testudinum and S. filiforme beds that are not as dense as in the narrow coastal fringe zone, and a "backreef zone" comprised mostly of $T$. testudinum (Tussenbroek, 2007; Tussenbroek et al., 2008).

\section{Submarine Springs ("Ojos de Agua")}

The geology of the Yucatan Peninsula is dominated by karstic limestone, which gives rise to networks of underground fissures and tunnels. Submarine springs, locally known as ojos de agua, are present throughout the lagoon and are capable of transporting freshwater and contaminants from the terrestrial environment to the marine environment (Ward, 1985; Ruíz-Rentería et al., 1998; Carruthers et al., 2005; Hernández-Terrones et al., 2010). An unidentified number of submarine springs are interspersed within the lagoon habitat in the PNAPM. The size, flow rate, and material (e.g., contaminants) transported by the ojos de agua present within the PNAPM vary greatly depending on weather conditions and water source characteristics (Payton et al., 2006; HernándezTerrones et al., 2010; M. Ladd, pers. obs).

\section{Hydrodynamics}

Major water patterns within the region are dominated by the presence of the Yucatan Current, which has a general north-to-south flow orientation (Coronado et al., 2007). An extensive study on the circulation patterns of the PNAPM region conducted by Coronado et al. (2007) found that surface currents within the reef lagoon on average flowed towards the open ocean at the two breaks in the coral reef formation and generally 
northwards throughout the reef lagoon. These results were highly variable, indicating that on any given day these surface currents have the potential to demonstrate different or totally opposite behavior from these averages. Furthermore, this study concluded that although the Yucatan Current influences the PNAPM reef lagoon circulation patterns, water entering over the reef crest is responsible for the majority of the currents observed, creating a surplus of water inside the lagoon which results in water flowing out through the available openings in the reef formation (Coronado et al., 2007). The two major breaks in the PNAPM are located in the northern region of the park and another in the south, both of which comprise large and relatively deep (6-8m) channels connecting the reef lagoon with the open ocean (Coronado et al., 2007). 


\section{CHAPTER II - ECOLOGICAL CHARACTERIZATION OF FIVE SITES WITHIN THE PARQUE NACIONAL ARRECIFE DE PUERTO MORELOS}

\section{INTRODUCTION}

Coral reefs worldwide are currently confronted by a multitude of stressors, exemplified by the fact that coral cover has declined $40 \%$ in the Caribbean region since the 1980 's, frequently accompanied with a phase shift to a community dominated by fleshy macroalgae (Done, 1992; Hughes, 1994; Gardner et al., 2003; Knowlton, 2004; Mumby et al., 2007; Côte et al., 2009). The cumulative effects of multiple chronic and acute stressors currently impacting coral reef ecosystems is credited with generating the observed degradation of resilience in Caribbean coral reefs. Resilience is interpreted as the ability of a system to absorb, adapt, or recover from a disturbance without changing to a fundamentally different state (Hollings, 1973; Nyström et al., 2000; Hughes et al., 2003; Bellwood et al., 2004). Stressors proven to contribute to decreased coral reef resilience (resilience detractors) include a loss of functional redundancy and grazing intensity from overfishing (McClanahan, 1994; Hawkins \& Roberts, 2004; Burkepile \& Hay, 2006; 2009; Mumby, 2006), enhanced macroalgal growth caused by eutrophication (Lapointe et al., 1987; 2010; Harrison \& Ward, 2001; Littler \& Littler, 2007), and pollution (Cortes \& Risk, 1985; Hodgson, 1990; Shimoda et al., 1998; Lapointe et al., 2010). The observed increased occurrence of coral disease (Bruno et al., 2003; Brandt \& McManus, 2009) and direct physical impacts resulting from tourism and fishing activities (Rouphael \& Inglis, 1997; 2001; Plathong et al., 2000) further stress coral reefs. Localscale stressors are compounded by global factors such as climate change, bleaching 
events, and natural disturbances, which function in complex and synergistic manners to reduce resilience (Wilkinson, 1999; Gardner et al., 2003; Hughes et al., 2003; HoeghGuldberg et al., 2007).

Marine protected areas (MPAs) have been proposed as an effective strategy to support and promote the resilience of coral reef ecosystems. When properly developed, implemented, and managed, MPAs can promote ecosystem characteristics shown to increase coral reef resilience and ecosystem function (resilience promoters) (Sobel \& Dahlgren, 2004; Bellwood et al., 2004; Moberg \& Folke, 2004; McCook et al., 2010). Case studies have demonstrated that effectively managed MPAs can support the existence and recovery of critical functional groups, such as increased abundance, size, and reproductive output of herbivorous fishes (Claudet et al., 2006; Floeter et al., 2006; Lester \& Halpern, 2008; Babcock et al., 2010), increased coral cover, and decreased macroalgae cover (Mumby et al., 2007; Durán \& Claro, 2009; McCook et al, 2010). My study provides ecological characterizations to evaluate differences in characteristics demonstrated to promote or detract from coral reef resilience at selected sites within the PNAPM. This report has two major purposes: 1) to provide the PNAPM with a detailed description of the ecological community of each study site, and 2) to compare site characteristics to deduce which sites are more likely to exhibit resilience in response to disturbances relative to the other sites in this study. For the comparison of resilience characteristics between sites I focus on four major components demonstrated to significantly influence the resilience of coral reef ecosystems. Hard coral cover, CCA cover, herbivore abundance, and nutrient levels $(\% \mathrm{~N}$ and $\mathrm{N}: \mathrm{P}$ from macroalgal samples $)$ have been demonstrated to play critical roles in preventing, promoting, or reversing phase 
shifts on coral reefs and will be the focus of the discussion (Bellwood et al., 2004, Hughes et al., 2007; Littler \& Littler, 1984; 2007; Mumby et al., 2007). I hypothesize that sites with lower herbivore biomass and higher nutrient levels will demonstrate decreased coral cover and increased macroalgal cover. Specifically, I expect that sites located in areas where fishing is permitted, such as Limones, will exhibit decreased fish and herbivore density and biomass.

\section{METHODS}

\section{Study Sites}

All study sites were located within the coral reef environment in the PNAPM. Five sites were studied: Limones (2059'11.31’N, 8647’51.82’N), La Bonanza $\left(20^{\circ} 57^{\prime} 48.89^{\prime} \mathrm{N}, 86^{\circ} 48^{\prime} 50.56^{\prime} \mathrm{N}\right)$, Tanchacte Norte (henceforth referred to simply as “Tanchacte”) (20॰54’34.71’N, 8650’8.54”N), Radio Pirata (2051'5.30”N, $\left.86^{\circ} 51^{\prime} 54.91^{\prime \prime} \mathrm{N}\right)$, and Jardines $\left(20^{\circ} 49^{\prime} 55.33^{\prime} \mathrm{N}, 86^{\circ} 52^{\prime} 40.72^{\prime \prime} \mathrm{N}\right)$. These sites are permanent monitoring locations within the PNAPM and represent a diverse spectrum of anthropogenic influences (e.g., fishing, tourism, etc.) (See Figure 2). All of the sites were located in the backreef region of the coral reef habitat, a highly used section of the PNAPM, at depths ranging from $0.5-4.0 \mathrm{~m}$. Limones is located at the extreme north end of the MPA within a fishing zone, which according to the PNAPM management plan permits fishing by the local fishing cooperative at distances greater than $500 \mathrm{~m}$ from the coral reef habitat, and is also used by tour boat operators from both Puerto Morelos and Cancun for snorkel tours (INE-SEMARNAP, 2000). Data collection was conducted in 
collaboration with the PNAPM monitoring activities during the summer of 2010 by myself and a trained group of PNAPM staff members.

La Bonanza is located within a small tourism zone (backreef) at the edge of the MPAs only scientific "no-take" area (forereef), which is surrounded by a fishing zone and approximately $3 \mathrm{~km}$ south of Limones. Tanchacte, Radio Pirata, and Jardines are located within tourism zones where fishing is not allowed. All study sites are utilized for tourist activities, though the intensity of tourist visitation varies greatly between sites (M. Ladd, unpub. data). These specific study sites were chosen to characterize the ecological composition of the coral reef environment with a varying number and intensity of stressors (e.g., fishing, tourism, poaching) to determine if inter-site differences exist in the number of characteristics that promote or detract from coral reef resilience. 


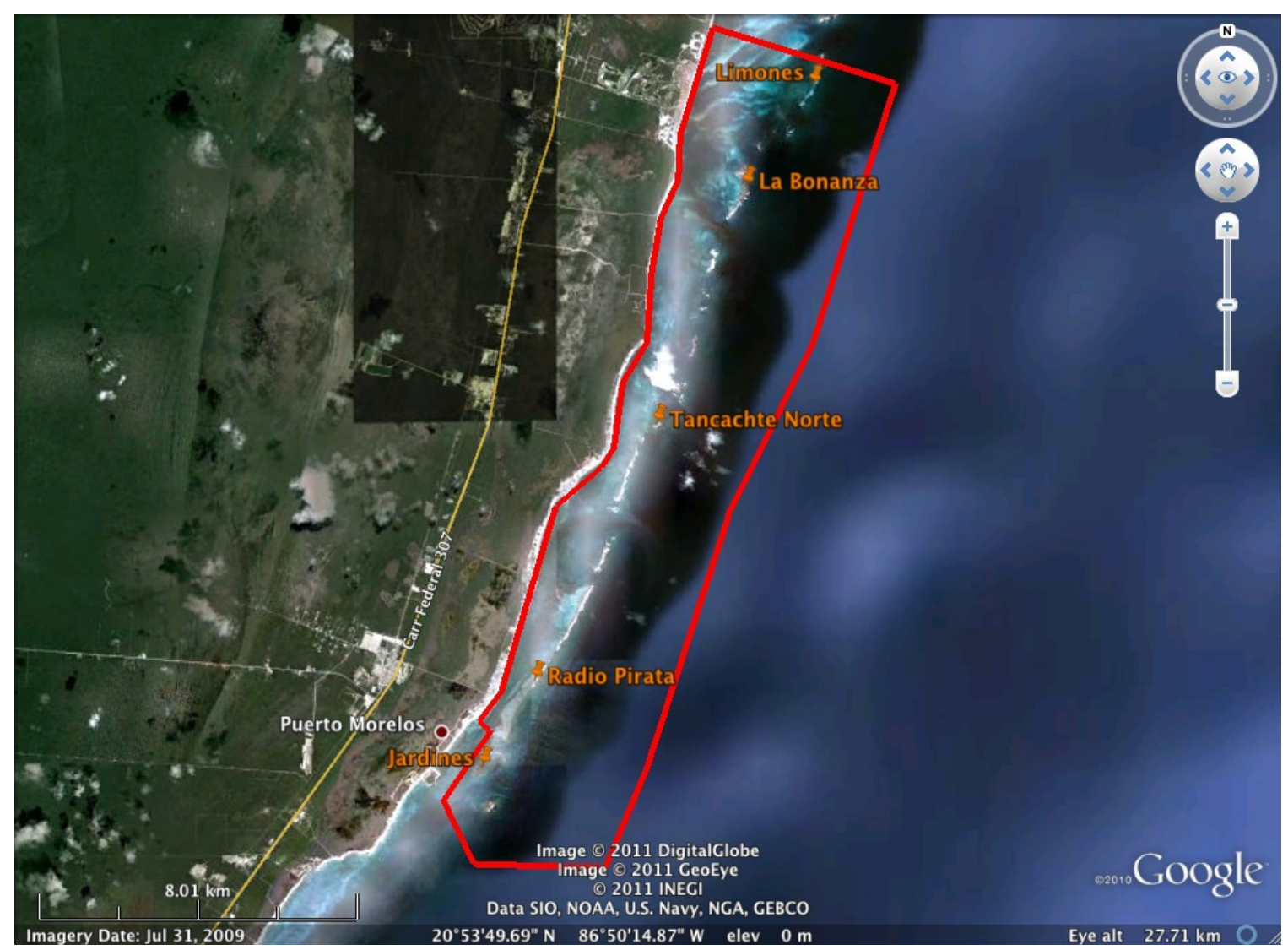

Figure 2. Study site locations within the PNAPM.

\section{Data Collection}

\section{Benthic Community Characterization}

Five $30 \mathrm{~m}$ point-intercept transects were conducted at each site to assess the benthic community composition, coral community characteristics, and rugosity. Transects were placed at locations where permanent monitoring transects have been conducted by the PNAPM monitoring program. Point-intercept transects were conducted in accordance with the protocols utilized by the Mesoamerican Barrier Reef System Project (MBRS), in which the substrate was identified directly under the transect line every $25 \mathrm{~cm}$ for a total of 120 points per transect (MBRS, 2003). This method was chosen because the PNAPM monitoring program staff currently utilizes these protocols 
with several modifications. In addition to the MBRS classification scheme, substrate was identified to the most specific taxonomic level possible for corals and macroalgae species. Specimen samples of macroalgae that could not be identified in the field were collected for identification in the laboratory by an expert. At the time of this study, only three transects were available for Tanchacte and Jardines, and no benthic community characterization surveys were available for the Radio Pirata study site.

The following major categories were used for the point-intercept transect substrate classification: crustose coralline algae (CCA), turf, macroalgae, turf-algal sediment complex (TAS), sponge, gorgonian, hard coral, sand, rock/rubble, seagrass, branched calcareous algae, and other. Category descriptions and examples can be found in Table 1. 


\begin{tabular}{|c|c|c|}
\hline Substrate Category & Description & Examples \\
\hline $\begin{array}{l}\text { Crustose coralline algae } \\
(\mathrm{CCA})\end{array}$ & $\begin{array}{l}\text { All encrusting crustose } \\
\text { coralline algae }\end{array}$ & Mesophyllum spp \\
\hline Turf & $\begin{array}{l}\text { Filamentous algae }<1 \mathrm{~cm} \\
\text { tall }\end{array}$ & $\begin{array}{l}\text { Gelidiela } \mathrm{spp}, \\
\text { Polysiphonia } \text { spp }\end{array}$ \\
\hline Macroalgae & Fleshy algae $>1 \mathrm{~cm}$ tall & $\begin{array}{l}\text { Dictyota spp, } \\
\text { Turbinaria spp, } \\
\text { Lobophora spp }\end{array}$ \\
\hline $\begin{array}{l}\text { Turf-algal sediment complex } \\
\text { (TAS) }\end{array}$ & $\begin{array}{l}\text { Mix of turf and sediment. } \\
\text { Sediment remains in turf } \\
\text { when disturbed }\end{array}$ & \\
\hline Sponge & $\begin{array}{l}\text { Both erect and encrusting } \\
\text { sponges }\end{array}$ & \\
\hline Gorgonian & $\begin{array}{l}\text { All organisms in the order } \\
\text { Gorgonacea }\end{array}$ & Sea fans, sea whips, etc. \\
\hline Hard coral & $\begin{array}{l}\text { All species of corals in the } \\
\text { order Scleractinia }\end{array}$ & $\begin{array}{l}\text { Acropora spp, Agaricia } \\
\text { spp, Diploria } \mathrm{spp} \text {, } \\
\text { Montastrea } \mathrm{spp}, \text { Porites } \\
\text { spp, Siderastrea } \mathrm{spp}, \\
\text { Isophyllia spp }\end{array}$ \\
\hline Sand & $\begin{array}{l}\text { Sandy-bottom with no other } \\
\text { organisms or material } \\
\text { present }\end{array}$ & \\
\hline Rock/Rubble & $\begin{array}{l}\text { Hard-bottom not covered by } \\
\text { any other substrate category }\end{array}$ & $\begin{array}{l}\text { Rock slab, uncolonized } \\
\text { dead coral fragments }\end{array}$ \\
\hline Seagrass & & $\begin{array}{l}\text { Syringodium spp, } \\
\text { Thallassia } \mathrm{spp}\end{array}$ \\
\hline Branched calcareous algae & Articulated calcareous algae & $\begin{array}{l}\text { Amphiroa spp, } \\
\text { Galaxaura } \mathrm{spp}, \\
\text { Halimeda } \mathrm{spp}\end{array}$ \\
\hline Other & $\begin{array}{l}\text { "Unidentifiable" substrate, } \\
\text { zoanthids, anenomies }\end{array}$ & \\
\hline
\end{tabular}

Table 1. Definition of substrate categories utilized in benthic community transects. Categories are an extension of those proposed by MBRS (2003).

\section{Coral Community Characterization}

The coral community at each site was characterized along the same $30 \mathrm{~m}$ transects as the point-intercept transects. The following data were taken for each hard coral colony larger than $10 \mathrm{~cm}$ in diameter that the transect line crossed: coral species, colony height $(\mathrm{cm})$, colony width $(\mathrm{cm})$, percent mortality, disease presence (identified if possible), TAS, CCA, macroalgae, sponge, polychaete, and trididemnum presence, conch, corallivore, and damselfish predation, and the presence of overturned or broken portions 
of the colony. Because each coral colony directly underneath the transect line was surveyed, sample sizes for coral community characterizations were different for each site.

\section{Architectural Index}

An architectural index consisting of three parts was developed to determine topographic complexity values for each site. 1) The maximum vertical relief within a $1 \mathrm{~m}$ radius was measured every $5 \mathrm{~m}$ along each $30 \mathrm{~m}$ transect and averaged in order to estimate rugosity. Rugosity measures were completed along the same transects as the pointintercept transects. 2) The area $\left(\mathrm{m}^{2}\right)$ of each coral colony surveyed was calculated. 3 ) Each coral colony was given a form-function rank based on morphological characteristics (i.e., branching, massive, etc.) from published data (See Appendix A). Form-function values provide a manner to integrate the differences in three-dimensional complexity between coral species growth forms. These three values; rugosity, area, and formfunction rank, were multiplied to generate architectural index values. The architectural index method provides a better estimation of topographic complexity, because traditional rugosity measures do not take into account the morphological characteristics of the vertical relief being measured (e.g., mounding vs. branching corals), which have different topographic complexities and consequences for the ecological community.

\section{Fish Community and Urchin Evaluations}

Fish communities were surveyed via belt transects using the methods described in the MBRS (2003) protocols with minor modifications. Twelve 30m belt transects were conducted in each site. Belt transects consisted of $2 \times 2 \times 30 \mathrm{~m}$ transects randomly located within the coral reef environment (i.e., not within sand barrens or seagrass beds) in the 
general area of the point-intercept transects within each study site. All belt transects were conducted between 8:00 AM and 4:00 PM. Only fish located inside the $2 \times 2 \times 30 \mathrm{~m}$ sampling area at the time of the survey were counted. For large schools of fish it was occasionally necessary to estimate numbers in 10 s or 20 s. In one pass each fish within the belt transect was recorded to the species level and placed into pre-defined size classes $(<5 \mathrm{~cm}, 5-10 \mathrm{~cm}, 10-20 \mathrm{~cm}, 20-30 \mathrm{~cm}, 30-40 \mathrm{~cm},>40 \mathrm{~cm})$, which were estimated with the aid of a $50 \mathrm{~cm}$ PVC tube with markings every $10 \mathrm{~cm}$ to avoid magnification problems (Bohnsack and Bannerot, 1986; Peckol et al., 2003). Training sessions were conducted with divers to practice length and abundance estimation measurements to ensure consistency in data collection. Humann and DeLoach (2002) reef fish identification fish guides were utilized for fish identification. The number of Diadema antillarum urchin individuals within each belt transect was recorded as well.

Rover diver surveys were conducted in each site to generate approximate abundance estimates and overall site biodiversity. One rover diver survey was conducted in each study site for 30 minutes, during which the entire site was surveyed. The purpose of the rover diver survey is to survey all areas of each site, especially those that may have been missed by the belt transects (e.g., crevices, caves, etc.) in order to identify the maximum number of species within each site. Approximations of the number of individuals of each species were taken. When more than 25 individuals of a species were seen, the following abundance classes were employed: 25-50 individuals, 50-75 individuals, 75-100 individuals, $>100$ individuals.

Fish biomass estimates were calculated using published weight-length relationships, where $\mathrm{W}=\mathrm{aL}^{\mathrm{b}}$ (Bohnsack \& Harper, 1988). Constants used to calculate 
biomass for each species observed and supporting references can be found in Appendix C. The mean length for each size class interval was used to calculate biomass for individuals placed in each category (e.g., for all individuals in the $11-20 \mathrm{~cm}$ size class, biomass estimates were calculated with a length of $15 \mathrm{~cm})$.

\section{Nutrient Analyses}

Carbon $(\mathrm{C})$, Nitrogen $(\mathrm{N})$, and Phosphorus $(\mathrm{P})$ tissue content was evaluated from six samples of macroalgae at each site. All samples were collected on June 22, 2010. Each sample was taken at a different location within each study site, determined by a random number of kicks in a random compass bearing. At each location a sample of Dictyota menstrualis and/or D. cervicornis was taken, placed into a ziplock bag and immediately put on ice. Upon the completion of macroalgae sample collection, all samples were transported to the Universidad Nacional Autónoma de México Instituto de Ciencias del Mar y Limnología (UNAM-ICMyL) laboratory and placed in the refrigerator. Each sample bag was removed from the refrigerator and its contents emptied into a small water container. Dictyota menstrualis and D. cervicornis material was separated from unwanted macroalgae and placed into another container with clean water. The desired material was then cleaned with freshwater to remove any sediment, sand, epifuana, and epiflora. Once the D. menstrualis/cervicornis complex was separated from unwanted material, it was placed into $10 \% \mathrm{HCl}$ solution to remove all carbonate material. The liquid was swished around in order to inundate all of the specimen material, and was left until bubbling ceased or five minutes had passed, whichever occurred first. The material was then removed from the $10 \% \mathrm{HCl}$ solution, and any 
remaining unwanted material was removed. Samples were then rinsed to eliminate any acid and the final sample was placed in a drying oven at $65^{\circ}$ Celsius for at least 48 hours. The dry samples were ground, placed in individual bags, and transported to the Marine Macroalgae Research Lab, located at Florida International University in Miami, Florida, for further processing. Samples were placed in the drying oven at $70^{\circ}$ Celsius for two hours before being reground and placed into vials for subsequent weighing and processing. The analyses of CNP content of macroalgae samples were completed at the Seagrass Ecosystems Research Lab at FIU in Miami, Florida. These analyses were conducted in September 2010 following the protocols developed by Fourqurean and Zieman (2002).

\section{Tourism Intensity}

Tourist visitation rates were used as a proxy to determine relative anthropogenic physical influence at each site. The PNAPM park surveillance data available on tourist visitation rates and bracelet sales for the year of 2009 (Available at: http://cobro.conanp. gob.mx/concentrados.php?anio=2009) were analyzed to determine the average number of visitors to each site per month. The total number of PNAPM visitor bracelets sold in 2009 was divided by the total number of visitors recorded by surveillance in 2009 in order to generate the proportion of all tourists recorded by surveillance activities. Recorded visitor numbers at each study site were then multiplied by this value to obtain an estimate of the annual number of visitors for each site. 


\section{Statistical analyses}

Descriptive characteristics were calculated for the percent cover of each substrate type, coral colony size, percent live cover, percent dead cover, and percent mortality. Species diversity for fish communities was evaluated by calculating the Shannon-Weiner Index (H').

A one-way analysis of variance (ANOVA) was employed to detect intra-site differences in the density and percent representation of fish functional groups and size classes. Inter-site differences in substrate percent cover, fish densities, and percentages of site populations for functional groups and size classes were detected using a multivariate analysis of variance (MANOVA) (Wilk's Lambda). An ANOVA was then employed to identify variables that were significantly different from each other. If significant differences were found a Fisher's Least Significant Different (LSD) test ( $\alpha=$ 0.05) was used to determine significant differences between sites. Assumptions of homogeneity of variances and normality were tested via Levene's test and visual examination of standardized residuals vs. fitted values. In the case that data did not fit assumptions of normality, a non-parametric Kruskal-Wallis test was employed to test my hypotheses. The same procedure was used to test for differences in fish diet group densities, size-class densities, and percent representation of fish populations between each of the study sites. For fish data two measures were compared for functional groups and size classes; the density and percentages. In order to compare differences in percentage of individuals in different functional groups or size classes, each transect was used as the sampling unit. Therefore, in the "mean percentage" value reported is the average of all transects in that site for that functional group or size class. However, also 
reported is the overall percentage of functional groups and size classes, which was calculated by dividing the total number of individuals observed in a functional group or size class (e.g., herbivores) by the total number of fish observed in the site.

Inter-site differences in $\% \mathrm{~N}, \% \mathrm{C}$, and $\% \mathrm{P}$ tissue content of macroalgae samples, $\mathrm{N}: \mathrm{P}, \mathrm{C}: \mathrm{N}$, and $\mathrm{C}: \mathrm{P}$ ratios, fish biomass, fish species diversity (H'), mean colony size, mean percent live and dead tissue, rugosity, and architectural index values were evaluated using an ANOVA and Fisher's LSD test $(\alpha=0.05)$. Assumptions of homogeneity of variances and normality were tested via Levene's test and visual examination of standardized residuals vs. fitted values. In the case that data did not fit assumptions of normality, a non-parametric Kruskal-Wallis test will be utilized for comparative analysis. Diversity indexes were calculated using PRIMER Version 5. Descriptive, univariate, and multivariate statistics were calculated using SPSS Version 15 statistical software package.

RESULTS

\section{SITE CHARACTERIZATIONS}

\section{Limones}

Benthic and fish community transects sampled in Limones ranged from 2 to 3 meters in depth. Turf was the most abundant substrate surveyed in Limones (mean \pm SE) $(27.33 \% \pm 1.00)$ followed by hard coral $(16.50 \% \pm 2.13)$ (See Figure 3$)$. 


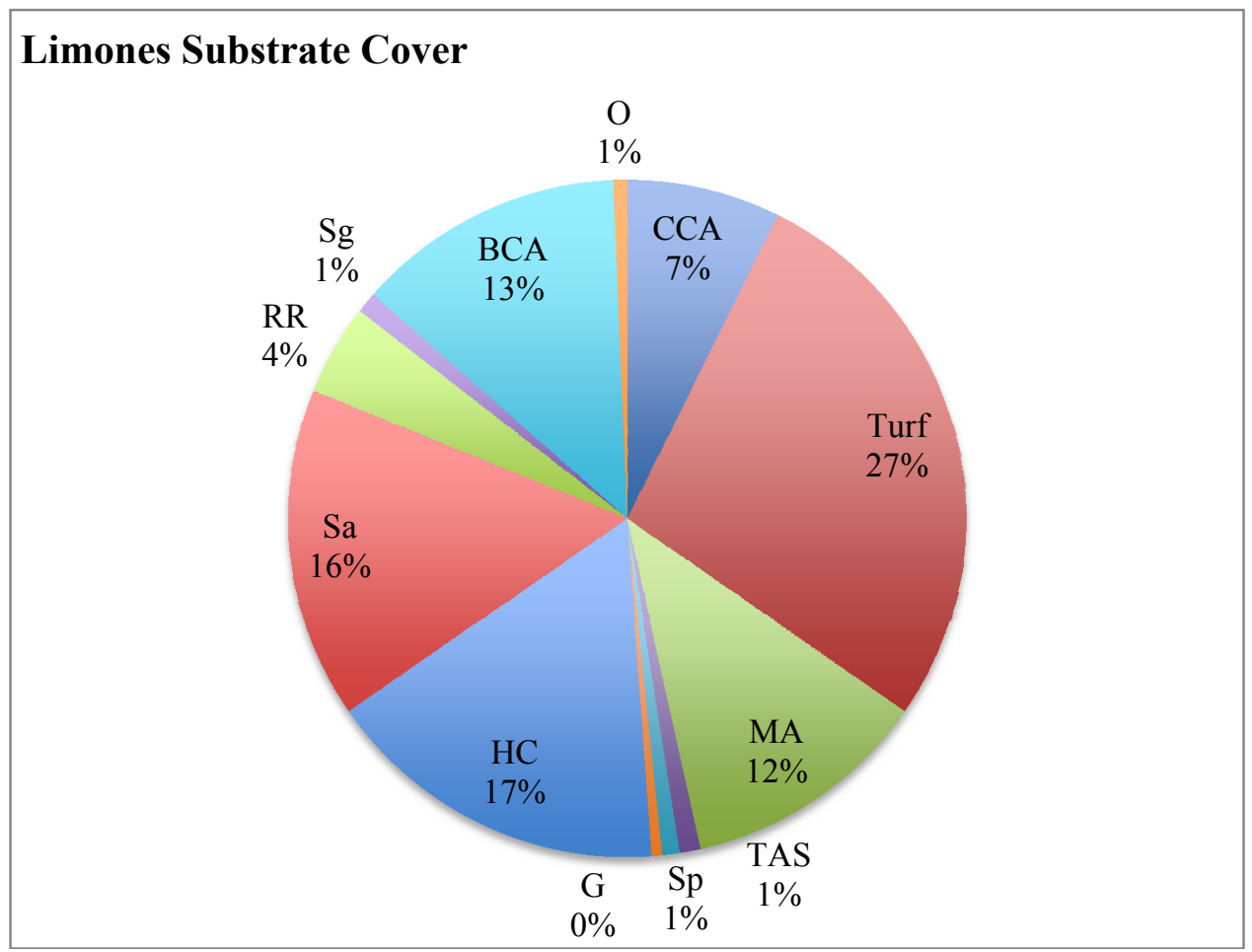

Figure 3. Mean percentage cover of substrate in Limones. MA = macroalgae, TAS $=$ turfalgal sediment, $\mathrm{Sp}=$ Sponge, $\mathrm{G}=$ gorgonian, $\mathrm{HC}=$ hard coral, $\mathrm{Sa}=$ sand, $\mathrm{RR}=$ Rock/Rubble, $\mathrm{Sg}=$ seagrass, $\mathrm{BCA}=$ branched calcareous algae, $\mathrm{O}=$ other.

Seven species of hard corals were indentified during sampling in Limones (See

Figure 3). Acropora palmata made up the vast majority of coral colonies surveyed in Limones, comprising $70 \%$ of all colonies sampled.

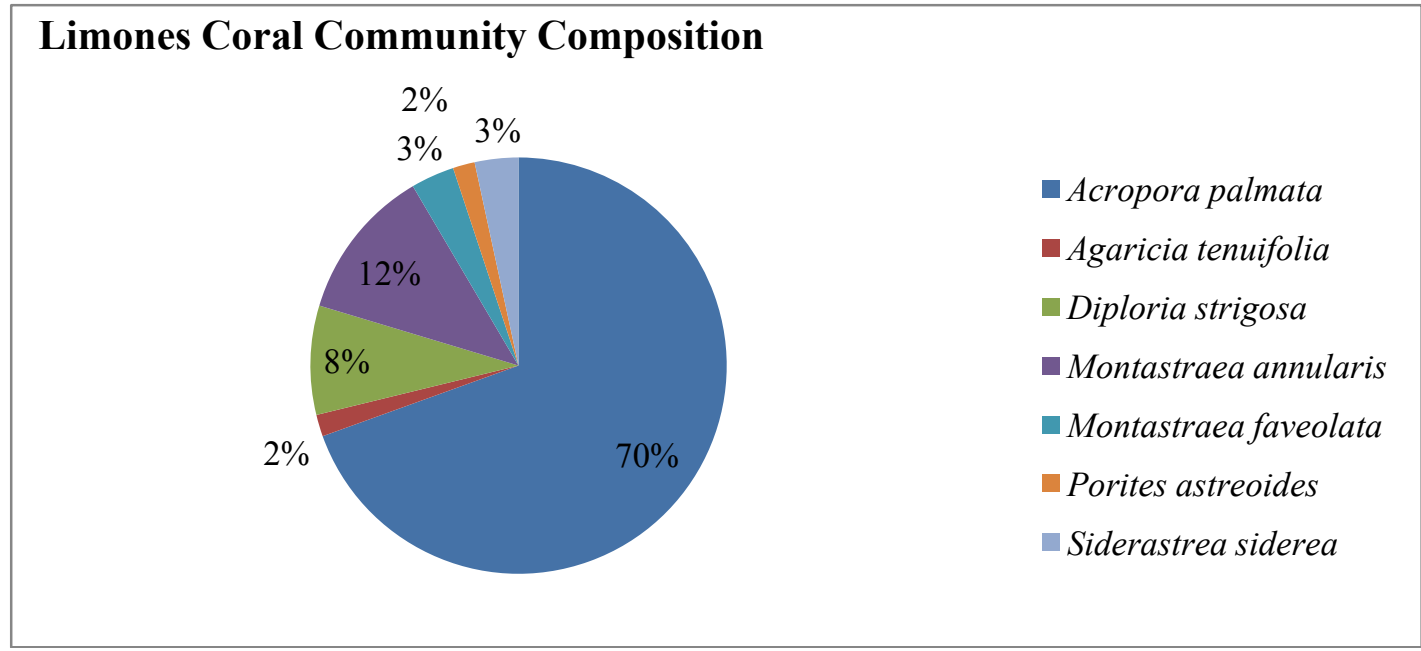

Figure 4. Community composition in of coral colonies in Limones $(n=59)$. 
The 59 coral colonies sampled in Limones demonstrated on average 18.03\% \pm 2.57 dead tissue and $81.97 \%$ live coral cover. Of the coral colonies surveyed in Limones $15.25 \%$ demonstrated signs of coral disease. The mean rugosity of Limones was $82.40 \pm 5.26$ and the mean architectural index score was $165.55 \pm 31.09$.

Nutrient tissue content analyses results are displayed below (See Table 2). The mean N:P ratio in Limones was $68.68 \pm 0.59, \mathrm{C}: \mathrm{N}$ was $19.00 \pm 0.75$, and $\mathrm{C}: \mathrm{P}$ was 1304.24 \pm 47.77 .

\begin{tabular}{lccc}
\hline \multicolumn{1}{c}{ Nutrient } & \% Tissue Content & SD & SE \\
\hline Phosphorous & 0.077 & 0.010 & 0.004 \\
Nitrogen & 2.380 & 0.313 & 0.128 \\
Carbon & 40.707 & 2.199 & 0.898 \\
\hline
\end{tabular}

Table 2. Percent nutrient content results for macroalgae nutrient analyses in Limones. A total of 945 fish were recorded in Limones, which had an overall species richness of 41 and a Shannon-Wiener diversity index score for fish communities of 2.936. The most abundant fish observed in Limones was the dusky damselfish Stegastes adustus, which represented $18.40 \%$ of all fishes recorded in the site (See Table 3).

\begin{tabular}{lcccl}
\hline Species & N & Mean Density $\left(\mathbf{m}^{2}\right)$ & \% of Total & Diet \\
\hline Stegastes adustus & 152 & 0.0974 & 16.09 & $\mathrm{H}$ \\
Thalassoma bifasciatum & 88 & 0.0564 & 9.31 & $\mathrm{~B}$ \\
Scarus iserti & 86 & 0.0551 & 9.10 & $\mathrm{H}$ \\
Microspathodon chrysurus & 80 & 0.0513 & 8.47 & $\mathrm{H}$ \\
Haemulon flavolineatum & 79 & 0.0506 & 8.36 & $\mathrm{~B}$ \\
\hline TOTAL & 485 & 0.3108 & 51.32 & \\
\hline
\end{tabular}

Table 3. Total number $(\mathrm{N})$, density $\left(\right.$ per $\left.\mathrm{m}^{2}\right)$, and percentage of the total site population for the five most abundant fishes observed in Limones. $\mathrm{H}=$ Herbivore; $\mathrm{B}=$ Benthophage.

The mean density of all fish was $0.606 \pm 0.053$ individuals per $\mathrm{m}^{2}$. Herbivores were the most abundant functional group present in Limones, accounting for $56.51 \%$ of the fish community sampled, followed by benthophagous fishes, which comprised 
$32.70 \%$ of the fish community. Table 4 summarizes the Limones fish community density results organized by functional groups based on diets. Limones had a mean total fish biomass (grams $/ \mathrm{m}^{2} \pm \mathrm{SE}$ ) of $23.74 \pm 3.74$ and a mean herbivore biomass of 13.11 \pm 2.84 .

Significant differences were detected between the mean percentage (ANOVA, $\mathrm{df}=5, \mathrm{~F}=81.525, \mathrm{P}<0.001)$ and mean density (ANOVA, $\mathrm{df}=5, \mathrm{~F}=47.183, \mathrm{P}<0.001$ ) of functional groups within the Limones fish community. Herbivores were by far the most prevalent functional group, comprising on average $59.36 \%$ of the Limones fish population, a significantly higher portion of the fish population than any other group.

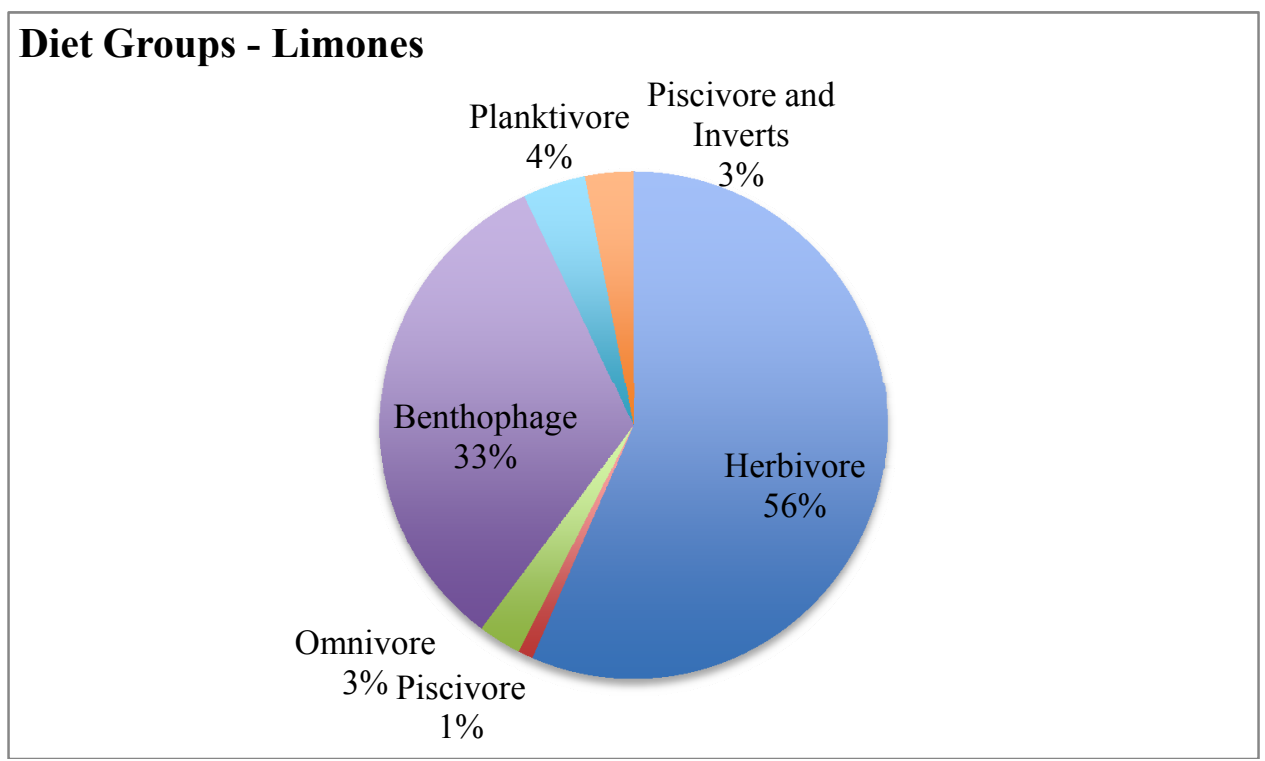

Figure 5. Percentage of fish population by diet group in Limones. 


\begin{tabular}{lcc}
\hline Diet group & Mean Density & SE \\
\hline Herbivore & $0.342(\mathrm{c})$ & 0.026 \\
Piscivore & $0.006(\mathrm{a})$ & 0.003 \\
Omnivore & $0.017(\mathrm{a})$ & 0.007 \\
Benthophage & $0.198(\mathrm{~b})$ & 0.041 \\
Planktivore & $0.024(\mathrm{a})$ & 0.010 \\
Piscivore and Invertebrates & 0.019 (a) & 0.004 \\
\hline
\end{tabular}

Table 4. Mean density (per $\mathrm{m}^{2}$ ) of diet groups in Limones. Values with different letters signify that a significant difference was detected.

Significant differences were detected between the density of different size class groups (ANOVA, $\mathrm{df}=5, \mathrm{~F}=23.017, \mathrm{P}<0.001$ ) as well as the percentage of individuals in each size class category with respect to the total site population surveyed (ANOVA, $\mathrm{df}=5, \mathrm{~F}=31.660, \mathrm{P}<0.001)$ (See Table 5). The size $6-10 \mathrm{~cm}$ size class comprised 52.38\% of the total Limones fish population, significantly higher than any other size class, as was that size classes density. Fishes of the $11-20 \mathrm{~cm}$ size class were the second-most prevalent and dense size class, followed by the $<5 \mathrm{~cm}$ size class. The density of Diadema antillarum within Limones was 0.00641 per $\mathrm{m}^{2}$.

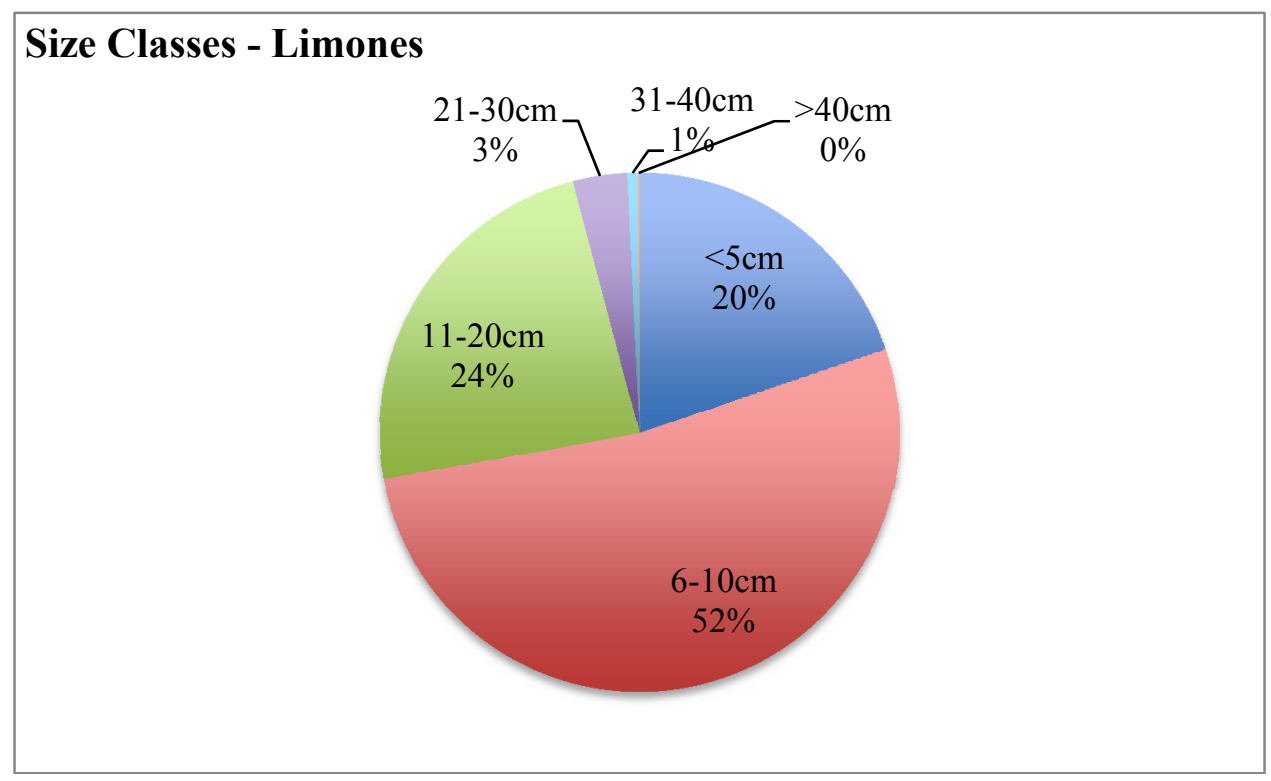

Figure 6. Percentage of fish population by size class in Limones. 


\begin{tabular}{lcc}
\hline Size Class & Mean density & SE \\
\hline$<5 \mathrm{~cm}$ & $0.120(\mathrm{~b})$ & 0.031 \\
$6-10 \mathrm{~cm}$ & $0.317(\mathrm{c})$ & 0.047 \\
$11-20 \mathrm{~cm}$ & $0.144(\mathrm{~b})$ & 0.03 \\
$21-30 \mathrm{~cm}$ & $0.021(\mathrm{a})$ & 0.005 \\
$31-40 \mathrm{~cm}$ & $0.004(\mathrm{a})$ & 0.002 \\
$>40 \mathrm{~cm}$ & $0.001(\mathrm{a})$ & 0.001 \\
\hline
\end{tabular}

Table 5. Mean density $\left(\mathrm{per}^{2}\right)$ of size classes within Limones. Values with different letters signify that a significant difference was detected.

\section{La Bonanza}

Sampling transects conducted in La Bonanza ranged in depth from 0.6 to 3 meters. Sand was the major benthic component of La Bonanza and comprised 33.47\% \pm 10.98 of the substrate. Hard coral cover comprised $3.45 \% \pm 0.58$ of the benthos and crustose coralline algae $1.04 \% \pm 0.50$.

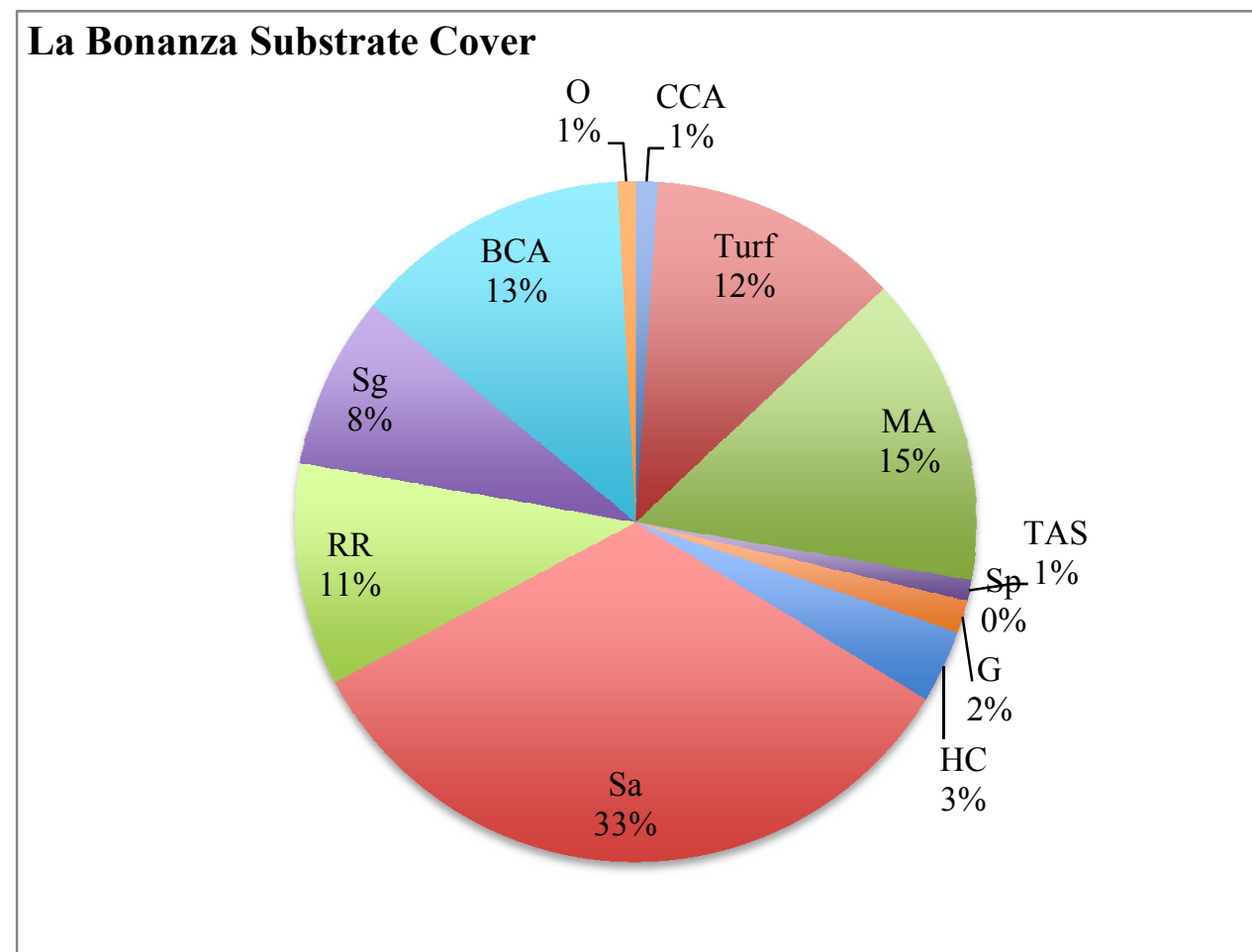

Figure 7. Mean percentage cover of substrate in La Bonanza. MA $=$ macroalgae, TAS $=$ turf-algal sediment, $\mathrm{Sp}=$ Sponge, $\mathrm{G}=$ gorgonian, $\mathrm{HC}=$ hard coral, $\mathrm{Sa}=$ sand, $\mathrm{RR}=$ Rock/Rubble, $\mathrm{Sg}=$ seagrass, $\mathrm{BCA}=$ branched calcareous algae, $\mathrm{O}=$ other. 
Five hard coral species were identified in La Bonanza coral community sampling transects (See Figure 8). Montastraea annularis (42\%) and Siderastrea siderea (38\%) were the most prevalent species at the site.

\section{La Bonanza Coral Community}

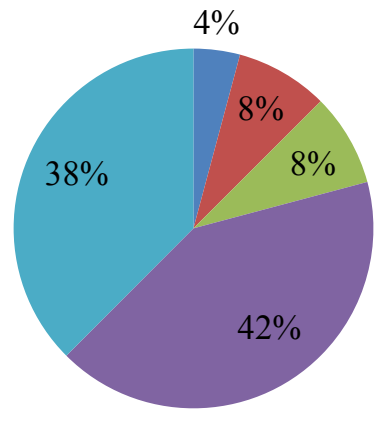

- Agaricia agaricites

- Agaricia tenuifolia

- Diploria strigosa

- Montastraea annularis

- Siderastrea siderea

Figure 8. Community coral composition in La Bonanza $(n=24)$.

The 24 coral colonies sampled in La Bonanza demonstrated an average of $42.58 \%$ \pm 7.18 dead coral tissue, generating a $57.42 \%$ mean live cover of hard coral tissue. No coral colonies surveyed in La Bonanza were affected by coral disease. La Bonanza had a rugosity of $79.40 \pm 9.03$ and an architectural index score of $51.65 \pm 10.20$.

Results of macroalgae nutrient tissue content analyses are summarized in Table 6 . The mean N:P ratio in La Bonanza was $97.53 \pm 14.04$, C:N $18.38 \pm 0.35$, and C:P 1800.66 \pm 276.71 .

\begin{tabular}{lccc}
\hline Nutrient & \% Tissue Content & SD & SE \\
\hline Phosphorous & 0.062 & 0.013 & 0.005 \\
Nitrogen & 2.587 & 0.227 & 0.093 \\
Carbon & 38.357 & 3.439 & 1.404 \\
\hline
\end{tabular}

Table 6. Nutrient content results for macroalgae nutrient analyses in La Bonanza.

The overall species richness of the 977 fish recorded in La Bonanza belt transects was 46, which had a Shannon-Weiner diversity index (H') score of 3.027. The striped parrotfish Scarus iserti was the most abundant fish observed in La Bonanza. 


\begin{tabular}{lcccc}
\hline \multicolumn{1}{c}{ Species } & N & Mean Density $\left(\mathbf{m}^{2}\right)$ & $\begin{array}{c}\text { \%of } \\
\text { Total }\end{array}$ & Diet \\
\hline Scarus iserti & 184 & 0.139 & 18.83 & $\mathrm{H}$ \\
Haemulon flavolineatum & 93 & 0.07 & 9.52 & $\mathrm{~B}$ \\
Stegastes adustus & 90 & 0.068 & 9.21 & $\mathrm{H}$ \\
Acanthurus coeruleus & 66 & 0.05 & 6.76 & $\mathrm{H}$ \\
Acanthurus bahianus & 61 & 0.046 & 6.24 & $\mathrm{H}$ \\
\hline TOTAL & $\mathbf{4 9 4}$ & $\mathbf{0 . 3 7 3}$ & $\mathbf{5 0 . 5 6}$ & \\
\hline
\end{tabular}

Table 7 . Total number $(\mathrm{N})$, density $\left(\right.$ per $\mathrm{m}^{2}$ ), and percentage of the total site population for the five most abundant fishes observed in La Bonanza. $\mathrm{H}=$ Herbivore; $\mathrm{B}=$ Benthophage.

The mean fish density within La Bonanza was $0.740 \pm 0.100$ individuals per $\mathrm{m}^{2}$.

Significant differences were observed between the mean percentage (ANOVA, $\mathrm{df}=5$, $\mathrm{F}=88.815, \mathrm{P}<0.001)$ and mean density (ANOVA, $\mathrm{df}=5, \mathrm{~F}=28.463, \mathrm{P}<0.001)$ of functional groups within the La Bonanza fish community. Herbivores were the densest functional group encountered and comprised $51.69 \%$ of the entire fish community. Benthophagous fishes comprised the second-largest functional group of fishes in La Bonanza, representing $35.11 \%$ of fishes sampled. La Bonanza had a mean total fish biomass $\left(\mathrm{g} / \mathrm{m}^{2}\right.$ $\pm \mathrm{SE})$ of $20.98 \pm 3.98$ and a mean herbivore biomass of $7.62 \pm 1.65$.

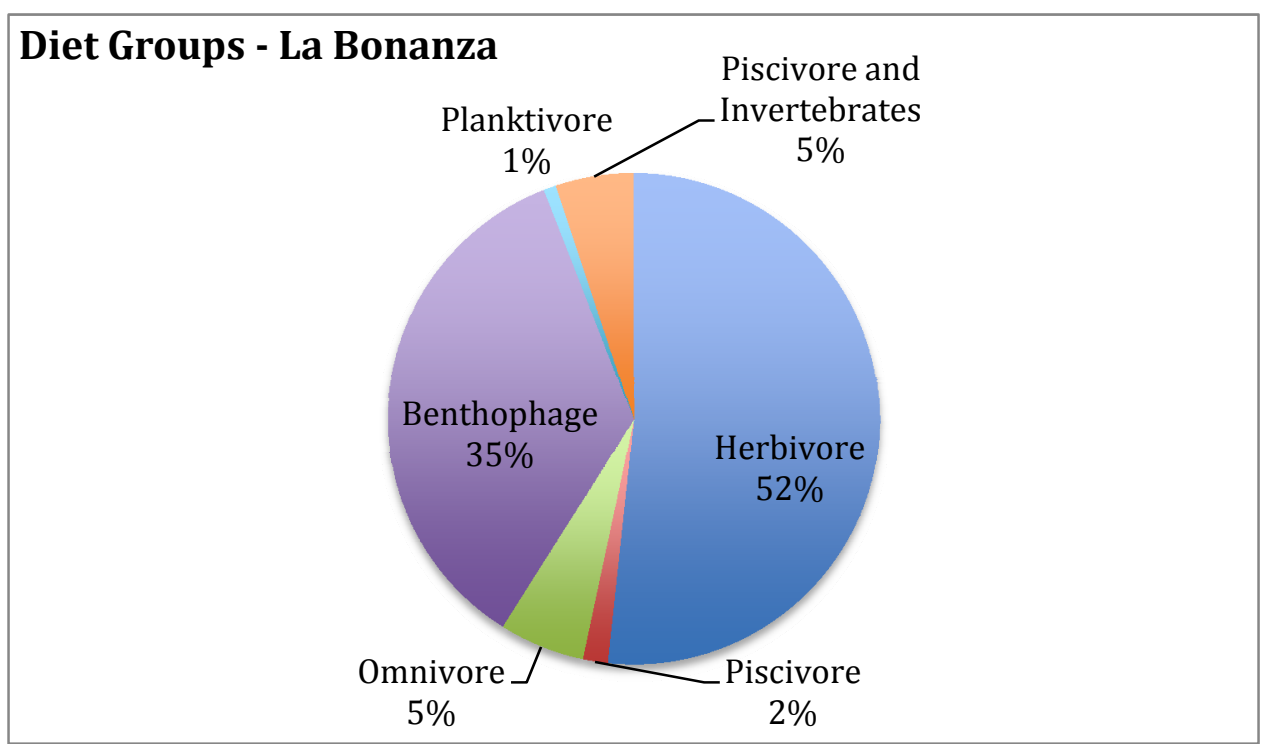

Figure 9. Percentage of fish population by diet group in La Bonanza. 


\begin{tabular}{lcc}
\hline Diet group & Mean Density & SE \\
\hline Herbivore & $0.383(\mathrm{c})$ & 0.044 \\
Piscivore & $0.012(\mathrm{a})$ & 0.003 \\
Omnivore & $0.042(\mathrm{a})$ & 0.018 \\
Benthophage & $0.260(\mathrm{~b})$ & 0.053 \\
Planktivore & $0.006(\mathrm{a})$ & 0.003 \\
Piscivore and Invertebrates & $0.038(\mathrm{a})$ & 0.021 \\
\hline
\end{tabular}

Table 8. Mean percentage and density $\left(\mathrm{per}^{2}\right)$ of diet groups in La Bonanza. Values with different letters signify that a significant difference was detected.

Significant differences were detected between the percentage (ANOVA, $\mathrm{df}=5$, $\mathrm{F}=30.566, \mathrm{P}<0.001)$ and density (ANOVA, $\mathrm{df}=5, \mathrm{~F}=17.13, \mathrm{P}<0.001$ ) of size classes within the La Bonanza fish community. Nearly half of the individuals counted in La Bonanza were in the size class of 6-10 $\mathrm{cm}(46.88 \%)$ representing the most abundant size class within the site, with the second-most abundant size class was of individuals $<5 \mathrm{~cm}$, accounting for $29.79 \%$ of the fish community.

No D. antillarum individuals were encountered in belt transects conducted in $\mathrm{La}$ Bonanza.

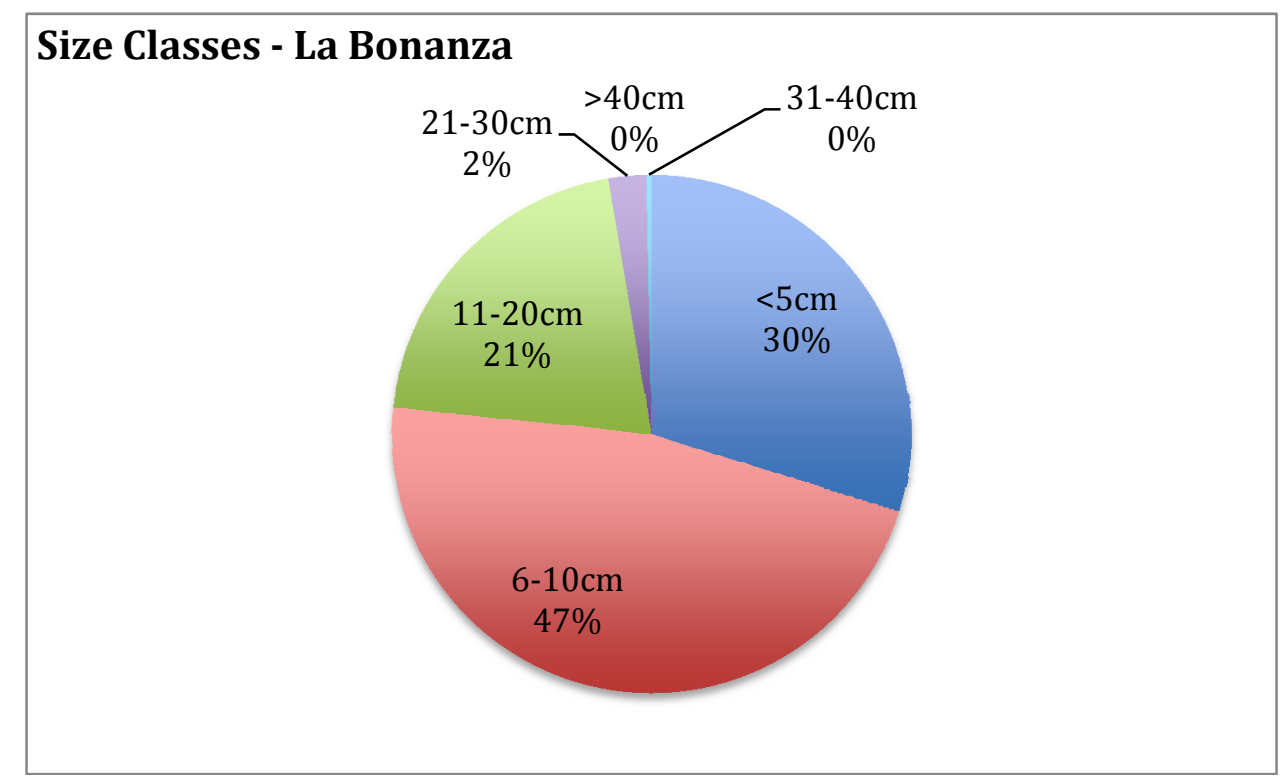

Figure 10. Percentage of fish population by size class in La Bonanza. 


\begin{tabular}{lcc}
\hline Size Class & Mean Density & SE \\
\hline$<5 \mathrm{~cm}$ & $0.221(\mathrm{~b})$ & 0.045 \\
$6-10 \mathrm{~cm}$ & $0.347(\mathrm{c})$ & 0.051 \\
$11-20 \mathrm{~cm}$ & $0.153(\mathrm{~b})$ & 0.050 \\
$21-30 \mathrm{~cm}$ & $0.017(\mathrm{a})$ & 0.004 \\
$31-40 \mathrm{~cm}$ & $0.002(\mathrm{a})$ & 0.001 \\
$>40 \mathrm{~cm}$ & $0(\mathrm{a})$ & 0 \\
\hline
\end{tabular}

Table 9. Mean density $\left(\mathrm{per}^{2}\right)$ of size classes within La Bonanza. Values with different letters signify that a significant difference was detected.

\section{Tanchacte}

Transects within Tanchacte were conducted in depths ranging from 1 to 4 meters.

Nearly half of the substrate surveyed in Tanchacte was characterized as macroalgae

$(47.50 \% \pm 2.55)$. Hard corals covered $8.34 \% \pm 3.00$ of the Tanchacte study site substrate.

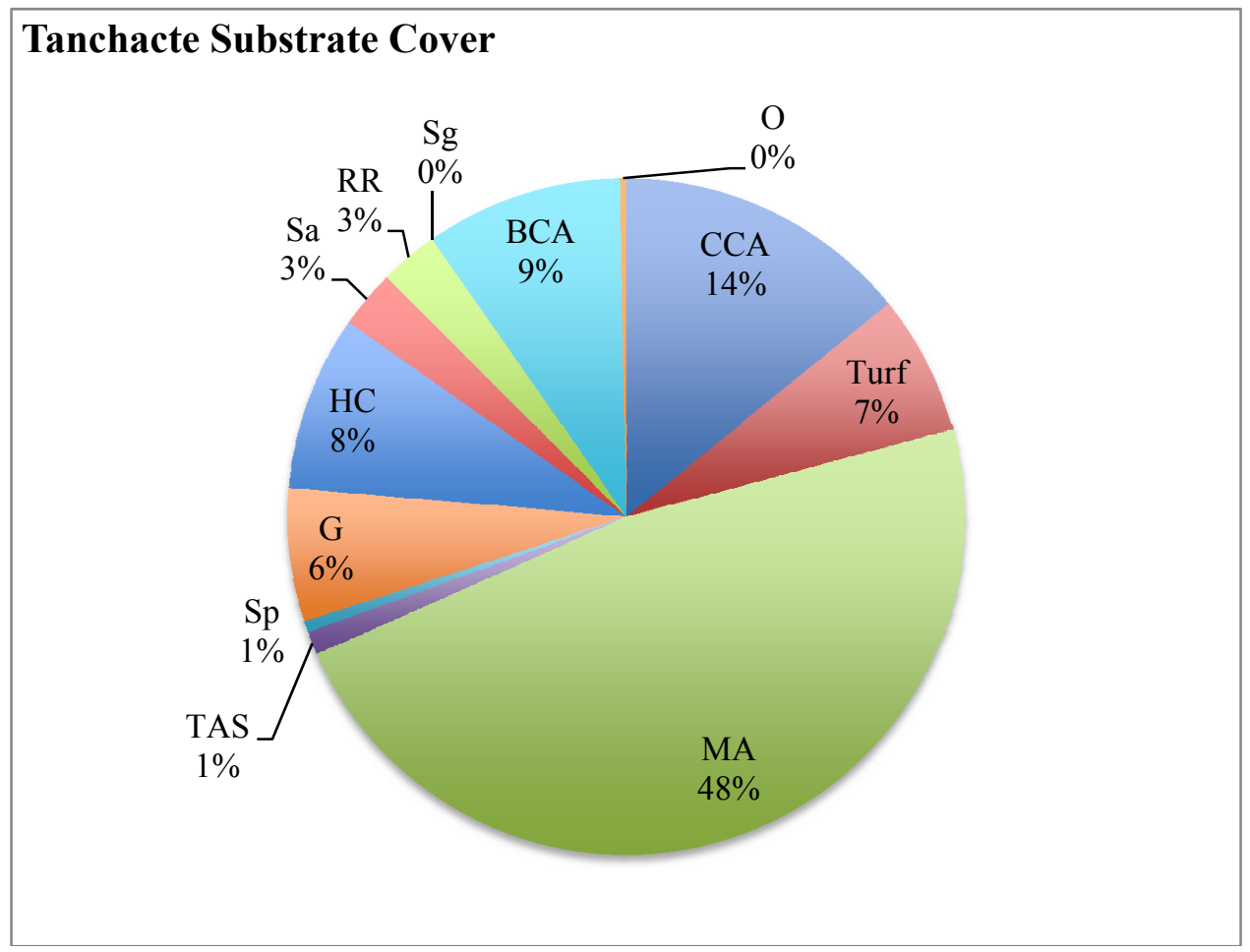

Figure 11. Mean percentage cover of substrate in Tanchacte. MA $=$ macroalgae, TAS $=$ turf-algal sediment, $\mathrm{Sp}=$ Sponge, $\mathrm{G}=$ gorgonian, $\mathrm{HC}=$ hard coral, $\mathrm{Sa}=$ sand, $\mathrm{RR}=$ Rock/Rubble, $\mathrm{Sg}=$ seagrass, $\mathrm{BCA}=$ branched calcareous algae, $\mathrm{O}=$ other.

Coral community composition transects identified a total of seven species of hard corals within Tanchacte (See Figure 12). Dipoloria strigosa was the most abundant 
species and represented $45 \%$ of all coral colonies sampled within the site. The remaining six species demonstrated fairly even representation throughout the site, with the highest value being 14\% (M. faveolata) and the lowest 3\% (Porites astreoides).

\section{Tanchacte Coral Community}

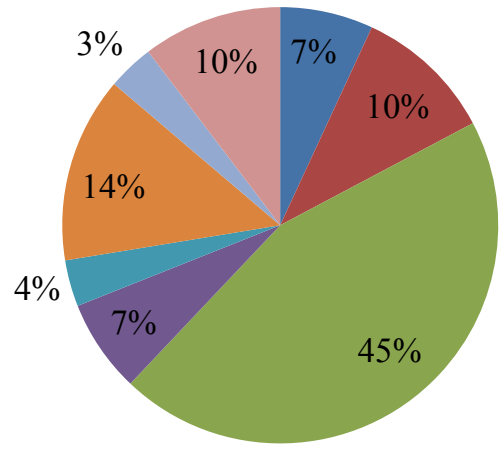

- Acropora palmata

- Agaricia tenuifolia

- Diploria strigosa

- Montastraea annularis

Montastraea cavernosa

- Montastraea faveolata

Porites astreoides

- Siderastrea siderea

Figure 12. Community composition of hard corals in Tanchacte $(n=29)$.

Of the 29 coral colonies sampled in Tanchacte, $31.03 \% \pm 5.45$ of coral tissue was

dead, while on average $68.97 \%$ of coral colony tissue was live tissue. No coral colonies surveyed in Tanchacte demonstrated signs of the presence of coral disease. The mean rugosity of Tanchacte was $105.93 \pm 14.54$ and the mean architectural index value was $77.15 \pm 22.69$.

Macroalgae nutrient analysis results are summarized in Table 10. The mean N:P ratio in Tanchacte was $102.84 \pm 7.37, \mathrm{C}: \mathrm{N} 15.95 \pm 0.48$, and C:P $1440.31 \pm 112.63$.

\begin{tabular}{lccc}
\hline \multicolumn{1}{c}{ Nutrient } & \% Tissue Content & SD & SE \\
\hline Phosphorous & 0.053 & 0.014 & 0.006 \\
Nitrogen & 2.672 & 0.235 & 0.096 \\
Carbon & 41.623 & 1.615 & 0.659 \\
\hline
\end{tabular}

Table 10. Percent nutrient content results for macroalgae nutrient analyses in Tanchacte. 
A total 682 fish were recorded in Tanchacte, representing 39 species and a Shannon-Weiner diversity index score of 2.883. The striped parrotfish $S$. iserti was the most abundant fish recoded in Tanchacte.

\begin{tabular}{lcccc}
\hline \multicolumn{1}{c}{ Species } & N & $\begin{array}{c}\text { Mean Density } \\
\left.\mathbf{( m}^{2}\right)\end{array}$ & \% of Total & Diet \\
\hline Scarus iserti & 104 & 0.072 & 15.25 & $\mathrm{H}$ \\
Acanthurus coeruleus & 78 & 0.054 & 11.44 & $\mathrm{H}$ \\
Acanthurus bahianus & 73 & 0.051 & 10.7 & $\mathrm{H}$ \\
Thalassoma bifasciatum & 66 & 0.046 & 9.68 & $\mathrm{~B}$ \\
Sparisoma viride & 48 & 0.033 & 7.04 & $\mathrm{H}$ \\
\hline TOTAL & $\mathbf{3 6 9}$ & $\mathbf{0 . 2 5 6}$ & $\mathbf{5 4 . 1 1}$ & \\
\hline
\end{tabular}

Table 11. Total number $(\mathrm{N})$, density $\left(\right.$ per $\left.\mathrm{m}^{2}\right)$, and percentage of the total site population for the five most abundant fishes observed in Tanchacte. $\mathrm{H}=$ Herbivore; $\mathrm{B}=$ Benthophage.

The mean overall fish density for Tanchacte was $0.474 \pm 0.039$ individuals per $\mathrm{m}^{2}$, the lowest total fish density for any of the sites in this study. The mean percentage (ANOVA, $\mathrm{df}=5, \mathrm{~F}=77.054, \mathrm{P}<0.001$ ) and mean density $(\mathrm{ANOVA}, \mathrm{df}=5, \mathrm{~F}=44.641$, $\mathrm{P}<0.001$ ) of diet groups within the Tanchacte fish community significantly differed. Herbivores were the most abundant and dense diet group encountered in Tanchacte, comprising $60.12 \%$ of all fishes surveyed, followed by benthophagous fishes, which represented $30.65 \%$ of the fish community. Tanchacte had a mean total fish biomass $\left(\mathrm{g} / \mathrm{m}^{2} \pm \mathrm{SE}\right)$ of $21.73 \pm 3.36$ and a mean herbivore biomass of $11.19 \pm 1.78$. 


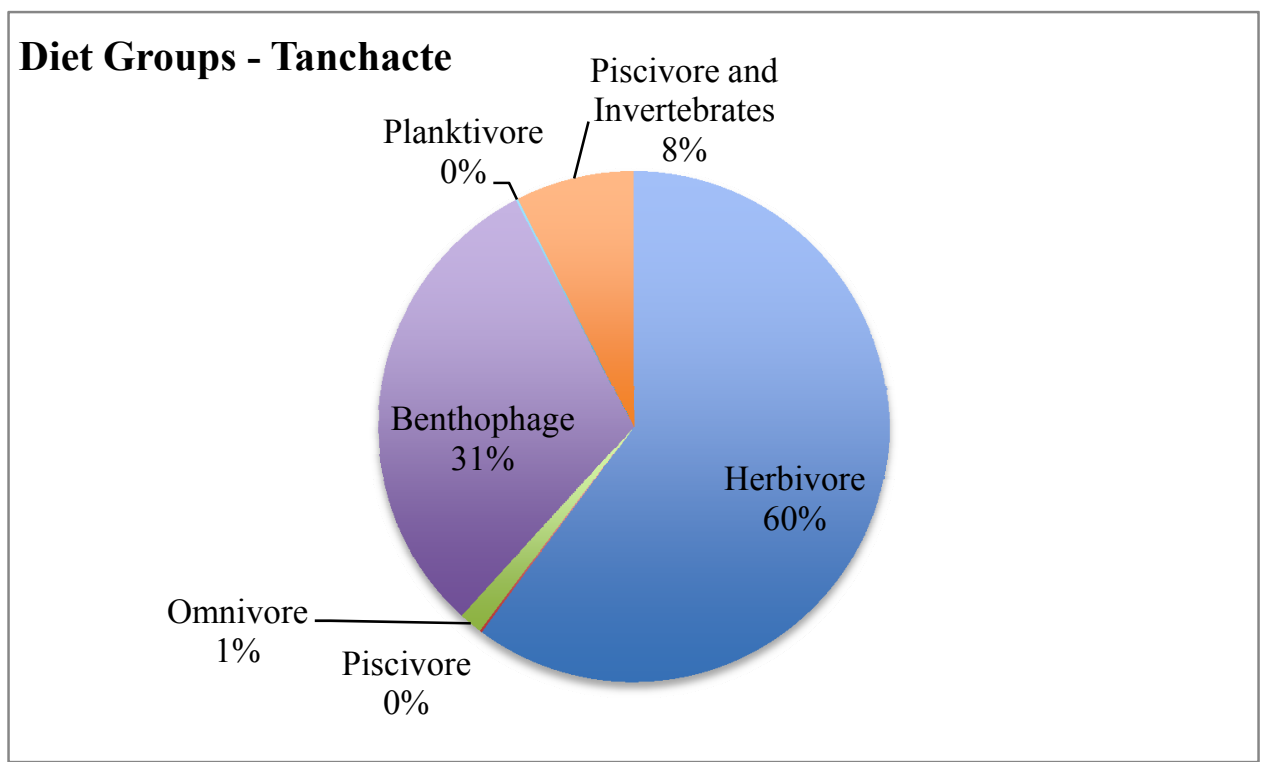

Figure 13. Percentage of fish population by diet group in Tanchacte.

\begin{tabular}{lcc}
\hline Diet group & Mean Density & SE \\
\hline Herbivore & 0.285 (c) & 0.035 \\
Piscivore & 0.001 (a) & 0.001 \\
Omnivore & 0.007 (a) & 0.003 \\
Benthophage & 0.145 (b) & 0.019 \\
Planktivore & 0.001 (a) & 0.001 \\
Piscivore and Invertebrates & 0.035 (a) & 0.014 \\
\hline
\end{tabular}

Table 12. Mean percentage and density $\left(\right.$ per $^{2}$ ) of diet groups in Tanchacte. Values with different letters signify that a significant difference was detected.

The percentage of individuals in different size classes within the Tanchacte fish community were significantly different (ANOVA, $\mathrm{df}=5, \mathrm{~F}=37.151, \mathrm{P}<0.001$ ) as were the densities of the different size classes (ANOVA, $\mathrm{df}=5, \mathrm{~F}=20.620, \mathrm{P}<0.001$ ). Individuals measuring 6-10 cm were the most abundant size class $(36.66 \%)$ and had the highest density in Tanchacte. Individuals in the size classes $<5 \mathrm{~cm}$ and $11-20 \mathrm{~cm}$ had very similar densities and represented $27.27 \%$ and $29.18 \%$ of the Tanchacte fish community, respectively.

No $D$. antillarum individuals were encountered during the belt transect surveys conducted in Tanchacte. 


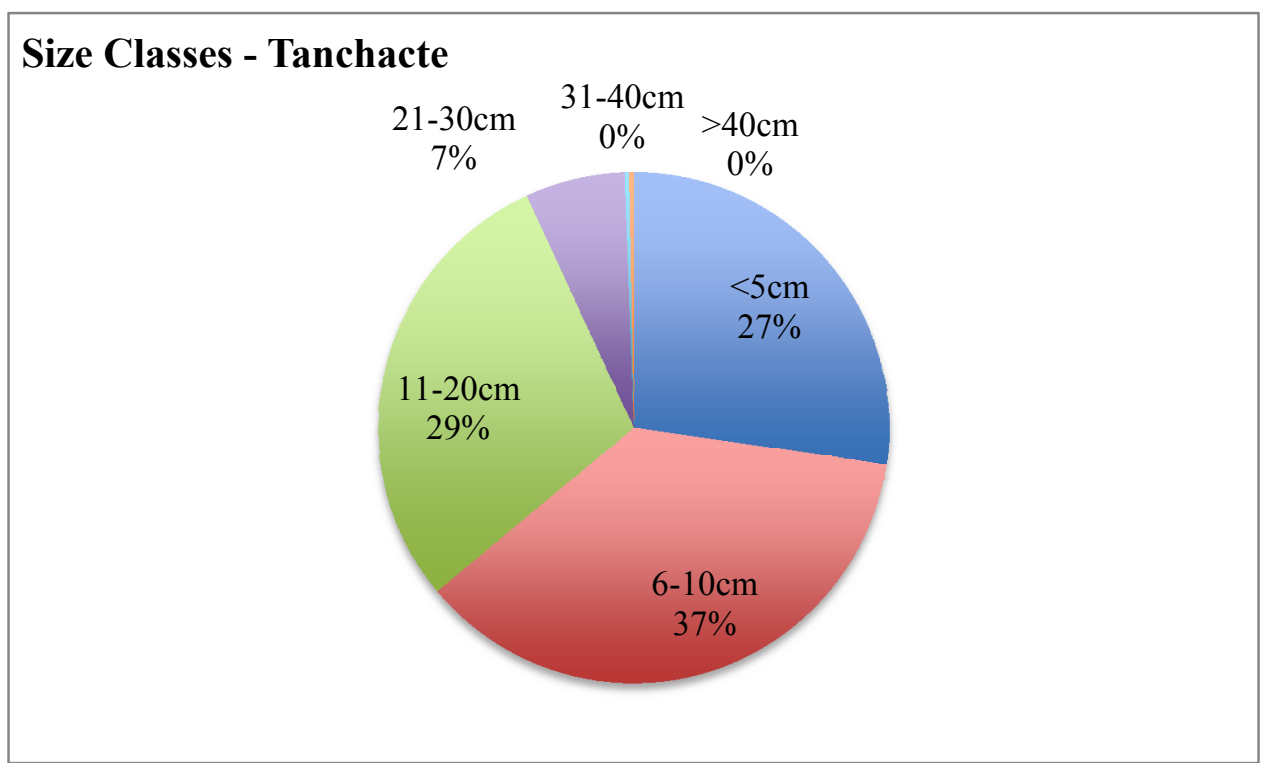

Figure 14. Percentage of fish population by size class in Tanchacte.

\begin{tabular}{lcc}
\hline Size Class & Mean Density & SE \\
\hline$<5 \mathrm{~cm}$ & $0.129(\mathrm{~b})$ & 0.0193 \\
$6-10 \mathrm{~cm}$ & $0.174(\mathrm{~b})$ & 0.028 \\
$11-20 \mathrm{~cm}$ & $0.138(\mathrm{~b})$ & 0.023 \\
$21-30 \mathrm{~cm}$ & $0.030(\mathrm{a})$ & 0.006 \\
$31-40 \mathrm{~cm}$ & $0.001(\mathrm{a})$ & 0.001 \\
$>40 \mathrm{~cm}$ & $0.001(\mathrm{a})$ & 0.001 \\
\hline
\end{tabular}

Table 13. Mean percentage and density $\left(\right.$ per $\mathrm{m}^{2}$ ) of size classes within Tanchacte. Values with different letters signify that a significant difference was detected.

\section{Radio Pirata}

No substrate or coral colony data were available for Radio Pirata at the time of this study.

The mean N:P ratio in Radio Pirata was 90.21 $\pm 5.00, \mathrm{C}: \mathrm{N} 15.95 \pm 0.14$, and C:P $1440.31 \pm 86.11$.

\begin{tabular}{lccc}
\hline \multicolumn{1}{c}{ Nutrient } & \% Tissue Content & SD & SE \\
\hline Phosphorous & 0.077 & 0.011 & 0.005 \\
Nitrogen & 3.091 & 0.078 & 0.035 \\
Carbon & 42.251 & 0.966 & 0.432 \\
\hline
\end{tabular}

Table 14. Percent nutrient content results for macroalgae nutrient analyses in Radio Pirata. 
A total of 1718 fishes were counted in the belt transects conducted in Radio

Pirata, representing 48 species and generating a Shannon-Weiner diversity index score of 3.091. The most abundant fish observed in Radio Pirata was the striped parrotfish $S$. iserti, which comprised $12.75 \%$ of all fishes recorded in the site.

\begin{tabular}{lcccc}
\hline \multicolumn{1}{c}{ Species } & N & Mean Density $\left.\mathbf{( m}^{2}\right)$ & $\begin{array}{c}\text { \% of } \\
\text { Total }\end{array}$ & Diet \\
\hline Scarus iserti & 219 & 0.1521 & 12.75 & $\mathrm{H}$ \\
Haemulon sciurus & 160 & 0.1111 & 9.31 & $\mathrm{~B}$ \\
Lutjanus apodus & 139 & 0.0965 & 8.09 & $\mathrm{PI}$ \\
Haemulon plumieri & 139 & 0.0965 & 8.09 & $\mathrm{~B}$ \\
Abudefduf saxatilis & 138 & 0.0958 & 8.03 & $\mathrm{~B}$ \\
\hline TOTAL & $\mathbf{7 9 5}$ & $\mathbf{0 . 5 5 2}$ & $\mathbf{4 6 . 2 7}$ & \\
\hline
\end{tabular}

Table 15. Total number $(\mathrm{N})$, density $\left(\right.$ per $\left.\mathrm{m}^{2}\right)$, and percentage of total site population for the five most abundant fishes observed in Radio Pirata. $\mathrm{H}=$ Herbivore; $\mathrm{B}=$ Benthophage; PI = Piscivore and Invertebrates.

Radio Pirata supported the fish community with the highest density of all sites surveyed (mean total fish density of $1.193 \pm 0.126$ individuals per $\mathrm{m}^{2}$ ). Significant differences existed between mean functional group percentages (ANOVA, $\mathrm{df}=5$, $\mathrm{F}=42.117, \mathrm{P}<0.001$ ) and mean densities (ANOVA, $\mathrm{df}=5, \mathrm{~F}=22.426, \mathrm{P}<0.001$ ) within the Radio Pirata fish community. Unlike all of the other sites, benthophagous fishes represented the highest density and abundance within Radio Pirata, comprising $51.80 \%$ of the entire fish community. Herbivores were the second-most abundant and dense group and comprised $31.08 \%$ of the Radio Pirata fish community. Radio Pirata had a mean total fish biomass $\left(\mathrm{g} / \mathrm{m}^{2} \pm \mathrm{SE}\right)$ of $65.98 \pm 11.56$ and a mean herbivore biomass of $14.98 \pm 3.72$. 


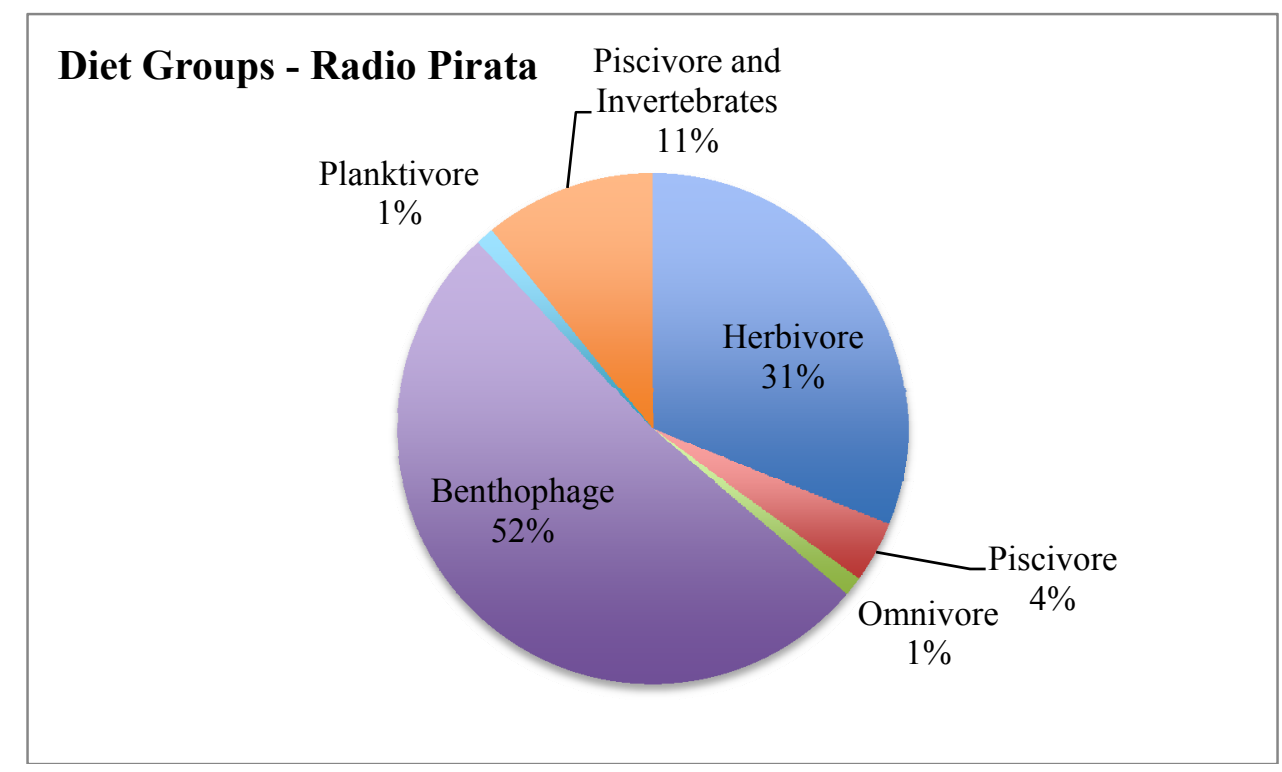

Figure 15. Percentage of fish population by diet group in Radio Pirata.

\begin{tabular}{lcc}
\hline Diet group & Mean Density & SE \\
\hline Herbivore & $0.371(\mathrm{~d})$ & 0.0419 \\
Piscivore & $0.047(\mathrm{a})$ & 0.015 \\
Omnivore & $0.015(\mathrm{a})$ & 0.005 \\
Benthophage & $0.618(\mathrm{c})$ & 0.113 \\
Planktivore & $0.014(\mathrm{a})$ & 0.006 \\
Piscivore and Invertebrates & 0.129 (a) & 0.037 \\
\hline
\end{tabular}

Table 16. Mean density (per $\mathrm{m}^{2}$ ) of diet groups in Radio Pirata. Values with different letters signify that a significant difference was detected.

Significant differences were detected between mean percent representation of size classes (ANOVA, $\mathrm{df}=5, \mathrm{~F}=18.860, \mathrm{P}<0.001)$ and mean density of size classes (ANOVA, $\mathrm{df}=5, \mathrm{~F}=13.253, \mathrm{P}<0.001)$ within the Radio Pirata fish community. The $6-10 \mathrm{~cm}$ and $11-$ $20 \mathrm{~cm}$ size classes both comprised significantly larger portions of the Radio Pirata fish community than any other group, and also had significantly higher densities. The mean density of $D$. antillarum in Radio Pirata was 0.0139 individuals per $\mathrm{m}^{2}$. 


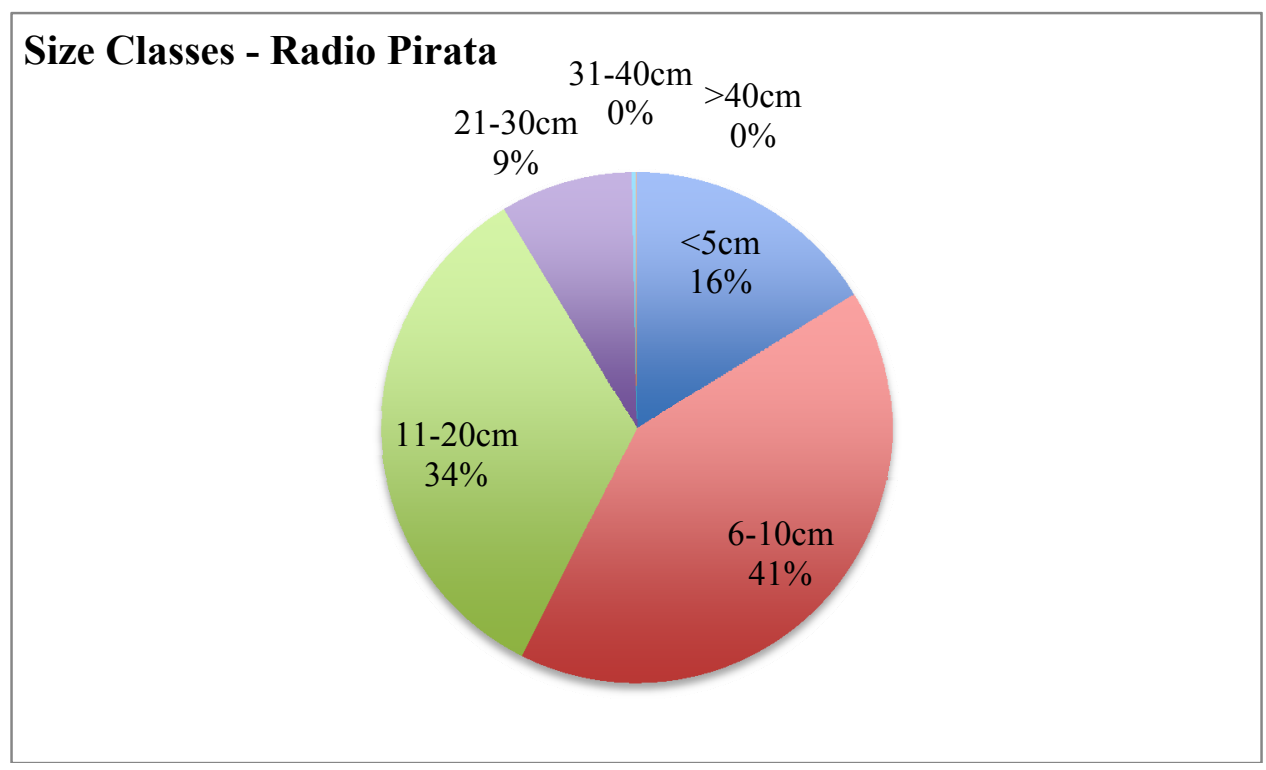

Figure 16. Percentage of fish population by size class in Radio Pirata.

\begin{tabular}{lcc}
\hline Size Class & Mean Density & SE \\
\hline$<5 \mathrm{~cm}$ & $0.194(\mathrm{~b})$ & 0.051 \\
$6-10 \mathrm{~cm}$ & $0.491(\mathrm{c})$ & 0.078 \\
$11-20 \mathrm{~cm}$ & $0.405(\mathrm{c})$ & 0.099 \\
$21-30 \mathrm{~cm}$ & $0.100(\mathrm{a}, \mathrm{b})$ & 0.03 \\
$31-40 \mathrm{~cm}$ & $0.003(\mathrm{a})$ & 0.002 \\
$>40 \mathrm{~cm}$ & $0.001(\mathrm{a})$ & 0.001 \\
\hline
\end{tabular}

Table 17. Mean density (per $\mathrm{m}^{2}$ ) of size classes within Radio Pirata. Values with different letters signify that a significant difference was detected.

Jardines

Sampling transects within Jardines were carried out at depths ranging from 3 to 3.5 meters. Fleshy macroalgae was the most prevalent benthic component in Jardines and comprised $23.89 \% \pm 4.55$ of the substrate. Sand $(20.00 \% \pm 5.46)$ was the next most prevalent benthic component followed by hard corals, which comprised $15.56 \% \pm 3.61$ of the substrate in Jardines. 


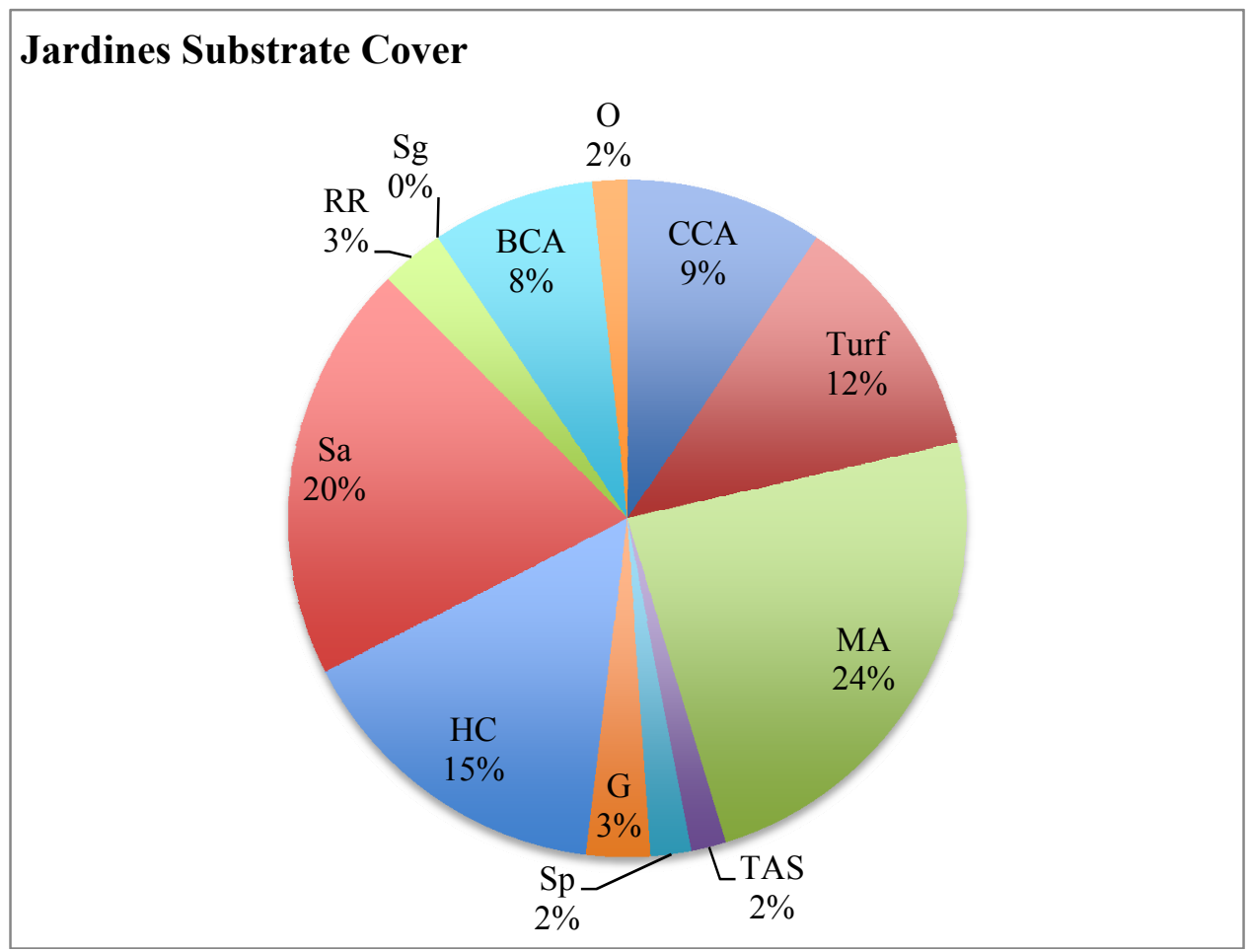

Figure 17. Mean percentage cover of substrate in Jardines. MA $=$ macroalgae, $\mathrm{TAS}=$ turf-algal sediment, $\mathrm{Sp}=$ Sponge, $\mathrm{G}=$ gorgonian, $\mathrm{HC}=$ hard coral, $\mathrm{Sa}=$ sand, $\mathrm{RR}=$ Rock/Rubble, $\mathrm{Sg}=$ seagrass, $\mathrm{BCA}=$ branched calcareous algae, $\mathrm{O}=$ other.

A total of eight species of hard corals were identified in Jardines, which contained the most even coral community composition of all sites, with no species representing more than $28 \%$ of colonies sampled. 


\section{Jardines Coral Community}

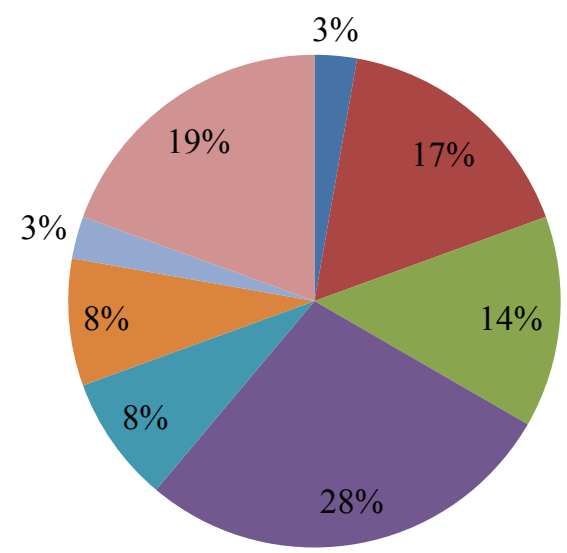

- Agaricia agaricites

- Agaricia tenuifolia

- Diploria strigosa

- Montastraea annularis

- Montastraea cavernosa

- Montastraea faveolata

- Porites astreoides

- Siderastrea siderea

Figure 18. Coral community composition in Jardines $(n=36)$.

The 36 coral colonies sampled in Jardines demonstrated $35.56 \% \pm 4.39$ dead tissue cover and $64.44 \%$ live tissue composition. $2.78 \%$ of the coral colonies sampled ( 1 out of 36) in Jardines demonstrated signs of coral disease presence. The average rugosity of the Jardines study site was $92.53 \pm 9.11$ and the average architectural index score was 111.43 \pm 28.87 .

Macroalgae nutrient analysis results are summarized in Table 18. The mean N:P ratio in Jardines was 99.09 $\pm 4.63, \mathrm{C}: \mathrm{N} 21.25 \pm 1.25$, and C:P $2120.67 \pm 185.98$.

\begin{tabular}{lccc}
\hline \multicolumn{1}{c}{ Nutrient } & \% Tissue Content & SD & SE \\
\hline Phosphorous & 0.059 & 0.010 & 0.004 \\
Nitrogen & 2.347 & 0.394 & 0.161 \\
Carbon & 41.893 & 2.702 & 1.103 \\
\hline
\end{tabular}

Table 18. Percent nutrient content results for macroalgae nutrient analyses in Jardines. A total of 1136 fish, representing 47 species were identified in Jardines, which had a Shannon-Weiner diversity index score of 3.003.

Jardines had a mean total fish density of $0.7889 \pm 0.1163$ individuals per $\mathrm{m}^{2}$. The bluehead Thalassoma bifasciatum was the most abundant fish observed in Jardines. 


\begin{tabular}{lcccc}
\hline Species & N & $\begin{array}{c}\text { Mean Density } \\
\left(\mathbf{m}^{2}\right)\end{array}$ & \% of Total & Diet \\
\hline Thalassoma bifasciatum & 240 & 0.1667 & 21.13 & $\mathrm{~B}$ \\
Chromis cyanea & 122 & 0.0847 & 10.74 & $\mathrm{PK}$ \\
Haemulon sciurus & 109 & 0.0757 & 9.6 & $\mathrm{~B}$ \\
Abudefduf saxatilis & 80 & 0.0556 & 7.04 & $\mathrm{~B}$ \\
Stegastes adustus & 66 & 0.0458 & 5.81 & $\mathrm{H}$ \\
\hline TOTAL & $\mathbf{6 1 7}$ & $\mathbf{0 . 4 2 8 5}$ & $\mathbf{5 4 . 3 2}$ & \\
\hline
\end{tabular}

Table 19. Total number $(\mathrm{N})$, density $\left(\right.$ per $\left.\mathrm{m}^{2}\right)$, and percentage of total site population for the five most abundant fishes observed in Jardines. $\mathrm{H}=$ Herbivore; $\mathrm{B}=$ Benthophage; $\mathrm{PK}=$ Planktivore.

Percent representation (ANOVA, $\mathrm{df}=5, \mathrm{~F}=30.412, \mathrm{P}<0.001)$ and mean density (ANOVA, $d f=5, F=11.690, P<0.001$ ) of functional groups within the fish community of Jardines significantly differed. The two densest diet groups were benthophagous and herbivorous fishes, with benthophagous fishes comprising $48.86 \%$ of the population surveyed and herbivores at $34.42 \%$. Jardines had a mean total fish biomass $\left(\mathrm{g} / \mathrm{m}^{2} \pm \mathrm{SE}\right)$ of $16.49 \pm 4.76$ and a mean herbivore biomass of $8.29 \pm 3.56$.

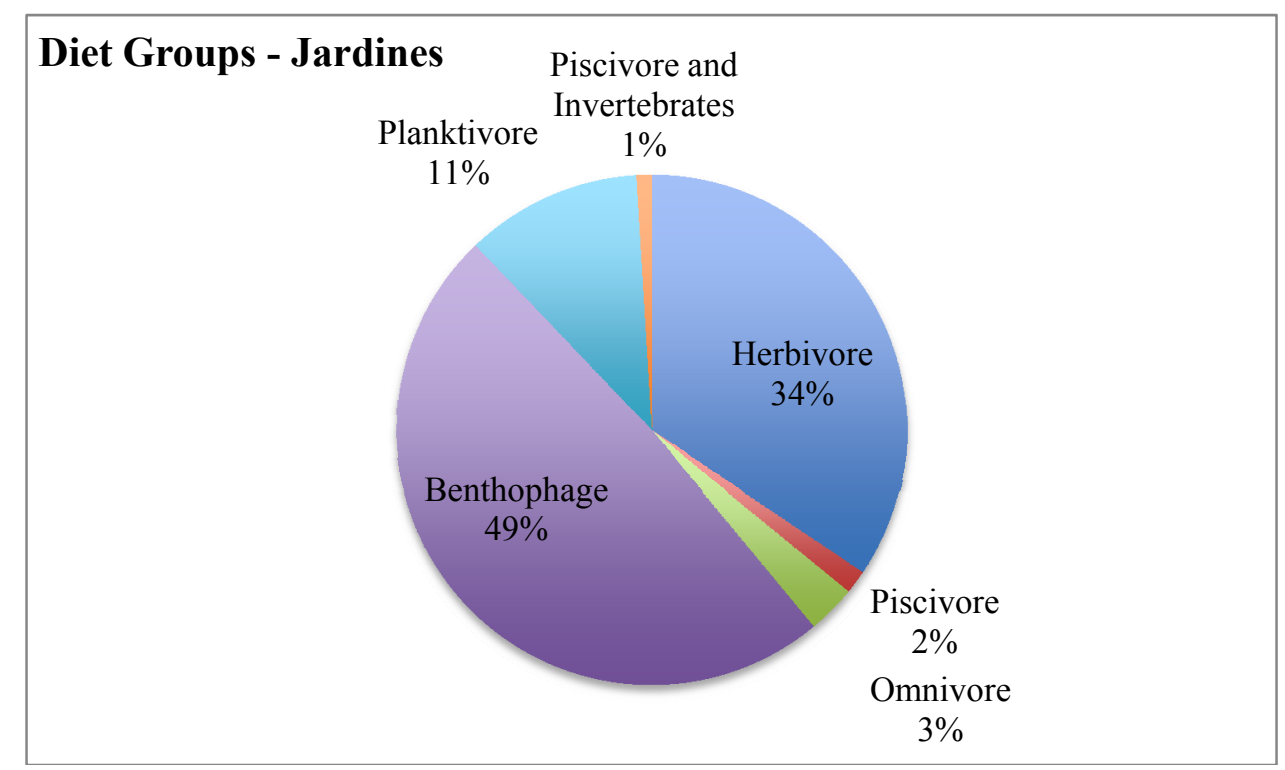

Figure 19. Percentage of fish population by diet group in Jardines. 


\begin{tabular}{lcc}
\hline Diet group & Mean Density & SE \\
\hline Herbivore & $0.272(\mathrm{~b})$ & 0.026 \\
Piscivore & $0.012(\mathrm{a})$ & 0.007 \\
Omnivore & $0.024(\mathrm{a})$ & 0.01 \\
Benthophage & $0.385(\mathrm{~b})$ & 0.106 \\
Planktivore & $0.088(\mathrm{a})$ & 0.031 \\
Piscivore and Invertebrates & $0.008(\mathrm{a})$ & 0.002 \\
\hline
\end{tabular}

Table 20. Mean density (per $\mathrm{m}^{2}$ ) of diet groups in Jardines. Values with different letters signify that a significant difference was detected.

Significant differences existed between the mean percentage of size classes within the Jardines fish population (ANOVA, $\mathrm{df}=5, \mathrm{~F}=33.864, \mathrm{P}<0.001$ ) and mean density of different size classes (ANOVA, $\mathrm{df}=5, \mathrm{~F}=12.043, \mathrm{P}<0.001$ ). Approximately half of all fish surveyed in Jardines were in the 6-10 cm size class (53.79\%), which was also the size class with the highest density. Individuals in the $<5 \mathrm{~cm}$ size class had the secondhighest density and comprised 31.69\% (SE) of the Jardines fish community, significantly higher than all other classes except for the $6-10 \mathrm{~cm}$ size class. No D. antillarum individuals were observed during belt transect sampling in Jardines.

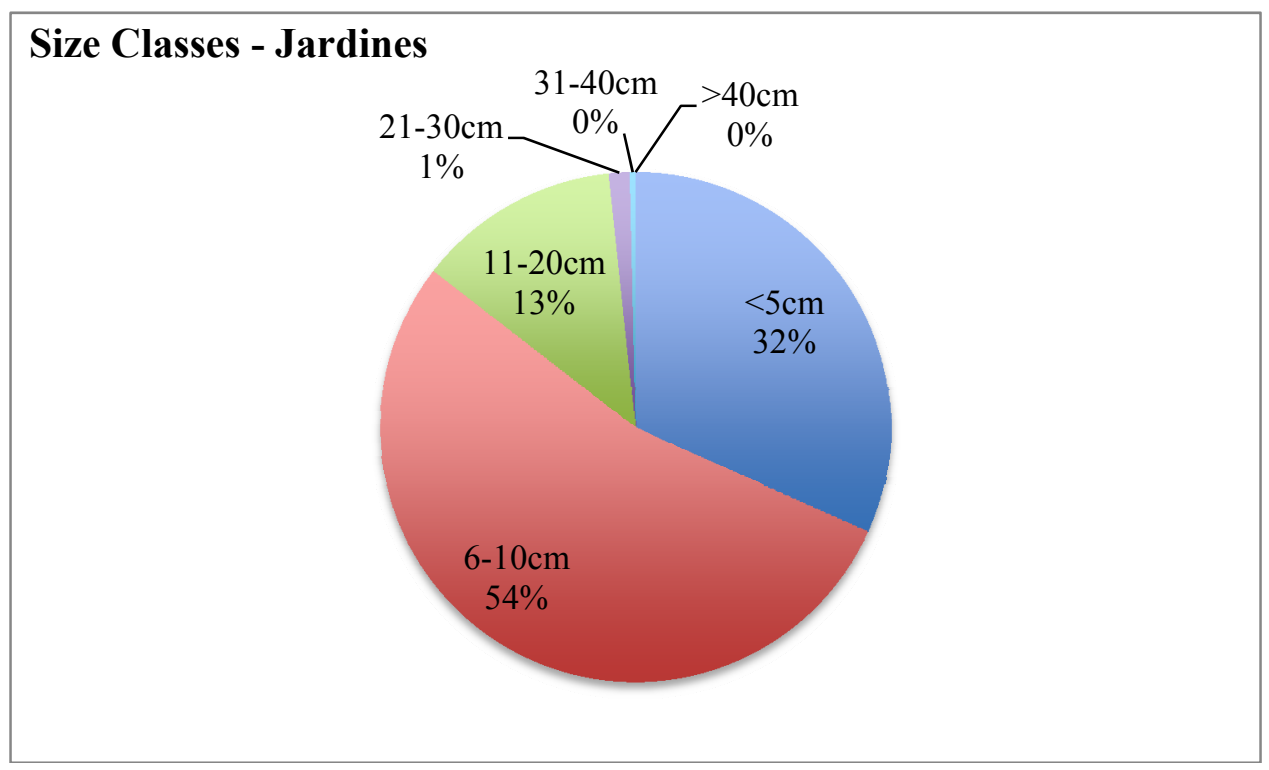

Figure 20. Percentage of fish population by size class in Jardines. 


\begin{tabular}{lcc}
\hline Size Class & Mean Density & SE \\
\hline$<5 \mathrm{~cm}$ & $0.25(\mathrm{~b})$ & 0.059 \\
$6-10 \mathrm{~cm}$ & $0.4243(\mathrm{c})$ & 0.104 \\
$11-20 \mathrm{~cm}$ & $0.1014(\mathrm{a})$ & 0.024 \\
$21-30 \mathrm{~cm}$ & $0.0104(\mathrm{a})$ & 0.005 \\
$31-40 \mathrm{~cm}$ & $0.0028(\mathrm{a})$ & 0.002 \\
$>40 \mathrm{~cm}$ & $0(\mathrm{a})$ & 0 \\
\hline
\end{tabular}

Table 21. Mean density $\left(\right.$ per $\left.^{2}\right)$ of size classes within Jardines. Values with different letters signify that a significant difference was detected.

\section{INTER-SITE COMPARISONS:}

\section{Benthic Community Composition}

Significant inter-site differences existed between the percent cover of six of the twelve substrate categories measured in this study (Wilks' Lambda, $\left(\mathrm{F}_{33,6.60}\right)=11.127$, $\mathrm{P}=0.002)$. Percent cover of crustose coralline algae (CCA), turf, macroalgae, gorgonians, hard corals, and seagrass substrate significantly varied between two or more sites (See Table 23 for $\mathrm{P}$ values). The CCA cover in La Bonanza (mean $\pm \mathrm{SE})(1.04 \pm 0.50)$ was significantly lower than at all other sites and was highest in Tanchacte $(14.17 \% \pm 3.15)$. Similarly, hard coral cover was significantly lower in La Bonanza than all other sites. Hard coral cover in Limones was the highest of any of the study sites $(16.5 \% \pm 2.13)$ and was significantly higher than in La Bonanza and Tanchacte. Limones also had a significantly higher turf cover than all other sites. Macroalgae cover was clearly higher in Tanchacte where it comprised $47.5 \% \pm 2.55$ of the substrate, which was significantly higher than all other sites. No significant differences in macroalgae cover were detected between the remaining three sites. Tanchacte also contained significantly higher gorgonian cover than any other site. Seagrass percent cover was substantially higher in La Bonanza compared to all other sites. 


\begin{tabular}{lcccc}
\hline \multicolumn{5}{c}{ SITE } \\
\hline Substrate & Limones & La Bonanza & Tanchacte & Jardines \\
\hline CCA & $7.33(\mathrm{~b})$ & $1.04(\mathrm{a})$ & $14.17(\mathrm{~b})$ & $9.44(\mathrm{~b})$ \\
Turf & $27.33(\mathrm{~b})$ & $11.95(\mathrm{a})$ & $6.66(\mathrm{a})$ & $11.95(\mathrm{a})$ \\
Macroalgae & $11.83(\mathrm{a})$ & $14.74(\mathrm{a})$ & $47.5(\mathrm{~b})$ & $23.89(\mathrm{a})$ \\
TAS & 1.00 & 1.00 & 1.11 & 1.67 \\
Sponge & 0.83 & 0.00 & 0.55 & 1.94 \\
Gorgonian & $0.5(\mathrm{a})$ & $1.55(\mathrm{a}, \mathrm{b})$ & $6.39(\mathrm{c})$ & $3.06(\mathrm{~b})$ \\
Hard Coral & $16.5(\mathrm{c})$ & $3.45(\mathrm{a})$ & $8.34(\mathrm{a}, \mathrm{b})$ & $15.56(\mathrm{~b}, \mathrm{c})$ \\
Sand & 15.83 & 33.47 & 2.78 & 20.00 \\
Rock/Rubble & 4.33 & 10.58 & 2.78 & 3.06 \\
Seagrass & $1(\mathrm{a})$ & $8.18(\mathrm{~b})$ & $0(\mathrm{a})$ & $0(\mathrm{a})$ \\
Branched & 12.83 & 13.19 & 9.44 & 7.78 \\
Calcareous Algae & & & & \\
Other & 0.67 & 0.86 & 0.28 & 1.67 \\
\hline
\end{tabular}

Table 22. Mean percent cover values for each substrate category by site. Sites with different letters of the same substrate category indicate significantly different values.

\begin{tabular}{lccc}
\hline Substrate & df & F & P value \\
\hline CCA & 3 & 5.691 & $0.012^{*}$ \\
Turf & 3 & 21.331 & $<0.001^{*}$ \\
Macroalgae & 3 & 12.520 & $0.001^{*}$ \\
TAS & 3 & 0.244 & 0.864 \\
Sponge & 3 & 1.328 & 0.311 \\
Gorgonian & 3 & 13.794 & $<0.001^{*}$ \\
Hard Coral & 3 & 9.012 & $0.002^{*}$ \\
Sand & 3 & 2.718 & 0.091 \\
Rock/Rubble & 3 & 5.609 & 0.197 \\
Seagrass & 3 & 1.823 & $0.012^{*}$ \\
Branched Calcareous Algae & 3 & 1.121 & 0.379 \\
Other & 3 & 1.040 & 0.410 \\
\hline
\end{tabular}

Table 23. ANOVA results for differences in percent cover of different substrate types. Significantly different $\mathrm{P}$ values are denoted with an asterisk (*).

Limones contained on average the largest coral colonies of all sites, although no significant inter-site differences were detected in mean coral colony size (Kruskal-Wallis, $\mathrm{df}=3$, Chi-Square $=2.167, \mathrm{P}=0.539$ ). 


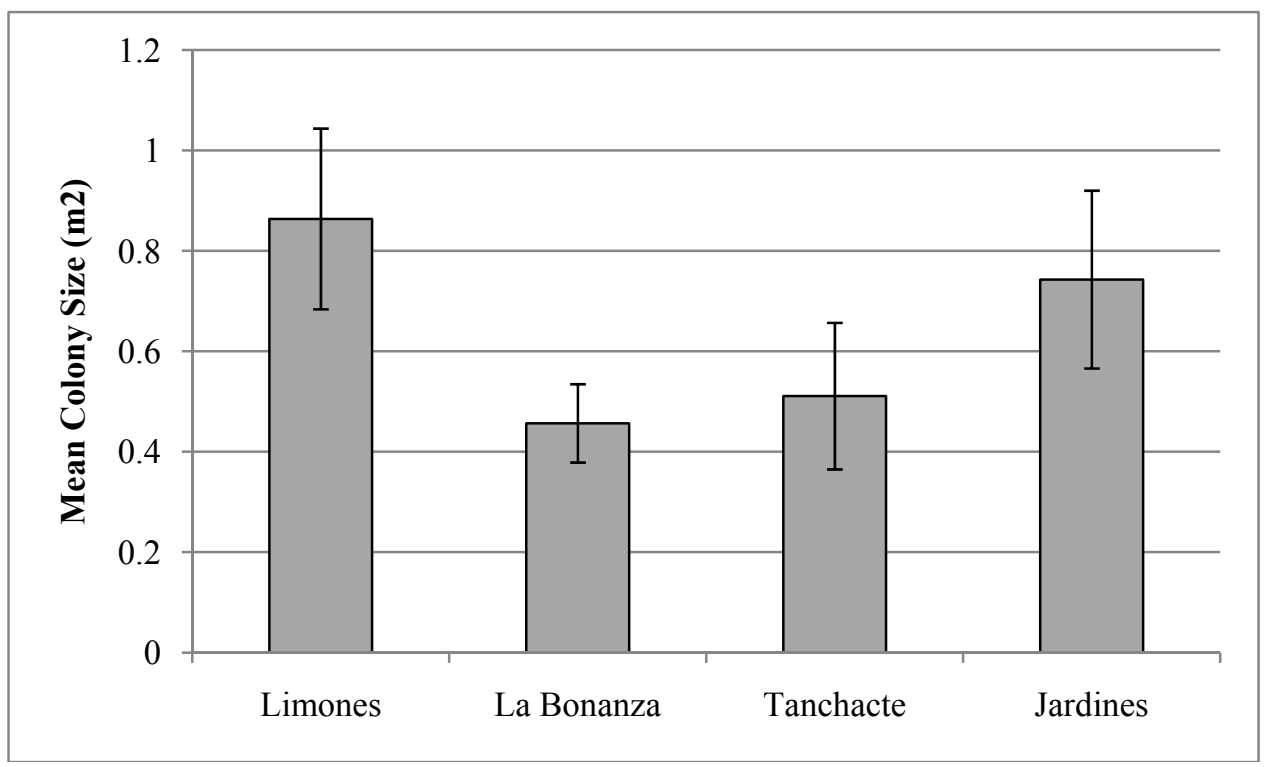

Figure 21. Mean coral colony size by site. (Limones, $n=59$; La Bonanza, $n=24$; Tanchacte, $n=29$; Jardines, $n=36$ ). Error bars represent \pm 1 SE.

Coral colonies in Limones were found to have the highest mean percentage of live coral tissue at $81.97 \% \pm 2.57$ (ANOVA, $\mathrm{df}=3, \mathrm{~F}=6.365, \mathrm{P}<0.001)$. The remaining three sites demonstrated similar values of mean live and dead coral cover, with La Bonanza having the lowest mean percentage of live coral colony tissue at $57.42 \% \pm 7.18$. No significant differences were found between the mean area of dead coral tissue and live coral tissue between sites (Wilks' Lambda, $\mathrm{F}_{(6,286)}=1.568, \mathrm{P}=0.156$ ). 


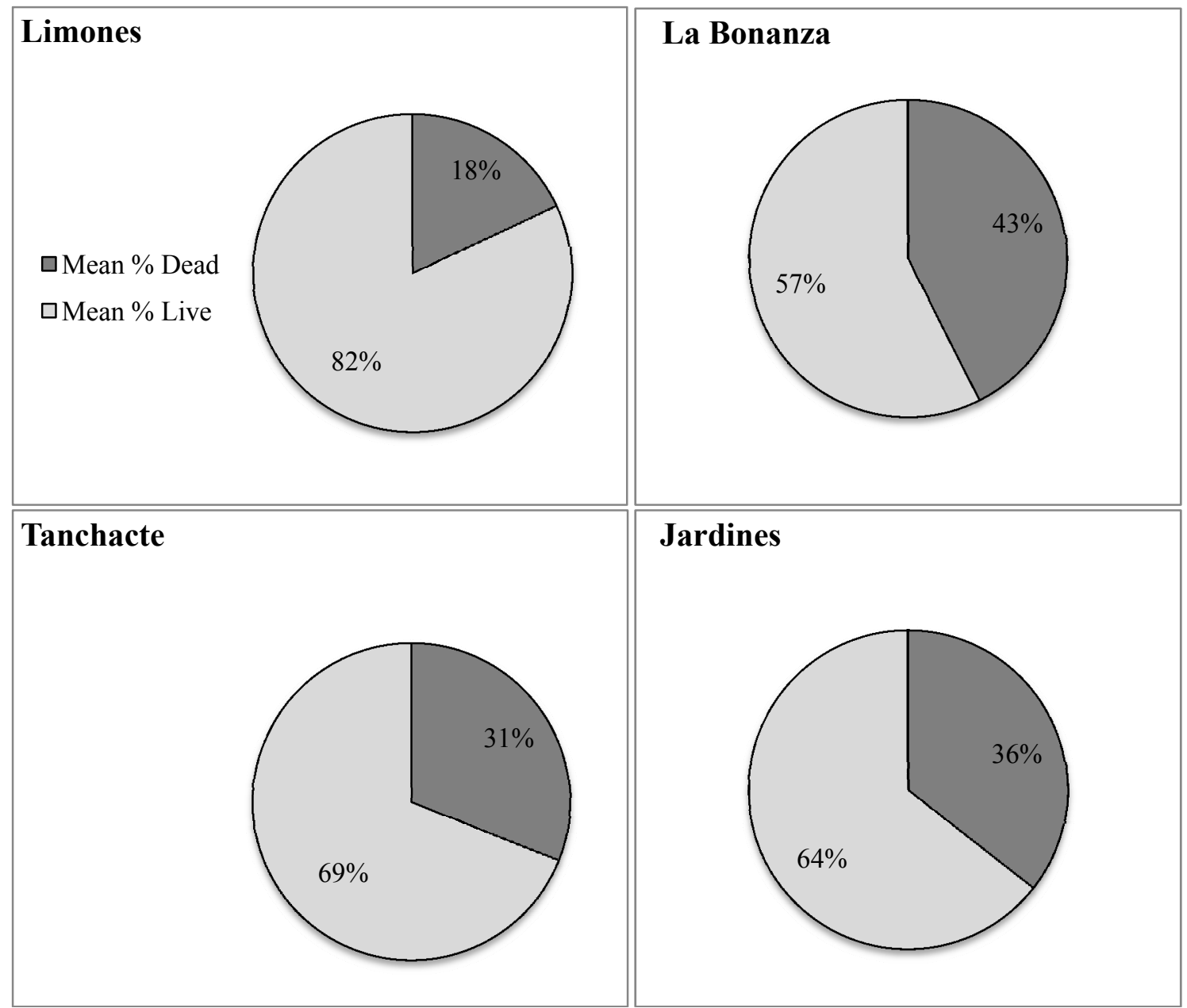

Figure 22. Mean percent of dead coral tissue and live coral tissue for all coral colonies surveyed by site.

No significant differences were detected in mean rugosity (Kruskal-Wallis, $\mathrm{df}=3$, Chi-square $=2.248, \mathrm{P}=0.522)$ or in mean architectural index scores (Kruskal-Wallis, $\mathrm{df}=3$, Chi-square $=6.543, \mathrm{P}=0.088$ ) between sites. 


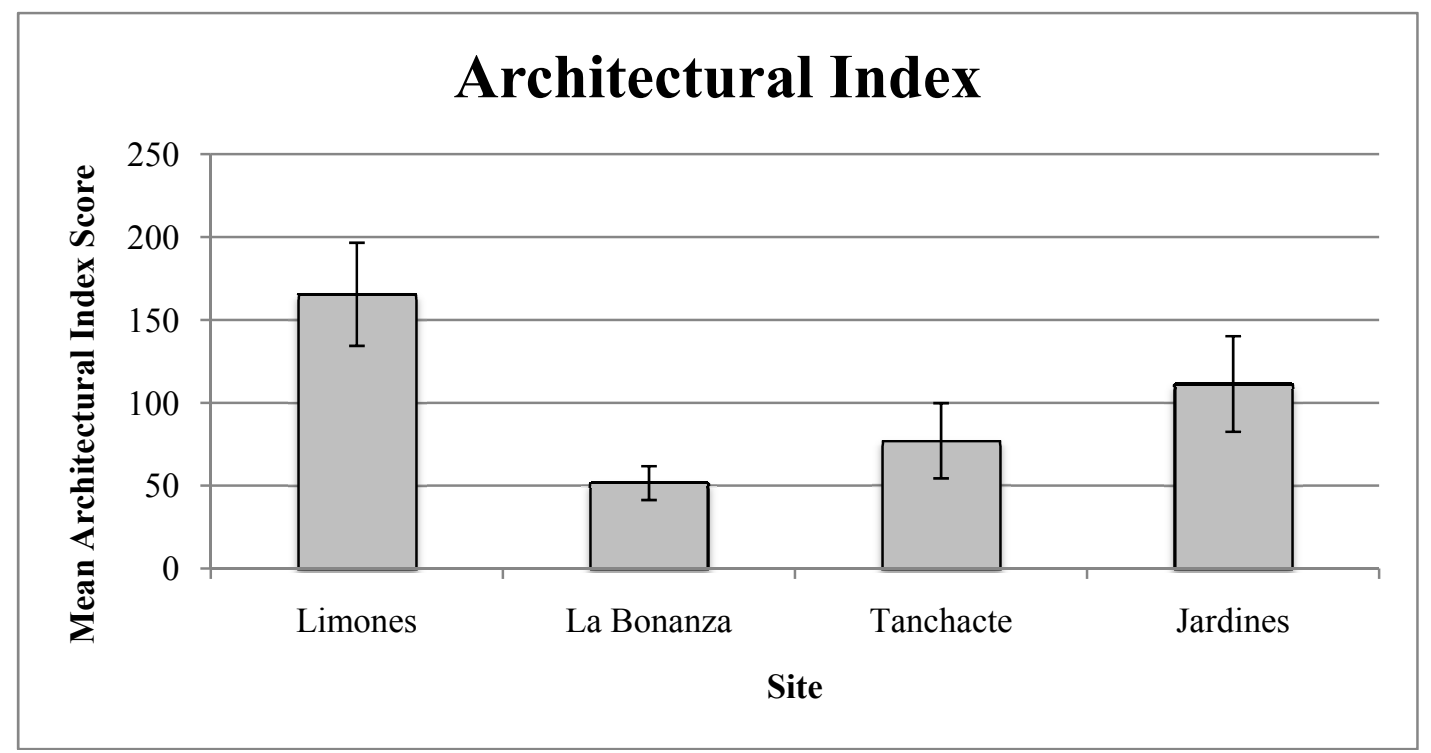

Figure 23. Mean architectural index scores by site. No significant differences were detected. Error bars represent \pm 1 SE.

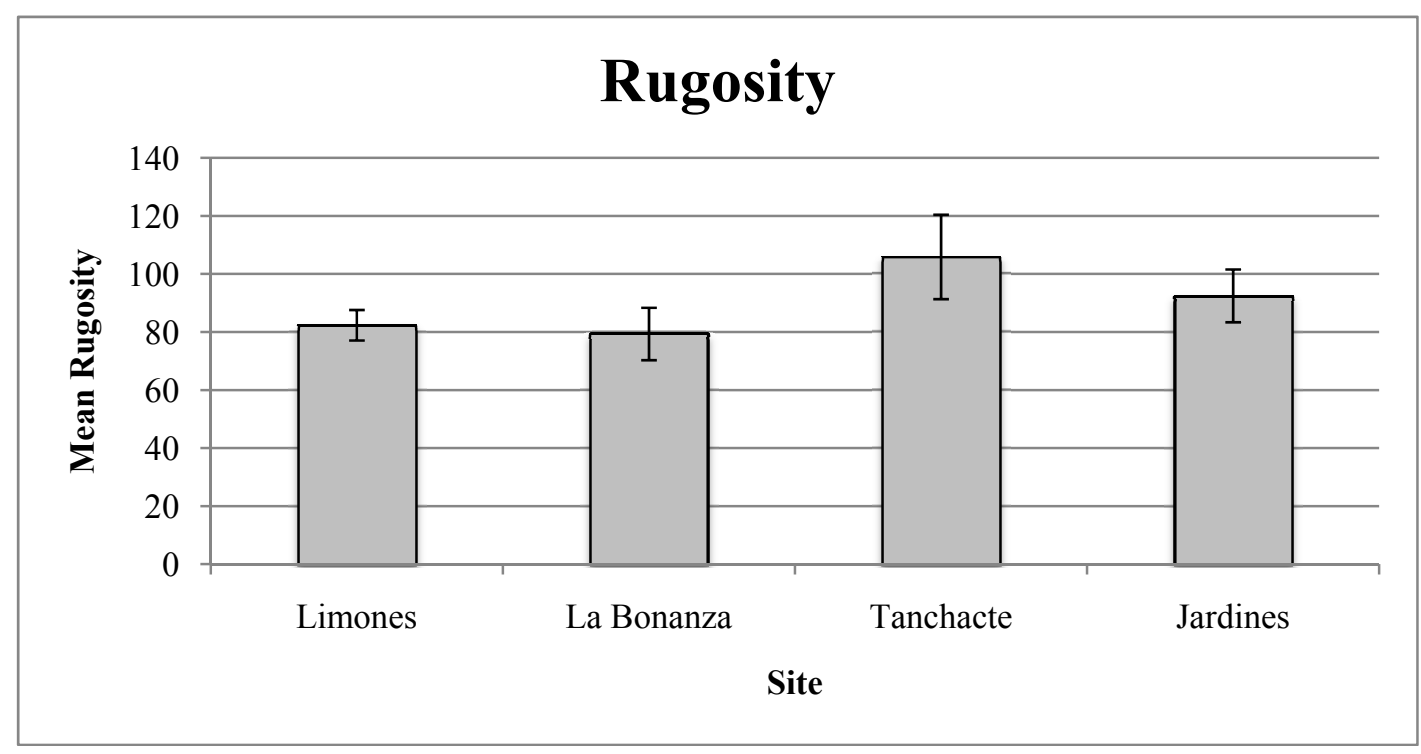

Figure 24. Mean rugosity scores by site. No significant differences were detected between sites. Error bars represent $\pm 1 \mathrm{SE}$.

\section{Nutrient Analysis}

Tissue phosphorus content ranged from $0.077 \%$ in Limones and Radio Pirata to $0.053 \%$ in Tanchacte. Percent tissue phosphorus content of macroalgae samples in Limones and Radio Pirata was significantly higher than in the other three sites (ANOVA, 
$\mathrm{df}=4, \mathrm{~F}=4.827, \mathrm{P}=0.005$ ). Percent tissue phosphorus content values did not significantly differ between La Bonanza, Tanchacte, and Jardines. Percent tissue nitrogen content ranged from $2.347 \%$ in Jardines to a high of 3.091\% in Radio Pirata, which was significantly higher than all four other sites (ANOVA, $\mathrm{df}=4, \mathrm{~F}=0.478, \mathrm{P}=0.002$ ). Although no significant differences were detected in tissue carbon content between sites (ANOVA, $\mathrm{df}=4, \mathrm{~F}=2.446, \mathrm{P}=0.074$ ), tissue carbon content was highest in Radio Pirata (42.51\%) and lowest in La Bonanza (38.36\%).

All sites showed macroalgae enriched in $\mathrm{N}$ but not $\mathrm{P}$. Mean N:P was significantly lower in Limones (68.68) than all study sites except for Radio Pirata, and was highest in Tanchacte (102.84) (ANOVA, $\mathrm{df}=4, \mathrm{~F}=3.082, \mathrm{P}=0.035)$. The highest $\mathrm{C}: \mathrm{N}$ ratio $(21.25)$ was found in Jardines, which was significantly higher than all other sites (ANOVA, $d f=4$, $\mathrm{F}=6.375, \mathrm{P}=0.001$ ), compared to 15.95 in Radio Pirata, which was significantly lower than all study sites. Jardines demonstrated the highest C:P ratio $(2,120.67)$ and Limones the lowest $(1,304.24)$ (ANOVA, $\mathrm{df}=4, \mathrm{~F}=3.905, \mathrm{P}=0.014)$. 


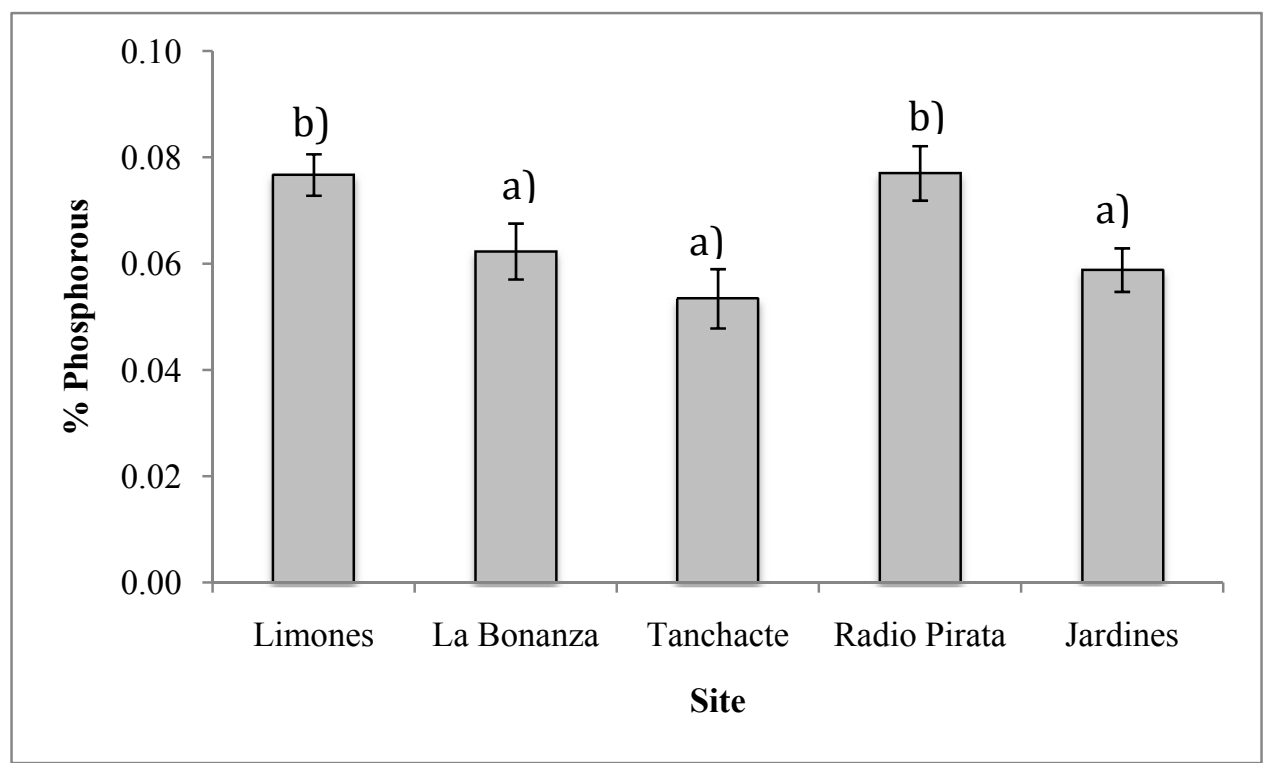

Figure 25. Tissue phosphorous content results (\%P) in Dictyota menstrualis/cervicornis complex. Significantly different values are denoted by different letters. Error bars represent $\pm 1 \mathrm{SE}$.

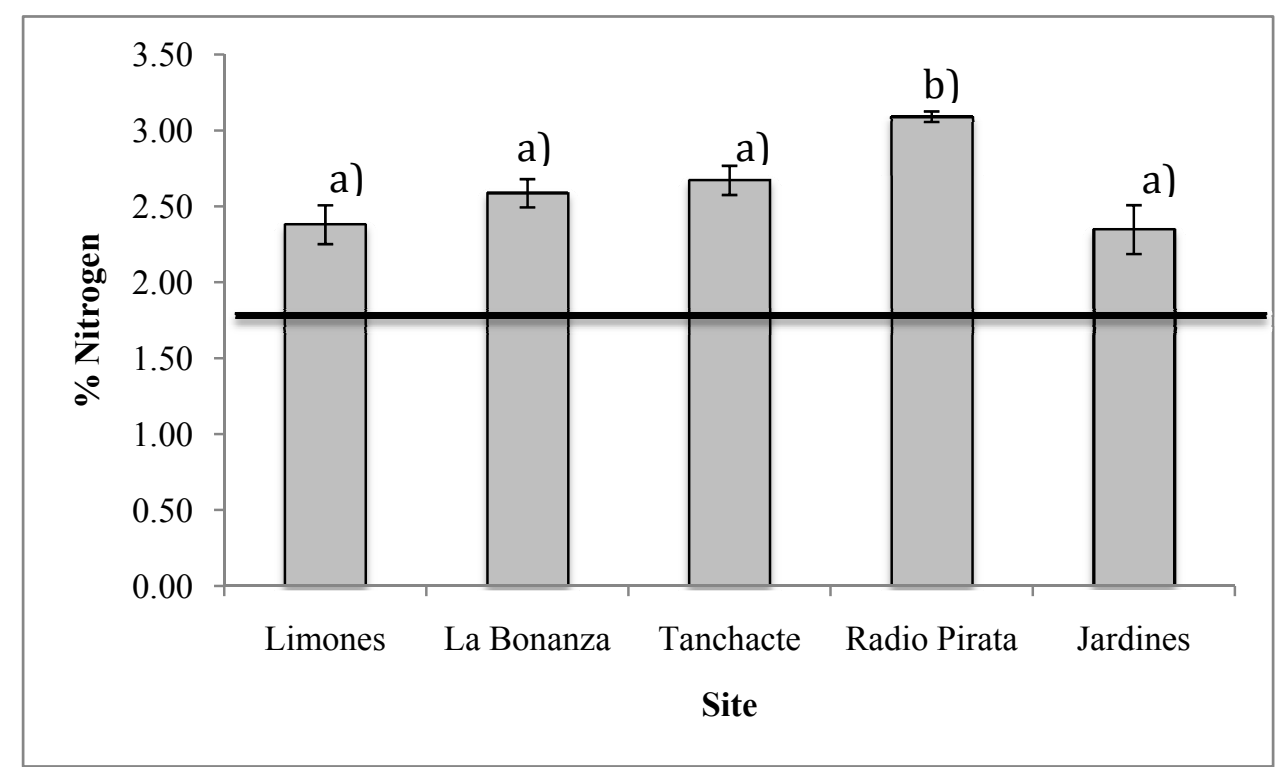

Figure 26. Tissue nitrogen content results (\% N) in Dictyota menstrualis/cervicornis complex. Significantly different values are denoted by different letters. The black line represents the general threshold of nitrogen replete (Atkinson \& Smith, 1983; Duarte, 1990). Error bars represent \pm 1 SE. 


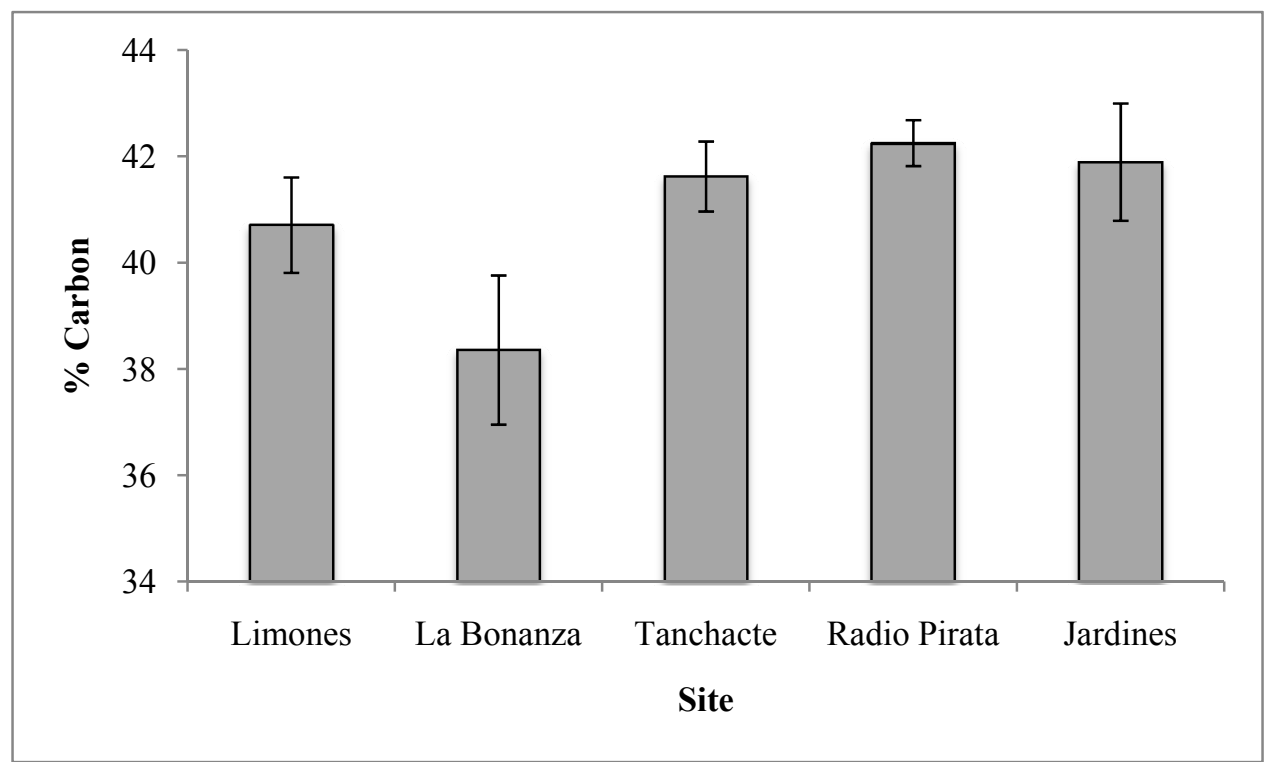

Figure 27. Tissue carbon content results $(\% \mathrm{C})$ in Dictyota menstrualis/cervicornis complex. Significantly different values are denoted by different letters. Error bars represent \pm 1 SE. No significant inter-site differences were detected.

\begin{tabular}{lccc}
\hline Site & $\mathbf{N}: \mathbf{P}$ & $\mathbf{C}: \mathbf{N}$ & $\mathbf{C : P}$ \\
\hline Limones & $68.68(\mathrm{a})$ & $19.00(\mathrm{~b})$ & $1304.24(\mathrm{a})$ \\
La Bonanza & $97.53(\mathrm{~b})$ & $18.38(\mathrm{~b})$ & $1800.66(\mathrm{~b}, \mathrm{c})$ \\
Tanchacte & $102.84(\mathrm{~b})$ & $18.26(\mathrm{~b})$ & $1866.56(\mathrm{~b}, \mathrm{c})$ \\
Radio Pirata & $90.21(\mathrm{a}, \mathrm{b})$ & $15.95(\mathrm{a})$ & $1440.31(\mathrm{a}, \mathrm{b})$ \\
Jardines & $99.09(\mathrm{~b})$ & $21.15(\mathrm{c})$ & $2120.67(\mathrm{c})$ \\
\hline
\end{tabular}

Table 24. N:P, C:N, and C:P tissue nutrient content ratios by site. Significantly different values are denoted by different letters.

\section{Fish Communities}

A total of 5,458 fish, representing 25 families, 37 genera, and 69 species were counted in the 60 belt transects conducted in this study. There were no significant differences in Shannon-Weiner diversity indices between sites (ANOVA, $\mathrm{df}=4, \mathrm{~F}=1.541$, $\mathrm{P}=0.20$ ). Overall, herbivores were the most abundant functional group of fish encountered, representing $43.50 \%$ of all fishes recorded. Benthophagous fishes were the second-most abundant functional group, comprising $42.25 \%$ of the PNAPM fish community sampled. Fishes measuring 6-10 cm represented $46.19 \%$ of all fishes 
observed, followed by the $11-20 \mathrm{~cm}$ size class (24.81\%) and the $<5 \mathrm{~cm}$ size class $(23.87 \%)$.

The five most common families comprised $88.58 \%$ of all fishes recorded in this study (See Table 25 below). Individuals from the Pomacentridae family, which includes damselfish and the sergeant major, was the most abundant and comprised nearly a quarter of all fish counted $(24.37 \%)$.

\begin{tabular}{clcc}
\hline Rank & \multicolumn{1}{c}{ Family } & N & \% of Total \\
\hline 1 & Pomacentridae & 1330 & 24.37 \\
2 & Haemulidae & 1093 & 20.03 \\
3 & Scaridae & 1074 & 19.68 \\
4 & Labridae & 795 & 14.57 \\
5 & Acanthuridae & 542 & 9.93 \\
\hline & TOTAL & $\mathbf{4 8 3 4}$ & $\mathbf{8 8 . 5 8}$ \\
\hline
\end{tabular}

Table 25. Abundance and percentage of total for the five most common families of fishes observed in fish surveys.

The 10 most abundant species observed comprised $64.41 \%$ of all fish sampled.

The striped parrotfish $S$. iserti was the most abundant fish species overall, followed by the bluehead T. bifasciatum and the dusky damselfish $S$. adustus. The ten most abundant species from the belt transect surveys of all sites are summarized in Table 26.

\begin{tabular}{clcc}
\hline Rank & Species & N & \% of Total \\
\hline 1 & Scarus iserti & 608 & 11.14 \\
2 & Thalassoma bifasciatum & 553 & 10.13 \\
3 & Stegastes adustus & 382 & 7.00 \\
4 & Haemulon flavolineatum & 379 & 6.94 \\
5 & Haemulon sciurus & 347 & 6.36 \\
6 & Acanthurus coeruleus & 318 & 5.83 \\
7 & Abudefduf saxatilis & 295 & 5.40 \\
8 & Haemulon plumieri & 220 & 4.03 \\
9 & Acanthurus bahianus & 214 & 3.92 \\
10 & Lutjanus apodus & 200 & 3.66 \\
\hline & TOTAL & $\mathbf{3 5 1 6}$ & $\mathbf{6 4 . 4 1}$ \\
\hline
\end{tabular}

Table 26. Abundance and percent of total for the ten most abundant species observed in belt transect surveys of PNAPM fish communities. 


\begin{tabular}{lccccccc}
\hline Species & $<\mathbf{5} \mathbf{c m}$ & $\mathbf{6 - 1 0} \mathbf{~ c m}$ & $\mathbf{1 1 - 2 0} \mathbf{~ c m}$ & $\mathbf{2 1 - 3 0} \mathbf{~ c m}$ & $\mathbf{3 1 - 4 0} \mathbf{~ c m}$ & $>\mathbf{4 0 c m}$ & Total \\
\hline S. iserti & 323 & 280 & 5 & 0 & 0 & 0 & 608 \\
T. bifasciatum & 296 & 250 & 7 & 0 & 0 & 0 & 553 \\
S. adustus & 84 & 294 & 4 & 0 & 0 & 0 & 382 \\
H. flavolineatum & 33 & 153 & 188 & 5 & 0 & 0 & 379 \\
H. sciurus & 13 & 100 & 207 & 24 & 3 & 0 & 347 \\
\hline TOTAL & $\mathbf{7 4 9}$ & $\mathbf{1 0 7 7}$ & $\mathbf{4 1 1}$ & $\mathbf{2 9}$ & $\mathbf{3}$ & $\mathbf{0}$ & $\mathbf{2 2 6 9}$
\end{tabular}

Table 27. Abundance of the five most abundant species by size category.

As can be seen in Table 28, the vast majority (70.06\%) of fish observed in this study were $10 \mathrm{~cm}$ or less in length, and only $\sim 5 \%$ of fish recorded were larger than $20 \mathrm{~cm}$. Fish in the $6-10 \mathrm{~cm}$ size class were the most abundant in all sites, followed by the $<5 \mathrm{~cm}$ size class. Radio Pirata had the highest proportion of fish in the $11-20$ and $21-30 \mathrm{~cm}$ size class.

\begin{tabular}{lccccccc}
\hline $\begin{array}{l}\text { Size } \\
\text { Category }\end{array}$ & Limones & La Bonanza & Tanchacte & $\begin{array}{c}\text { Radio } \\
\text { Pirata }\end{array}$ & Jardines & Total & $\begin{array}{c}\text { \% of } \\
\text { Total }\end{array}$ \\
\hline$<5 \mathrm{~cm}$ & 187 & 291 & 186 & 279 & 360 & 1303 & 23.87 \\
$6-10 \mathrm{~cm}$ & 495 & 458 & 250 & 707 & 611 & 2521 & 46.19 \\
$11-20 \mathrm{~cm}$ & 224 & 202 & 199 & 583 & 146 & 1354 & 24.81 \\
$21-30 \mathrm{~cm}$ & 32 & 23 & 43 & 144 & 15 & 257 & 4.71 \\
$31-40 \mathrm{~cm}$ & 6 & 3 & 2 & 4 & 4 & 19 & 0.35 \\
$>40 \mathrm{~cm}$ & 1 & 0 & 2 & 1 & 0 & 4 & 0.07 \\
\hline Total & $\mathbf{9 4 5}$ & $\mathbf{9 7 7}$ & $\mathbf{6 8 2}$ & $\mathbf{1 7 1 8}$ & $\mathbf{1 1 3 6}$ & $\mathbf{5 4 5 8}$ & \\
\hline
\end{tabular}

Table 28. Size class abundance by site.

\begin{tabular}{lccccc}
\hline Size Class & Limones & La Bonanza & Tanchacte & Radio Pirata & Jardines \\
$<5 \mathrm{~cm}$ & 19.79 & 29.79 & 27.27 & 16.24 & 31.69 \\
$6-10 \mathrm{~cm}$ & 52.38 & 46.88 & 36.66 & 41.15 & 53.79 \\
$11-20 \mathrm{~cm}$ & 23.70 & 20.68 & 29.18 & 33.93 & 12.85 \\
$21-30 \mathrm{~cm}$ & 3.39 & 2.35 & 6.30 & 8.38 & 1.32 \\
$31-40 \mathrm{~cm}$ & 0.63 & 0.31 & 0.29 & 0.23 & 0.35 \\
$>40 \mathrm{~cm}$ & 0.11 & 0.00 & 0.29 & 0.06 & 0.00 \\
\hline Total & $\mathbf{1 0 0}$ & $\mathbf{1 0 0}$ & $\mathbf{1 0 0}$ & $\mathbf{1 0 0}$ & $\mathbf{1 0 0}$ \\
\hline
\end{tabular}

Table 29. Percent of total site populations represented by each size class.

Fish Density

Significant differences existed in the overall densities of fish communities (ANOVA, $\mathrm{df}=4, \mathrm{~F}=8.721, \mathrm{P}<0.001$ ), with Radio Pirata containing a significantly denser 
fish community than all other sites. No significant differences existed between the densities of the remaining four sites.

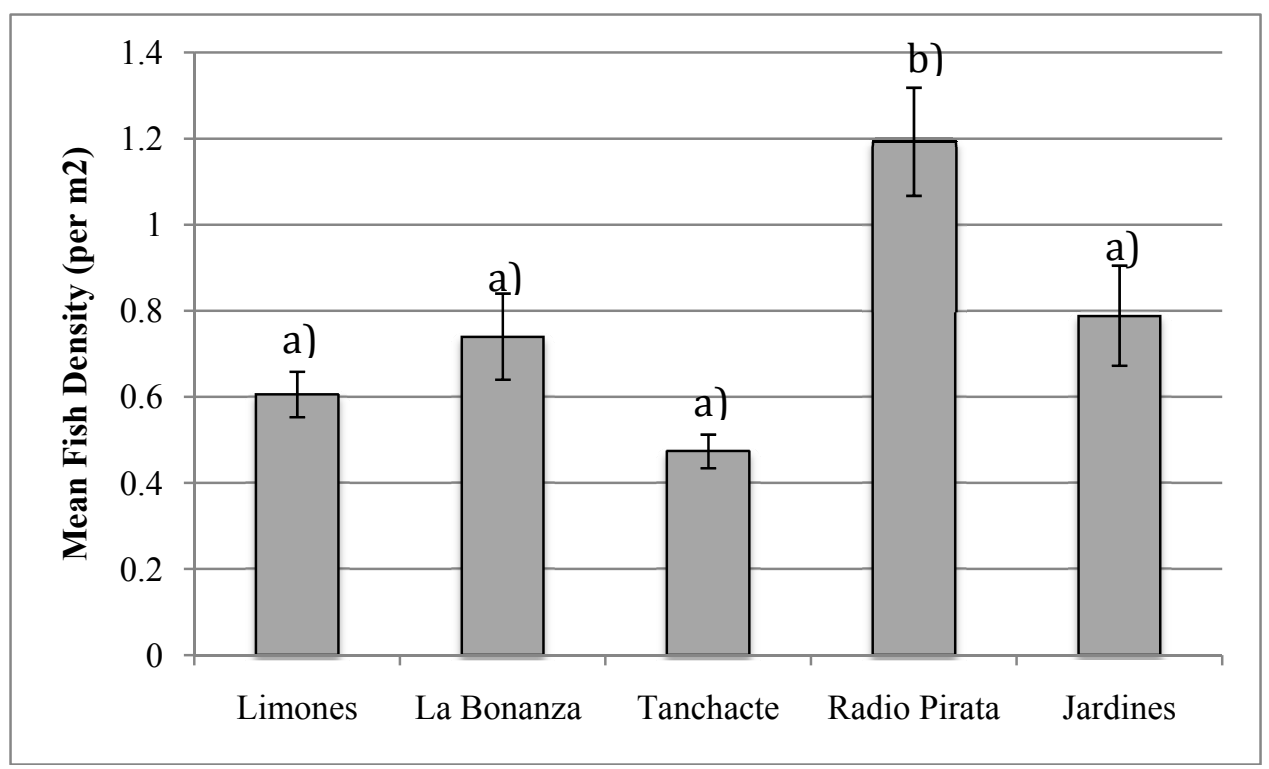

Figure 28. Overall fish community densities by site. Sites designated with different letters signify that a significant difference in density was detected. Error bars represent \pm 1 SE.

Significant differences were observed in the densities of different size classes between study sites (Wilks' Lambda $=0.347, \mathrm{~F}_{(24,176)}=2.596, \mathrm{P}<0.001$ ). Specifically, significant inter-site differences in fish densities of the size classes $6-10 \mathrm{~cm}, 11-20 \mathrm{~cm}$, and $21-30 \mathrm{~cm}$ were found. Densities of the $6-10 \mathrm{~cm}$ size class in Radio Pirata and Jardines were significantly higher than in Tanchacte, which had the lowest density of fishes in that size class. In the $11-20 \mathrm{~cm}$ and $21-30 \mathrm{~cm}$ size class Radio Pirata was observed to have significantly higher densities of fishes than all other study sites. 


\begin{tabular}{lccc}
\hline Size Category & df & $\begin{array}{c}\text { Chi- } \\
\text { Square }\end{array}$ & P value \\
\hline$<5 \mathrm{~cm}$ & 4 & 5.970 & 0.201 \\
$6-10 \mathrm{~cm}$ & 4 & 14.265 & $0.006^{*}$ \\
$11-20 \mathrm{~cm}$ & 4 & 15.168 & $0.004^{*}$ \\
$21-30 \mathrm{~cm}$ & 4 & 17.132 & $0.002^{*}$ \\
$31-40 \mathrm{~cm}$ & 4 & 0.594 & 0.964 \\
$>40 \mathrm{~cm}$ & 4 & 3.586 & 0.465 \\
\hline
\end{tabular}

Table 30. Kruskal-Wallis test of significance for differences in size class densities between sites. Values denoted with an asterisk $\left(^{*}\right)$ signify that a significant difference was found between one or more sites. 

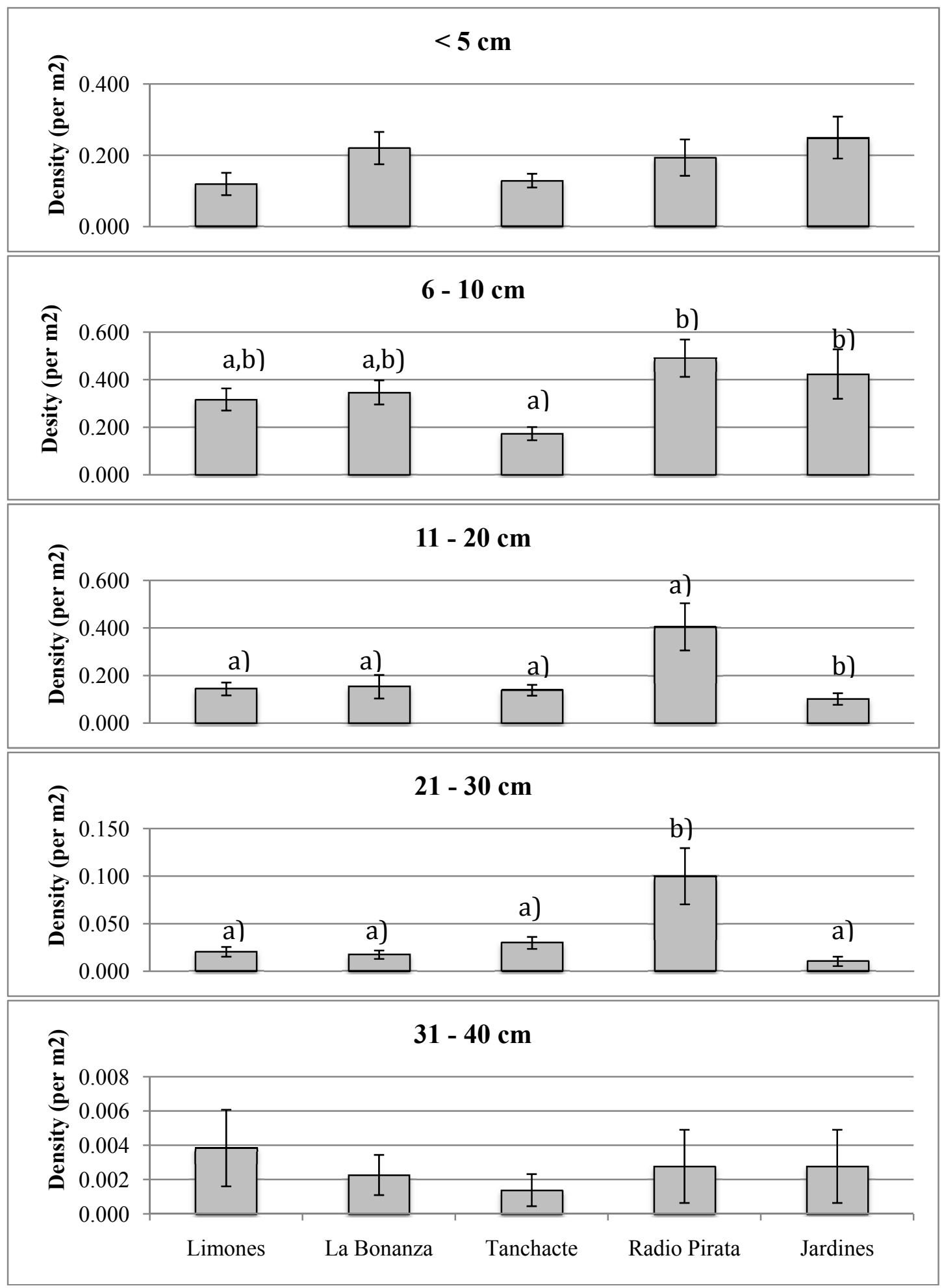

Figure 29. Size class densities by site. Significantly different values are denoted with different letters. Error bars represent \pm 1 SE. 


\section{Fish Percentage of Site Populations}

Significant differences were observed between sites in the percentage of fish representing each size class (Wilks Lambda $=0.529, \mathrm{~F}_{(20,170)}=.799, \mathrm{P}=0.024$ ). The use of percentage is a relevant measure because it compares size class abundance relative to all fish observed within a site, which provides information regarding which size classes are more prevalent in different sites. The MANOVA results for inter-site differences in size class percentages are summarized below in Table 31. The percentage of fish in the 11$20 \mathrm{~cm}$ size class within Radio Pirata was significantly higher than in La Bonanza and Jardines, as was the percentage of fish in the $11-20 \mathrm{~cm}$ size class in Tanchacte compared to Jardines, but not the other sites. Similarly, the percentage of fish in the $21-30 \mathrm{~cm}$ size class in Radio Pirata was significantly higher than all sites except for Tanchacte.

\begin{tabular}{lccc}
\hline Size Class & df & F & Sig. \\
\hline$<5 \mathrm{~cm}$ & 4 & 1.853 & 0.132 \\
$6-10 \mathrm{~cm}$ & 4 & 1.397 & 0.247 \\
$11-20 \mathrm{~cm}$ & 4 & 3.222 & $0.019^{*}$ \\
$21-30 \mathrm{~cm}$ & 4 & 3.904 & $0.007^{*}$ \\
$31-40 \mathrm{~cm}$ & 4 & 0.497 & 0.774 \\
$>40 \mathrm{~cm}$ & 4 & 1.295 & 0.283 \\
\hline
\end{tabular}

Table 31. MANOVA results for differences in the percent of fish in each size class relative to the total number of fish observed in each site. Size classes with significant inter-site differences are denoted with an asterisk $(*)$.

\begin{tabular}{lcccccc}
\hline Site & $\mathbf{5 c m}$ & $\mathbf{6 - 1 0 c m}$ & $\mathbf{1 1 - 2 0} \mathbf{c m}$ & $\mathbf{2 1 - 3 0 c m}$ & $\mathbf{3 1 - 4 0} \mathbf{c m}$ & $>\mathbf{4 0 c m}$ \\
\hline Limones & 20.63 & 51.10 & $23.67(\mathrm{a}, \mathrm{b}, \mathrm{c})$ & $3.78(\mathrm{a}, \mathrm{b})$ & 0.69 & 0.12 \\
La Bonanza & 29.12 & 48.37 & $19.13(\mathrm{a}, \mathrm{b})$ & $2.87(\mathrm{a}, \mathrm{b})$ & 0.50 & 0.00 \\
Tanchacte & 28.04 & 36.48 & $28.14(\mathrm{~b}, \mathrm{c})$ & $6.39(\mathrm{~b}, \mathrm{c})$ & 0.32 & 0.35 \\
Radio Pirata & 17.74 & 41.88 & $31.24(\mathrm{c})$ & $8.81(\mathrm{c})$ & 0.29 & 0.03 \\
Jardines & 34.27 & 51.12 & $12.99(\mathrm{a})$ & $1.36(\mathrm{a})$ & 0.25 & 0.00 \\
\hline
\end{tabular}

Table 32. Percent of site populations represented by each size class. Values with different letters signify significantly different percentages for that size class. 
Significant inter-site differences were detected between the density of all functional groups except for herbivores (Wilks' Lambda $=0.211, \mathrm{~F}_{(24,176)}=4.107$, $\mathrm{P}<0.001)$.

\begin{tabular}{lccc}
\hline Diet Group & df & Chi-Square & Sig. \\
\hline Herbivore & 4 & 6.893 & 0.142 \\
Piscivore & 4 & 21.255 & $0.000^{*}$ \\
Omnivore & 4 & 16.669 & $0.002^{*}$ \\
Benthophage & 4 & 19.015 & $0.001^{*}$ \\
Plankitove & 4 & 18.478 & $0.001^{*}$ \\
Piscivore and Invertebrates & 4 & 12.822 & $0.012^{*}$ \\
\hline
\end{tabular}

Table 33. Kruskal-Wallis test of significance for differences in diet group densities between sites. Values denoted with an asterisk $\left(^{*}\right)$ signify that a significant difference was found between one or more sites.

Radio Pirata contained significantly higher densities of piscivores, benthophages, and piscivore/invertebrate feeders than any other site. Although no significant differences were observed, La Bonanza, Radio Pirata, and Limones contained the highest densities of herbivorous fishes. Jardines contained significantly higher densities of planktivores compared to all other sites. 

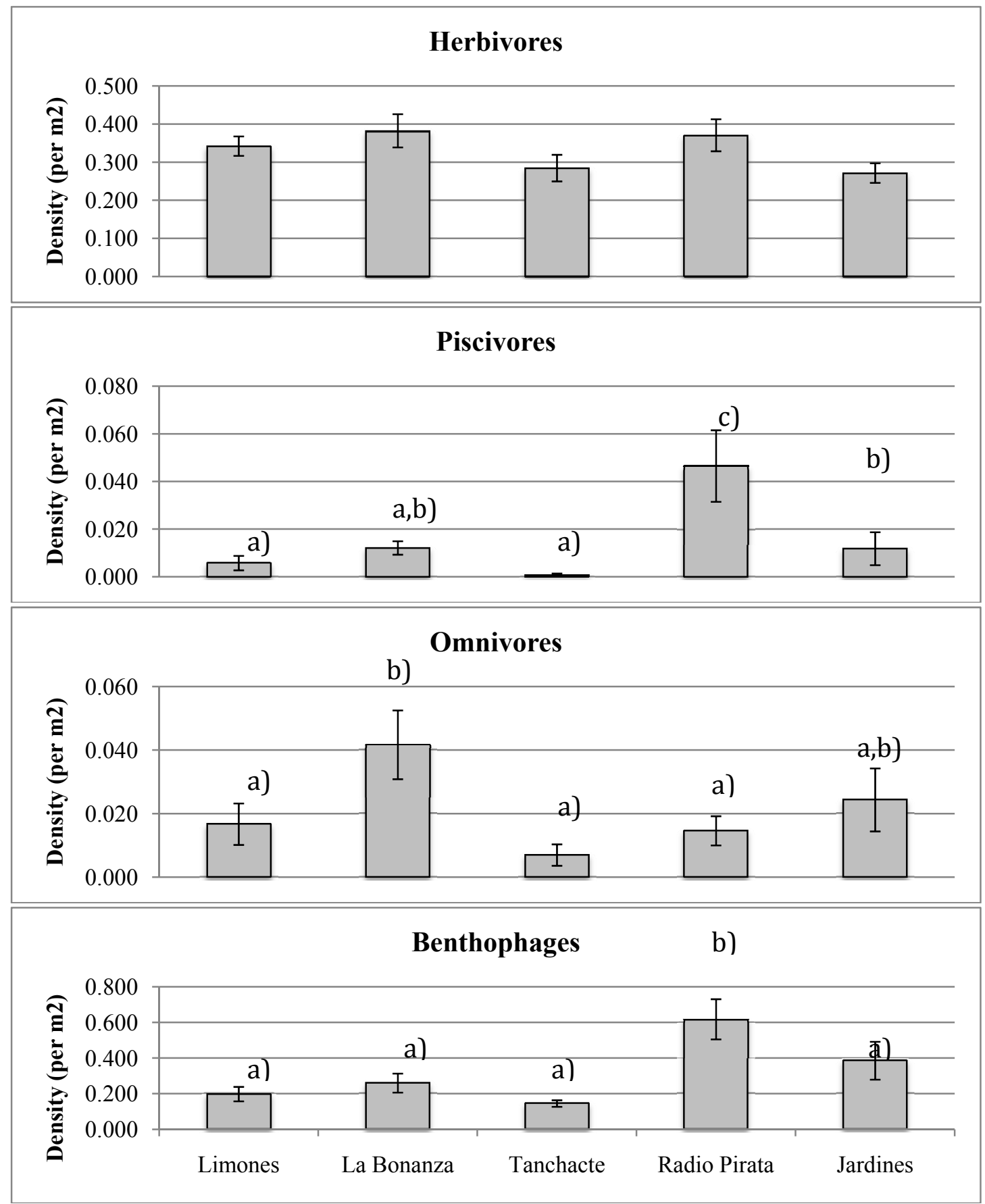

Figure 30. Diet group densities by site. Significantly different values are denoted with different letters. Error bars represent \pm 1 SE. 

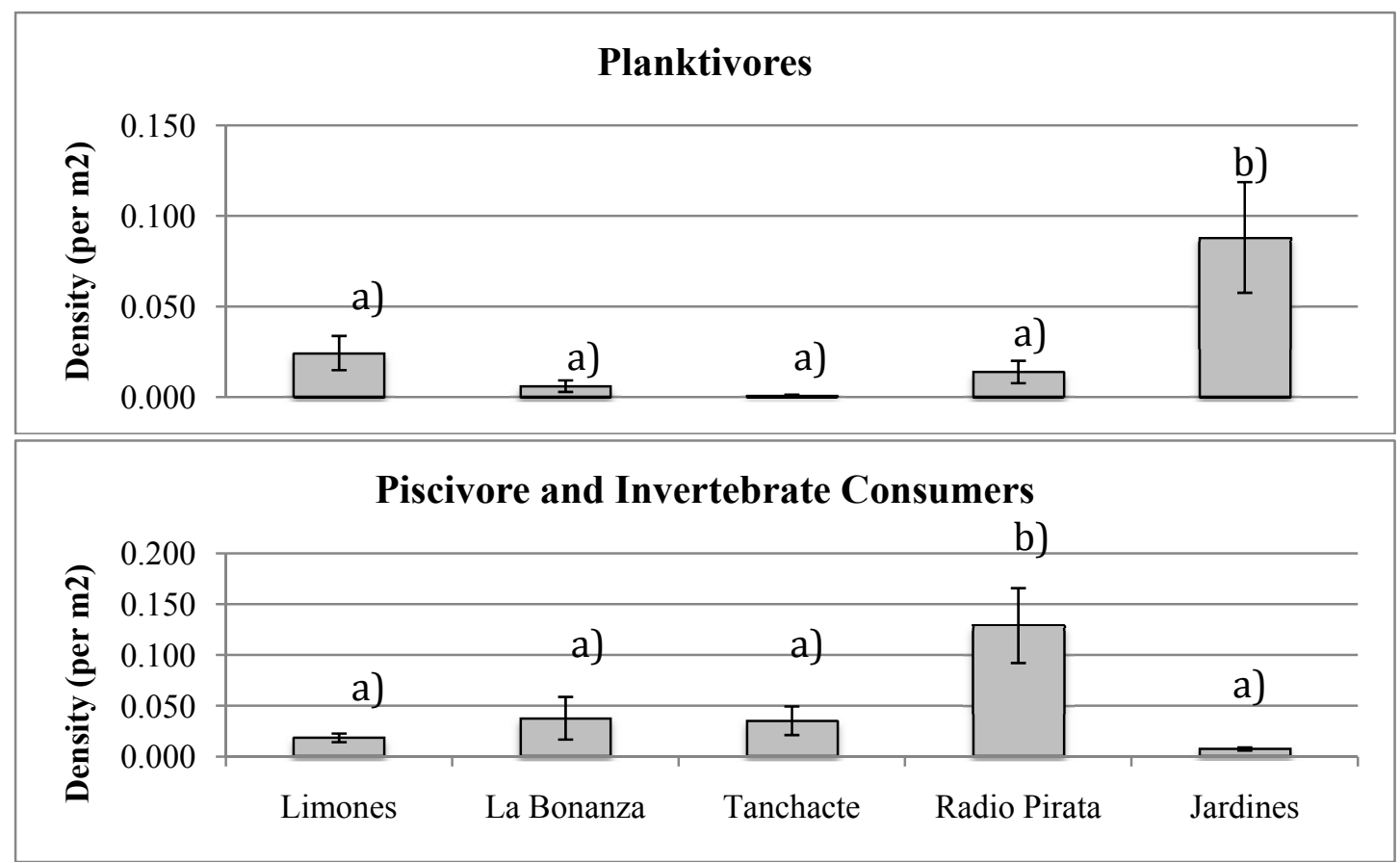

Figure 31. Diet group densities by site. Significantly different values are denoted with different letters. Error bars represent \pm 1 SE.

\begin{tabular}{lccc}
\hline Diet Group & df & F & P Value \\
\hline Herbivore & 4 & 5.810 & $0.001^{*}$ \\
Piscivore & 4 & 3.350 & $0.016^{*}$ \\
Omnivore & 4 & 3.209 & $0.019^{*}$ \\
Benthophage & 4 & 3.139 & $0.021^{*}$ \\
Planktivore & 4 & 7.185 & $<0.001^{*}$ \\
Piscivore and Invertebrates & 4 & 4.244 & $0.005^{*}$ \\
\hline
\end{tabular}

Table 34. ANOVA test of significance for differences in diet group percentages between sites. Values denoted with an asterisk $\left({ }^{*}\right)$ signify that a significant difference was found between one or more sites.

The Tanchacte fish population contained the highest percentage of herbivores compared to all sites $(60.12 \%)$, which was significantly higher than in Radio Pirata and Jardines, but not the other two sites. Piscivores constituted a significantly higher percentage of the Radio Pirata fish community compared to any other site. Benthophages in Radio Pirata comprised $51.80 \%$ of the fish community, a significantly higher percentage than all sites except for Jardines, where bethophagous fish represented $48.86 \%$ of the population. 


\begin{tabular}{lcccccc}
\hline Site & Herbivore & Piscivore & Omnivore & Benthophage & Planktivore & $\begin{array}{c}\text { Piscivore and } \\
\text { Invertebrates }\end{array}$ \\
\hline Limones & $56.51(\mathrm{~b}, \mathrm{c}, \mathrm{d})$ & $0.95(\mathrm{a})$ & $2.75(\mathrm{a}, \mathrm{b})$ & $32.70(\mathrm{a})$ & $4.02(\mathrm{a})$ & $3.07(\mathrm{a})$ \\
La Bonanza & $51.69(\mathrm{~b}, \mathrm{c}, \mathrm{d})$ & $1.64(\mathrm{a})$ & $5.63(\mathrm{c})$ & $35.11(\mathrm{a})$ & $0.82(\mathrm{a})$ & $5.12(\mathrm{a})$ \\
Tanchacte & $60.12(\mathrm{~d})$ & $0.15(\mathrm{a})$ & $1.47(\mathrm{a}, \mathrm{b})$ & $30.65(\mathrm{a})$ & $0.15(\mathrm{a})$ & $7.48(\mathrm{a}, \mathrm{b})$ \\
Radio Pirata & $31.08(\mathrm{a})$ & $3.90(\mathrm{~b})$ & $1.22(\mathrm{a})$ & $51.80(\mathrm{~b})$ & $1.16(\mathrm{a})$ & $10.83(\mathrm{~b})$ \\
Jardines & $34.42(\mathrm{a}, \mathrm{b}, \mathrm{c})$ & $1.50(\mathrm{a})$ & $3.08(\mathrm{~b}, \mathrm{c})$ & $48.86(\mathrm{a}, \mathrm{b})$ & $11.18(\mathrm{~b})$ & $0.97(\mathrm{a})$ \\
\hline
\end{tabular}

Table 35. Percent of site populations represented by each diet group. Values with different letters signify significantly different percentages for that diet group.

\section{Fish Biomass}

Significant differences were found in the mean total biomass between sites (Kruskal-Wallis, $\mathrm{df}=4$, Chi-Square $=17.84, \mathrm{P}=0.001$ ), but not for mean herbivore biomass (ANOVA, $\mathrm{df}=4, \mathrm{~F}=1.159, \mathrm{P}=0.339$ ) (See Figure 32 and Figure 33).

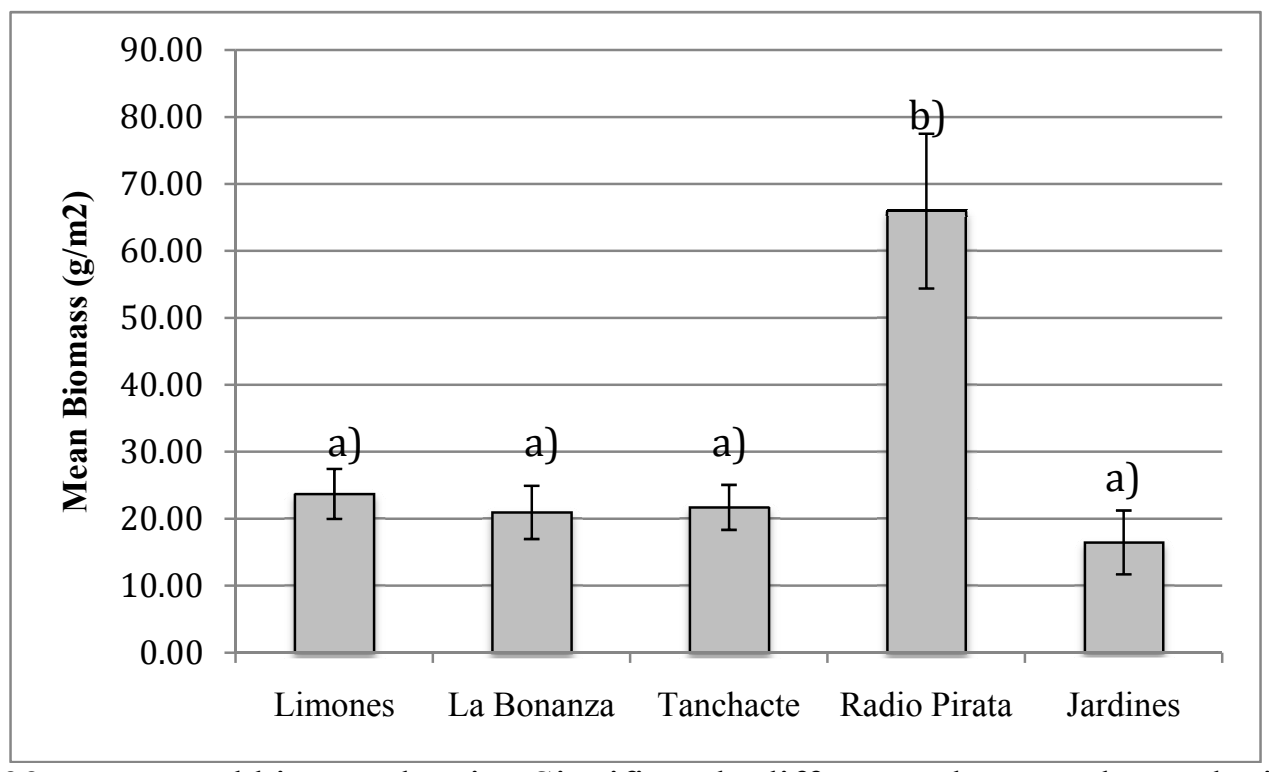

Figure 32. Mean total biomass by site. Significantly different values are denoted with different letters. Error bars represent \pm 1 SE. 


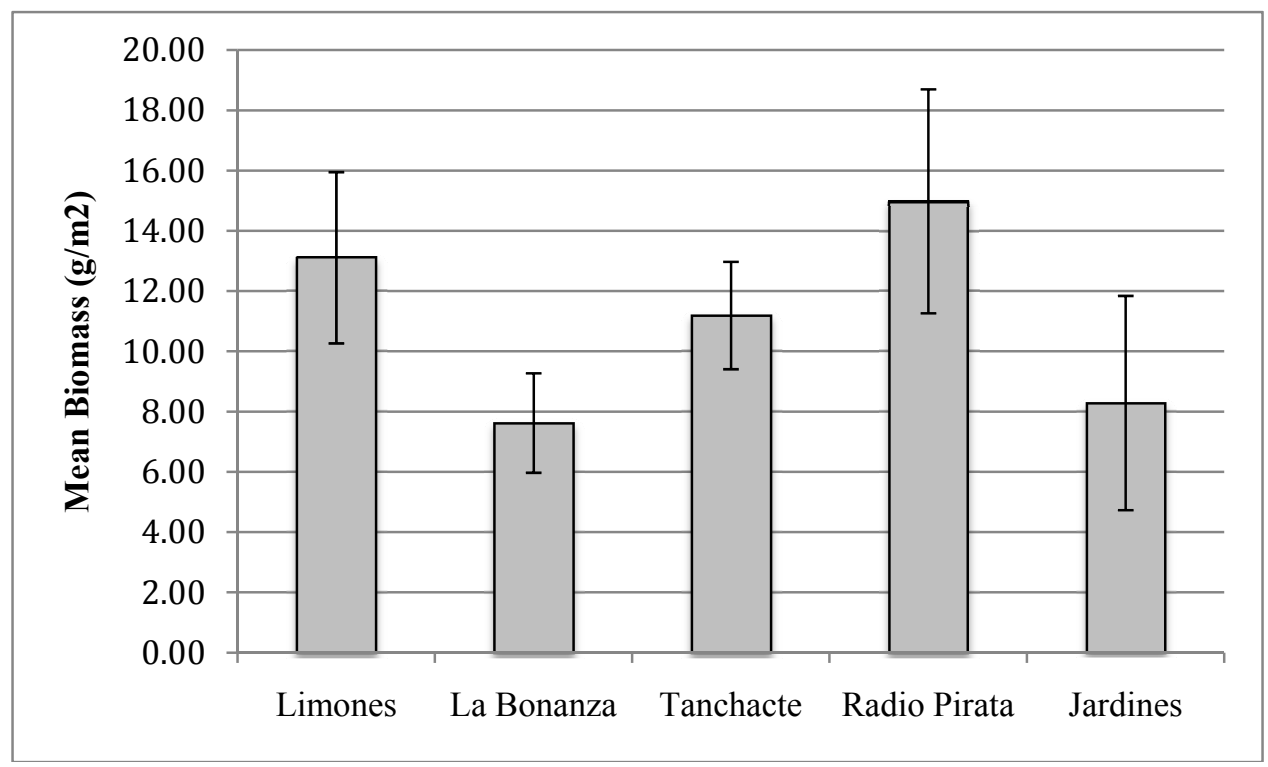

Figure 33. Mean herbivore biomass by site. No significant differences were detected. Error bars represent $\pm 1 \mathrm{SE}$.

\section{Tourist Data}

A total of 13,179 visitors were recorded by PNAPM staff surveillance activities over the course of 10 months in 2009 , accounting for $10.6 \%$ of the 124,327 PNAPM tourist bracelets sold that year. Average tourist visitor numbers per month of study sites from surveillance data taken by PNAPM guards (adjusted for lack of complete visitor data; see methods for details) are displayed below in Figure 34. Radio Pirata had by far the highest mean monthly visitation rate $(2,341 \pm 760)$, significantly higher than all other study sites (Kruskal-Wallis, $\mathrm{df}=4$, Chi-Square $=27.65, \mathrm{P}<0.001$ ), and Jardines the lowest $(12 \pm 10)$. Since data were collected at all sites each day that surveillance was conducted, these numbers provide relative estimates that can be used to compare tourist visitation rates between sites. 


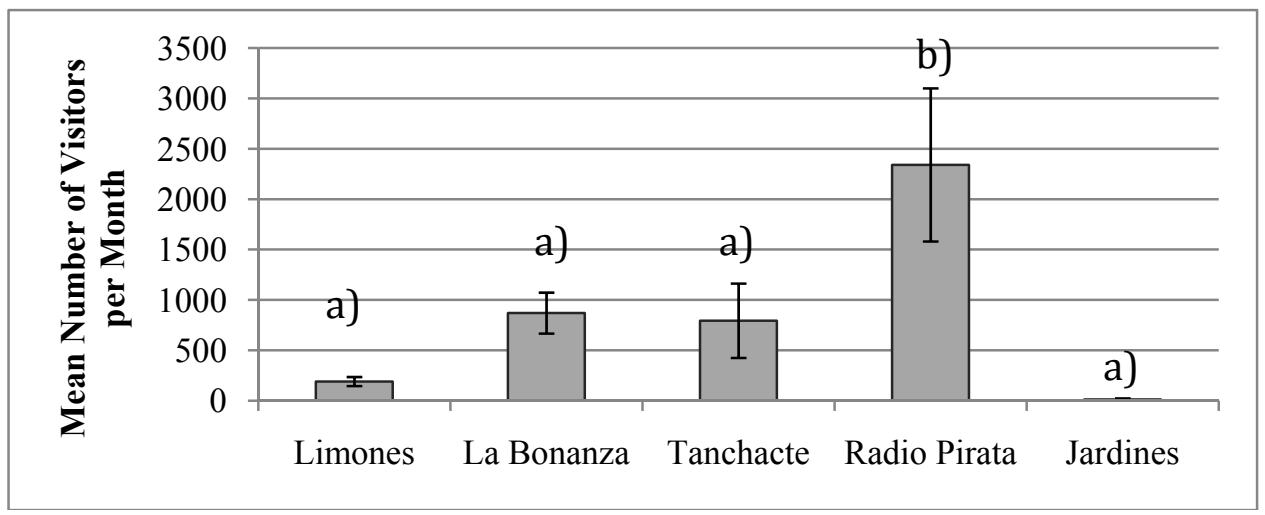

Figure 34. Mean number of visitors per month by site. Error bars represent $\pm 1 \mathrm{SE}$.

\section{DISCUSSION}

The results of this study demonstrate that sites within the PNAPM greatly differ in the number of characteristics that contribute to and detract from coral reef ecosystem resilience. Sites ranged from containing more than six characteristics recognized as contributing to resilience to over six characteristics demonstrated to detract from coral reef resilience. I first discuss site-specific characteristics that contribute to resilience in response to potential disturbances from the multiple stressors impacting coral reef ecosystems (promoters) and or detract from this resilience (detractors). Emphasis is given to characteristics not included in the four major resilience factors previously mentioned. Next I examine in detail results of the four major resilience factors of hard coral cover, CCA cover, herbivore density and biomass, and nutrient levels across all sites, highlighting important ecosystem implications. Finally, inferences are made regarding the current status and potential future directions of the ecological states of studied sites. 


\section{Limones}

The ecological characteristics observed in Limones suggest that it is one of the more resilient sites in this study. Promoters of resilience observed in Limones included high coral cover, a high architectural index score, the largest mean coral colony size and lowest percent mortality, as well as a high density and biomass of herbivorous fishes compared to other sites. High percent cover of turf and the highest coral colony disease frequency were two significant measures recorded in Limones that detract from coral reef ecosystem resilience.

High coral and low macroalgae cover has been correlated with herbivore abundance in a host of manipulative experiments (Diaz-Pulido \& McCook, 2003; Burkepile \& Hay, 2006; 2009; Hughes et al., 2007). Limones demonstrated the secondhighest density and biomass of herbivorous fish (although not significant) along with the highest coral cover and lowest macroalgae cover. These findings coincide with the conclusions of previous studies demonstrating a positive relationship between an abundance of herbivores and increased coral reef resilience via macroalgae removal and the promotion of the persistence of corals (Bellwood et al., 2004; Mumby, 2006; Hughes et al., 2007; Burkepile \& Hay, 2008; Cheal et al., 2010). Interestingly, Limones is the only site totally surrounded by a fishing zone. Although herbivore density and biomass were not significantly higher than the other study sites, the relatively high abundance of larger herbivores within the site does not support the hypothesis that areas where fishing is permitted will demonstrate decreased herbivore density and biomass. Further investigation is required to determine the factors responsible for disparities in herbivore 
densities and MPA zoning strategies. Limones contained the lowest N:P ratio of all study sites, which may also be contributing to the lower macroalgae cover observed at this site.

The life history traits of A. palmata, abundance of this species ( $70 \%$ of all corals sampled in Limones), large size, and low tissue mortality confer a high degree of resilience to this site. Acropora palmata has been demonstrated to be a highly resilient coral species, capable of growing up to $10 \mathrm{~cm} / \mathrm{yr}$, and has the ability to quickly recolonize after disturbances if under the appropriate conditions (Gladfelter et al., 1978; Crabbe, 2009). Further, A. palmata is a foundation species that generates a high degree of habitat complexity and greatly contributes to the structure upon which the entire coral reef community depends (Gladfelter et al., 1978; Lirman, 1999).

Limones received the highest architectural index score of any site, largely as a result of the dominance of $A$. palmata, a branching species that provides significant topographic complexity compared to other species (e.g., mounding species). Gratwicke and Speight (2005) demonstrated via experimental manipulation that both topographic complexity and a variety of substrate forms in a coral reef environment were positively correlated with increases in the abundance and diversity of fish species (also see Almany, 2004; Wilson et al. 2007). Both abundance and diversity of functional groups are identified as major contributors to increased coral reef resilience via functional redundancy and representation (Bellwood et al., 2004; Knowlton \& Jackson, 2008). Although Limones did not have the most diverse fish community, the high habitat complexity of this site is more likely to promote an abundance and diversity of fish species compared to sites with a homogenous and less-complex reef habitat, assuming all other variables (e.g., fishing pressure) are equal. 
A very high abundance and density of damselfishes was observed in Limones, where they comprised $33 \%$ of all fishes recorded in the site. The high abundance of damselfish in Limones may be a result of the high habitat complexity observed at this site, as was found by a study conducted by Beukers and Jones (1997), which concluded that the survivorship of a damselfish species on the Great Barrier Reef was significantly positively correlated to increased habitat complexity. Interestingly, Limones also exhibited a very high percent substrate cover of turf (27.33\%), significantly higher than any other site. Damselfish are extremely territorial fishes that actively maintain macroalgal gardens for food consumption (Ferreira et al., 1998; McCook et al., 2001; Hata et al., 2002), which may partially explain the high turf cover observed in Limones. Previous studies have documented adverse effects of damselfish colonization on host coral colonies, including decreased immunological responses due to energy depletion (Potts, 1977; Peters, 1984). The high abundance of both damselfish and coral disease on A. palmata colonies warrants further investigation to determine if damselfish promote coral disease presence in Limones.

\section{Jardines}

Jardines also demonstrated multiple ecological characteristics shown to promote coral reef resilience, including high CCA and coral cover (Hughes et al., 2007; Ledlie et al., 2007; Littler \& Litter, 2007; Mumby et al., 2007). Although Jardines contained the highest overall density of fish, this site also contained the lowest density of herbivores, possibly contributing to the moderate macroalgae cover $(24 \%)$ observed at this site. Jardines also demonstrated low herbivore biomass, further suggesting decreased grazing 
intensity within the site. This finding is contrary to the expectation that sites within recreation zones will demonstrate increased herbivore density and biomass, although results do support the hypothesis that areas where fishing is not permitted will demonstrate a higher abundance of fishes overall. The lack of herbivore density and biomass in Jardines is a serious problem, highlighting the importance of monitoring functional groups in coral reef assessments and the need to protect herbivore populations. Based on the relatively high $(\sim 15 \%)$ coral cover observed in Jardines, the reduced grazing intensity in this site has not yet resulted in the coral-to-macroalgae phase shift that has occurred in many areas throughout the Caribbean in recent decades (Done, 1992; Hughes, 1994; Mumby et al., 2007).

\section{La Bonanza}

La Bonanza displayed multiple characteristics demonstrated to detract from coral reef ecosystem resilience and promote the transition to a less desirable benthic community composition. The CCA and hard coral cover were lower in La Bonanza than any other site, both of which are crucial for the recruitment, survival, and persistence of corals, which provide the structure upon which the rest of the ecosystem depends upon (Lirman, 1999; Hughes et al., 2007; Littler \& Littler, 2007). Coral colonies in La Bonanza demonstrated the highest percentage of dead tissue and were on average smaller than any other site, decreasing reproductive potential (Hughes \& Connell, 1987; Soong, 1993). Small colony size and subsequent suppressed reproductive output coupled with the very low coral cover observed in La Bonanza greatly reduces the possibly for coral larval production and retention within the site, as well as decreased larval export to other 
sites (Soong, 1993; Elmhirst et al., 2009). The fact that only $1 \%$ of the substrate surveyed in the site was categorized as CCA further decreases the chances of successful coral larval recruitment, creating a feedback system that promotes the proliferation of other benthic organisms such as macroalgae (Ledlie et al., 2007; Litter \& Littler, 2007; Mumby \& Steneck, 2008).

La Bonanza is next to a scientific 'no-take' zone (forereef area), which may be functioning to partially protect fish populations and contribute to the results observed in this study. Macroalgae tissue content analyses revealed that nitrogen levels in La Bonanza were high relative to other study sites. Elevated nitrogen levels can significantly increase macroalgal growth and cover in the absence of sufficient herbivory (Littler \& Littler, 1984; 2007; Burkepile \& Hay, 2006; Hughes et al., 2007). The high density of herbivores found in La Bonanza (although not significant) may be temporarily preventing this site from undergoing a phase-shift to a macroalgal-dominated state by continuously grazing macroalgae growth promoted by high nitrogen levels, as observed in an experimental study by Burkepile and Hay (2009). However, La Bonanza contained the lowest herbivore biomass of any site, suggesting that although herbivore densities may be high in the site, the majority of these fish are small individuals. It has been demonstrated that larger herbivores have a disproportionately higher role in macroalgal grazing activity (Bonaldo \& Bellwood, 2008; Durán \& Claro, 2009). Therefore, the low herbivore biomass observed in La Bonanza may be contributing to the severely degraded state of this site, yet is confounded by the lack of macroalgal proliferation predicted by ecological models for a site with depressed herbivore biomass (Littler \& Littler, 2007). One possible explanation is that the high density of small-sized herbivores is able to 
maintain a fairly low macroalgal cover by continuously grazing new macroalgae recruits. The loss of high herbivore densities at this site could prove absolutely devastating and result in an even more pronounced loss of community and ecosystem resilience and function, demonstrating the importance of maintaining and enforcing the no-take management restrictions in this area.

\section{Tanchacte}

Tanchacte had the highest percent CCA cover of any study site, but also demonstrated a mean substrate cover of nearly $50 \%$ macroalgae, much higher than any other site. Macroalgae, CCA, and branched calcareous algae comprised $71.11 \%$ of the benthos in Tanchacte. Percent nitrogen tissue content was very high in Tanchacte, as was the N:P ratio, both of which have the potential to contribute to the overwhelming macroalgal abundance observed at this site (Lapointe et al., 1987; Lapointe, 1997; McCook, 1999; Lapointe et al., 2010). Herbivory has been demonstrated to be a key factor in maintaining coral dominance on coral reefs by keeping macroalgae biomass in check, especially during recovery after large disturbances (Hughes, 1994; Hughes et al. 2007), while the absence of sufficient herbivory in combination with increased nutrient levels can greatly enhance macroalgae growth and cover (Diaz-Pulido et al., 2003; Burkepile \& Hay, 2006). The moderate herbivore biomass and low herbivore density observed in this study suggest that the latter may be occurring in Tanchacte; specifically that decreased herbivorous fish densities in conjunction with elevated nutrient levels are promoting macroalgae growth and abundance. 
These findings indicate a red flag for Tanchacte, which is demonstrating characteristics similar to those observed in other areas of the Caribbean just before completing a phase-shift from a coral-dominated state to a macroalgae-dominated state (Done, 1992; Hughes, 1994; Mumby et al., 2007). Specifically, the low herbivore densities and high nitrogen levels and macroalgae cover observed are clear indicators that this site is in danger of undergoing a phase-shift (Knowlton, 1992; Scheffer et al., 2001; McManus \& Polsenberg, 2004; Hughes et al., 2007; Mumby et al., 2007). Similar to Jardines, the ecological community present in Tanchacte may be teetering on the verge of community shift towards a seriously degraded state dominated by macroalgae and ecological characteristics not conducive to a healthy coral reef ecosystem.

\section{Nutrients}

Percent nutrient tissue content analysis results indicated that all study sites contain excess nitrogen and are phosphorus limited. Samples from all sites demonstrated N:P ratios well above proposed global median N:P levels of 30:1 (Atkinson \& Smith, 1983). The hypothesis that the PNAPM is a P-limited system is supported by observed percent nutrient tissue contents, which revealed that all sites were well above the proposed $1.8 \%$ saturation threshold for $\% \mathrm{~N}$ and below the $0.20 \%$ threshold for $\% \mathrm{P}$ (Duarte, 1990). These results agree with the conclusions of Lapointe et al. (1992) that carbonate-rich waters, as are found in the PNAPM, are commonly P-limited.

Tanchacte had the highest N:P ratio, indicating very high levels of $\mathrm{N}$ in the site. Closer scrutiny of the data reveals that Radio Pirata contained the highest $\% \mathrm{~N}$ and $\% \mathrm{P}$, therefore the $\mathrm{N}: \mathrm{P}$ ratio is not as high, but $\% \mathrm{~N}$ at this site was higher than in any other site. 
The C:N ratios were lowest in Radio Pirata, which also had the second-lowest C:P ratio of all sites in this study. Sites with low C:N and C:P ratios indicate elevated nutrient levels (Lapointe et al., 2010). Radio Pirata is the site closest to the Puerto Morelos town center, which has high population density, coastal development, and anthropogenic influences compared to the other study sites (M. Ladd, unpub. data). Unfortunately, no benthic community data were available for Radio Pirata at the time of this study to discuss relationships with these factors. Jardines, which had the lowest $\% \mathrm{~N}$, highest C:N, and second-highest and C:P ratio is most likely the site least impacted by anthropogenic nutrient inputs. The general water currents in the PNAPM run from south to north (See Coronado et al., 2007), therefore nutrient inputs from the Puerto Morelos town center (north of Jardines) are most likely being transported northwards, supported by diluted nutrient concentrations as one travels north.

Nitrogen enrichment studies have demonstrated that elevated nitrogen levels can contribute to increased macroalgae growth (Lapointe et al., 1987; Lapointe, 1997; McCook, 1999; Lapointe et al., 2010), which is supported by the results of this study. Limones contained the lowest N:P ratio and had the lowest macroalgae cover of all study sites. Conversely, Tanchacte had the highest N:P ratio and a significantly higher macroalgal cover than any other study site, supporting the hypothesis that elevated nutrient levels within the PNAPM are adversely impacting the coral reef ecosystem.

\section{Fish Communities}

Although no significant differences were detected in herbivore density or biomass between sites, Limones and La Bonanza, the two sites with relatively higher herbivore 
densities, demonstrated lower macroalgae cover. Tanchacte and Jardines demonstrated the lowest densities of herbivores and also the highest cover of macroalgae, further supporting the hypothesis of the importance of top-down regulation of macroalgae by herbivores. However, observed herbivore biomass values did not coincide with observed herbivore densities. For example, La Bonanza demonstrated the highest density of herbivores, but actually contained the lowest herbivore biomass. These findings highlight the importance of calculating and reporting both of these measures to properly characterize coral reef fish communities and make inferences about their ecological consequences. Based on herbivore density alone, La Bonanza appears to contain the 'healthiest' herbivore community relative to the other sites. However, herbivore biomass results reveal the limited grazing and reproductive potential of this high herbivore density community, since the majority of the individuals are small (Winemiller \& Rose, 1992; Hendry et al., 2001; Bonaldo \& Bellwood, 2008). Herbivore biomass was nearly two times higher in Limones compared to La Bonanza, a difference that could not be detected through herbivory density estimates alone.

Total fish biomass estimates were nearly equal across all study sites (except Radio Pirata). The fact that no significant differences were observed between sites located in fishing and tourism zones is critical for management to recognize and act upon. If zoning strategies were functioning as intended, to protect fish populations in areas where fishing is not permitted (i.e. tourism zones), then clear inter-site differences in herbivore abundance and biomass should be observable (Lester \& Halpern, 2008; McCook et al., 2010). Management needs to recognize the ramifications of these results and integrate both density and biomass into future monitoring protocols. 
An alternative hypothesis for the high macroalgae cover in Tanchacte is that this site contains an abundance of unpalatable or chemically defended species of macroalgae, such as Dictyota spp. that herbivores preferentially avoid, though this hypothesis requires further investigation (Paul, 1992; Steinberg, 1992; De Lara-Isassi et al., 2000). Burkepile and Hay (2008) demonstrated that certain herbivores selectively target specific macroalgae species, generating differential influences on the prevention or reversal of a phase shift. Tanchacte may lack sufficient populations of herbivores necessary to target and reduce the macroalgae populations currently present in this site, contributing to the high macroalgal cover observed.

Of all fish recorded in this study, $70 \%$ were $10 \mathrm{~cm}$ or smaller in length, with just over $5 \%$ of fish being larger than $20 \mathrm{~cm}$. These findings coincide with the observations of Peckol et al. (2003), who documented few individuals larger than $20 \mathrm{~cm}$ in a study conducted on the Mesoamerican Barrier Reef in Belize. While it can be expected that large fish will not dominate fish populations, this is an alarming figure for the PNAPM. Larger fish have increased reproductive capacity and consume more vegetative mass (Winemiller \& Rose, 1992; Hendry et al., 2001; Durán \& Claro, 2009), and therefore greatly increase grazing intensity on coral reefs. Bonaldo and Bellwood (2008) demonstrated that the feeding habits and impacts of a species of parrotfish on the Great Barrier Reef changed with an increase in size, consequently changing the role of this species in the ecosystem as individuals grow. Herbivore size is especially relevant in the PNAPM, as several sites would benefit from the decreased macroalgae cover and increased CCA exposure generated by feeding habits of larger individuals. 
Results demonstrated unclear relationships between zoning strategies and herbivore abundance and biomass. The highest density yet lowest biomass of herbivores was found in the site adjacent to a no-take area, and the second-highest density of herbivores was observed in an area surrounded by a fishing zone. Further, several study sites located in recreational areas, which theoretically do not have fishing pressure, displayed reduced herbivore density and biomass. The results of this study provide pertinent information for the PNAPM management staff indicating that managerial action should be taken to better protect fish populations within in the park.

\section{Hard Coral and CCA Cover}

Hard coral cover was higher in Limones and Jardines compared to the other study sites, while CCA cover was fairly uniform across sites except in La Bonanza, where it only comprised $1 \%$ of the substrate. Coral cover is essential for the maintenance and persistence of the coral-dominated state that characterizes a functioning coral reef ecosystem (Knowlton, 2001; Graham et al., 2006; Hughes et al., 2007; Mumby et al., 2007). Without the presence of abundant and healthy coral colonies, the foundation of coral reef ecosystems begins to erode, eventually leading to a phase shift or ecosystem collapse (Graham et al., 2006; Mumby \& Steneck, 2008). CCA cover is another essential component for a resilient coral reef, as this substrate provides settlement sites for new coral recruits and subsequent coral growth (Harrington et al., 2004; Hughes et al., 2007; Littler \& Littler, 2007). CCA also plays a critical role in cementing fragments of coral and other hard materials to form the reef substrate (Littler \& Littler, 1997; Littler et al., 2006). Although larval connectivity patterns are unknown for these study sites, the high 
coral cover observed in Limones and Jardines has the potential to serve as a source of larvae for coral recruitment if larvae are retained within sites. Regardless of if recruits come from within or from other locations, the high abundance of available substrate (i.e., CCA) in Jardines provides conditions favorable for coral larvae settlement, many of which require CCA as a cue in order to successfully settle and recruit (Harrington et al., 2004; Litter \& Litter, 2007).

Coral cover at all sites except La Bonanza was higher than the average cover reported by Rodríguez-Martínez et al. (2010) for the PNAPM for 1993 - 2005. However, this should be interpreted with caution, as the 2010 report is only comprised of data from one coral reef study site within the PNAPM. A meta-analysis conducted by Schutte et al. (2010) reported a mean coral cover of approximately $22 \%$ and macroalgal cover of $18 \%$

for the Mesoamerica Barrier Reef region. Based on these regional averages, several sites in this study demonstrated high macroalgal cover and low coral cover.

\section{Ecosystem Function}

An analysis of previous coral reef study results conducted by Knowlton and Jackson (2008) generated a model suggesting that ecosystem function decline occurs before more detectable signs such as coral and fish diversity patterns are observable. Tanchacte contained nearly $50 \%$ macroalgal cover and demonstrated the lowest density and diversity (39) of fish species in rover diver surveys, compared to the next lowest (47) in Limones. La Bonanza, another site characterized as having low resilience, demonstrated the lowest coral diversity, coral cover, and herbivore biomass of all study sites. These sites both contained the lowest architectural index scores as well, which can 
be interpreted as a measure of ecosystem integrity, as it is based on the abundance and size of coral colonies, the foundation upon which the rest of the ecosystem is based upon. Knowlton and Jackson (2008) posit that the loss of ecosystem function will eventually generate visible effects, first in the form of reduced coral richness, and then in the form of reduced "richness of coral associates" (e.g., fish). Following this line of thought, it is possible that the low density, biomass, and diversity of fishes and corals in these two sites are signs of changes in ecosystem structure and the indication of impending comprised ecosystem function.

Relative Dominance Model (Littler \& Littler, 1984; 2007)

Littler and Littler $(1984 ; 2007)$ provide a basic conceptual model to predict changes in coral reef ecosystem benthic community composition based on two major drivers of coral reef resilience; herbivory and nutrients (See Figure 35). 


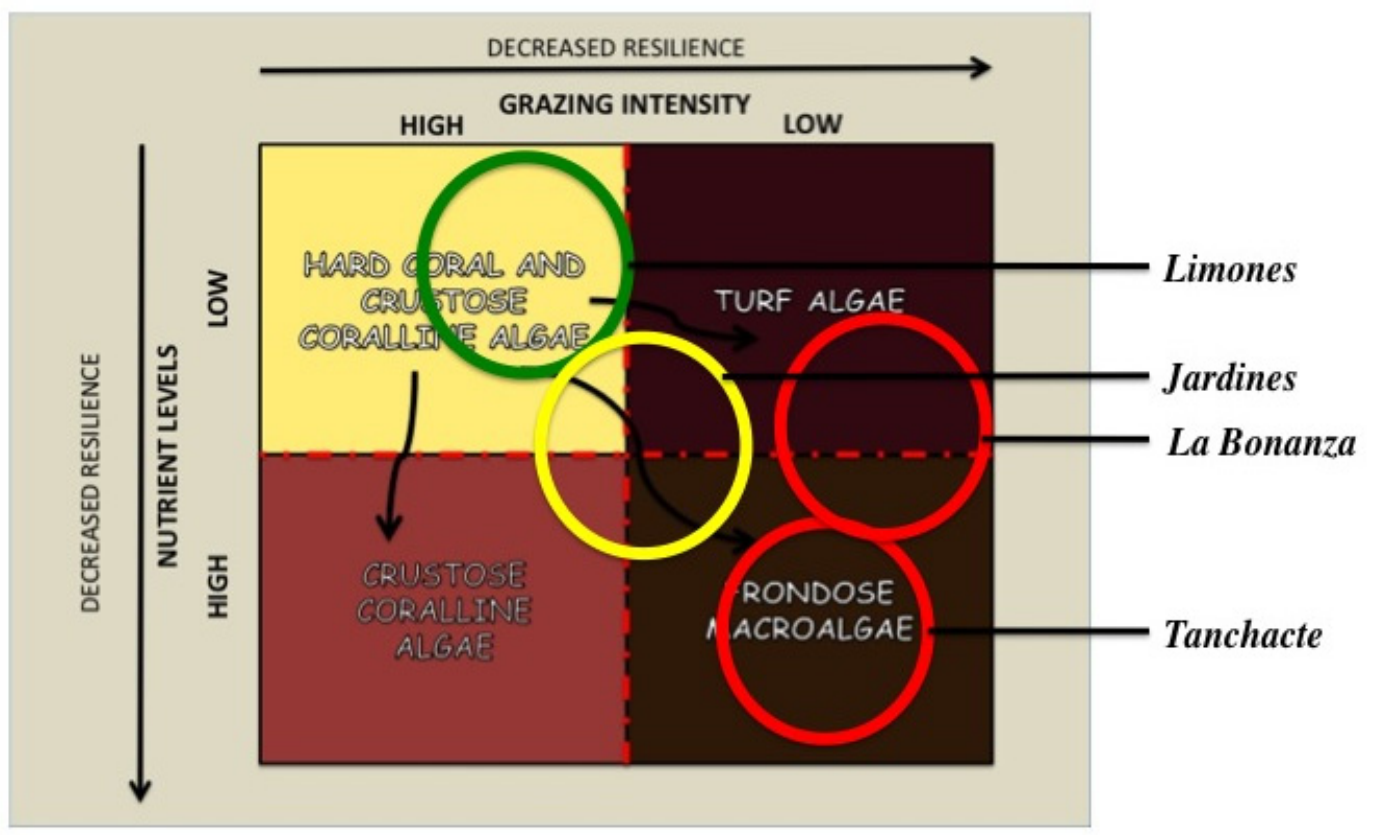

Figure 35. Modified version of the Relative Dominance Model (RDM) proposed by Littler and Littler (2007). Circles indicate the proposed position of each study site based on results from ecological characterizations. As described in the original article by Littler and Littler (2007), the dotted lines separating different states represent critical tipping points of seriously compromised resilience leading towards a phase shift to an alternative state.

'Ideal' coral reef conditions are characterized by low nutrient levels and high levels of grazing activity. Limones was the study site that demonstrated characteristics most similar to this scenario, and was the site that contained the highest coral cover and herbivore biomass. Herbivore densities were moderate relative to the other sites and the $\mathrm{N}: \mathrm{P}$ ratio was the lowest of any study site, although Limones exhibited a very high percent coverage of turf. For this reason this site is placed on the threshold of massive corals/CCA dominance and dense turf algae dominance. Jardines also contained a high percent coral cover, but also demonstrated $\sim 25 \%$ macroalgal cover as well as moderate CCA and turf cover. The lower $\% \mathrm{~N}$ observed in Jardines may not be promoting macroalgal growth as much as in other sites with elevated $\% \mathrm{~N}$ values (e.g., Tanchacte). 
Jardines had the second-lowest density and biomass of herbivores, suggesting that this site may be at a critical threshold in which the system could proceed in a variety of directions. In accordance with RDM predictions, increased nutrients without a concurrent increase in grazing intensity would push the system towards a 'frondose macroalgae' dominated state. However, if grazing intensity does increase with an increase in nutrients, then CCA would be predicted to dominate. Increased grazing pressure in the absence of elevated nutrient levels should theoretically push the system towards a 'desired' coral- and CCA-dominated state, while reduced grazing intensity would be predicted to promote a 'dense turf' state. The results found in Jardines should be taken as a warning. The relatively high coral and CCA cover observed in Jardines with a lack of herbivores may signal that this site is approaching a threshold that could be easily crossed in favor of macroalgal or non-coral dominance, as has been observed elsewhere in the past (Done, 1992; Hughes, 1994; McCook 1999).

La Bonanza showed significantly lower coral and CCA cover than all other sites, and is placed in a highly degraded area of the RDM. Although La Bonanza contained the highest density of herbivorous fishes, it also contained the lowest herbivore biomass. The high herbivore density may be offsetting the influence of high $\% \mathrm{~N}$ and N:P observed at this site, which would otherwise potentially result in much higher macroalgal cover than the $\sim 15 \%$ documented at this site (Littler et al. 2006; Littler \& Littler, 2007). The RDM suggests that a loss of herbivore density in La Bonanza could produce the inertia necessary to surpass the threshold towards a macroalgal-dominated state. This site already contains many attributes characteristic of decreased resilience, and the loss of grazing activity, even if it is by small individuals, has the potential to induce a phase 
shift. In the occurrence of such a phase shift, the low coral and CCA cover currently present in La Bonanza would generate a serious hysteresis effect, promoting the existence of a macroalgal dominated state and making it very difficult to drive the system towards a coral- or CCA-dominated state (Knowlton, 2004; Mumby \& Steneck, 2008; Mumby, 2009).

Characteristics observed in Tanchacte suggest that this site has already crossed the threshold necessary to revert to a macroalgal-dominated state. As predicted by the RDM, the low herbivore densities, biomass, and elevated nutrient levels found in Tanchacte have likely promoted the macroalgae dominance observed at this site. Tanchacte also contained the highest coverage of CCA (not significant), characteristic of a system with elevated nutrients and intense grazing pressure, possibly a relic of a previous presence of higher herbivore densities or biomass with the observed elevated nutrient levels.

Since N:P ratios were well above the 30:1 global median and $\% \mathrm{~N}$ above the proposed 1.8\% saturation threshold (Atkinson \& Smith, 1983; Duarte, 1990) at all study sites, it is unlikely that nutrient levels can be considered "low" at any of the study sites. It is therefore essential to maintain and promote herbivore populations in order to increase grazing pressure to avoid crossing critical thresholds of resilience loss. Decreasing nutrient levels would simultaneously benefit the resilience of study sites where sufficient herbivory is present, and reduce hysteresis effects hindering a shift away from a macroalgae-dominated state.

Interestingly, the site dominated by macroalgal cover (Tanchacte) and the most degraded site (La Bonanza) demonstrated significantly higher tourist visitation rates 
compared to the other study sites. No statistical differences were observed in the two major drivers of coral reef ecosystems proposed by the RDM (i.e. herbivory and nutrient levels), suggesting that tourism activities may be having a serious negative impact on the coral reef ecosystem within the PNAPM. With projected increases in coastal development, population growth, and subsequent tourism levels throughout the region, PNAPM management must investigate the impacts of tourism to determine if these activities adversely impact the benthic environment, and then modify management actions accordingly. Lastly, all sampling for this study was conducted during two months in the summer. The observed differences, or lack thereof, between sites may be a result of temporal cycles, highlighting the importance of re-sampling in the winter as well as continuous monitoring by the PNAPM to identify trends and the factors responsible for observed intersite differences.

\section{CONCLUSIONS}

The factors utilized in this study were successful in providing a comparative analysis of basic ecological characteristics contributing to coral reef resilience, and therefore should continue to be monitored within the PNAPM and integrated into monitoring programs of other MPAs. This study did not quantify several aspects recognized to be significant factors in coral reef resilience (e.g., recruitment and connectivity). However, the results presented in this report provide a foundational characterization for the study sites upon which the PNAPM can build and incorporate additional factors. The lack of statistically significant difference in herbivore communities and nutrient levels and intersite differences in benthic cover did not 
conform to predictions based on the RDM (Littler \& Littler, 1984; 2007), and did not support the hypothesis that sites with lower herbivore biomass and higher nutrient levels would demonstrate decreased coral cover and increased macroalgal cover.

Several sites within the PNAPM demonstrate clear warning signs indicative of decreased resilience. Results from this study suggest that top-down regulation in the form of herbivore density and biomass and bottom-up mechanisms of elevated nutrient levels are influencing the PNAPM coral reef ecosystem, but that additional factors may exist that are playing a large role in site characteristics (e.g. tourism intensity). Differences in the level and intensity of these drivers are likely a major factor contributing the observed inter-site differences in ecosystem characteristics. These results emphasize the urgent need to increase the protection of fish populations on the coral reef environment in the PNAPM. The mixed relationships observed between herbivore densities and biomass and management zoning strategy highlights the necessity to enforce current zoning strategies.

These results provide critical information to coral reef managers regarding resource use, management, and protection, as sites containing more resilient attributes are more likely to rebound from disturbances and resist phase shifts to an alternative state (Nyström et al., 2000; Hughes et al., 2003; Bellwood et al., 2004). Sites with few resilience promoters and an abundance of attributes that detract from resilience may be approaching critical tipping points towards a phase shift, or may have already surpassed them. The application of these results is critical to move forward from merely characterizing sites to adapting management strategies according to results to attempt to prevent a phase shift from occurring. 


\section{CHAPTER III - STRESSOR PROXY MAP}

\section{INTRODUCTION}

Coral reefs worldwide are subjected to a multitude of threats, ranging from global factors such as climate change and ocean acidification (Hughes et al., 2003; HoeghGuldberg et al., 2007) to local threats such as coastal development (Cortes \& Risk, 1985; Babcock \& Smith, 2002; Lapointe et al., 2010), overfishing (Jennings \& Polunin, 1997; Bryant et al., 1998; Hawkins \& Roberts, 2004), eutrophication (Harrison \& Ward, 2001; Bruno et al., 2003; Loya, 2004; McManus \& Polsenberg, 2004), and direct physical impacts (Rouphael \& Inglis, 1997; 2001; Plathong et al., 2000), among many others. All of these stressors in conjunction with biotic and abiotic factors influence coral reef ecosystem function and the ecosystem services that coral reefs provide (Moberg \& Folke, 1999; Maynard et al., 2010a). Hundreds of millions of people in coastal regions throughout the world depend upon these ecosystem services, which include shoreline protection, fisheries, nursery grounds, and tourism (Reaka-Kudla, 1996; Moberg \& Folke, 1999; Brander et al., 2007). The coral reef structure and associated inhabitants comprise the fundamental core of these ecosystem services. Consequently, the maintenance of these critical ecosystem functions depends upon the protection of key ecosystem processes and members of coral reef ecosystems (e.g., fish, corals), and the major factors impacting them (Mumby, 2006; Maynard et al., 2010a).

The coral reef ecosystem present within the Parque Nacional Arrecife de Puerto Morelos (PNAPM) is central to the well-being of the ecological and social communities of Puerto Morelos. The livelihood and survival of this beachfront town, comprised of 
hotels, tourism operations, restaurants, and boutique shops, depends upon the revenue generated from national and international tourists drawn to visit the beach and coral reef, as does the significant revenue generated from snorkeling and diving in the PNAPM.

Approximately one-third of Caribbean coral reefs are considered threatened by coastal development, which includes impacts from coastal erosion, sedimentation, pollution, and tourism development (Burke \& Maidens, 2004). The eastern coast of the Yucatan Peninsula, which includes Puerto Morelos, is currently undergoing rapid development and population growth (Coronado et al., 2007; Murray 2007; HernándezTerrones et al., 2010). Increased runoff and sedimentation rates associated with coastal development can decrease coral cover and biodiversity (Cortes \& Risk, 1985; Hodgson, 1990; Shimoda et al., 1998), coral settlement and survivorship rates (Babcock \& Smith, 2002; Birrel et al., 2005), and reduce egg fertilization in some coral species (Harrison \& Ward, 2001). Nutrient enrichment studies have demonstrated that increased nutrient levels can also increase the frequency and intensity of coral diseases (Bruno et al., 2003). As coastal development progresses it produces a host of potentially devastating threats to the PNAPM coral reef ecosystem, including increased pollution, nutrient levels, resource use (e.g., fishing), and tourism, all of which have been demonstrated to negatively influence coral reef ecosystem function (Fabricius et al., 2005; Haynes et al., 2007; Reopanichkul et al., 2009; Lapointe et al., 2010). The significant increase in macroalgae abundance observed in the Caribbean over the past several decades was unlikely caused by eutrophication alone, but elevated nutrient levels in conjunction with other stressors (e.g., decreased grazing intensity) can generate serious negative consequences for coral reef ecosystems (McManus \& Polsenberg, 2004, Burkepile \& 
Hay, 2006; 2009). Ecological models predict that increased nutrient levels coupled with decreased grazing intensity will result in a shift from a coral-dominated state to a macroaglae-dominated state after a large disturbance (Littler \& Littler, 1984; 2007; McManus \& Polsenberg, 2004; Littler et al., 2006). Elevated nutrient levels can significantly increase macroalgal growth (Lapointe et al., 1987; Lapointe, 1997; Lapointe et al., 2010), which in turn can interfere with coral reproductive potential (Foster et al., 2008), settlement (Birrel et al., 2005), and the resilience of a coral-dominated state (Elmhirst et al., 2009). Elevated nutrient levels from nearby anthropogenic sources have been observed to kill $50 \%$ of corals as a result of macroalgal blooms (Loya, 2004), correlated with significant increases in coral disease intensity (Bruno et al., 2003), prevalence (Patterson et al., 2002), and macroalgae cover (Reopanichkul et al., 2009; Lapointe et al., 2010).

Grazing by herbivores has been demonstrated to promote coral and crustose coralline algae cover, decrease macroalgal cover, and assist in recovery from disturbances such as hurricanes (Mumby, 2006; Hughes et al., 2007; Burkepile \& Hay, 2008; 2009; Durán \& Claro, 2009). A significant body of literature exists supporting the hypothesis that herbivory on coral reefs exerts a stronger influence on macroalgae abundance compared to elevated nutrient levels (Diaz-Pulido \& McCook, 2003; Burkepile \& Hay, 2006; 2009; Furman \& Heck, 2008). Numerous studies have been published demonstrating the negative impacts of artisanal fishing practices, which occur within the PNAPM, including decreased biomass of targeted fish species (Jennings \& Polunin, 1997), reduced population density and species richness (McClanahan, 1994; Jennings \& Lock, 1996), and decreased coral cover and increased macroalgae cover 
(Hawkins \& Roberts, 2004). Evidence of the negative impacts of fishing practices on coral reef communities is bolstered by studies documenting the effects of marine reserves in which fishing is not permitted, which have demonstrated increased fish stocks, size, age, density, and biodiversity (Claudet et al., 2006; Floeter et al., 2006; Friedlander et al., 2007; Harmelin-Viven et al., 2010), increased top predator biomass, and decreased coral mortality (Babcock et al., 2010; McCook et al., 2010; Taylor \& Mcllwain, 2010). Mumby et al. (2007) demonstrated that contrary to common trophic-cascade predictions, marine reserve establishment in the Bahamas not only resulted in increased piscivore (top predator) biomass, but also increased grazing rates and significantly decreased macroalgal cover, further indicating the vital importance of healthy fish populations in maintaining coral reef persistence and ecosystem function.

Snorkeling and S.C.U.B.A tourist activities have been documented to cause significant damage to coral reef communities (Harriot et al., 1997; Rouphael \& Inglis 1997; 2001; Plathong et al., 2000; Barker \& Roberts, 2004). For example, Zakai and Chadwick-Furman (2002) found that during a 60-minute period, divers broke on average 1.7 corals. Tabular and branching corals, which provide the most three-dimensional structure to coral reef communities, are the form-function group most impacted by tourism activities (Planthong et al., 2000; Rouphael \& Inglis, 2001; Zakai \& ChadwickFurman, 2002). High tourism intensity has been associated with decreased coral cover and increased cover of dead coral and coral rubble (Tratalos \& Austin, 1999). Tourism within the PNAPM is a major portion of the local economy, which has attracted on average 134,000 visitors per year since 2002 (Reyes Bonilla, 2009; M. Ladd, unpub. data). In such high numbers, tourism activities such as snorkeling and S.C.U.B.A within 
the PNAPM have the potential to seriously adversely affect coral reef ecosystems if they are not closely regulated and monitored.

Submarine springs, locally known as "ojos de agua", are a fairly common natural feature throughout the PNAPM. Ojos de agua are fissures in the karstic limestone parent material that comprises the Yucatán Peninsula, which transport freshwater from inland areas out to the marine environment (Back, 1985; Carruthers et al. 2005; Young et al., 2008; Hernández-Terrones et al., 2010). The flow rate and materials (e.g., contaminants) transported by submarine springs present within the PNAPM vary greatly depending on prevailing weather conditions, seasonal variations, and water source characteristics (Paytan et al., 2006; Hernández-Terrones et al., 2010). Several studies have demonstrated that submarine springs have the capacity to transport nutrients and pollutants from inland sources to the marine environment, including within the PNAPM (Carruthers et al., 2005; Paytan et al., 2006; Mutchler, et al., 2007; Young et al., 2008; Hernández-Terrones et al., 2010). The lack of sewage treatment and collection facilities in Puerto Morelos suggests that the submarine springs present within the PNAPM have the potential to exert negative influences on the coral reef environment via the transportation of nutrients and pollutants (Harrison \& Ward, 2001; Paytan et al., 2006; Elmhirst et al., 2009; Lapointe et al., 2010). Hernández-Torrones et al. (2010) found that within the PNAPM, E. coli densities were highest in submarine springs, and Lapointe et al. (2010) documented that nitrogen from submarine springs caused eutrophic conditions at nearby reef sites, implying a direct connection between terrestrial anthropogenic wastes and the marine environment. 
Although the PNAPM management staff has knowledge of the presence of these stressors, their distribution and relative intensities have never been systematized, quantified, or mapped. Knowledge of the distribution and intensity of factors influencing ecosystem processes is essential to make decisions regarding the management and conservation of a coral reef ecosystem within a marine protected area (NRC, 2001; Agardy et al., 2003; Sobel \& Dahlgren, 2004).

The goal of this study was to identify and create an interactive map of the distribution and intensity of the major stressors present within the PNAPM. It is hypothesized that stressor intensity will be highest in areas closest to human population and development centers (i.e., the Puerto Morelos town center). Further, it is expected that stressors will demonstrate patterns associated with the general south to north currents characteristic of the Puerto Morelos reef lagoon (Coronado et al., 2007).

\section{METHODS}

Stressor Proxies

The major stressors present within the PNAPM were identified through a review of available literature pertaining to the region, in-situ data collection, personal observations, and conversations with local experts, including scientists from the Universidad Nacional Autónoma de México Instituto de Ciencias del Mar y Limnología (UNAM-ICMyL), veteran PNAPM monitoring and surveillance staff members, and local community members. While other stressors impacting the coral reef ecosystem certainly exist within the PNAPM, the five stressors selected in this study represent the most prevalent stressors present in the park identified to contain the capacity to negatively 
influence the coral reef ecosystem. Each stressor was assigned a proxy, defined as: "a specific variable that can be measured which can be used to estimate a variable of interest due to a close correlation between the proxy variable and the variable of interest" (Grimsditch and Salm, 2006). The five stressors identified were; 1) coastal development, 2) eutrophication, 3) fishing pressure, 4) tourism pressure, and 5) submarine springs (i.e., "ojos de agua"). It should be noted that coastal development as a stressor to be mapped refers to the distribution of coastal development along the PNAPM coastline. Eutrophication, which is a consequence of coastal development, is considered as a different stressor for mapping purposes, although both are clearly associated. Evidence for the potential of each stressor to negatively influence coral reef ecosystems, the proxy utilized to appropriately quantify the stressor, and data collection methods are elaborated below. The stressor proxy map was created using Google Earth Inc. (2009) software.

\section{Coastal Development - Concentrations of Population and Development}

Coastal development distribution was mapped using the information provided by Google Earth maps (version 5.2.1.1588). The most recent map available (2010) of the land area adjacent to the PNAPM was viewed in high resolution at an eye altitude of approximately 500 meters to identify the distribution of coastal development along the shoreline of the PNAPM. These images provide sufficient detail to distinguish undeveloped land clearings from developed areas and identify the location of all structures adjacent to the marine environment. Hotel guest capacities were obtained from multiple online travel guides and websites to better understand the size of each hotel 
relative to others (Available at: http://www.tripadvisor.com, http://www.expedia.com, and http://www.hotelandtravelindex.com).

\section{Eutrophication, $N, P$ and $\delta^{15} N$}

Nutrient levels were quantified for each of the five selected study sites using percent tissue nutrient content analyses of macroalgae samples of Dictyota spp. as a proxy. All samples were cleaned, dried at $60^{\circ}$ Celsius for at least 48 hours and ground at the UNAM-ICMyL. Carbon, nitrogen, and phosphorus tissue content analyses were conducted at the Seagrass Ecosystems Research Lab at Florida International University in Miami, Florida following the protocols developed by Fourqurean and Zieman (2002).

$\delta^{15} \mathrm{~N}$ has been identified as a reliable indicator of anthropogenic inputs of nitrogen to the marine environment (Lapointe et al., 2005; Risk, 2009; Risk et al., 2009), and Dicyota spp. has been proven a reliable macroalgal indicator (Umezawa et al. 2002). Macroalgae samples of Dictyota menstrualis and D. cervicornis were taken at five sites throughout the PNAPM (three samples per site) for the calculation of $\delta^{15} \mathrm{~N}$ values (See Figure $\mathbf{2}$ for study site locations). Preliminary site evaluations concluded that this complex of Dictyota spp. was present and sufficiently abundant at all sites. In-situ identification of the two species, which were commonly observed to grow in close association, was not feasible, and therefore it was necessary to use a species complex rather than one species because of insufficient material of one or the other at several sites. Results were presented in the standard notion $\delta^{15} \mathrm{~N}(\% \mathrm{\%})=\left[\left(\mathrm{R}_{\text {sample }} / \mathrm{R}_{\text {standard }}\right)-1\right] \times 10^{3}$ using atmospheric nitrogen as a standard and Vienna Pee Dee belemnite for carbon. The precision of the measurements was better than $\pm 0.2 \%$ for $\delta^{15} \mathrm{~N}$ and \pm 0.08 for $\delta^{13} \mathrm{C}$ 
(Anderson \& Fourqurean, 2003). Isotope analyses were conducted at the SERC Stable Isotope Lab at Florida International University with a standard elemental analyzer isotope ratio mass spectrometer (EA-IRMS) following the protocols described by Anderson and Fourqurean (2003). The distribution of coastal development and hotel visitor capacities in combination with $\delta^{15} \mathrm{~N}$ stable isotope data provides an appropriate proxy to determine relative differences of coastal development influence intensity throughout the PNAPM.

\section{Fishing Pressure}

Fishing pressure distribution was qualitatively mapped using several information sources. The PNAPM management plan was utilized to locate areas in which fishing permission is granted to members of the local fishing cooperative. The PNAPM staff input in and in-situ observations of poaching and regulation infractions were integrated into the qualitative assessment of fishing pressure intensity. Both are important aspects, because only local knowledge identifies that poachers intentionally target certain areas of the PNAPM more frequently than others, generating variable fishing pressure within fishing zones.

\section{Tourism Pressure}

General tourism distribution was mapped using the PNAPM management plan zoning strategy. The PNAPM surveillance data, which records the number of boats and tourists at each tourism site (on days when surveillance activities are conducted), generated specific values of visitation rates for each of the study sites. The total number of PNAPM visitor bracelets (required for tourists to participate in activities within the park) sold in 2009 (http://cobro.conanp.gob.mx/concentrados.php?anio=2009) was 
divided by the total number of visitors recorded by surveillance in 2009 in order to generate the proportion of all tourists that visited the PNAPM in 2009 recorded by surveillance activities. Recorded visitor numbers at each study site were then multiplied by this value to obtain an estimate of the annual number of visitors for each site.

\section{Ojos de Agua}

All ojo de agua locations were taken in-situ with a handheld Garmin GPSMAP ${ }$ 276C GPS unit. The PNAPM staff, who have superior experience and knowledge of the park, provided information regarding the location of known submarine springs within the park. On very calm days ojos de agua can be located by sight (a slightly turbulent area within an otherwise smooth surface), as well as smell. The lagoon of the PNAPM was searched using this method during routine surveillance activities to locate previously undocumented ojos de agua. In the instance that a potential ojo de agua was identified, a diver entered the water with snorkel gear, free-dove to the bottom, and confirmed that water was flowing from a fissure in the substrate.

All data (except visitor rates) were collected from June to August of 2010. For site-specific measurements (i.e., nutrient contents and tourism rates) five representative study sites where chosen throughout the PNAPM; 1) Limones, 2) La Bonanza, 3) Tanchacte, 4) Radio Pirata, and 5) Jardines (See Figure 2, Chapter 2). Stressor distributions were mapped using Google Earth Inc. version 5.2.1.1588 (2009) software. Google Earth was the program chosen to create this map because it is user-friendly, free to use, and therefore can be utilized, modified, and updated by PNAPM staff and others without requiring specialized computer software or training. 


\section{RESULTS}

\section{Coastal Development - Concentrations of Population and Development}

Radio Pirata, located just to the north of the Puerto Morelos town center, was the study site determined to be most influenced by coastal development, primarily consisting of residential, hotel, and restaurant development. Coastal development in Puerto Morelos has expanded from the town center, consequently this region has been exposed to anthropogenic influences for a longer period of time compared to areas farther to the north. However, the majority of human development in the Puerto Morelos town center is comprised of small residences and restaurants, with several small hotels ( $<30$ rooms) and the largest hotel, Ojo de Agua, which contains 36 rooms. Development to the north consists almost exclusively of large hotel complexes. Limones and La Bonanza are situated offshore of the Moon Palace hotel, a megaresort containing 2,031 rooms with a 27-hole golf course behind it. Tanchacte is located in an area with less coastal development; the closest hotels are Zoetry Paraiso de la Bonita (90 rooms) and the Azul Beach Hotel (98 rooms). Jardines was thought to be the site least impacted by coastal development because of its location in the less developed, extreme south of the PNAPM. Eutrophication, $N, P$ and $\delta^{15} N$

Radio Pirata demonstrated significantly higher percent tissue content of nitrogen (ANOVA, $\mathrm{df}=4, \mathrm{~F}=0.478, \mathrm{P}=0.002$ ) than all other sites. The percent tissue content of phosphorus in Radio Pirata and Limones was significantly higher than the other three study sites (ANOVA, $\mathrm{df}=4, \mathrm{~F}=4.827, \mathrm{P}=0.005$ ). Radio Pirata contained the highest $\% \mathrm{~N}$, with a gradual decline in percent nitrogen from Radio Pirata northward. Jardines, the site 
at the southern extreme of the PNAPM, demonstrated the lowest nitrogen tissue content as well as low tissue phosphorus content. The highest N:P ratio (102.84) was observed in Tanchacte and the lowest (68.68) in Limones, which was significantly lower than all other sites except Radio Pirata (ANOVA, df $=4, \mathrm{~F}=3.082, \mathrm{P}=0.035$ ). The $\mathrm{C}: \mathrm{N}$ ratios were lowest in Radio Pirata (15.95) and highest in Jardines (21.15). The lowest C:P occurred in Limones $(1,304.24)$ and the highest in Jardines $(2,120.67)$. Tables detailing percent nutrient content and nutrient ratio results can be found in Chapter 2 (See Figure 25, Figure 26, Figure 27, and Table 24).

Mean $\delta^{15} \mathrm{~N}$ values ranged from +2.09 to $+1.08 \%$ from Jardines to Limones, with an overall average of $+1.50(\mathrm{SD}=0.47, \mathrm{SE}=0.11)($ See Figure 36). Significant differences were detected between $\delta^{15} \mathrm{~N}$ values (ANOVA, $\mathrm{df}=4, \mathrm{~F}=7.279, \mathrm{P}=0.003$ ). $\delta^{15} \mathrm{~N}$ was significantly higher in Jardines than all sites except for Radio Pirata.

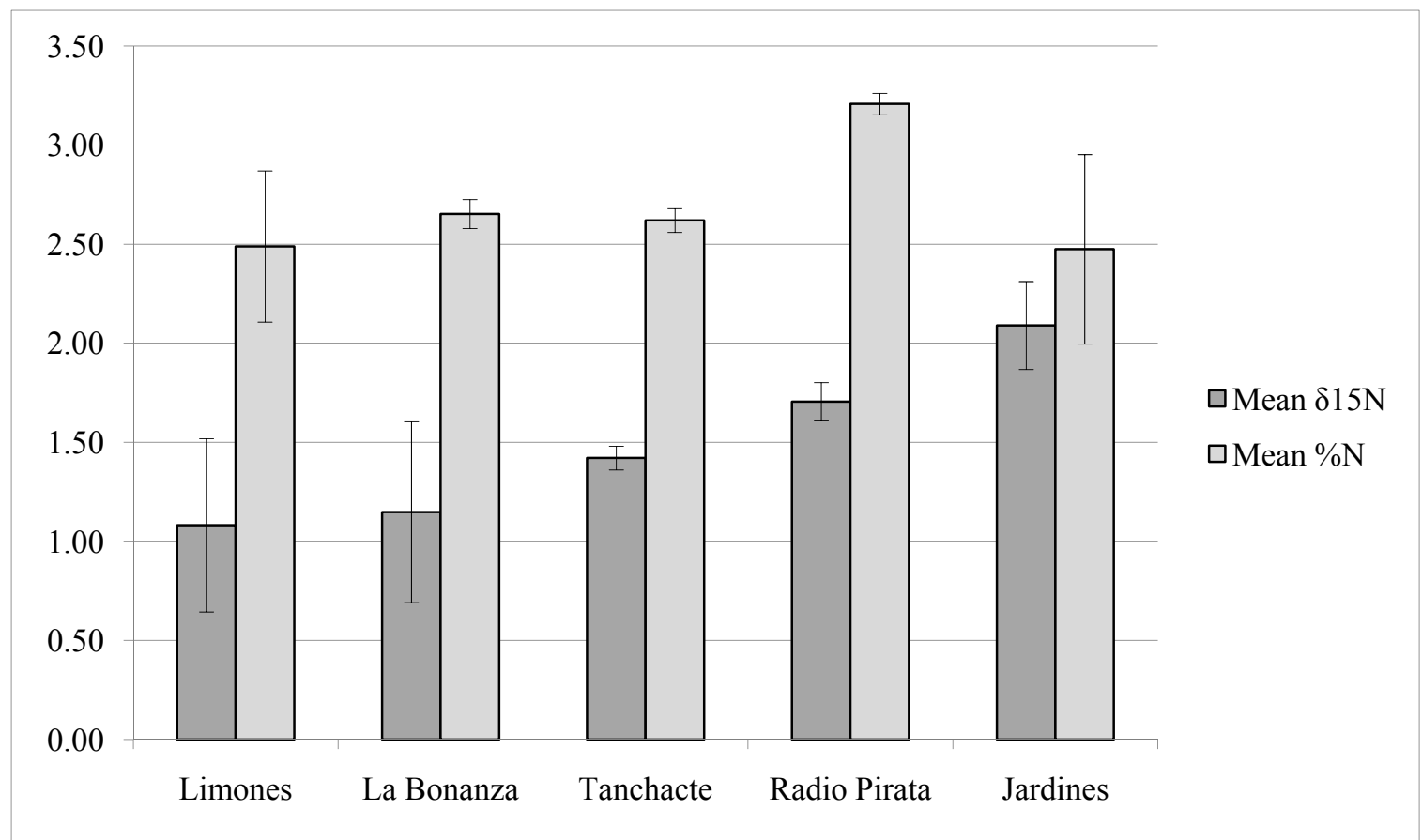

Figure 36. Mean $\delta^{15} \mathrm{~N}$ and $\% \mathrm{~N}$ values by site. Error bars represent $\pm 1 \mathrm{SD}$. 


\section{Fishing Pressure}

Fishing pressure was found to be most intense in Limones, which is surrounded by an area where fishing is permitted. Local knowledge and in-situ observations revealed that Limones was also subject to the highest levels of illegal poaching, elevating the fishing intensity in this area. An area zoned for fishing concessions also surrounds La Bonanza, which is bounded by a small "semi-intensive" recreational zone on the backreef and a scientific no-take area on the forereef. Jardines, situated at the southern extreme of the PNAPM, is within a small tourism zone but is very close to a large navigation channel in which fishing is not restricted. Recreational and commercial fishermen were often observed infringing upon these boundaries and fishing illegally nearby or within the Jardines study site (Luis Alberto Ramos, PNAPM, pers. comm.; M. Ladd, pers. obs.). Tanchacte is located within the second-largest recreation zone of the PNAPM, but also is bounded to the north and south by a fishing zone. Radio Pirata is positioned in the center of the largest recreational zone within the PNAPM, and was identified as being subjected to the lowest level of fishing pressure of all the sites in this study.

\section{Tourism Pressure}

Tourist activities were by far the most intense at Radio Pirata, which had on average (mean $\pm \mathrm{SE}) 2,341( \pm 760)$ visitors per month, more than two times the average number of visitors per month at any other study site. La Bonanza demonstrated the next highest level of tourists per month $(870 \pm 203)$, which was similar to visitor levels at Tanchacte (794 \pm 369$)$. An average of $190 \pm 45$ tourists visited Limones per month. 
Jardines had the lowest mean visitation rate of $12 \pm 10$ visitors per month, much lower than any other study site.

\section{Ojos de Agua}

A total of 21 ojos de agua were identified and located within the PNAPM. The highest concentration of ojos de agua was found in the lagoon area south of Tanchacte, where 14 ojos de agua were identified and mapped. Four ojos de agua were found north of Tanchacte within 4.5 kilometers of La Bonanza. No ojos de agua were located as far north as La Bonanza, and the only ojo de agua identified in the southern region of the PNAPM was directly in front of the town center. Examples of the different layers developed for the stressor proxy map can be found in Appendix C.

\section{DISCUSSION}

\section{Coastal Development - Concentrations of Populations and Development}

Radio Pirata was clearly the site most influenced by high human population and coastal development density. This site experiences elevated tourist visitation rates, an indirect effect of nearby increased coastal development and proximity to the Puerto Morelos town center, which provides a close access point for a large number of tour boat operators. The only public beach access to the PNAPM is located directly in front of the Puerto Morelos town center, further increasing national and international tourist loads. Until recently, the majority of large-scale anthropogenic development adjacent to the PNAPM has been centralized around the Puerto Morelos town center. Only within the past two decades have multiple large hotels been constructed in formerly undeveloped coastal regions to the north. Given its location, Radio Pirata has been exposed to the 
effects of coastal development for a longer period of time than any other site, exaggerating the influence of coastal development in this area.

Eutrophication, $N, P$ and $\delta^{15} N$

Coastal development contains the potential to significantly impact the PNAPM coral reef environment via eutrophication resonating from anthropogenic wastes and activities (Hunter \& Evans, 1995; Lapointe, 1997; Lapointe et al., 2010). Limones and La Bonanza demonstrated the highest- and second-highest percent tissue phosphorus content, and are also located directly in front of the massive hotel resort complex Moon Palace that contains over 2,000 guest rooms and a 27-hole golf course, which could contribute to elevated phosphorus levels in the area. Phosphorus is commonly applied in large quantities in order to maintain golf courses, and has been observed to leach into surrounded watersheds (Geron, 1993; Wong et al., 1998). The percent phosphorus content in Limones was slightly higher than in La Bonanza, suggesting that if phosphorus is coming from Moon Palace, it is being carried in a general northward pattern and exerting a stronger influence on Limones compared to La Bonanza. Results from this study cannot confirm that the high levels of $\% \mathrm{P}$ found in La Bonanza and especially Limones originate from inputs to maintain this golf course. However, this observation generates the hypothesis that nutrients from the Moon Palace golf course are entering the marine environment and influencing the coral reef. Further investigations utilizing analyses that can confirm the source of nutrients (e.g., stable isotope signatures) found in the coral reef environment would provide important information regarding the influence of coastal development on the coral reef ecosystem. The PNAPM could use this information to develop fertilizer application regulations and set standards within the park 
that must be conformed to by hotels. Furthermore, such information would provide clues as to the impact of smaller and distant coastal development on sites such as Tanchacte, which at this point is totally speculative due to a lack of sufficient information. Phosphorus may be an especially important nutrient to monitor within the PNAPM. Results from nutrient analyses in this study coincide with previous conclusions indicating that the calcareous PNAPM environment is a P-limited system (Atkinson \& Smith, 1983; Duarte, 1990; Hernández-Terrones et al., 2010; Lapointe et al., 2010). Therefore, increasing P levels in the PNAPM may produce more adverse effects compared to elevated $\mathrm{N}$ levels, which have already surpassed the proposed saturation threshold for this nutrient (Duarte, 1990; McClanahan et al., 2002).

Percent tissue nitrogen content values found in this study were highest at Radio Pirata and progressively decreased moving northward with the general PNAPM lagoon water currents (Coronado et al., 2007). This pattern of percent nitrogen content supports the proposed hypothesis of high nutrient inputs closest to the largest concentration of human population density and development (i.e., the Puerto Morelos town center). Lapointe et al. (2010) documented that anthropogenic wastewater runoff caused a gradient of eutrophic conditions resonating from human sewage inputs. Jardines, located to the south of the Puerto Morelos town center, contained the lowest $\% \mathrm{~N}$ value, which supports the hypothesis that $\mathrm{N}$ is being transported from the Puerto Morelos town center north via water currents.

The N:P ratios did not follow the same patterns observed in $\% \mathrm{P}$ and $\% \mathrm{~N}$, which is logical because this value is comprised of the relationship between the two nutrients. For example, Radio Pirata contained the highest $\% \mathrm{~N}$ and \%P levels, but the second lowest 
$\mathrm{N}: \mathrm{P}$ ratio. For this reason, $\% \mathrm{P}$ and $\% \mathrm{~N}$ provide more appropriate indicators of eutrophication compared to the N:P ratio, which is also common measure of elevated nutrients (Lapointe et al., 2010).

The $\delta^{15} \mathrm{~N}$ values were on average highest in Jardines and gradually decreased moving northward, with Limones demonstrating the lowest $\delta^{15} \mathrm{~N}$ value. As predicted, these results closely mirror patterns in \% $\mathrm{N}$ values at all sites except for Jardines (See Figure 36). These are important results that demonstrate a close relationship between concentrations of human development, anthropogenic inputs of $\mathrm{N}$, and elevated nutrient levels. A host of studies have demonstrated correlations between anthropogenic $\mathrm{N}$ inputs and elevated $\delta^{15} \mathrm{~N}$ levels (Umezawa et al., 2002; Lapointe et al., 2005; Risk et al., 2009; Lapointe et al., 2010). The results from this study coincide with past findings and largely support the hypotheses that stressor intensity will be highest closest to human population centers, and that stressors will be influenced by the south to north currents typical of the PNAPM reef lagoon.

However, the $\delta^{15} \mathrm{~N}$ values encountered in Jardines do not conform to these expectations. On the basis of the water currents and the relatively low coastal development in front of and to the south of Jardines, it was expected that anthropogenic $\mathrm{N}$ inputs would be minimal in the site. On the contrary, results from $\delta^{15} \mathrm{~N}$ stable isotope analysis suggest that Jardines is actually the site most influenced by anthropogenic inputs of N, possibly explained by several hypotheses. Jardines' $\delta^{15} \mathrm{~N}$ levels may be higher than all other study sites due to high primary productivity rates, which can lead to the depletion of available $\delta^{14} \mathrm{~N}$ isotopes and an increase in the $\delta^{15} \mathrm{~N}$ signature (Anderson \& 
Fourqurean, 2003). The lower $\% \mathrm{~N}$ observed in Jardines would contribute to a quicker accumulation of $\delta^{15} \mathrm{~N}$, since there is less overall $\mathrm{N}$ available in this site compared to the others. Another possible explanation is that there is a substantial anthropogenic source of $\mathrm{N}$ reaching Jardines, which may resonate from the Hotel Cid (350 rooms) and a marina to the south of Jardines, as well as a large commercial shipping dock located just to the north of the Jardines study site. It is possible that one or a combination of these sources are releasing large levels of $\mathrm{N}$ into the marine environment that are influencing the coral reef environment in Jardines.

Another possible explanation for observed $\delta^{15} \mathrm{~N}$ values is the distance of each study site to the shoreline. Umewaza et al. (2002), and Lapointe et al. (2005) (in Japan and southern Florida, respectively) demonstrated patterns of decreased $\delta^{15} \mathrm{~N}$ values with distance from the shoreline. In this study Jardines and Radio Pirata were the two sites closest to the shoreline $(\sim .75 \mathrm{~km})$, while distance from the shore to study sites increased moving northward $($ Tanchacte $=\sim 1 \mathrm{~km}$, La Bonanza $=\sim 1.5 \mathrm{~km}$, Limones $=\sim 2.75 \mathrm{~km})$, supporting the hypothesis that $\delta^{15} \mathrm{~N}$ values decrease as distance from the shoreline increases. The observed patterns in $\delta^{15} \mathrm{~N}$ values is unlikely solely a product of one of these factors, but rather a combination of proposed explanations.

All study sites demonstrated $\delta^{15} \mathrm{~N}$ values lower than those observed in past studies of coral reef sites known to be influenced by anthropogenic inputs of N (e.g., Umezawa et al., 2002; Lapointe et al., 2005; Risk et al., 2009; Lapointe et al., 2010), but are still slightly higher than averages reported for macroalgae on coral reefs not receiving anthropogenic $\mathrm{N}$ inputs (France et al., 1998). Risk et al. (2009) reported that $\delta^{15} \mathrm{~N}$ values 
were significantly lowered when samples were acidified before processing (Kennedy et al., 2005), as was done with the samples in this study. The protocols used to clean the macroalgae samples in this study may have confounded the nitrogen stable isotope results by reducing $\delta^{15} \mathrm{~N}$ values, as has been observed in past studies

Regardless of whether the true $\delta^{15} \mathrm{~N}$ values should be higher, all samples were processed using the same protocols and therefore observed patterns are valid. The overall pattern observed from the results of this study indicates that anthropogenic $\mathrm{N}$ inputs are most impacting the coral reef ecosystem closest to human population centers (Jardines and Radio Pirata), and decrease as one moves to the north. Re-sampling the Dictyota spp. complex used in this study and conducting stable isotope analyses on samples not submerged in an acidic solution should be conducted to determine if the $\delta^{15} \mathrm{~N}$ results reported in this study are lower than true values. Establishing baseline $\delta^{15} \mathrm{~N}$ values for the PNAPM should be a priority, as these values are imperative to track trends in anthropogenic $\mathrm{N}$ inputs impacting the marine environment (Risk et al., 2009).

\section{Fishing Pressure}

Limones was the site most influenced by fishing pressure, largely because of the high levels of poaching that occur in this site. Poaching intensity is higher in Limones than all other sites because of its location in the extreme north of the PNAPM. This site is the closest access point for anyone coming from Cancun or north of the PNAPM, and is also the farthest site for PNAPM park guards to conduct surveillance and patrol activities. Furthermore, tour operators from Cancun comprise the majority of visitors to this site, thus information sharing between tour operators and PNAPM guards is minimal 
compared to closer to the Puerto Morelos town center, where local fisherman and tour boat operators commonly report regulation infractions (M. Ladd, pers. obs.).

Consequently, park guards normally do not visit this region more than once per day, providing ample opportunity for poachers to illegally fish unbothered. Jardines, located in the extreme southern region of the park is also subject to high poaching rates relative to the rest of the study sites. Jardines is located next to a shipping channel in which fishing restrictions to not apply. Recreational and commercial fishermen were often observed encroaching on the boundaries of this channel, fishing nearby the Jardines site or even within the coral reef area (M. Ladd, pers. obs.).

The identification of these two areas of high illegal activity within the PNAPM demonstrates the utility of this stressor proxy map. Documenting such information allows park guards to maximize the efficiency of their limited time on the water by directing surveillance activities to areas known to be problematic. The addition of the number of reported and observed infractions within each site to the stressor proxy map would prove a useful tool to track the progress of current monitoring and direct future activities.

\section{Tourism Pressure}

Similar with coastal development and eutrophication, Radio Pirata was the site that demonstrated the highest intensity of tourism pressure, receiving $266 \%$ more visitors than the next most visited study site. The high visitation rates observed in Radio Pirata in combination with elevated nutrient levels presents a worrisome situation. Tourism activities have been demonstrated to negatively impact coral reef ecosystems through 
both direct physical damage (Rouphael \& Inglis, 1997; 2001; Plathong et al., 2000) and indirect effects (Burke \& Maidens, 2004). As aforementioned, Radio Pirata has been exposed to anthropogenic influences longer than any other study site. The long-term exposure to the multiple stressors observed in Radio Pirata has the potential to provoke chronic degradation and erosion of ecosystem resilience in this site. La Bonanza and Tanchacte demonstrated similar moderate levels of tourism activity, likely because of their proximity to the Moon Palace hotel megaresort and multiple other large hotels complexes.

These results suggest a rational pattern of increased tourism activity associated with proximity to coastal development. This is an important pattern to recognize for future managerial planning as coastal development continues to expand within the PNAPM. Tour operators are required to tie their boats to mooring balls, effectively limiting the number of boats and therefore tourists that can visit a site at one time ( 3 boats per mooring ball). The PNAPM staff needs to take into account the observed relationship between coastal development distribution and tourism intensity to prepare for future construction along the coastlines. As tourism increases within the PNAPM, the proactive placement of mooring balls will be critical to designate areas where snorkel tours will be allowed and to avoid the degradation of fragile, recovering, or critically important areas. The ability to modify management strategies (e.g., mooring ball locations) when relevant knowledge emerges is critical for the future successful management and conservation of the PNAPM coral reef ecosystem.

Carruthers et al. (2005) and Hernández-Terrones et al. (2010) demonstrated that submarine springs can transport nutrients and influence the marine environment, and 
provide the most in depth studies characterizing submarine springs in the Puerto Morelos region. On the basis of the water movement patterns posited by Coronado et al. (2007), Tanchacte would be the site most influenced by the high concentration of ojos de agua located to the south of this site. However, the limited knowledge regarding the level of contamination generated by individual ojos de agua and the fate of these contaminants renders conclusions of the impacts of ojos de agua on specific coral reef sites within the PNAPM invalid. Nonetheless, ojos de agua possess the potential to exert significant impacts on the PNAPM coral reef ecosystem. Further investigations directed at answering these questions should be undertaken to determine the impact exerted by ojos de agua on specific sites within the PNAPM coral reef environment.

\section{CONCLUSIONS}

This study successfully identified five major stressors impacting the PNAPM coral reef environment and mapped their relative distributions. The development of the stressor proxy map allowed for the distinction of differential impacts resonating from large human and development centers, which were associated with elevated $\% \mathrm{~N}$ from the Puerto Morelos town center, and increased \%P levels near large hotel complexes. Further, this studied identified that there are significant anthropogenic inputs of $\mathrm{N}$ entering the Puerto Morelos marine environment, although the determining the sources of this nutrient was beyond the scope of this study and requires further investigation. The integration of multiple stressors into an interactive map provides an applicable management tool for the PNAPM to aid in future decision-making regarding activities permitted within the park, their distribution, and acceptable activity levels. Further, this 
map can help to evaluate current management strategies, recognize vulnerable areas, and predict differential influences depending on the stressors of focus (e.g., the use of $\mathrm{P}$ in golf course management will have a strong impact in the PNAPM, as elevated P levels in calcareous environments can be especially detrimental). The relatively simple technology used to create and required to use this map enables it to serve as a template for marine protected area managers worldwide to assist in improving coral reef resource management and conservation.

The recognition of stressor distribution and intensity within the PNAPM is an important step towards implementing study results to adapt and improve management strategy effectiveness. This is the first map produced documenting the distributions and relative intensities of multiple coral reef stressors within the PNAPM. Previous studies conducted in the region have investigated several of the stressors mapped in this study as possible causative factors for observed results or have focused on one specific stressor (Rodríguez-Martínez, 2008; Reyes Bonilla, 2009; Hernández-Terrones, 2010), but none have attempted to integrate all of them in a map in order to document their cumulative intensities and potential impacts. The results of this study provide a base for the PNAPM that can be expanded, modified, and updated as new information becomes available and time progresses. Relevant stressors that can impact the coral reef environment that should be incorporated into this map include sedimentation and regulation infraction frequencies. Updating the stressor proxy map annually with subsequent ecological monitoring data would provide a manner to track changes and observe trends within the PNAPM. Viewing this data in the same context as the major stressors influencing study sites provides unique insight regarding potential mechanisms responsible for observed 
patterns, and allows for the development of hypotheses and management strategies that can be tested.

While this study identifies the general distributions of major stressors within the PNAPM, more specific studies are required to better understand the influences that these stressors are imposing upon the coral reef environment. For example, identifying of the sources of nutrients found in the reef environment can provide critical information not only to recognize where these are coming from, but also to develop regulatory and management initiatives. Nutrient analysis results can provide with a scientific base to lobby for values to set acceptable limits for hotels and residences along the coast to work towards decreasing the intensity of stressors affecting the PNAPM coral reef ecosystem.

This study provides an example for MPAs worldwide for the relatively simple and low-cost development of an important management tool. Bridging the gap between documenting degradation and acting upon these results is a critical step that must be taken to support the existence and persistence of coral reefs in the PNAPM and worldwide. 


\section{CHAPTER IV - RESILIENCE INDEX}

\section{INTRODUCTION}

Resilience is now widely recognized as a management priority for MPAs focused on the preservation of coral reef ecosystems and the ecological services they provide (Hughes et al., 2003; Bellwood et al., 2004; Keller et al., 2009; Maynard et al., 2010a). Resilience is a critical attribute for the persistence of coral reef ecosystems currently confronted by multiple stressors and to resist phase shifts in the face of unpredictable catastrophes and complex effects of climate change (Hughes et al., 2007; Keller et al., 2009; Cheal et al., 2010). Coral reef experts have recently recognized an acute need to develop methods that translate scientific results into comprehensive summaries that can be understood and acted upon by local managerial staff (Keller et al. 2009; Hughes et al., 2010; Maynard et al. 2010b). The resilience index framework of Maynard et al. (2010a) provides a pertinent management tool to successfully translate scientific results into a format that can accomplish these goals.

Promoters of coral reef ecosystem resilience supported by published literature include herbivore abundance (Mumby et al., 2007; Burkepile \& Hay, 2008) functional group representation (Bellwood et al., 2003; 2004; Burkepile \& Hay, 2008), coral cover (Mumby et al., 2007) and an abundance of resistant and resilient species (Bellwood et al., 2004; Maynard et al., 2010a). Connectivity and recruitment have also been identified as crucial promoters or detractors of coral reef resilience (Sale et al., 2005; Elmhirst et al., 2009). Physical impacts, disease, eutrophication, pollution, and sedimentation from local 
and distant sources stress coral reefs and decrease ecosystem resilience (Cortes and Risk, 1985; Morton, 1994; Bruno et al., 2003; Burke and Maidens, 2004; Fabricius, 2005; Hoegh-Guldberg et al., 2007). Increased ocean temperatures have been correlated with increased frequency of coral-bleaching events and disease outbreaks (Rosenberg \& BenHaim, 2002, Burke \& Maidens, 2004), further stressing coral reefs and decreasing ecosystem resilience.

Marine protected areas must manage for an uncertain future (e.g., bleaching events, hurricanes, etc.) by promoting local factors to maximize the resilience of coral reef ecosystems and enhance their ability to resist and rebound from disturbances (Bellwood et al., 2004; Maynard et al., 2010a). The current situation of increasing coastal development and marine-oriented activity levels in Puerto Morelos, in conjunction with past studies of declining coral cover (Jordán-Dahlgren et al., 1981; Rodriguez-Martinez, 1993 in Rentería et al., 1999; Rodríguez-Martínez, 2008; Rentería et al., 1999) suggest that sites within the PNAPM coral reef ecosystem may be reaching critical tipping points in ecosystem resilience (Knowlton, 1992; Littler \& Littler, 2007). The Maynard et al. (2010a) resilience index provides a framework to determine the resilience of sites within the PNAPM coral reef environment relative to each other. Further, the resilience index provides a method to identify local management actions that can be taken to most benefit resilience at each site and increase management efficacy.

This study evaluated the utility of a broadly applicable management tool proposed by Maynard et al. (2010a). The research specifically focused on 1) stressors adversely impacting coral reef resilience that can be mitigated via altered management strategies and 2) refining the original index for specific applicability to the PNAPM. I hypothesize 
that sites demonstrating the highest number of resilience promoters and that are least impacted by anthropogenic activities will receive the highest resilience scores. This research comes at a critical time, as the PNAPM is currently revising its management plan, zoning, and natural resource conservation strategy after 10 years of establishment.

\section{METHODS}

\section{Resilience Indicators}

Resilience index scores for each study site were calculated using the indicators provided by Maynard et al. (2010a) framework, which also supplies a description of each indicator and its role in coral reef resilience. Several of the original indicators are not relevant to the study site (e.g., "reduction in light stress"), and therefore were not included in this study. Additionally, no information was available for several indicators relevant to the PNAPM, thus these indicators were excluded from the calculation of study site resilience scores as well (see indicator descriptions below). The original index was then refined via the addition of new indicators as well as the modification and removal of indicators from the original Maynard et al (2010a) resilience index. Sites were ranked using the refined index to determine relative resilience values and management influence potential with the refined index specifically tailored to the PNAPM region. A description of the additions and modifications is presented below.

Indicators were assigned weights based on current published literature demonstrating the importance of these indicators in contributing to (or detracting from) coral reef resilience in combination with site-specific characteristics of the PNAPM. For example, fishing is prevalent in some areas of the PNAPM, and therefore is hypothesized 
to exert a strong influence on the distribution and abundance of herbivorous fishes, which have been demonstrated to significantly increase coral reef ecosystem resilience (Jennings \& Polunin, 1997; Hawkins \& Roberts, 2004; Mumby, 2006). As posited by Maynard et al. (2010a), the indicators used for this study represent the major factors hypothesized to influence coral reef ecosystem resilience and ecological processes.

\section{Resilience Index Score Calculation}

Interval ranges were calculated for each indicator in order to assign individual study sites a score that measured the value of each site relative to the others. The minimum value for a given indicator was subtracted from the maximum value to generate the range for the data. Interval size for each of the resilience index scores $(1,2$, or 3$)$ was calculated by dividing the range by 3 . Specific interval range values were determined by adding the interval size to the minimum value (upper-bound of category one), then adding the interval size multiplied by 2 to the minimum value (upper bound of category two) to generate three different categories for the resilience index scores.

Example: Coral Cover

Maximum value: 16.50

Max - Min $=16.50-3.45=13.05$ (Range)

Upper Bound for Interval 1: $3.45+4.35=7.80$

Upper Bound for Interval 2: $3.45+(4.35 \times 2)=12.15$

\begin{tabular}{|c|c|}
\hline Range & Resilience Score \\
\hline $3.45-7.80$ & 1 \\
\hline $7.81-12.15$ & 2 \\
\hline $12.16-16.50$ & 3 \\
\hline
\end{tabular}

Table 36. Sample resilience score calculation results.

Minimum value: 3.45

$13.05 / 3=4.35$ (Interval Size)

Resilience index scores calculated by this method are denoted with an asterisk $(*)$ following the resilience indicator title. 
1) Free from fishing pressure - Resilience index values for fishing pressure were determined via qualitative methods. Sites located within a fishing zone were given the lowest score of 1 , as fishing pressure is assumed to be highest in these areas. Personal observations as well as park staff input regarding illegal fishing activity were taken into account to properly assign scores for the remaining sites located in tourism-zoned areas, which are subjected to variable rates of poaching.

2) Free from contamination/pollution* - Contamination and pollution values were determined via percent tissue nitrogen content and N:P ratio results of macroalgae samples from each site (See Chapter 2 Methods for nutrient analysis methodology). Sites with lower total $\% \mathrm{~N}$ and $\mathrm{N}: \mathrm{P}$ ratios received higher resilience scores for these values (i.e., less eutrophication).

3) Survived hot water events - Insufficient data regarding the history of coral colony survival of past hot water events at study sites prevented the calculation of resilience index scores for this indicator, although it is recognized as an important indicator for PNAPM coral reef resilience.

4) Free from large physical impacts - Insufficient data pertaining to the history of large physical impacts at study sites prevented the calculation of resilience index scores for this indicator. However, it is recognized that this is an important indicator when evaluating coral reef ecosystem resilience in the PNAPM. 
5) Connectivity - Insufficient data regarding connectivity patterns in the PNAPM prevented the calculation of resilience index scores for this indicator, although it is recognized as an important indicator for PNAPM coral reef resilience.

6) Exposure to upwelling - A review of published data on local water currents (See Coronado et al., 2007) established that no variable effects of upwelling could be determined for any of the study sites. Consequently, no resilience index scores were given for this indicator.

7) Reduction in light stress - The lack of nearby terrestrial topography (e.g., mountains and cliffs) that could provide shading and subsequent reduction in light stress renders this indicator irrelevant in the PNAPM. Thus, no resilience index scores were given for this indicator.

8) Water mixing - Insufficient data regarding site-specific water movement patterns in the PNAPM prevented the calculation of resilience index scores for this indicator.

\section{Local-Scale Indicators}

9) Coral cover * - Mean percent coral cover for each site was derived from benthic community characterization data collected in-situ and was utilized to determine resilience index scores for this indicator. Sites with higher coral cover received higher scores for this indicator.

10) Resistant/tolerant coral species - Each coral species identified in coral community composition surveys was qualitatively assigned a resilience score and a resistance score 
based on interpretations of available published literature (See Table 37). In each site, the frequency of each coral species was multiplied by the resilience score for that species.

These values were then summed to provide an overall resilience score for the coral community composition of each site. The same process was conducted to generate a resistance score for each site. The average of the resilience and resistance score was calculated and this value was used to determine the score for 'resistant/tolerant coral species' indicator at each site.

\begin{tabular}{|c|c|c|c|}
\hline Species & Resilience Score & Resistance Score & Source \\
\hline Agaricia agaricites & 3 & 1 & (Hughes and Tanner, 2000) \\
\hline A. tenuifolia & 3 & 1 & $\begin{array}{l}\text { (Aronson \& Precht, 1997; } \\
\text { Aronson et al., 2004) }\end{array}$ \\
\hline Diploria strigosa & 2 & 2 & (Edmunds, 2010) \\
\hline Montastrea cavernosa & 1 & 3 & (Torres \& Morelock, 2002) \\
\hline Porites astreoides & 3 & 3 & $\begin{array}{l}\text { (Bythell et al., 1993; Torres \& } \\
\text { Morelock, 2002; Green et al., } \\
\text { 2008; Edmunds, 2010) }\end{array}$ \\
\hline Siderastraea siderea & 2 & 3 & (Torres \& Morelock, 2002) \\
\hline M. annularis & 1 & 3 & $\begin{array}{l}\text { (Hughes \& Tanner, 2000; } \\
\text { Edmunds \& Elahi, 2007) }\end{array}$ \\
\hline M. faveolata & 1 & 2 & \\
\hline Acropora palmata & 3 & 1 & (Lirman, 1999; Jones et al., 2008) \\
\hline
\end{tabular}

Table 37. Resilience and resistance values for each coral species encountered with supporting references from which these values were derived.

11) Presence of herbivores * - Herbivore presence scores were derived from mean herbivore biomass calculations for each site. Herbivore biomass accounts for the disproportionately influential role of larger herbivores compared to smaller individuals in macroalgal removal (Bonaldo \& Bellwood, 2008; Durán \& Claro, 2009). Sites with the higher herbivore biomass were given a higher score for this indicator.

12) Absence of coral disease * - Coral disease frequency was determined by dividing the number of diseased colonies by the total number of colonies surveyed in each site, and 
then was multiplied by 100 to generate the percentage of disease colonies within each site. These percentages were utilized to assign values for this resilience indicator, with sites with higher disease frequency receiving lower scores for this indicator.

13) Abundance of large colonies * - The mean size $\left(\mathrm{m}^{2}\right)$ and standard deviation of all coral colonies surveyed within the five study sites was calculated. Large colonies were defined as colonies larger than the overall mean colony size +1 standard deviation. The number of coral colonies larger than this size was then counted for each site to generate large colony frequencies, which were utilized to calculate resilience index scores for this indicator. Sites with higher frequency of large colonies received higher scores for this indicator.

14) Substrate availability * - Mean percent cover of crustose coralline algae (CCA) for each site was derived from the benthic community data collected in-situ and used to determine resilience index scores. Sites with higher CCA cover received higher scores for this indicator.

15) Free from anthropogenic physical impacts * - Tourist visitation rates were used as a proxy to determine relative anthropogenic physical impacts in each site. The PNAPM surveillance data, which record the number of boats and visitors at each tourism site (on days when surveillance activities are conducted), generated specific values of visitation rates for each of the study sites. The total number of PNAPM visitor bracelets (required for tourists to participate in activities within the park) sold in 2009 was divided by the total number of visitors recorded by surveillance in 2009 to determine the proportion of all tourists that visited the PNAPM in 2009 recorded by surveillance activities. Recorded 
visitor numbers at each study site were then multiplied by this value to obtain an estimate of the annual number of visitors for each site, which was utilized to determine 'free from anthropogenic physical impacts' resilience index scores. Sites with higher tourist visitation rates received lower scores for this indicator.

16) Topographic complexity * - An architectural index consisting of three parts was created to determine topographic complexity values for each site. 1) Rugosity, defined as the mean of maximum vertical relief of measurements taken every $5 \mathrm{~m}$ within a $1 \mathrm{~m}$ of the $30 \mathrm{~m}$ transect line, was calculated for each transect. 2) The area $\left(\mathrm{m}^{2}\right)$ of each coral colony surveyed (those directly below the transect line) was calculated. 3) Each coral colony was given a form-function rank based on morphological characteristics (more structurally-complex species were given a higher rank) (See Appendix A). Formfunction values provide a manner to integrate the variability in three-dimensional complexity between different coral species growth forms. For each coral colony these three values; 1) rugosity, 2) area, and 3) form-function rank, were multiplied to generate architectural index scores. The mean architectural index score was then calculated for each site and this value was utilized in the calculation of resilience index scores for topographic complexity. Sites with the higher architectural index scores received higher scores for this indicator.

This method provides a better estimation of topographic complexity, because traditional rugosity measures do not take into account the morphological characteristics of the vertical relief being measured (e.g., mounding vs. branching corals), which have different three-dimensional complexities. 
17) Coral submersion * - Site depth was calculated by averaging the depth values of mooring balls within the PNAPM located at each site. While these mooring balls are slightly outside the reef, they provide accurate estimates of relative site depth, and results were in accordance with personal observations (i.e., shallow sites where not characterized as deep, or vis-versa). Mean mooring ball depth values of each site were used in calculation of resilience index scores for coral submersion, with shallower sites receiving lower scores than deeper sites for this indicator.

18) Presence of Diadema antillarum * - Contrary to the original resilience index presented by Maynard et al. (2010a), which considered "presence of bioeroders" as a negative attribute, presence of the historically keystone grazer D. antillarum was calculated. High densities of $D$. anitillarum have been demonstrated to significantly decrease macroalgae cover by up to 10 times and significantly increase juvenile coral density and diversity (Edmunds \& Carpenter, 2001; Carpenter \& Edmunds, 2006). The presence of $D$. antillarum not only promotes coral recruitment and survival, but has also been associated with decreased incidence of coral diseases in M. annularis (Jordán-Garza et al., 2008), therefore, the presence of $D$. antillarum was considered a positive attribute for a site. Before the massive die-off of $D$. antillarum in the early 1980s high densities ( $\sim 70$ individuals per $\left.\mathrm{m}^{2}\right)$ of $D$. antillarum were actually observed to decrease coral recruitment via intense grazing activity (Sammarco 1982). However, D. antillarum densities reported in the Puerto Morelos region are several orders of magnitude lower than historic densities, therefore the grazing activity that these urchins confer to a site is considered a positive contribution to the resilience of a site. The number of $D$. antillarum 
individuals per $\mathrm{m}^{2}$ was calculated for each study site based on belt transect data taken insitu, and these values where used for the calculation of resilience index scores for this indicator. Sites demonstrating higher densities of $D$. antillarum received higher scores for this indicator.

19) Free from sedimentation - Insufficient data on site-specific sedimentation rates prevented the calculation of resilience index scores for this indicator, although it is recognized as an important resilience factor within the PNAPM.

A number of modifications to original indicators and additional indicators were developed to refine the resilience index for specific applicability to the PNAPM. A total of 11 modifications and additions were developed from this study, and are described below.

\section{Refined Resilience Index - Additions}

1) Free from land-based anthropogenic inputs - I propose the addition of $\delta^{15} \mathrm{~N}$ stable nitrogen isotope ratio analysis to determine relative levels of land-based anthropogenic inputs influencing each site. $\delta^{15} \mathrm{~N}$ stable isotope analyses can be derived from macroalgae samples obtained at each site, and provide pertinent information regarding the amount of nitrogen in a site that has come from anthropogenic inputs (Risk, 2009; Risk et al., 2009; Lapointe et al., 2010). The $\delta^{15} \mathrm{~N}$ values therefore provide a reliable indicator for the influence of anthropogenic terrestrial activities on each study site. I also propose the use of percent nitrogen tissue content $(\% \mathrm{~N})$ for the calculation of the 'free from contamination/pollution' indicator, which can be easily quantified from the same 
macroalgae samples as $\delta^{15} \mathrm{~N}$ and provide insight regarding relative nutrient levels at each site.

2) Coastal Development - Coastal development is not evenly distributed throughout the PNAPM. Several sites are located directly in front of large hotel complexes, while others are in relatively undeveloped areas. Coastal development can seriously impact the coral reef environment through increased sedimentation (Cortes \& Risk, 1985; Hodgson, 1990), contamination (Shimoda et al., 1998; Fabricius et al., 2005), and resource use (Burke \& Maidens, 2004). Consequently, quantifying levels of coastal development adjacent to coral reef sites will provide a relevant indicator addressing potential anthropogenic impacts on a site. The proper calculation of this indicator requires detailed knowledge of local-scale water patterns to determine the fate of inputs resonating from coastal development. Integrating $\delta^{15} \mathrm{~N}$ results into this indicator can assist in this assessment, as they can provide insight regarding the source of nutrients commonly found in the coral reef environment.

3) Macroalgae Cover and 4) Turf Cover - Macroalgae and turf are important benthic components of coral reef ecosystems that can provide information about the current state of a coral reef community (Littler \& Littler, 1984; 2007; Done, 1992; Hughes, 1994). Documenting trends in macroalgae, turf, and coral cover over time within study sites can determine if current management actions are functioning to increase coral reef resilience as intended, or if changes need to be made. Increased macroalgal and turf cover has been associated with decreased coral cover, recruitment, and survival (Birrel et al., 2005; 
Foster et al., 2008; Burkepile \& Hay, 2009), and decreased coral reef resilience (Knowlton, 2004; Elmhirst et al., 2009).

5) Biodiversity - The role of functional representation and redundancy supporting coral reef ecosystem resilience is backed by studies correlating high coral cover with increased biodiversity (Bellwood et al., 2003; 2004). Burkepile and Hay (2008) experimentally demonstrated the positive effects of herbivore biodiversity, showing that in one year coral cover increased $22 \%$ in mixed herbivore treatments (two species) compared to single species treatments, where macroalgal cover was 3-6 times higher. The addition of a 'biodiversity' indicator for fish communities will improve the resilience index and can be easily computed from fish community belt transects that are already a part of the PNPAM monitoring protocols.

6) Abundance of invasive species (Pterois volitans) - The original resilience index does not have any indicators that take into account the abundance or influence of invasive species. The recent invasion of the Indo-Pacific lionfish Pterois volitans in the Caribbean constitutes a major threat to the integrity and longevity of coral reef ecosystems (Shingova 1998; Bax et al., 2003; Morris et al., 2010). Since the first observation of lionfish in the PNAPM in February 2009, populations have exploded, with over 1,500 individuals removed from the park to date (Ladd \& Caamal Madrigul, unpub. data). Lionfish have been demonstrated to reduce native fish recruitment by $80 \%$ (Albins \& Hixon, 2008), clearly demonstrating the serious potential impacts of this species. The presence of lionfish within a site has the potential to significantly decrease resilience by influencing important ecosystem components such as fish density and diversity. For this 
reason, I propose the addition of an 'abundance of lionfish' indicator, which can be easily quantified during the same time as fish community belt transect sampling.

7) Abundance of Diadema antillarum - After the massive die-off of $D$. antillarum in the early 1980's, populations have been observed to be recovering in some areas of the Caribbean and have been correlated with increased coral cover and decreased macroalgal abundance, i.e., increased resilience (Edmunds \& Carpenter, 2001; Carpenter \& Edmunds, 2006). Therefore, the addition of 'abundance of a D. antillarum' indicator provides significant information regarding sites that support higher densities of these important grazers. On the basis of the critical role these organisms can contribute to increased coral reef resilience, sites observed with high densities should be targeting for the protection and promotion of D. antillarum populations (Lessios, 1998; Carpenter \& Edmunds, 2006).

\section{Modifications}

The original resilience index contains one category, 'free from anthropogenic physical impacts', which includes physical disturbances such as damage from snorkelers and anchoring. Current PNAPM monitoring protocols do not assess damage inflicted upon coral colonies from snorkelers, and all boats are required to tie up to mooring balls, rendering anchor damage obsolete. Therefore, I propose the use of mean annual tourist visitation rates to each site as a proxy for relative levels of anthropogenic physical impacts, based on the demonstrated relationship between increased tourism levels and increased physical damage (Harriot et al., 1997; Rouphael \& Inglis 1997; 2001; Plathong et al., 2000; Barker \& Roberts, 2004). These figures can be easily calculated from data 
collected by park guards throughout the year, and does not add an additional metric to current in-situ sampling methods.

Four indicators from the original resilience index were recognized as important indicators for the calculation of resilience scores, but were not quantified for this study due to multiple factors. A lack of access to expert knowledge prohibited the calculation of the 'survived hot water events in the past' indicator. Obtaining information to calculate scores for this indicator would greatly benefit the resilience index, as it has been concluded that coral colonies that have survived past hot water events contain more resistant zooxanthellae and are more likely to survive future hot water events, which are predicted to increase (Baker, 2001; Baker et al., 2004; Grimsditch \& Salm, 2006; HoeghGulberg et al., 2007). Quantifying the 'free from large physical impacts' indicator between sites proved a subjective process, and it was concluded that insufficient information precluded including this indicator for this study. However, Puerto Morelos is located in a region known for a high frequency of hurricanes, which can have localized and variable effects on the coral reef environment within the PNAPM (Jordán-Dahlgren \& Rodríguez-Martínez, 1998; Maldonado Cuevas, 2008). Therefore, further investigation to determine scores for this indicator would contribute to resilience index rankings. Connectivity is a critical component of ecosystem dynamics and a factor that can significantly contribute to or detract from resilience (Elmhirst et al., 2009; Maynard et al., 2010a). Unfortunately, quantifying connectivity is a complex process and was beyond the scope of this study. Sedimentation was the fourth and final resilience indicator relevant to the PNAPM not quantified in this study. The current PNAPM monitoring protocols do not include sedimentation measures, and therefore they were not 
available for study site characterizations. Sedimentation is relatively simple to measure and should be included in future PNPAM monitoring activities for all sites.

Three of the indicators contained in the original resilience index are not relevant to the PNAPM. Specifically, 'reduction in light stress', 'water mixing', and 'exposure to upwelling' were identified as indicators that should be removed from the PNAPMspecific resilience index. These indicators were determined as not pertinent to sites within the PNAPM based on the topography, water currents, and water movement patterns characteristic of the PNAPM.

\section{Management Influence Potential}

Three of the original resilience indicators used in this study were identified as having the potential to be influenced by management action. These three indicators were 1) free from fishing pressure, 2) free from contamination and pollution, and 3) free from anthropogenic physical impacts. As discussed by Maynard et al. (2010a), these three factors are based on human activities and therefore have the highest potential to be positively influenced by management activities. The refined resilience index contained an additional three indicators identified as having the potential to be influenced by management action; 1) free from land-based anthropogenic impacts, 2) herbivore abundance, and 3) abundance of invasive species ( $P$. volitans).

\section{RESULTS}

\section{Original Index}

Resilience scores from the original Maynard et al. (2010a) index ranged from 45 to 69. Limones received the highest resilience score of 69, followed by Jardines (61), 
then Tanchacte (57), and lastly La Bonanza (45) (See Figure 37). There was no clear relationship between zoning strategy and resilience scores. Limones was the only site characterized as having high resilience. Tanchacte and Jardines received scores indicating that these sites were moderately resilient, while La Bonanza was the only site to receive a score classified as low resilience. Radio Pirata is not included in overall resilience rankings because no substrate data (e.g., coral cover) was available for the site at the time of data analysis.

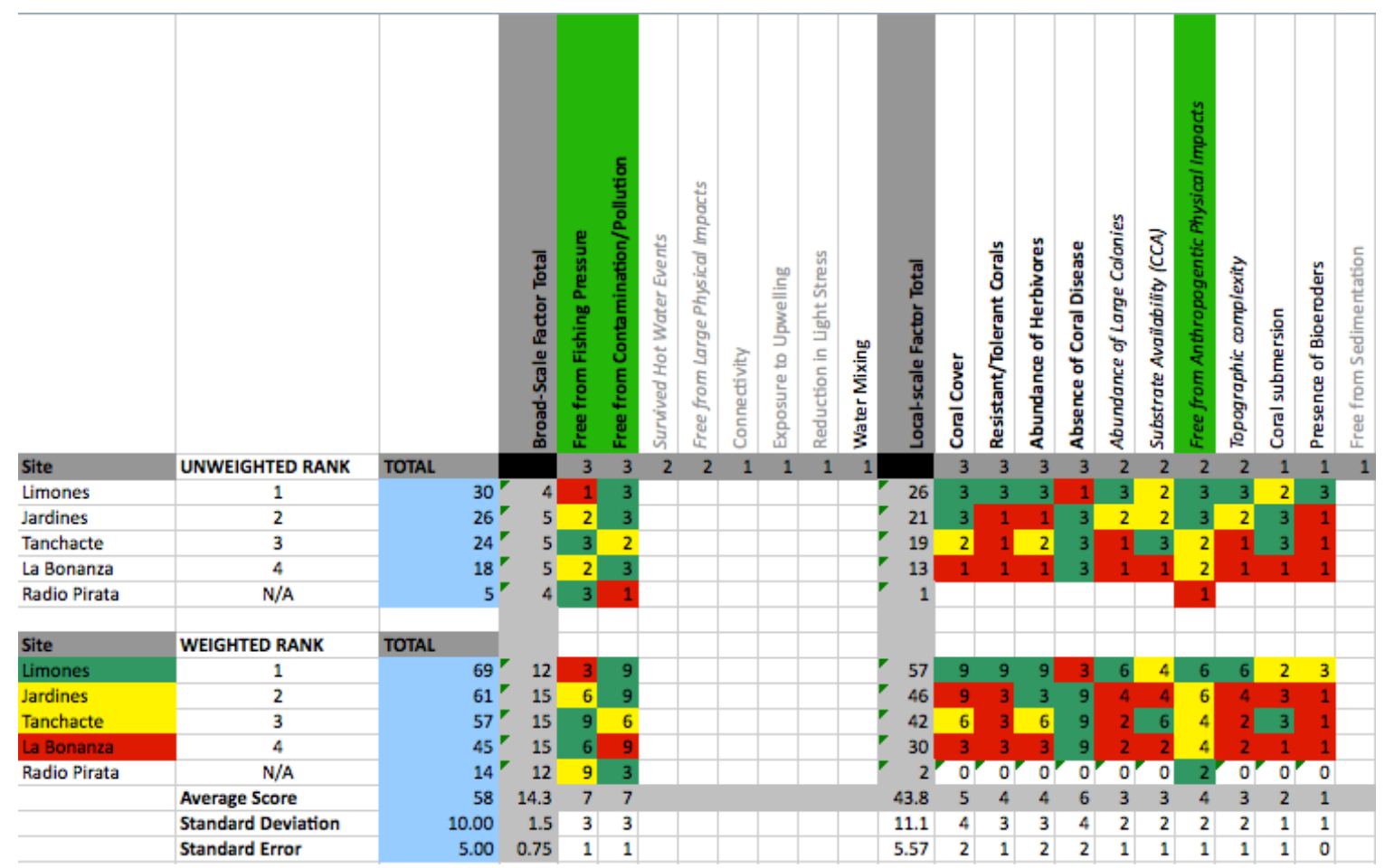

Figure 37. Resilience rankings (un-weighted and weighted) and scores for all resilience indicators for each study site using the original Maynard et al. (2010a) framework. For weightings; 3 = critical, $2=$ very important, and $1=$ important. Indicators in grey font were not given scores due to a lack of available information or because they were determined not relevant to the study site. Indicators highlighted in green have the potential to be influenced by PNAPM management.

Original Index - Management Influence 
Radio Pirata received the lowest score (14) based on resilience indicators that can be influenced by management activities, and therefore was identified as the site with the highest potential to be positively influenced by management intervention (See Figure 38). Limones, La Bonanza, and Tanchacte received moderate scores (18 and 19). Jardines received the highest score (21) based on management influence potential.

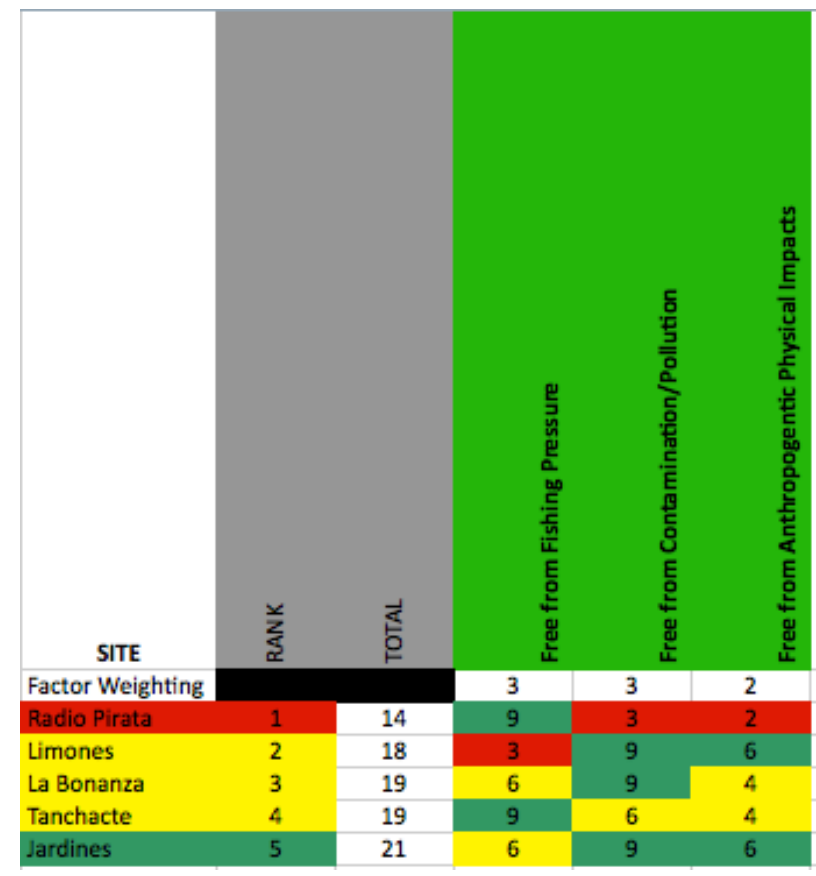

Figure 38. Management influence potential rankings based on the total score for each site for indicators identified as having the potential to be influenced by management activities based on the original Maynard et al. (2010a) framework. Sites that receive the lowest score have the highest ranking, and therefore the highest potential to be positively influenced by management intervention.

\section{Refined Index}

Resilience values generated from the refined index ranged from 94 to 64 (See Figure 39). Site rankings were the same as in the original index, with Limones being the only site ranked as containing high resilience. Jardines and Tanchacte were identified as moderately resilient, and La Bonanza was ranked as a low-resilience site. 


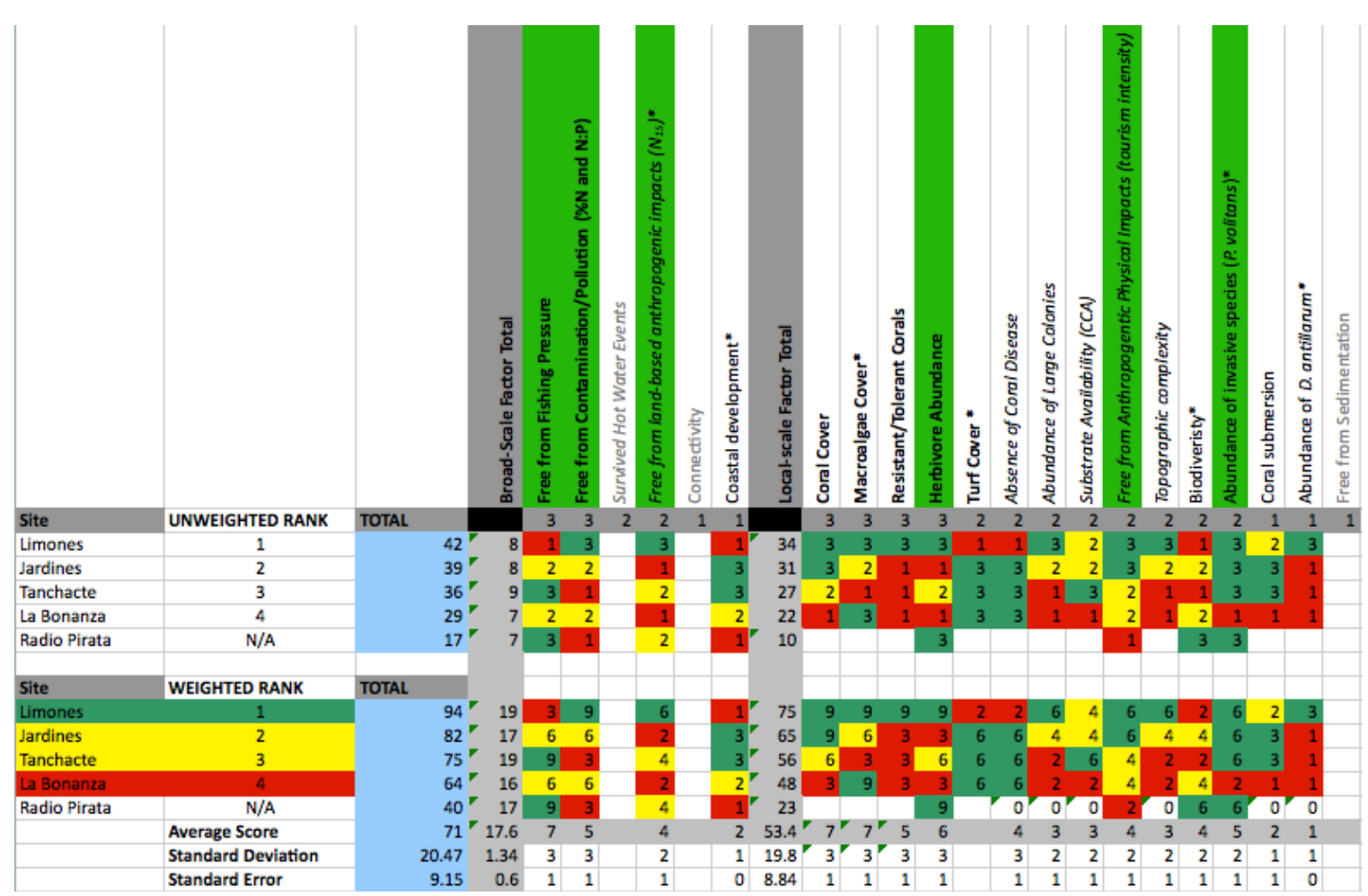

Figure 39. Resilience rankings (un-weighted and weighted) and scores for all resilience indicators for each study site using the refined index (from this study). For weightings; 3 $=$ critical, $2=$ very important, and $1=$ important. Indicators in grey font were not given scores due to a lack of available information or because they were determined not relevant to the study site. Indicators highlighted in green have the potential to be influenced by PNAPM management.

\section{Refined Index - Management Influence}

Management influence potential rankings based on the refined index were much different than those generated by the original index (See Figure 40). La Bonanza received the lowest score (20), and was the site that was identified as having the most potential to benefit from management intervention. Radio Pirata (24), Jardines (26), and Tanchacte (26) were identified as having moderate potential to be influenced by management intervention, while Limones received the highest score (30) based on management influence potential. 


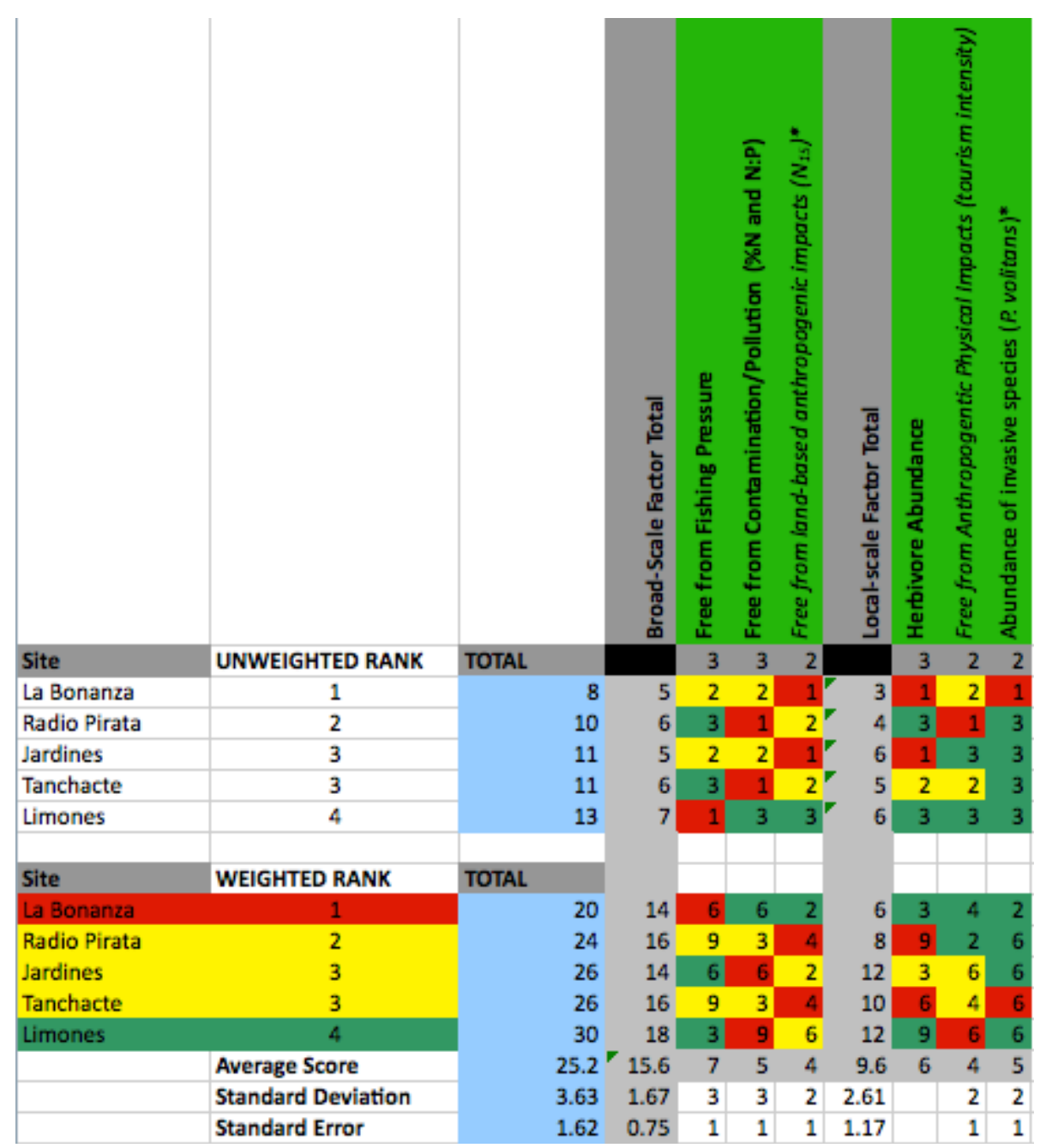

Figure 40. Management influence potential rankings based on the total score for each site for indicators identified as having the potential to be influenced by management activities based on the refined index. In accordance with the original Maynard et al. (2010a) framework, sites that receive the lowest score have the highest ranking, and therefore the highest potential to be positively influenced by management intervention.

\section{DISCUSSION}

Six indicators found to contribute to decreased site resilience were identified as having the potential to be influenced by management intervention. Fishing pressure and closely related herbivore abundance were two of the major indicators contributing to decreased coral reef resilience in several sites. The keystone role that herbivores play in reducing macroalgae cover and promoting the persistence of coral populations is 
undeniable (Hughes et al., 2007; Burkepile \& Hay, 2008; 2009). The current PNAPM zoning strategy allocates two large zones for fishing by the local fishing cooperative, which comprise a significant portion of the entire park. Results indicated that the resilience of several sites could substantially benefit from increased herbivore density and biomass (Hughes et al., 2007; Burkepile \& Hay, 2008). Reducing the size of fishing zones, or breaking them up to create spatial refuges between fishing areas could help to ameliorate decreased herbivore abundances. While it is clear that herbivore populations must be increased in herbivore-depauperate areas to promote resilience, it is important to ensure that fishing intensity is not simply reallocated elsewhere within the park. Collaboration with local fisherman and education of the benefits of increased herbivore populations for the longevity of fishing operations is essential to obtain the support required to modify this management strategy (Bajracharya et al., 2005; Wunder, 2006; Hind et al., 2010). Without the support of fisherman, regulation compliance issues will likely nullify the closure of current fishing areas. It is essential to confer the results of this study to stakeholders so that they are able to understand the reasons behind management strategy modifications and how these changes will ultimately benefit all resource users.

‘Abundance of invasive species', specifically regarding lionfish abundance, was the third indicator that can be influenced by management action. Invasive lionfish populations can have devastating impacts on native fish communities, demonstrated by a study conducted in the Bahamas, which found that lionfish reduced native fish recruitment by more than $80 \%$ (Albins \& Hixon, 2008). An abundance of lionfish has the potential to greatly reduce herbivore populations, even if fishing pressure is 
decreased. Therefore, taking management action to focus lionfish removal efforts in sites that lionfish are found can help to alleviate pressures acting to decrease herbivore abundance and detract from coral reef resilience.

'Free from contamination and pollution' was another resilience indicator identified to have the potential to be influenced through management intervention. Analysis of the data reveals that all sites surveyed in this study displayed $\% \mathrm{~N}$ and N:P ratios well above the globally-accepted median levels (1.8\% and 30:1), indicating elevated nitrogen levels at all study sites (Atkinson \& Smith, 1983; Duarte, 1990; Lapointe et al., 2010). Elevated nutrient levels can increase macroalgal growth (Lapointe et al., 1987; Lapointe, 1997), especially in the absence of sufficient grazing intensity (Mumby, 2006; Hughes et al., 2007; Burkepile \& Hay, 2008), effectively decreasing ecosystem resilience. Coastal development (i.e., hotels and residences) along the PNAPM shoreline is most likely responsible for the elevated nutrient levels observed in this study. No sewer system exists in Puerto Morelos, and the porous karstic geology and submarine springs that characterize the region generate a system susceptible to significant nutrient inputs from anthropogenic sources (Back, 1985; Rodríguez-Martínez, 2008; Hernández-Terrones et al., 2010; Lapointe et al., 2010). The improved health of coral reefs in Kaneohe Bay, Hawaii after reduction in anthropogenic nutrient inputs through management action and stakeholder cooperation provides a promising example of the potential positive impacts from management intervention (Hunter \& Evans, 1993). The PNAPM does not currently assess nutrient levels at monitoring sites, likely because of the lack of expertise and funding. The PNAPM management team must develop nutrient level baselines and future targets to set management goals for reducing nutrient levels 
within the PNAPM. Additional investigations are necessary to assess sanitization and wastewater practices currently employed at hotels and residences adjacent to the PNAPM, information that can be utilized to develop regulations, such as requiring hotels to treat wastewater before it is discharged. Acceptance of responsibility on the part of hotels is necessary to facilitate reductions in nutrient levels and increase resilience within the PNAPM coral reef environment. A discussion of the political and legal actions required to impose such regulations is beyond the scope of this paper, but it is clear that the success of such initiatives will largely depend on support from multiple stakeholders and entities within and outside the PNAPM.

Tourism in the form of snorkel tours is undeniably a massive component of the local economy, exemplified by the approximately 125,000 people that visited the PNAPM in 2009 and generated nearly USD \$232,000 in entrance fee revenue alone (http://cobro.conanp.gob.mx/concentrados.php?anio=2009). Closing the PNAPM to tourism activities is clearly not a reasonable suggestion; however, management strategies can be adapted to reduce pressure on fragile, ecologically important, and recovering areas, and shift tourism pressure to areas identified as more resistant and adept to handle larger tourist capacities.

Limones demonstrated the highest coral cover of any site, most of which was the branching species A. palmata, which provides essential fish habitat and reef structure (Beukers \& Jones, 1997; Lirman, 1999) and is easily damaged by direct physical impacts (Plathong et al., 2000; Rouphael \& Inglis, 2001; Zakai \& Chadwick-Furman, 2002). Tourism pressure should be diverted from areas such as Limones to promote the existence and proliferation of the high coral cover and important coral species observed 
here. Increasing tourism levels is an especially important point when considering the future placement of mooring balls, which dictate where snorkeling tours can be carried out. Assessment of potential sites for tourism activities should be conducted before making management decisions to identify sites best prepared to handle tourism pressures and those that should be protected.

The distinction between sites that possess resilient and resistant characteristics has important management implications. According to published literature, sites characterized as "resilient" are theoretically those sites best prepared to recover from a disturbance without completing a phase shift to an alternate state (Nyström et al., 2000; Hughes et al., 2003; Bellwood et al. 2004). On the other hand, the evaluation of sites for their "resistance" value can provide managers with rankings for sites based on their ability to withstand impacts generated from direct physical impacts (i.e., tourism) (Rouphael \& Inglis, 1997; Plathong et al., 2000). This distinction is important, as resistant sites that can withstand elevated activity levels may be more appropriate for locating heavy tourist intensity, while resilient sites may be better candidates for conservation priority.

Herbivory is a major factor driving coral reef ecosystem resistance and plays a major role in recovery after large disturbances (i.e. resilience) (Mumby, 2006; Hughes et al., 2007; Littler \& Littler, 2007). However, numerous studies have identified that not all herbivorous fishes share the same functional roles, with some species responsible for maintaining low macroalgae cover, while others are required to initiate the shift from a macroalgal-dominated state towards coral dominance (Bellwood et al., 2006; Burkepile \& Hay, 2008). Bellwood et al. (2004) classify the herbivore functional group into three 
specific functional groups; grazers, scrapers, and bioeroders, each of which has been identified to have a unique and important role in coral reef resilience. Therefore, the separation of 'abundance of herbivores' from the original resilience index into 'abundance of grazers', 'abundance of scrapers', and 'abundance of bioeroders' provides a more comprehensive assessment of a fish community and the resilience and resistance conferred to each site. Currently there is a lack of information pertaining to the feeding habits of many herbivorous fishes found in the Caribbean region. As new information becomes available and the majority of fish identified in fish community surveys can be placed into functional categories (e.g. scrapers vs. grazers), the separation of the 'herbivore abundance' indicator into more specific functional groups would improve the designation of resistant and resilient sites.

Utilizing the refined resilience index proposed in this study to determine resistance scores only requires the modification the coral community composition indicator and the separation of the herbivore abundance indicator into specific herbivore functional groups. Variable life-history traits of different coral species confer very different levels of resilience and resistance to a site (e.g., slow-growing mounding species vs. fast-growing branching species). For the 'resistant/resilient corals' indicator, utilizing one set of values for coral species based on resilience weights for resilience score calculations, and a different set of values for the calculation of resistance values for each site can help to designate sites that are either more resilient or resistant (See Table 37 for proposed values). This distinction can provide managers important information to assist in managerial decision-making. 
Including measures of the three indicators from the original resilience index not quantified in this study along with the proposed indicators will greatly increase the accuracy and viability of resilience index scores for coral reef sites within the PNAPM. While this preliminary study provides a resilience characterization of several sites within the PNAPM, utilization of the refined index for future assessments of additional sites will generate a more precise assessment of site resilience. This adaptive framework can be continuously updated and revised as new information becomes available and the usefulness of resilience indicators is tested. While these suggestions are for the PNAPM, these revisions are largely applicable to other MPAs within the Caribbean region that share many characteristics with the PNAPM.

\section{CONCLUSIONS}

This is the first attempt to calculate resilience index scores using the Maynard et al. (2010a) framework for multiple sites within a Caribbean MPA. The results of this study demonstrate the utility of using a resilience index to improve coral reef management and conservation within a MPA. This study successfully detected differences in resilience values between multiple sites within the PNAPM and identified management actions that can be taken to increase the resilience of specific sites. Further, this study refined the original Maynard et al. (2010a) resilience index for specific applicability to the PNAPM, which better indentifies management actions that can be taken to promote site resilience and improves the accuracy of resilience assessments in the PNAPM. Lastly, this study generated results that can be directly applied by PNAPM management to improve coral reef conservation and management efficacy. 
The results presented here provide an example for MPA managers throughout the Caribbean region of the relative simplicity and utility of conducting such assessments to assist in managerial decisions. The PNAPM would greatly benefit from an extensive assessment of all current and potential coral reef sites within the park to prioritize sites for tourism, fishing, and conservation, as zoning strategies were developed more than 10 years ago when a different set of conditions and characteristics affected the coral reef ecosystem. The resilience index proposed in this study (refined from the original Maynard et al. (2010a) framework) provides the most appropriate assessment tool currently available to the PNAPM to characterize sites within the MPA.

It is critical that PNPAM officials act quickly to adapt management strategies to promote coral reef resilience at sites within the PNAPM. Although PNAPM management does not have the capacity to influence stressors from distant sources or the incidence of natural catastrophes, it does have the ability to significantly increase the resilience of the coral reef ecosystem by working to ameliorate the local stressors identified in this study. The success of management intervention to promote coral reef resilience will depend largely on support and collaboration between all stakeholders and resources users within the PNAPM. Moving beyond simply characterizing sites to managing local factors for resilience is essential to maintain the health and existence of the PNAPM coral reef ecosystem. 


\section{CHAPTER V - CONCLUSIONS}

\section{Major Findings}

The purpose of this study was to provide the PNAPM with useful and applicable information to improve coral reef ecosystem management and conservation. The ecological characterizations reported in Chapter 2 successfully characterized the ecological communities of four sites within the PNAPM, established baselines of important ecosystem indicators (e.g., nutrient levels, fish size and functional group densities, substrate cover), and determined inter-site differences in characteristics demonstrated to promote or detract from coral reef ecosystem resilience. The interactive stressor proxy map developed in Chapter 3 provides a novel management tool for the PNAPM to assist in managerial decisions. The stressor proxy map indentified differences in the distribution and intensity of multiple stressors influencing the PNAPM coral reef ecosystem, provides a base for the PNAPM to build upon, and serves as an example of a cost-effective management tool for MPA managers worldwide. Chapter 4 combined the information from the first two chapters along with additional information to test the applicability and utility of a general framework to determine relative resilience values at multiple study sites (Maynard et al., 2010a). This study successfully determined differences in the relative resilience values at four sites studied within the PNAPM, identified sites that can most benefit from management intervention, and recognized management adaptations that would most increase resilience at specific sites. The original resilience index was refined to a detailed framework with specific applicability to the PNAPM, which can greatly improve site characterizations and assist in future managerial decisions. The refined framework can be used by MPAs throughout 
the Caribbean region to characterize sites of interest with similar characteristics to the PNAPM.

The combination of the three chapters presented in this study provides the PNAPM with a 'managerial tool chest' to improve management efficacy and bolster conservation initiatives. The results from this study can be used to evaluate current management strategies and assist in the development of adaptive management strategies to accomplish MPA goals and objectives. Furthermore, the information and tools generated by this study can guide future decisions regarding regulations and monitoring protocols.

\section{Future Directions}

In the face of an uncertain future, it is imperative that the PNAPM take management actions to promote the resilience of the coral reef ecosystem upon which the natural and human communities in the region depend. The development of adaptive management strategies that utilize the best available knowledge to protect critical habitat and recovering areas, allocate tourism distribution, and regulate fishing activity will be critical in promoting resilience within the PNAPM. Consistent monitoring of coral reef sites is necessary to evaluate current management practices and determine strategies that need to be modified. Furthermore, characterizing current and potential sites with the refined resilience index proposed in this study will greatly assist in determining the viability of specific sites for multiple uses. The establishment of baselines for essential indicators such as nutrient levels and sources provides managers with the scientific basis 
to lobby for regulations that can extend beyond the marine environment such as terrestrial watershed management initiatives.

\section{Stakeholder Involvement}

Multiple stakeholders with varied interests and priorities characterize marine protected areas, creating a complex and difficult situation for MPA managers to effectively act upon scientific results. Increased stakeholder participation and awareness are two approaches that have been successful in the past to increase regulation compliance and support (Baral \& Heinen, 2007; Hind et al., 2010). Understanding and awareness by different stakeholder groups with regards to why specific management actions are being taken is essential in order to effectively manage and conserve coral reef resources.

Improved collaboration between the PNAPM, scientific research entities, and NGOs that conduct research within the park could greatly enhance management and conservation initiatives through increased natural resources knowledge and the processes affecting them. For example, although the PNAPM office and UNAM-ICMyL campus are within $2 \mathrm{~km}$ of each other, interactions between PNAPM management staff and UNAM scientists are minimal. Proper management of the PNAPM should be a priority for these research institutions, as they too largely depend upon a healthy marine environment within the PNAPM to conduct their research. It is urgent that scientists working in the PNAPM realize the importance of conferring study results to park management so that these results can be used to update adaptive management strategies. 
The survival of coral reefs within MPAs depends upon the ability of managers to devise realistic, inclusive, and effective approaches that promote coral reef resilience and protect ecosystem function. Ultimately, the success of these management initiatives will depend on the participation, support, and collaboration from the multiple user groups that rely on the ecosystem services generated by the coral reef ecosystem for their livelihood. 


\section{LIST OF REFERENCES}

Almany, G.R. 2004. Differential effects of habitat complexity, predators and competitors on abundance of juvenile and adult coral reef fishes. Oecologia 141:105-113. doi 10.1007/s00442-004-1617-0.

Anderson, W.T. \& Fourqurean, J.W. 2003. Intra- and interannual variability in seagrass carbon and nitrogen stable isotopes from south Florida, a preliminary study. Organic Geochemistry 34:185-194.

Aronson, R.B. \& Precht, W.F. 1997. Biological disturbance, and community structure of a Holocene coral reef. Paleobiology 23(3):326-346.

Aronson, R. B., Macintyre, I.G., Wapnick, C.M., \& O'Neil, M.W. 2004. Phase shifts, alternative states, and the unprecedented convergence of two reef systems. Ecology 85:1876-1891.

Atkinson, M.J. \& Smith, S.V. 1983. C:N:P ratios of benthic marine plants. Limnology and Oceanography. 28(3):568-574.

Babcock, R. \& Smith, L., 2002. Effects of sedimentation on coral settlement and survivorship. Proceedings $9^{\text {th }}$ International Coral Reef Symposium, Bali, Indonesia. 2327 October.

Babcock, R.C., Shears, N.T., Alcala, A.C., Barrett, N.S., Edgar, G.J., Lafferty, K.D., McClanahan, T.R., \& Russ, G.R. 2010. Decadal trends in marine reserves reveal differential rates of change in direct and indirect effects. PNAS Early Edition. www.pnas.org/cgi/doi/10.1073/pnas.0908012107.

Back W. 1985. Hydrogeology of the Yucutan. In: Ward W.C., Weidie A.E., Back W. (eds) Geology and Hydrogeology of the Yucatan and Quaternary Geology of Northeastern Yucatan. New Orleans Geological Society, New Orleans, LA. USA.

Bajracharya, S. B., Furley, P. A., \& Newton, A. C. 2005. Effectiveness of community involvement in delivering conservation benefits to the Annapurna conservation area, Nepal. Environmental Conservation 32(3): 239-247.

Baker, A.C. 2001. Reef corals bleach to survive change. Nature 411:765-766.

Baral, N. \& Heinen, J.T. 2007. Resources use, conservation attitudes, management intervention and park-people relations in the Western Terai landscape of Nepal. Environmental Conservation 34(1):64-72.

Barker, N.L. \& Roberts, C.M., 2004. Scuba diver behaviour and the management of diving impacts on coral reefs. Biological Conservation 120:481-489. 
Bax N., Williamson A., Aguero M., Gonzalez E., Greeves W. 2003. Marine invasive alien species: a threat to global biodiversity. Marine Policy 27:313-323.

Bellwood, D.R., Hughes, T.P., Folke, C., and Nyström, M. 2004. Confronting the coral reef crisis. Nature 429:827-833.

Bellwood, D. R., T. P. Hughes, and A. S. Hoey. 2006. Sleeping functional group drives coral reef recovery. Current Biology 16:2434-2439.

Beukers, J.S. \& Jones, G.P. 1997. Habitat complexity modifies the impact of piscivores on a coral reef fish population. Oecologia 114:50-59.

Birrell, C.L., McCook, L.J., \& Willis, B.L. 2005. Effects of algal turfs and sediment on coral settlement. Marine Pollution Bulletin 51:408-414.

Bohnsack, J.A. \& Bannerot, S.P. 1986. A stationary visual census technique for quantitatively assessing community structure of coral reef fishes. NOAA Technical Report National Fish and Wildlife Service. 41:1-15.

Bohnsack, J. A.; Harper, D. E., 1988: Length-weight relationships of selected marine reef fishes from the Southeastern United States and the Caribbean. NOAA Technical Memorandum NMFS-SEFC-215, Miami, Florida, 31 pp.

Bonaldo, R.M. and D.R. Bellwood. 2008. Size-dependent variation in the functional role of the parrotfish Scarus rivulatus on the Great Barrier Reef, Australia. Marine EcologyProgress Series 360:237-244.

Bouchon-Navaro, Y., Bouchon, C., Kopp, D., \& Louis, M. 2006. Weight-length relationships for 50 fish species collected in seagrass beds of the Lesser Antilles. Journal of Applied Ichthyology 22:322-324.

Brander, L.M., Van Beukering, P., \& Cesar, H.S.J. 2007. The recreational value of coral reefs - A meta analysis. Ecological Economics 63:209-218.

Brandt, M.E. \& McManus, J.W. 2009. Disease incidence is related to bleaching extent in reef-building corals. Ecology 90(10): 2859-2867.

Bruggeman, J.H., van Oppen, M.H., \& Breeman, A.M. 1994a. Foraging by the stoplight parrotfish Sparisoma viride. I. Food selection in different, socially determined habitats. Marine Ecology Progress Series 106:41-55.

Bruggeman, J.H., Kuyper, M.M., \& Breeman, A.M. 1994b. Comparative analysis of foraging and habitat use by the sympatric Caribbean parrotfish Scarus vetula and Sparisoma viride (Scaridae). Marine Ecology Progress Series 112:51-66. 
Bruno, J.F., Petes, L.E., Harvell, C.D., \& Hettinger, A. 2003. Nutrient enrichment can increase the severity of coral diseases. Ecology Letters 6(12): 1056-1061.

Bruno, J.F. \& Selig, E.R. 2007. Regional decline of coral cover in the Indo-Pacific timing, extent, and subregional comparisons. PLos ONE 2(8):e711.

doi:10.1371/journal.pone.0000711.

Bryant, D., Burke, L., McManus, J., \& Spalding, M.1998. Reefs at risk: A map based indicator of threats to the world's coral reefs. World Resources Institute, Washington, DC.

Burke, L. \& Maidens, J. 2004. Reefs at Risk in the Caribbean. Washington, DC: World Resources Institute.

Burkepile, D.E. \& Hay, M.E. 2006. Herbivore vs. nutrient control of marine primary producers: Context-dependent effects. Ecology 87:3128-3139.

Burkepile, D.E. and Hay, M.E. 2008. Herbivore species richness and feeding complementarity affect community structure and function on a coral reef. Proceedings of the National Academy of Sciences of the United States of America 105:16201-16206.

Burkepile, D.E. and Hay, M.E. 2009. Nutrient vs. herbivore control of macroalgal community development and coral growth on a Caribbean reef. Marine Ecology Progress Series 389:71-84.

Bythell, J.C., Gladfelter, E.H., \& Bythell, M. 1993. Chronic and catastrophic natural mortality of three common Caribbean reef corals. Coral Reefs 12:143-152.

CARICOMP. 2000. Status and temporal trends at CARICOMP coral reef sites. Proceedings of the $9^{\text {th }}$ International Coral Reef Symposium1:325-329.

Carruthers, T.B., van Tussenbroek, B.I., \& Dennison, W.C. 2005. Influence of submarine springs and wastewater on nutrient dynamics of Caribbean seagrass meadows. Estuarine, Coastal and Shelf Science 64:191-199.

Cheal, A.J., MacNeil, M.A., Cripps, E., Emslie, M.J., Jonker, M., Schaffelke, B., \& Sweatman, H. 2010. Coral-macroalgal phase shifts or reef resilience: links with diversity and functional roles of herbivorous fishes on the Great Barrier Reef. Coral Reefs: 29:1005-1015. doi 10.1007//s00338-010-0661-y

Claro, R. \& Parenti, L.R. 2001. The marine ichtyofauna of Cuba. p 21-57. In: Claro, R., Lindeman, K, Parenti, L. (Eds) Ecology of the marine fishes of Cuba. Smithsonian Institution Press Washington, DC. 
Claudet, J., Pelletier, D, Jouvenel, J.Y., Bachet, F., \& Galzin, R., 2006. Assessing the effects of marine protected area (MPA) on a reef fish assemblage in a northwestern Mediterranean marine reserve: Identifying community-based indicators. Biological Conservation 130(3):349-369.

Coronado, C., Candela, J., Igleasias-Prieto, R., Sheinbaum, J., López, M., OcampoTorres, F.J. 2007. On the circulation in the Puerto Morelos fringing reef lagoon. Coral Reefs 26: 149-163.

Cortes, J.N. \& Risk, M.J. 1985. A reef under siltation stress: Cahuita, Costa Rica. Bulletin of Marine Science 36:339-356.

Côte, I.M., Gill, J.A., Gardner, T.A., Watkinson, A.R. 2005. Measuring coral reef decline through meta-analyses. Philosophical Transactions of the Royal Society 360:385-395.

Crabbe, M.C. 2009. Scleractinian coral population size structures and growth rates indicate coral resilience on the fringing reefs of North Jamaica. Marine Environmental Research 67:189-198.

De Lara-Isassi, G., Álvarez-Hernández, S., Collado-Vides, L. 2000. Ichtyotoxic activity of extrancts from Mexican marine macroaglae. Journal of Applied Phycology. 12:45-52.

Diaz-Pulido, G. \& McCook. L.J. 2003. Relative roles of herbivory and nutrients in the recruitment of coral-reef seaweeds. Ecology 84:2026-2033.

Done, T.J. 1992. Phase shifts in coral reef communities and their ecological significance. Hydrobiologia 247:121-132.

Duarte, C.M. 1990. Seagrass nutrient content. Marine Ecology Progress Series 67:201207.

Dudgeon, S.R., Aronson, R.B., Bruno, J.F., \& Precht, W.F. 2010. Phase shifts and stable states on coral reefs. Marine Ecology Progress Series. 413:201-216.

doi:10.3354/meps08751.

Durán, A. \& Claro, R. 2009. Actividad alimentaria de los peces herbívoros y su impacto en arrecifes con diferente nivel de degradación antrópica. Revista de Biología Tropical 57(3):687-697.

Edmunds, P.J. 2010. Population biology of Porites astreoides and Diploria strigosa on a shallow Caribbean reef. Marine Ecology Progress Series 418:87-104.

Edmunds, P.J. \& Elahi, R. 2007. The demographics of a 15-year decline in cover of the Caribbean reef coral Montastraea annularis. Ecological Monographs. 77(1):3-18. 
Elmhirst, T., Connolly, S.R., \& Hughes, T.P. 2009. Connectivity, regime shifts and the resilience of coral reefs. Coral Reefs 28: 949-957.

Fabricius, K. E. 2005. Effects of terrestrial runoff on the ecology of corals and coral reefs: review and synthesis. Marine Pollution Bulletin 50:125-146.

Ferreira, C.L., Conçalves, J.A., Coutinho, R., \& Peret, A.C. 1998. Herbivory by the Dusky Damselfish Stegastes fuscus (Cuvier, 1830) in a tropical rocky shore: effects on the benthic community. Journal of Experimental Marine Biology and Ecology 229:241264.

Floeter, S.R., Halpern, B.S., \& Ferriera, C.L., 2006. Effects of fishing and protection on Brazilian reef fishes. Biological Conservation 128:391-402.

Fourqurean, J.W. \& Zieman, J.C., 2002. Nutrient content of the seagrass Thalassia testudinum reveals regional patterns of relative availability of nitrogen and phosphorus in the Florida Keys USA. Biogeochemistry 61:229-245.

Friedlander, A.M., Brown, E.K., Monaco, M.E., 2007. Coupling ecology and GIS to evaluate efficacy of marine protected areas in Hawaii. Ecological Applications 17(3):715-730.

Furman, B.T. \& Heck, K.L. 2008. Effects of nutrient enrichment and grazers on coral reefs: an experimental assessment. Marine Ecology-Progress Series 363:89-101.

Gardner, T.A. Côte, I.M. Gill, J.A., Grant, A., \& Watkinson, A.R. 2003. Long-term region-wide declines in Caribbean corals. Science 301:958-960.

Geron, C.T. 1993. Effect of establishment method and fertilization practices on nitrate leaching from turfgrass. Journal of Environmental Quality 22:119-125.

Gladfelter, E.H., Monahan, R.K., \& Gladfelter, W.B. 1978. Growth rates of five reef building corals in the northeastern Caribbean. Bulletin of Marine Science 28(4):728-734.

Google Inc. (2009). Google Earth (Version 5.2.1.1588) [Software]. Available from http://www.google.com/earth/index.html.

Graham, N.J., Wilson, S.K., Jennings, S., Polunin, N.C., Bijoux, J.P., \& Robinson, J. 2006. Dynamic fragility of oceanic coral reef ecosystems. PNAS 103(22):8425-8429.

Gratwicke, B. \& Speight, M.R., 2005. Effects of habitat complexity on Caribbean marine fish assemblages. Marine Ecology Progress Series 292:301-310. 
Green, D.H., Edmunds, P.J., \& Carpenter, R.C. 2008. Increasing relative abundance of Porites astreoides on Caribbean reefs mediated by an overall decline in coral cover. Marine Ecology Progress Series. 359:1-10.

Grimsditch, G.D. \& Salm, R.V., 2006. Coral Reef Resilience and Resistance to Bleaching. IUCN, Gland, Switzerland. 52pp.

Harmelin-Vivien, M., Le Dirách, L., Bayle-Sempere, J., Charbonnel, E., García-Charton, J.A., Ody, D., Pérez-Ruzafa, A., Reñones, O., Sánchez-Jerez, P., \& Valle, C., 2008. Gradients of abundance and biomass across reserve boundaries in six Mediterranean marine protected areas: Evidence of fish spillover? Biological Conservation 141:18291839.

Harriot, V.J., Davis, D. \& Banks, S.A. 1997. Recreational diving and its impacts in marine protected areas in Eastern Australia. Ambio 26(3): 173-179.

Harrington, L., Fabricius, K., De'ath, G., \& Negri, A. 2004. Recognition and selection of settlement substrata determine post-settlement survival in corals. Ecology 85(12):43283437.

Harrison, P.L. \& Ward, S., 2001. Elevated levels of nitrogen and phosphorous reduce fertilization success of gametes from scleractinian reef corals. Marine Biology 139:10571068 .

Hata, H., Nishirhira, M., \& Kamura, S. 2002. Effects of habitat-conditioning by the damselfish Stegastes nigricans (Lacepède) on the community structure of benthic algae. Journal of Experimental Marine Biology and Ecology 280:95-116.

Hawkins, J.P., Roberts, C.M., Van’t Hof, T., De Meyer, K., Tratalos, J., \& Aldam, C., 1999. Effects of recreational scuba diving on Caribbean coral and fish communities. Conservation Biolog. 13(4):888-897.

Haynes, D., Brodie, J., Waterhouse, J., Bainbridge, Z., Bass, D., \& Hart, B., 2007. Assessment of the water quality and ecosystem health of the Great Barrier Reef (Australia): conceptual models. Environmental Management 40:993-1003.

Hendry, A.P., Day,T., \& Cooper, A.B. 2001. Optimal size and number of propagules allowance for discrete stages and effects of maternal size on reproductive output and offspring fitness. The American Naturalist 157(4):387-407

Hernández-Terrones L, Rebolledo-Vieyra M, Merino-Ibarra M, Soto M, Le Cossec, Monroy-Ríos E (2010) Groundwater pollution in a karstic region (NE Yucatan): baseline nutrient content and flux to coastal ecosystems. Water, Air, \& Soil Pollution. Published on line on 06 November 2010, DOI $10.1007 / \mathrm{s} 11270-010-0664-\mathrm{x}$ 
Hind, E.J., Hiponia, M.C. \& Gray, T.S. 2010. From community-based to centralized national management - a wrong turning for the governance of the marine protected area in Apo Island, Philippines? Marine Policy 34:54-62.

Hodgson, G. 1990. Sediment and the settlement of larvae of the reef coral Pocillopora damicornis. Coral Reefs 9:41-43.

Hoegh-Guldberg, O., Mumby, P.J., Hooten, A.J., Steneck, R.S., Greenfield, P., Gomez, E., Harvell, C.D., Sale, P.F., Edwards, A.J., Caldeira, K. et al. 2007. Reefs in trouble. Science 314: 1737-1742.

Holling, C.S. 1973. Resilience and stability of ecological systems. Annual Review of Ecology and Systematics 4:1-23.

Hughes, T.P. 1994. Catastrophes, phase shifts, and large-scale degradation of a Caribbean coral reef. Science 265:1547-1551.

Hughes, T.P. \& Connell, J.H. 1999. Multiple stressors on coral reefs: A long-term perspective. Limnology and Oceanography 44:932-940.

Hughes, T.P. \& Tanner, J.E. 2000. Life histories and long-term decline of Caribbean corals. Ecology 81(8)2250-2263.

Hughes, T.P., Baird, A.H., Bellwood D.R., Card M., Connolly S.R., Folke C., Grosberg R., Hoegh-Guldberg O., Jackson J.C., Kleypas J., Lough J.M., Marshall P., Nyström, M., Palumbi, S.R., Pandolfi, J.M, Rosen, B., \& Roughgarden, J. 2003. Climate change, human impacts, and the resilience of coral reefs. Science 301:929-933.

Hughes, T.P., Rodrigues, M.J., Bellwood, D.R., Ceccarelli, D., Hoegh-Guldberg, O., McCook, L., Moltschaniwskyj, N., Pratchett, M.S., Steneck, R.S., \& Willis, Bette. 2007. Phase shifts, herbivory, and the resilience of coral reefs to climate change. Current Biology 17:1-6. doi:10.1016/j.cub.2006.12.049

Hughes, T.P., Graham, N.A., Jackson, J.B., Mumby, P.J., \& Steneck, R.S. 2010. Rising to the challenge of sustaining coral reef resilience. Trends in Ecology and Evolution. 25(11):633-642.

Humann, P. \& DeLoach, N. 2002. Reef fish identification: Florida, Caribbean, Bahamas $3^{\text {rd }}$ Edition. New World Pulbications Inc. Jacksonville, FL.

Hunter, C.L. \& Evans, C.W. 1995. Coral reefs in Kaneohe Bay, Hawaii - two centuries of western influence and two decades of data. Bulletin of Marine Science 57(2):501-515. 
Instituto Nacional de Ecología (INE) -SEMARNAP. 2000. Programa de Manejo Parque Nacional Arrecife de Puerto Morelos, México. México, D.F.

International Union for Conservation of Nature (IUCN). 2009. Category II National Park. http://www.iucn.org/about/work/programmes/pa/pa_products/wcpa_categories /pa_categoryii/. Accessed February 19, 2011.

Jennings, S. \& Lock, J.M., 1996. Population and ecosystem effects of reef fishing. Fish and Fisheries Series 20:193-218.

Jennings, S. \& Polunin, N.V.C. 1997. Impacts of predator depletion by fishing on the biomass and diversity of non-target reef fish communities. Coral Reefs 16:71-82.

Jones, A.M., Berkelmans, R., van Oppen, M.H., Mieog, J.C., \& Sinclair, W. 2008. A community change in the algal endosymbionts of a scleractinian coral following a natural bleaching event: field evidence of acclimatization. Proceedings of the Royal Society B 275:1359-1365.

Jordán, E., Merino, M., Moreno, O., \& Martin, E. 1981. Community structure of coral reefs in the Mexican Caribbean. Proceedings of the $4^{\text {th }}$ International Coral Reef Symposium 2:303-308.

Jordán-Garza, A.G., Maldonado, M.A., Baker, D.M., \& Rodríguez-Martínez, R.E. 2008. High abundance of Diadema antillarum on a Mexican Reef. Coral Reefs 27(2):295. doi: 10.1007/s00338-007-0338-3.

Keller, B.D., Gleason, D.F., McLeod, E., Woodley, C.M., Airamé, S., Causey, B.D., Friedlander, A.M., Grober-Dunsmore, R., Johnson, J.E., Miller, S.L., \& Steneck, R.S. 2009. Climate change, coral reef ecosystems, and management options for marine protected areas. Environmental Management 44:1069-1088.

Kennedy, P., Kennedy, H., \& Papadimitriou, S. 2005. The effect of acidification on the determination of organic carbon, total nitrogen and their stable isotopic composition in algae and marine sediment. Rapid Communications in Mass Spectrometry. 19:10631068.

Knowlton, N. 1992. Thresholds and multiple stable states in coral reef community dynamics. American Zoology 32:674-682.

Knowlton, N. 2001. The future of coral reefs. PNAS 98(10):5419-5425.

Knowlton, N. 2004. Mutliple "stable" states and the conservation of marine ecosystems. Progress in Oceanography. 60:387-396. 
Knowlton, N. \& Jackson, J.B. 2008. Shifting baselines, local impacts, and global change on coral reefs. PLoS Biology 6(2): e54.

Lapointe, B.E. 1997. Nutrient thresholds for bottom-up control of macroalgal blooms on coral reefs in Jamaica and southeast Florida. Limnology and Oceanography 42(5):11191131.

Lapointe, B.E., Littler, M.M., \& Littler, D.S. 1987. A comparison of nutrient-limited productivity in macroalgae from a Caribbean barrier reef and from a mangrove ecosystem. Aquatic Botany 28:243-255.

Lapointe, B.E., Littler, M.M., \& Littler, D.S. 1992. Nutrient availability to marine macroalgae in siliciclastic versus carbonate-rich coastal waters. Estuaries 15(1):75-82.

Lapointe, B.E., Barile, P.J., Littler, M.M., \& Littler, D.S. 2005. Macroalgal blooms on southeast Florida coral reefs II. Cross-shelf discrimination of nitrogen sources indicates widespread assimilation of sewage nitrogen. Harmful Algae 4:1106-1122.

Lapointe, B.E., Langton, R., Bedford, B.J., Potts, A.C., Day, O., Hu, C., 2010. Landbased nutrient enrichment of the Buccoo Reef Complex and fringing coral reefs of Tobago, West Indies. Marine Pollution Bulletin 60:334-343.

Ledlie, M.H., Graham, N.J., Bythell, J.C., Wilson, S.K., Jennings, S., Polunin, N.C., \& Hardcastle, J. 2007. Phase shifts and the role of herbivory in the resilience of coral reefs. Coral Reefs 26:641-654.

Lessios, H.A. 1988. Mass mortality of Diadema antillarum in the Caribbean: what have we learned? Annual Review of Ecology and Systematics 19: 371-393.

Lester, S.E. \& Halpern, B.S. 2008. Biological responses in marine no-take reserves versus partially protected areas. Marine Ecology Progress Series 367:49-56.

Lirman, D. 1999. Reef fish communities associated with Acropora palmata: relationships to benthic attributes. Bulletin of Marine Science 65(1):235-252.

Littler, M.M. \& Littler, D.S. 1984. Models of tropical reef biogeneiss: the contribution of algae. In: Round, F.E. \& Chapman, D.J., editors. Progress in Phycological Research Volume 3. Biopress, Bristol. pp 323-364.

Littler, M.M. \& Littler, D.S. 1997. Disease-induced mortality of crustose coralline algae on coral reefs provides rationale for the conservation of herbivorous fish stocks.

Proceedings of the $8^{\text {th }}$ International Coral Reef Symposium 1:719-724.

Littler, M.M., Littler, D.S., \& Brooks, B.L. 2006. Harmful algae on tropical coral reefs: Bottom-up eutrophication and top-down herbivory. Harmful Algae 5:565-585. 
Littlter, M.M. \& Littler, D.S. 2007. Assessment of coral reefs using herbiovry/nutrient assays and indicator groups of benthic primary producers: a critical synthesis, proposed protocols, and critique of management strategies. Aquatic Conservation: Marine and Freshwater Ecosystems 17: 195-215.

Loya, Y. 2004. The coral reefs of Eilat - past, present and future: three decades of coral community structure studies. In: Rosenberg, E., Loya, Y, editors. Coral Reef Health and Disease. Springer, Berlin.

Maldonado Cuevas, M.A. 2008. Evaluación de la condición de las comunidades coralinas que se desarrollan en sitios de visita, destinados al uso turístico semi-intensivo, dentro de las Unidades Arrecífales del Parque Nacional Arrecife de Puerto Morelos. Report prepared for the Parque Nacional Arrecife de Puerto Morelos, Puerto Morelos, Mexico.

Maynard, J.A., Marshall, P.A., Johnson, J.E., \& Harman, S. 2010a. Building resilience into practical conservation: identifying local management responses to global climate change in the southern Great Barrier Reef. Coral Reefs 29:381-391.

Maynard, J.A., Anthony, K.R., Afatta, S., Dahl-Tacconi, N., \& Hoegh-Guldberg, O. 2010b. Making a model meaningful to coral reef managers in a developing nation: a case study of overfishing and rock anchoring in Indonesia. Conservation Biology 24(5):13161326.

MBRS (Mesoamerican Barrier Reef Systems Project). 2003. Manual of methods for the MBRS synoptic monitoring program: Selected methods for monitoring physical and biological parameters for use in the Mesoamerican region. Mesoamerican Barrier Reef Systems Project Coordinating Unit, Belize City, Belize.

McCook, L.J. 1999. Macroalgae, nutrients and phase shifts on coral reefs: scientific issues and management consequences for the Great Barrier Reef. Coral Reefs 18:357367.

McCook, L.J., Jompa, J., \& Diaz-Pulido, G. 2001. Competetion between corals and algae on coral reefs: a review of evidence and mechanisms. Coral Reefs 19:400-417.

McCook, L.J., Ayling, T., Cappo, M., Choat, J.H., Evans, R.D., De Freitas, D.M., Heupel, M., Hughes, T.P., Jones, G.P., Mapstone, B., et al. 2010. Adaptive management of the Great Barrier Reef: A globally significant demonstration of the benefits of networks of marine reserves. PNAS Early Edition.

McClanahan, T.R., 1994. Kenyan coral reef lagoon fish: effects of fishing, substrate complexity, and sea urchins. Coral Reefs 13:231-241. 
McClanahan, T.R., Cokos, B.A., Sala, E. 2002. Algal growth and species composition under experimental control of herbivory, phosphorus and coral abundance in Glovers Reef, Belize. Marine Pollution Bulletin 44:441-451.

McManus, J.W. \& Polsenberg, J.F. 2004. Coral-algal phase shifts on coral reefs: ecological and environmental aspects. Progress in Oceanography 60: 263-279.

Moberg, F. \& Folke, C. 1999. Ecological goods and services of coral reef ecosystems. Environmental Economics 29:215-233.

Morris, J.A., Akins, J.L., Barse, A., Cerino, D., Freshwater, D.W., Green, S.J., Muñoz, R.C., Paris, C., \& Whitfield, P.E. 2010. Biology and Ecology of the invasive lionfishes, Pterois miles and Pterois volitans. Proceedings of the $61{ }^{\text {st }}$ Gulf and Caribbean Fisheries Institute.

Mumby, P. J. 2006. The impact of exploiting grazers (scaridae) on the dynamics of Caribbean coral reefs. Ecological Applications 16:747-769.

Mumby, P.J. 2009. Phase shifts and the stability of macroalgal communities on Caribbean coral reefs. Coral Reefs 28:761-773.

Mumby, P.J. \& Harborne, A.R. 2010. Marine reserves enhance the recovery of corals on Caribbean reefs. PLos ONE 5(1)e8657. doi:10.1371/journal.pone.0008657

Mumby, P. J., Harborne, A.R., Williams, J., Kappel, C.V., Brumbaugh, D.R., Micheli, F., Holmes, K.E., Dahlgren, C.P., Paris, C.B., \& Blackwell, P.G. 2007. Trophic cascade facilitates coral recruitment in a marine reserve. Proceedings of the National Academy of Sciences of the United States of America 104:8362-8367.

Mumby, P.J. \& Steneck, R.S. 2008. Coral reef management and conservation in light of rapidly evolving ecological paradigms. Trends in Ecology and Evolution 23(23): 555563.

Murray, G. 2007. Constructing paradise: the impacts of big tourism in the Mexican coastal zone. Coastal Management 35:339-355.

Mutchler, T., Dunton, K.H., Townsend-Small, A., Fredriksen, S., Rasser, M.K., 2007. Isotopic and elemental indicators of nutrient sources and status of coastal habitats in the Caribbean Sea, Yucatan Peninsula, Mexico. Estuarine, Coastal and Shelf Science 74:449457.

NRC (National Research Council). 2001. Marine Protected Areas: Tools for Sustaining Ocean Ecosystems. National Academy Press, Washington, D.C. 
Nyström, M., Folke, C., \& Moberg, F. 2000. Coral reef disturbance and resilience in a human-dominated environment. Trends in Ecological Evolution 15: 413-417.

Paddack, M.J., Cowen, R.K., \& Sponaugle, S. 2006. Grazing pressure of herbivorous coral reef fishes on low coral-cover reefs. Coral Reefs 25:461-472.

Patterson, K.L., Porter, J.W., Ritchie, K.B., Polson, S.W., Mueller, E. Peters, E.C., Santavy, D.L., \& Smith, G.W. 2002. The etiology of white pox, a lethal disease of the Caribbean elkhorn coral, Acropora palmata. PNAS 99(13):8725-8730.

Paytan, A., Shellenbarger, G.G., Street, J.H., Conneea, M.E., Davis, K., Young, M.B., Moore, W.S., 2006. Submarine groundwater discharge: an important source of new organic nitrogen to coral reef ecosystems. American Society of Limnology and Oceanography 51(1):343-348.

Paul, V.J. 1992. Seaweed chemical defenses on coral reefs. In: Paul, V. J. (ed.) Ecological roles of marine natural products. Cornell University Press, New York, p. 2450 .

Peters, E.C. 1984. A survey of cellular reactions to environmental stress and disease in Caribbean scleractinian corals. Helgoländer Meeresunters 37:113-137.

Peckol, P.M., Curran, H.A., Floyd, E.Y., Robbart, M.L., Greenstien, B.J., \& Buckman, K.L. 2003. Assessment of selected reef sites in northern and south-central Belize, including recovery from bleaching and hurricane disturbances (stony corals, algae and fish). Pp. 146-171 in Lang J.C. (Ed), Status of Coral Reefs in the western Atlantic: Results of initial Surveys, Atlantic and Gulf Rapid Reef Assessment (AGRRA) Program. Atoll Research Bulletin 496.

Plathong, S., Inglis, G.J., \& Huber, M.E., 2000. Effects of self-guided snorkeling trails on corals in a tropical marine park. Conservation Biology 14(6):1821-1830.

Potts, D.C. 1977. Suppression of coral populations by filamentous algae within damselfish territories. Journal of Experimental Marine Biology and Ecology 28:207-216.

Randall, J.E. 1967. Food habits of reef fishes of the West Indies. Studies in Tropical Oceanography 5:665-847

Reaka-Kudla, M.L. 1996. The Global Biodiversity of Coral Reefs: A Comparison with Rain forests. Pages 83-93 in Reaka-Kudla, M.L, Wilson, D.E., \& Wilson, E.O, editors. Biodiversity II: Understanding and Protecting Our Biological Resources. Joseph Henry Press, Washington D.C. USA. 
Rentería, R. F., Van Tussenbroek, B. I., \& Jordán-Dahlgren, E. 1998. Puerto Morelos, Quintana Roo, México. In: Caribbean Coral Reef, seagrass and mangrove sites. B. Kjerve (Ed). 57-66. UNESCO, Paris.

Reopanichkul, P., Schlacher, T.A., Carter, R.W., \& Worachananant, S., 2009. Sewage impacts coral reefs at multiple levels of ecological organization. Marine Pollution Bulletin 58: 1356-1362.

Reyes Bonilla, H. 2009. Estudio para establecer la capacidad de carga turística y límites de cambio acceptable par alas actividades recreativas del Parque Nacional Arrecife de Puerto Morelos. Final Report. Universidad Autónoma de Baja California Sur, Baja California Sur, Mexico.

Risk, M.J. 2009. The reef crisis and the reef science crisis: Nitrogen isotopic ratios as an objective indicator of stress. Marine Pollution Bulletin 58:787-788.

Risk, M.J. Lapointe, B.E., Sherwood, O.A., \& Bedford, B.J. 2009. The use of $\delta^{15} \mathrm{~N}$ in assessing sewage stress on coral reefs. Marine Pollution Bulletin 58:793-802.

Rodríguez-Martínez, R. E. 2008. Community involvement in marine protected areas: the case of Puerto Morelos reef, Mexico. Journal of Environmental Management 88:11511160 .

Rodríguez-Martínez, R.E., Ruíz-Rentería, F., van Tussenbroek, B., Barba-Santos, G., Escalante-Mancera, E., Jordán-Garza, G., \& Jordán-Dahlgren, E. 2010. Environmental state and tendencies of the Puerto Morelos CARICOMP site, Mexico. Revista de Biología Tropical 58:23-43.

Rouphael, A.B. \& Inglis, G.J., 1997. Impacts of recreational scuba diving at sites with different reef topographies. Biological Conservation 82:329-336.

Rouphael, A.B. \& Inglis G.J., 2001. “Take only photographs and leave only footprints"?: An experimental study of the impacts of underwater photographers on coral reef dive sites. Biological Conservation 100:281-287.

Sammarco, P.W. 1982. Effects of grazing by Diadema antillarum Philippi (Echinodermata: Echinoidea) on algal diversity and community structure. Journal of Experimental Marine Biology and Ecology. 65:83-105.

Sandin, S.A., Sampayo, E.M., \& Vermeij, M.A. 2008. Coral reef fish and benthic community structure of Bonaire and Curaçao, Netherlands Antilles. Caribbean Journal of Science 44(2):137-144.

Scheffer, M., Carptenter, S., Foley, J.A., Folke, C., \& Walker, B. 2001. Catastrophic shifts in ecosystems. Nature 413:591-596. 
Schutte, V.W., Selig, E.R., \& Bruno, J.F. 2010. Regional spatio-temporal trends in Caribbean coral reef benthic communities. Marine Ecology Progress Serios 402:115-122. doi:10.3354/meps08438.

Shimoda, T., Ichikawa, T., \& Mastukawa, y. 1998. Nutrient conditons and their effects on coral growth in reefs around Ryukyu Islands. Bulletin of the National Research Institute of Fisheries Science 12:71-80.

Shiganova T.A. 1998. Invasion of the Black Sea by the ctenophore Mnemiopsis leidyi and recent changes in the pelagic community structure. Fisheries Oceanography 7:305-301.

Sobel, J.A. \& Dalgren, C.P. 2004. Marine reserves: a guide to science, design and use. Island Press, Washington, D.C.

Soong, K. 1993. Colony size as a species character in massive reef corals. Coral Reefs $12: 77-83$.

Steinberg, P.D. 1992. Geographical variation in the interac- tion between marine herbivores and brown algal secondary metabolites. In: Paul, V. J. (ed.) Ecological roles of marine natural products. Cornell University Press, New York, p. 51-92.

Taylor, B.M \& McIlwain, J.L., 2010. Beyond abundance and biomass: effects of marine protected areas on the demography of a highly exploited reef fish. Marine Ecology Progress Series 441:243-258.

Tratalos, J.A. \& Austin, T.J., 2001. Impacts of recreational SCUBA diving on coral communities of the Caribbean island of Grand Cayman. Biological Conservation 102:6775.

Torres, J.L. \& Morelock, J. 2002. Effect of terrigenous sediment influx on coral cover and linear extension rates of three Caribbean massive coral species. Caribbean Journal of Science 28(3-4):222-229.

Umezawa, Y., Miyajima, T., Yamamuro, M., Kayanne, H., \& Koike, I. 2002. Fine-scale mapping of land-derived nitrogen in coral reefs by $\delta^{15} \mathrm{~N}$ in macroalgae. Limnology and Oceanography 47(5):1405-1416.

Wilkinson, C.R. 1999. Global and local threats to coral reef functioning and existence: review and predictions. Marine Freshwater Resources 50:867-878.

Wilson, S. K., Graham, N. J., Polunin, N. C., 2007. Appraisal of visual assessments of habitat complexity and benthic composition on coral reefs. Marine Biology 151:10691076. 
Wilson, S.K., Adjeroud, M., Bellwood, D.R., Berumen, M.L., Booth, D., -Marie Bozec, Y., Chabanet, P., Cheal, A., Depczynski, M., \& Feary, D.A. 2010. Crucial knowledge gaps in current understanding of climate change impacts on coral reef fishes. The Journal of Experimental Biology 213: 894-900.

Winemiller, K.O. \& Rose, K.A. 1992. Patterns of life-history diversification in North American fishes - implications for population regulation. Canadian Journal of Fisheries and Aquatic Sciences 49:2196-2218.

Wong, J.C., Chan, C.Y., \& Cheung, K.C. 1998. Nitrogen and phosphorus leaching from fertilizer applied on golf course - Lysimeter study. Water, Air and Soil Pollution 107:335-345.

Wunder, S. 2006. Are direct payments for environmental services spelling doom for sustainable forest management in the tropics? Ecology and Society 11(2): 23.

Young, M.B., Gonneea, M.E., Fong, D.A., Moore, W.S., Herrera-Silveira, J., Paytan, A., 2008. Characterizing sources of groundwater to a tropical coastal lagoon in a karstic area using radium isotopes and water chemistry. Marine Chemistry 109:377-394.

Zakai, D. \& Chadwick-Furman, N.E., 2002. Impacts of intensive recreational diving on reef corals at Eilat, northern Red Sea. Biological Conservation 105: 179-187. 
Appendix A: Architectural Index - Coral morphologies and form-function scores

\begin{tabular}{|c|c|c|c|c|}
\hline Species & Authority & Weight & $\begin{array}{l}\text { Form (McCook } \\
\text { et al., 2001) }\end{array}$ & Notes \\
\hline Agaricia agaricites & Linnaeus 1758 & 1 & Foliose & Plate \\
\hline A. tenuifolia & Dana 1848 & 1 & Foliose & $\begin{array}{l}\text { Plate/small } \\
\text { projections }\end{array}$ \\
\hline Diploria strigosa & Dana 1848 & 1 & Massive & Medium sized \\
\hline Montastrea cavernosa & Linnaeus 1766 & 1 & Massive & Medium sized \\
\hline Porites astreoides & Lamarck 1816 & 1 & Massive & Medium sized \\
\hline Siderastraea siderea & Ellis 1786 & 1 & Massive & Medium sized \\
\hline M. annularis & Ellis 1786 & 2 & Massive & Large sized \\
\hline M. faveolata & Ellis 1786 & 2 & Massive & Large sized \\
\hline Acropora palmata & Lamarck 1816 & 3 & Branching & $\begin{array}{l}\text { High degree of 3-D } \\
\text { complexity }\end{array}$ \\
\hline
\end{tabular}


Appendix B: Fish diet group classification

\begin{tabular}{|c|c|c|c|}
\hline Family & Species & Authority & Diet \\
\hline \multirow[t]{3}{*}{ Acanthuridae } & Acanthurus bahianus & Castelnau, 1855 & $\mathrm{H}$ \\
\hline & A. coeruleus & Bloch \& Schneider, 1801 & $\mathrm{H}$ \\
\hline & A. chirurgus & Bloch, 1787 & $\mathrm{H}$ \\
\hline \multirow[t]{3}{*}{ Chaetodontidae } & Chaetodon capistratus & Linnaeus, 1758 & B \\
\hline & C. ocellatus & Bloch, 1787 & B \\
\hline & C. striatus & Linnaeus, 1758 & B \\
\hline Pomacanthidae & Pomacanthus paru & Bloch, 1787 & B \\
\hline \multirow[t]{10}{*}{ Pomacentridae } & Abudefduf saxatilis & Linnaeus, 1758 & B \\
\hline & Chromis cyaneus & Poey, 1860 & PK \\
\hline & Microspathodon chrysurus & Cuvier, 1830 & $\mathrm{H}$ \\
\hline & Stegastes fuscus & Troschel, 1865 & $\mathrm{H}$ \\
\hline & S. adustus & Jordan \& Rutter, 1987 & $\mathrm{H}$ \\
\hline & S. diencaeus & Cuvier, 1830 & $\mathrm{H}$ \\
\hline & S. leucostictus & Müller \& Troschel, 1848 & $\mathrm{O}$ \\
\hline & S. partitus & Poey, 1868 & $\mathrm{H}$ \\
\hline & S. planifrons & Cuvier, 1830 & $\mathrm{O}$ \\
\hline & S. variabilis & Castelnau, 1855 & $\mathrm{H}$ \\
\hline \multirow[t]{10}{*}{ Scaridae } & Scarus coelestinus & Bloch \& Schneider, 1801 & $\mathrm{H}$ \\
\hline & S. guacamaia & Cuvier, 1829 & $\mathrm{H}$ \\
\hline & S. iserti & Bloch, 1789 & $\mathrm{H}$ \\
\hline & S. taeniopterus & Desmarest, 1831 & $\mathrm{H}$ \\
\hline & S. vetula & Bloch \& Schneider, 1801 & $\mathrm{H}$ \\
\hline & Sparisoma atomarium & Poey, 1861 & $\mathrm{H}$ \\
\hline & S. aurofrenatum & Valenciennes, 1840 & $\mathrm{H}$ \\
\hline & S. chrysopterum & Bloch \& Schneider, 1801 & $\mathrm{H}$ \\
\hline & S. rubripinne & Valenciennes, 1840 & $\mathrm{H}$ \\
\hline & S. viride & Bonnaterre, 1788 & $\mathrm{H}$ \\
\hline \multirow[t]{5}{*}{ Serranidae } & Cephalopholis cruentata & Lacepède, 1802 & PI \\
\hline & Epinephelus cruentatus & Lacepède, 1802 & PI \\
\hline & E. fulvus & Linnaeus, 1758 & PI \\
\hline & E. guttatus & Linnaeus, 1758 & PI \\
\hline & Mycteroperca & Valenciennes, 1828 & $\mathrm{P}$ \\
\hline \multirow[t]{3}{*}{ Lutjanidae } & Lutjanus apodus & Walbaum, 1792 & PI \\
\hline & L. griseus & Linnaeus, 1758 & $\mathrm{P}$ \\
\hline & L. jocu & Bloch \& Schneider, 1801 & PI \\
\hline
\end{tabular}


L. mahogoni

L. synagris

Ocyurus chrysurus

Haemulidae

Balistidae

Aulostomidae

Labridae

Monacanthidae

Tetraodontidae

Carangidae

Dasyatidae

Gerreidae

Grammatidae

Holocentridae

Kyphosidae

Ostraciidae

Mullidae

Scorpaenidae

Sphyraenidae

Urolophidae

Muraenidae
Anisotremus virginicus

Haemulon carbonarium

H. chrysargyreum

H. flavolineaturm

H. macrostomun

H. parra

H. plumieri

H. sciurus

Canthidermis sufflamen

Aulostomus maculatus

Bodianus rufus

Halichoeres bivittatus

H. gamoti

H. maculpinna

H. poeyi

H. radiatus

Lachnolaimus maximus

Thalassoma bifasciatum

Cantherhines pullus

Canthigaster rostrata

Caranx ruber

Dasyatis americana

Gerres cinereus

Gramma loreto

Holocentrus

Kyphosus

Lactoprys bicaudalis

Mulloidichthys

Pseudupeneus maculatus

Pterois volitans/miles

Sphyraena barracuda

Urolophus jamaicensis

Gymnothoras obesus
Cuvier, $1828 \quad \mathrm{P}$

Linnaeus, 1758 PI

Bloch, 1791

Linnaeus, $1758 \quad$ B

Poey, 1860 B

Günther, 1859 B

Desmarest, $1823 \quad$ B

Günther, $1859 \quad$ B

Desmarest, $1823 \quad$ B

Lacepède, $1801 \quad B$

Shaw, 1803 B

Mitchill, 1815

B

Valenciennes, $1841 \quad$ PK

Linnaeus, $1758 \quad$ B

Bloch, $1791 \quad$ B

Valenciennes, $1839 \quad$ B

Müller \& Troschel, $1848 \quad$ B

Steindachner, $1867 \quad$ B

Linnaeus, $1758 \quad$ B

Walbaum, $1792 \quad$ B

Bloch, $1791 \quad$ B

Ranzani, $1842 \quad$ O

Bloch, $1786 \quad$ O

Bloch, $1793 \quad P$

Hildebrand \& Schroeder, 1928 B

Walbaum, $1792 \quad$ B

Poey, 1868 PK

Osbeck, 1765 B

Linnaeus, 1766/Cuvier $1831 \quad \mathrm{H}$

Linnaeus, $1758 \quad$ B

Cuvier, $1829 \quad$ B

Bloch, 1793 B

Linneaus, $1758 \quad P$

Edwards, $1771 \quad P$

Cuvier, $1816 \quad$ B

Whitley, $1932 \quad \mathrm{P}$

Diet group classification for all fish identified in this study. Fish diets were determined based on the data published by Randall (1967) and Claro and Parenti (2001). 


\begin{tabular}{lc}
\hline Functional Group & Code \\
\hline Herbivore & $\mathrm{H}$ \\
Piscivore & $\mathrm{P}$ \\
Omnivore & $\mathrm{O}$ \\
Benthophage & $\mathrm{B}$ \\
Planktivore & PK \\
Piscivore and Invertebrates & PI \\
\hline Functional diet group codes. &
\end{tabular}




\section{APPENDIX C: Biomass Calculation Values by Species}

Values used for species-specific biomass calculations using the equation: $W=a L^{b}$. The mean value for each size class was utilized to calculated specific biomass estimates for each size class (i.e., $2.5 \mathrm{~cm}$ for $0-5 \mathrm{~cm}$ size class, $7.5 \mathrm{~cm}$ for $6-10 \mathrm{~cm}$ size class, etc.). Values for several species were not available (denoted by "NA" in the 'log a' column) and were excluded from biomass analysis. No values were available for $S$. adustus or $S$. diecaeus, so biomass for the species was calculated using the values for $S$. planifrons. Values from Bohnsack and Harper (1988), Bouchon-Navaro et al. (2006), Paddack et al. (2006), and Sandin et al. (2008).

\begin{tabular}{|c|c|c|c|}
\hline Species & $\log \mathbf{a}$ & $\mathbf{a}$ & b \\
\hline Abudefduf saxatilis & -4.7859 & $1.637 \mathrm{E}-05$ & 3.142 \\
\hline Acanthurus bahianus & -4.6005 & $2.509 \mathrm{E}-05$ & 2.9752 \\
\hline Acanthurus chirurgus & -5.9255 & $1.187 \mathrm{E}-06$ & 3.5328 \\
\hline Acanthurus coeruleus & -4.2165 & $6.074 \mathrm{E}-05$ & 2.8346 \\
\hline Anisotremus virginicus & -4.9963 & $1.009 \mathrm{E}-05$ & 3.1674 \\
\hline Aulostomus maculatus & NA & & \\
\hline Bodianus rufus & -4.8936 & $1.278 \mathrm{E}-05$ & 3.0532 \\
\hline Cantherhines pullus & -3.7282 & 0.000187 & 2.5632 \\
\hline Canthidermis sufflamen & -4.8095 & $1.551 \mathrm{E}-05$ & 3.0554 \\
\hline Canthigaster rostrata & -5.8424 & $1.437 \mathrm{E}-06$ & 3.6378 \\
\hline Carangoides ruber & -5.3687 & $4.279 \mathrm{E}-06$ & 3.237 \\
\hline Caranx ruber & -5.3687 & $4.279 \mathrm{E}-06$ & 3.237 \\
\hline Cephalopholis cruentata & -5.355 & $4.416 \mathrm{E}-06$ & 3.237 \\
\hline Chaetodon capistratus & -4.8475 & $1.421 \mathrm{E}-05$ & 3.1897 \\
\hline Chaetodon ocellatus & -4.482 & $3.296 \mathrm{E}-05$ & 2.9838 \\
\hline Chaetodon striatus & -4.794 & $1.607 \mathrm{E}-05$ & 3.1395 \\
\hline Chromis cyanea & -4.8921 & $1.282 \mathrm{E}-05$ & 3.1519 \\
\hline Dasyatis americana & -5.5182 & $3.032 \mathrm{E}-06$ & 2.6742 \\
\hline Epinephelus cruentatus & -5.355 & $4.416 \mathrm{E}-06$ & 3.237 \\
\hline Epinephelus fulvus & -4.6508 & $2.235 \mathrm{E}-05$ & 2.933 \\
\hline Epinephelus guttatus & -5.068 & $8.551 \mathrm{E}-06$ & 3.1124 \\
\hline Gerres cinereus & -4.8195 & $1.515 \mathrm{E}-05$ & 3.0843 \\
\hline Gramma loreto & NA & & \\
\hline Gymnothoras obesus & -6.1561 & $6.981 \mathrm{E}-07$ & 3.1577 \\
\hline Haemulon carbonarium & -4.8879 & $1.295 \mathrm{E}-05$ & 3.0559 \\
\hline Haemulon chrysargyreum & -2.5578 & 0.002768 & 2.1567 \\
\hline Haemulon flavolineatum & -5.0428 & $9.062 \mathrm{E}-06$ & 3.1581 \\
\hline Haemulon macrostomun & -4.6419 & $2.2809 \mathrm{E}-05$ & 3.0295 \\
\hline Haemulon parra & -4.6947 & $2.0198 \mathrm{E}-05$ & 2.9932 \\
\hline Haemulon plumieri & -5.0781 & 8.354E-06 & 3.1612 \\
\hline Haemulon sciurus & -4.7114 & $1.9436 \mathrm{E}-05$ & 2.9996 \\
\hline Halichoeres bivittatus & -4.8117 & $1.5428 \mathrm{E}-05$ & 2.9391 \\
\hline Halichoeres gamoti & -5.6591 & $2.192 \mathrm{E}-06$ & 3.3747 \\
\hline Halichoeres maculpinna & -6.2524 & $5.592 \mathrm{E}-07$ & 3.6932 \\
\hline Halichoeres poeyi & -4.8117 & $1.5428 \mathrm{E}-05$ & 2.9391 \\
\hline
\end{tabular}




\begin{tabular}{|lccc} 
Halichoeres radiatus & -4.9221 & $1.197 \mathrm{E}-05$ & 3.0382 \\
Holocentrus adscensionis & -3.6218 & 0.0002389 & 2.5596 \\
Kyphosus sectatrix/incisor & -4.8397 & $1.446 \mathrm{E}-05$ & 3.0801 \\
Lachnolaimus maximus & -4.6801 & $2.089 \mathrm{E}-05$ & 2.988 \\
Lactoprys bicaudalis & -2.4461 & 0.003580 & 2.0976 \\
Lutjanus apodus & -4.6909 & $2.038 \mathrm{E}-05$ & 2.9779 \\
Lutjanus griseus & -4.5159 & $3.049 \mathrm{E}-05$ & 2.8809 \\
Lutjanus jocu & -4.3683 & $4.283 \mathrm{E}-05$ & 2.8574 \\
Lutjanus mahogoni & -4.087 & $8.185 \mathrm{E}-05$ & 2.719 \\
Lutjanus synagris & -4.3452 & $4.517 \mathrm{E}-05$ & 2.8146 \\
Microspathodon chrysurus & -4.7033 & $1.980 \mathrm{E}-05$ & 3.0825 \\
Mulloidichthys martinicus & -6.3369 & $4.604 \mathrm{E}-07$ & 3.6627 \\
Mycteroperca acutirostris & -4.9169 & $1.211 \mathrm{E}-05$ & 3.0305 \\
Ocyurus chrysurus & -4.1108 & $7.748 \mathrm{E}-05$ & 2.718 \\
Pomacanthus paru & -4.8182 & $1.520 \mathrm{E}-05$ & 3.1264 \\
Pseudopeneus maculatus & -4.8231 & $1.503 \mathrm{E}-05$ & 3.0257 \\
Pterois volitans/miles & $\mathrm{NA}$ & & \\
Scarus coelestinus & -4.8764 & $1.329 \mathrm{E}-05$ & 3.0618 \\
Scarus guacamaia & -4.8714 & $1.345 \mathrm{E}-05$ & 3.0626 \\
Scarus iserti & -4.8887 & $1.292 \mathrm{E}-05$ & 3.0548 \\
Scarus taeniopterus & -4.1836 & $6.552 \mathrm{E}-05$ & 2.7086 \\
Scarus vetula & -5.0162 & $9.634 \mathrm{E}-06$ & 3.1109 \\
Sparisoma atomarium & -4.9446 & $1.136 \mathrm{E}-05$ & 3.0275 \\
Sparisoma aurofrenatum & -5.7587 & $1.743 \mathrm{E}-06$ & 3.4291 \\
Sparisoma chrysopterum & -5.1754 & $6.677 \mathrm{E}-06$ & 3.1708 \\
Sparisoma rubripinne & -4.8701 & $1.349 \mathrm{E}-05$ & 3.0641 \\
Sparisoma viride & -4.5223 & $3.004 \mathrm{E}-05$ & 2.9214 \\
Sphyraena barracuda & -5.3865 & $4.107 \mathrm{E}-06$ & 3.0825 \\
Stegastes adustus & -4.2781 & $5.271 \mathrm{E}-05$ & 2.8569 \\
Stegastes diencaeus & -4.2781 & $5.271 \mathrm{E}-05$ & 2.8569 \\
Stegastes leucostictus & -4.4057 & $3.929 \mathrm{E}-05$ & 2.8868 \\
Stegastes partitus & -4.8921 & $1.282 \mathrm{E}-05$ & 3.1519 \\
Stegastes planifrons & -4.2781 & $5.271 \mathrm{E}-05$ & 2.8569 \\
Stegastes variabilis & -4.3258 & $4.723 \mathrm{E}-05$ & 2.8365 \\
Thalassoma bifasciatum & -4.8865 & $1.299 \mathrm{E}-05$ & 2.9162 \\
Urolophus jamaicensis & -5.2244 & $5.965 \mathrm{E}-06$ & 3.0826 \\
\hline
\end{tabular}


APPENDIX D: Examples of Interactive Stressor Proxy Map Layers

Boundary of the Parque Nacional Arrecife de Puerto Morelos and study site locations.

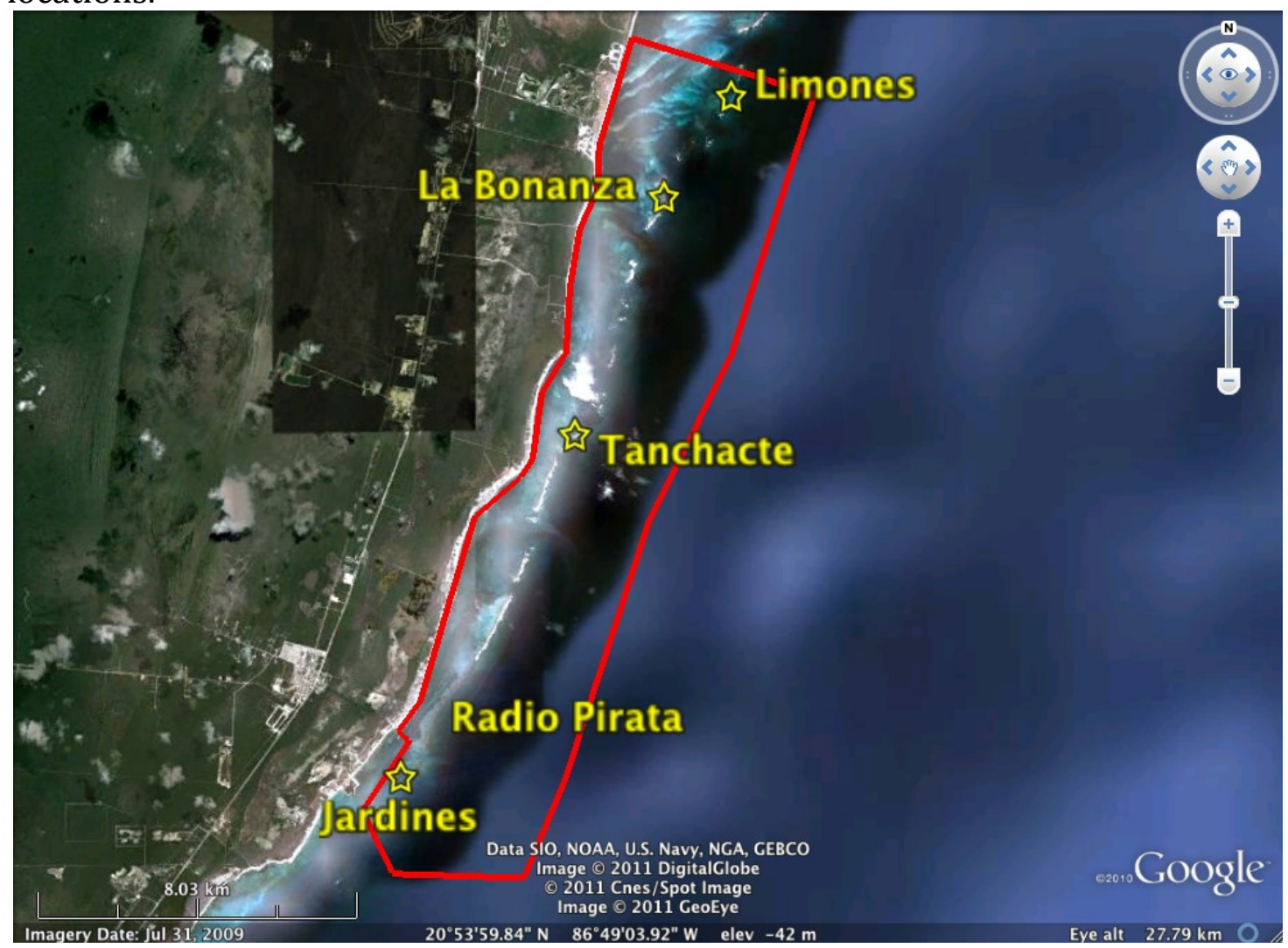


Zoning strategy of the PNAPM with study site locations.

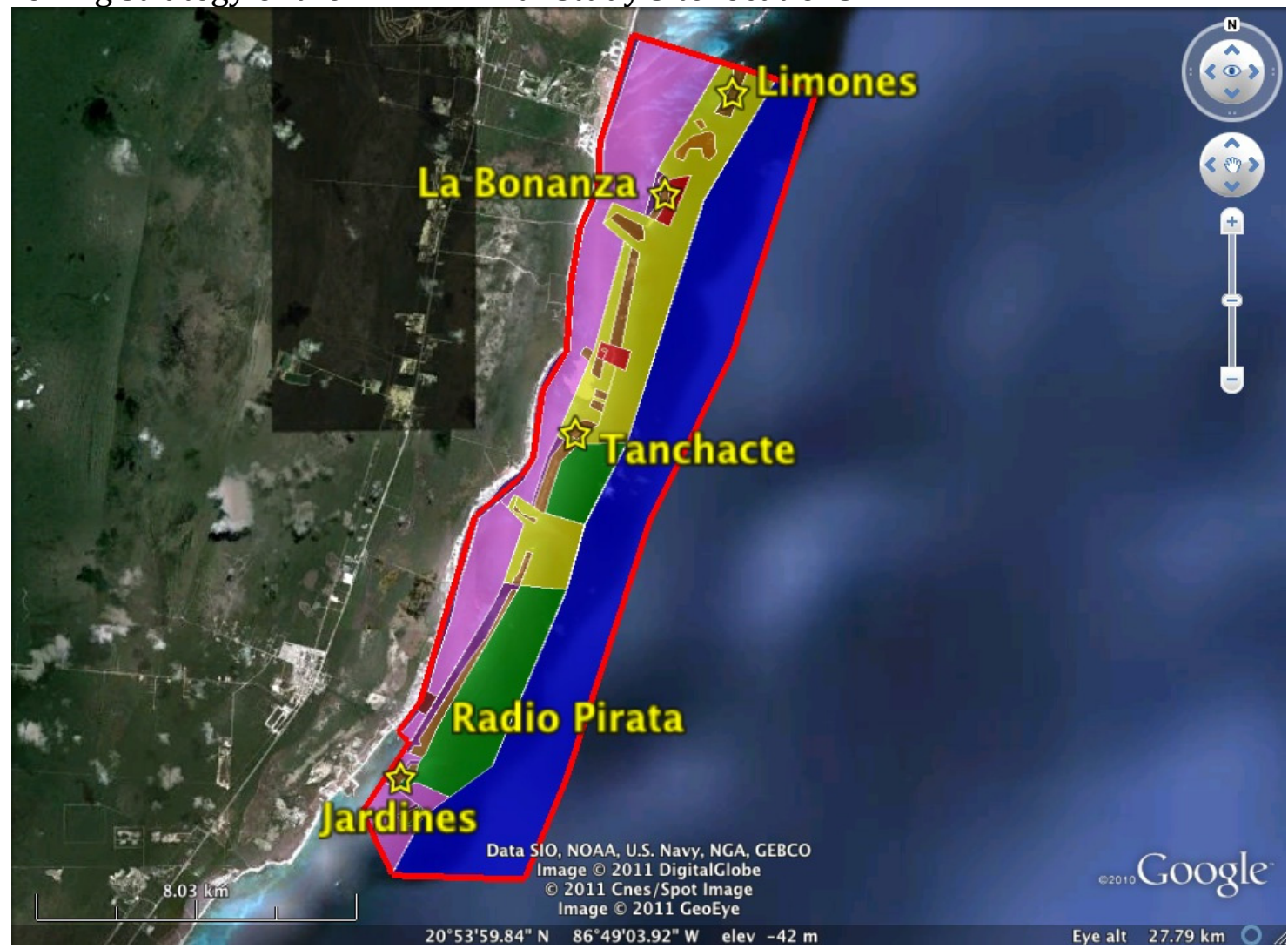


Study site locations with mooring balls distribution.

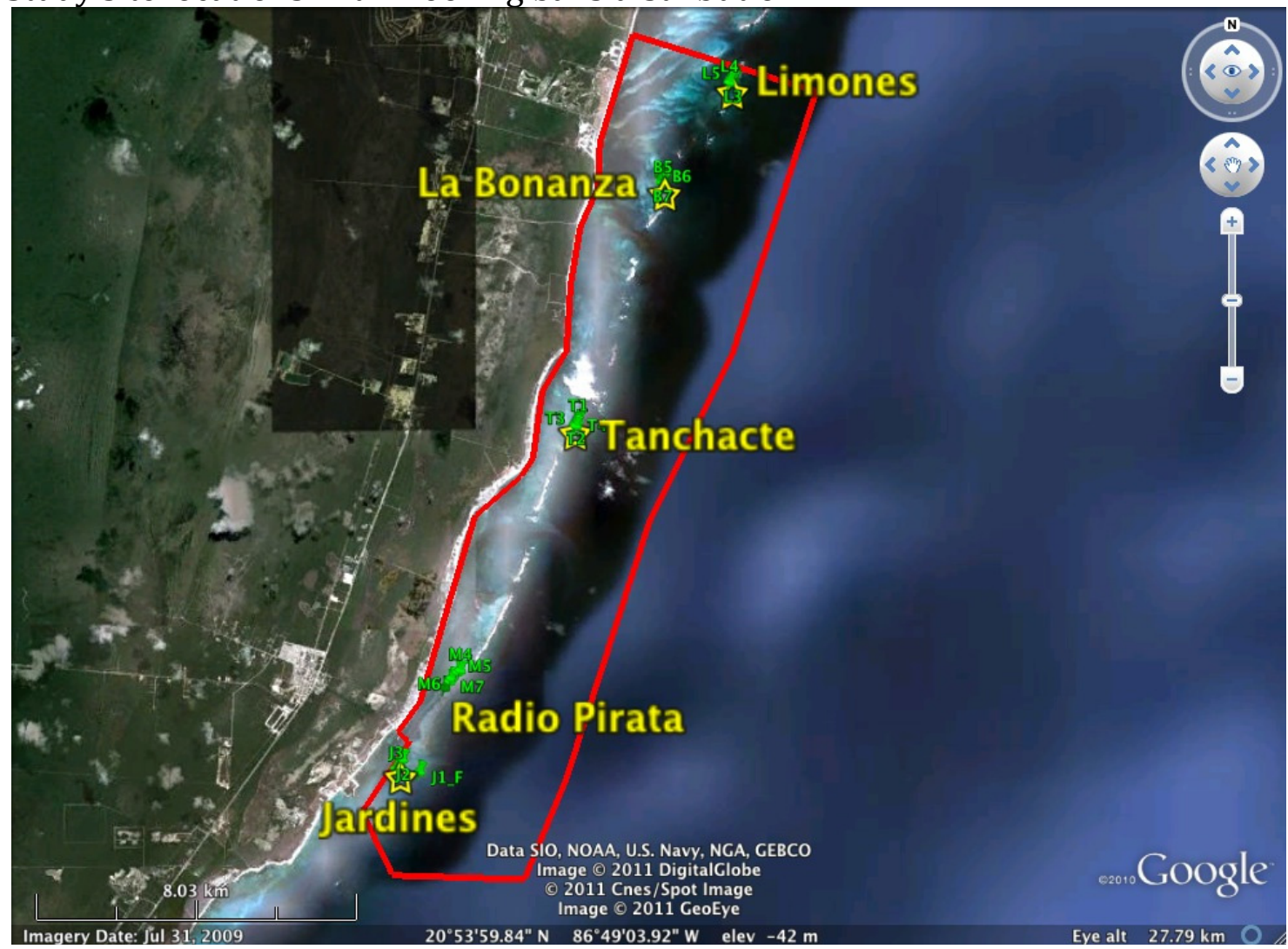


Ojo de agua distribution.

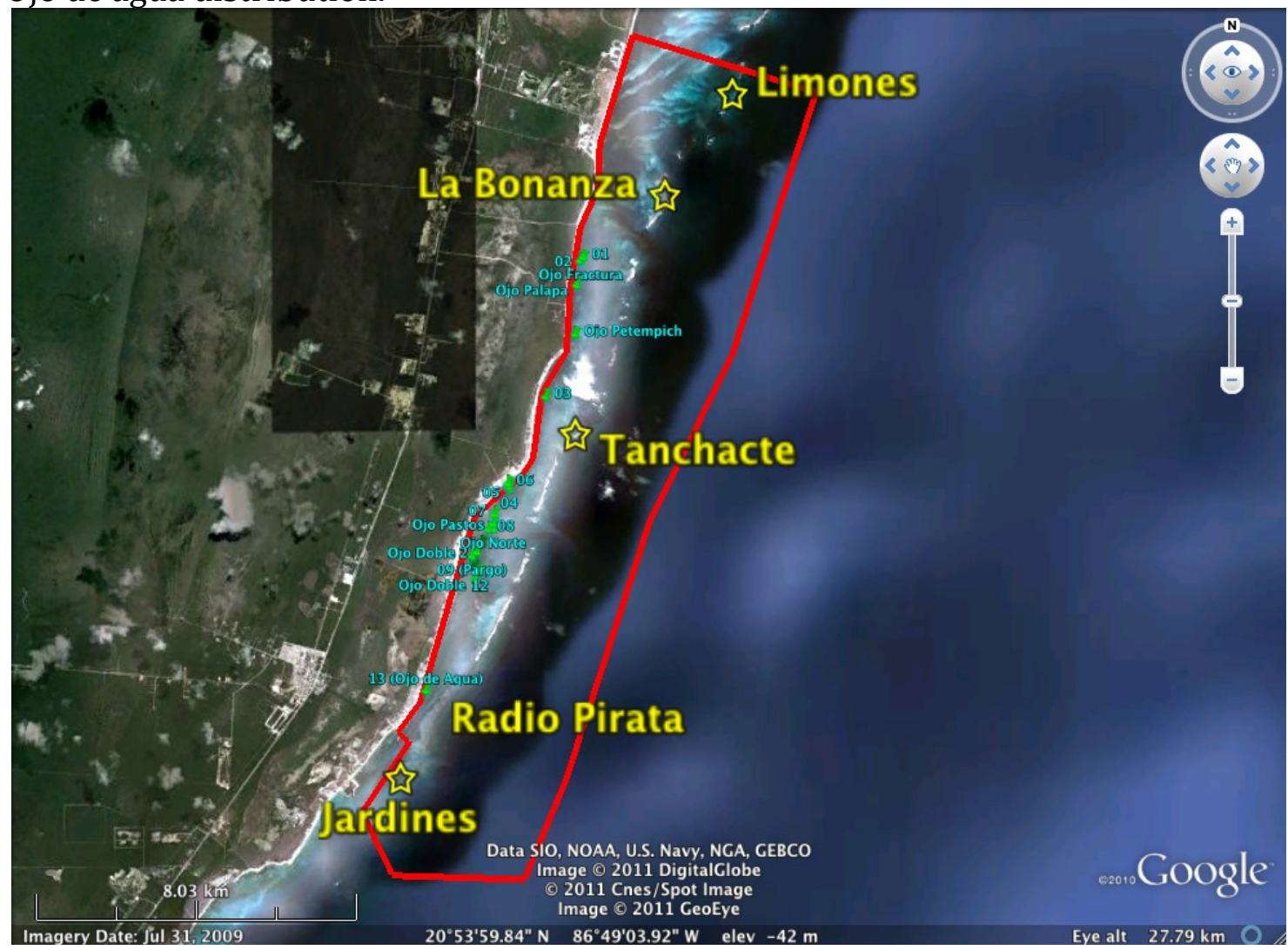


Ecological characterization and resilience index results for La Bonanza.

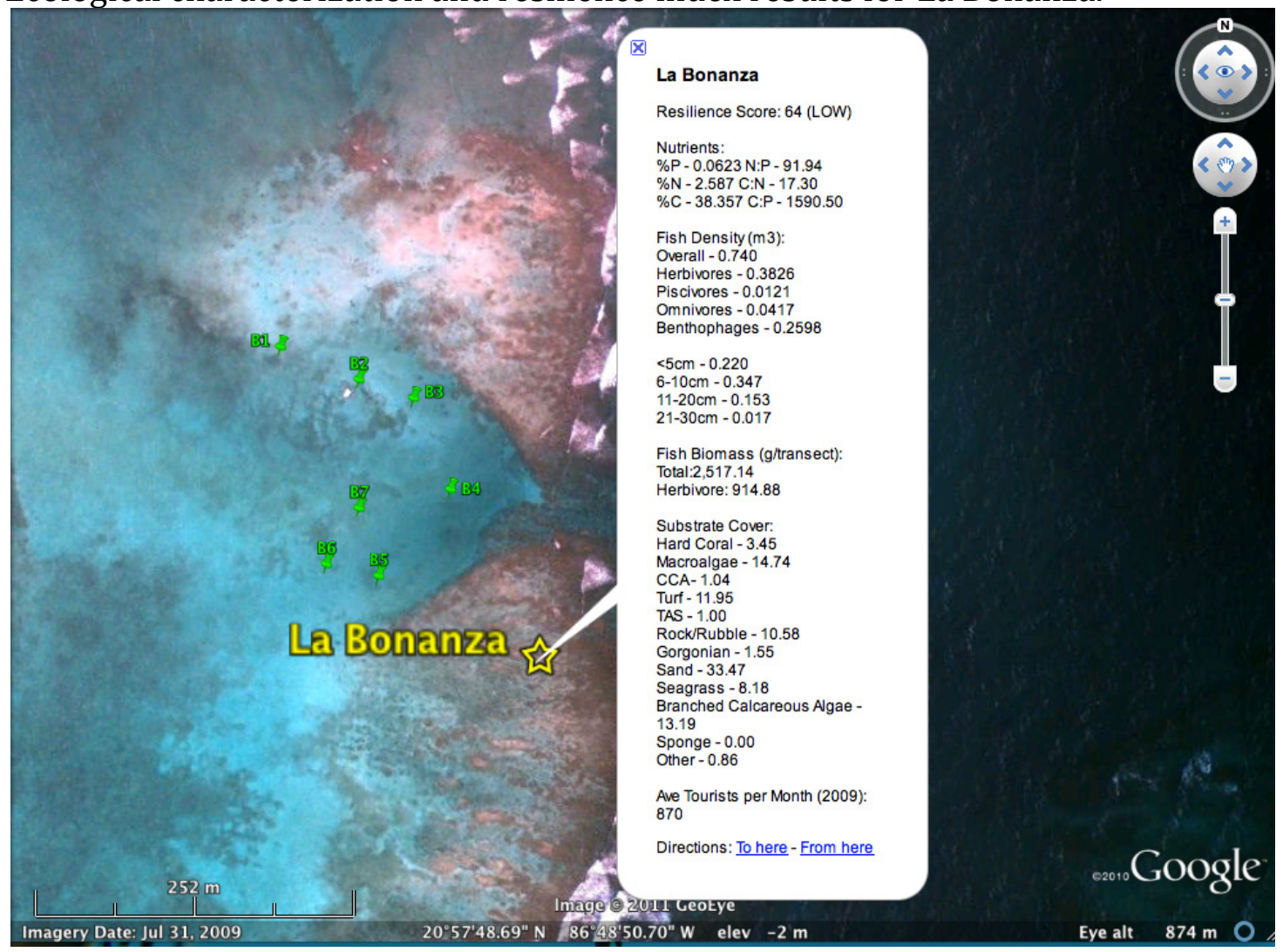


Coastal distribution and example of information available for specific hotels.

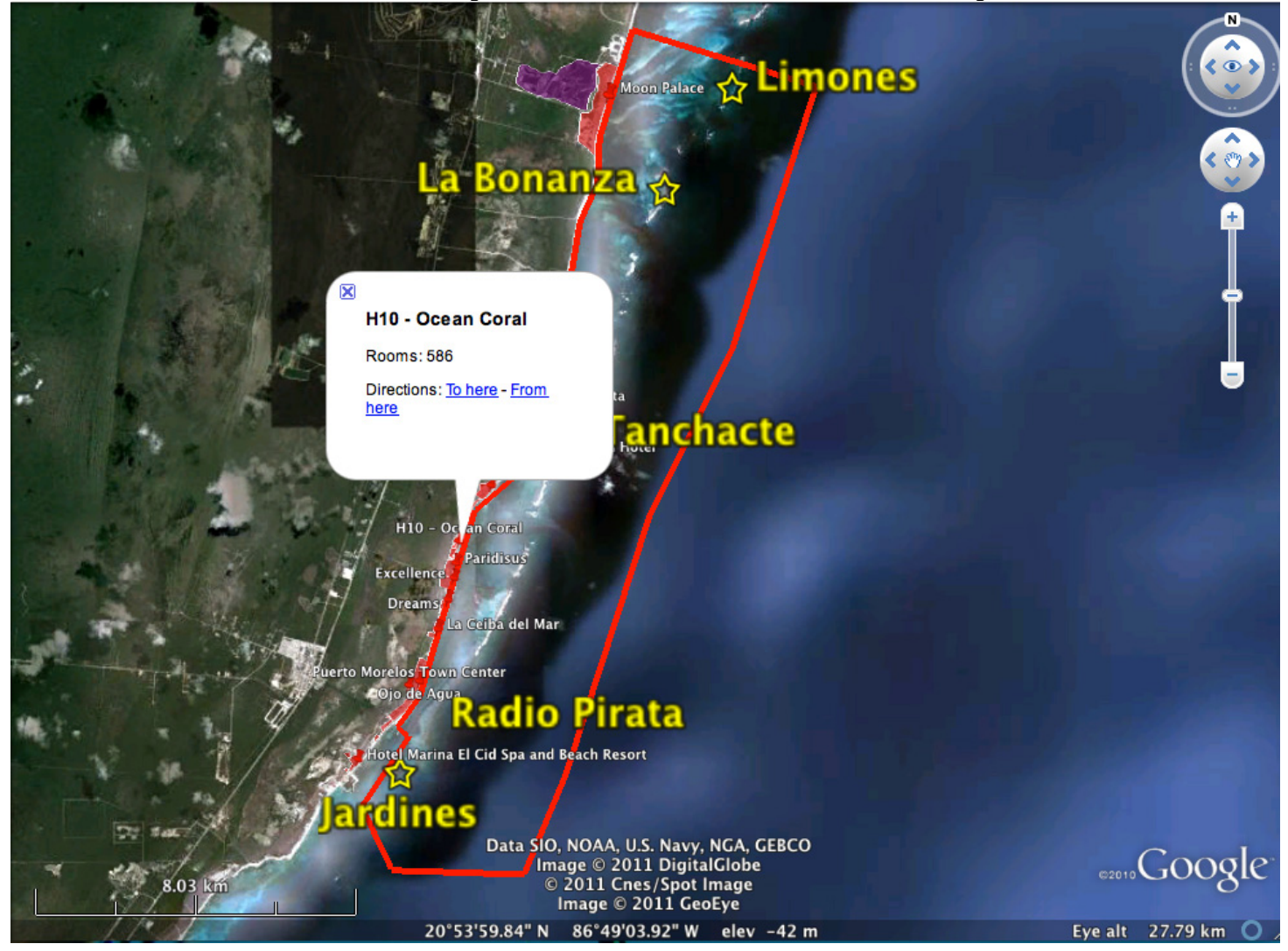


All layers of the stressor proxy map.

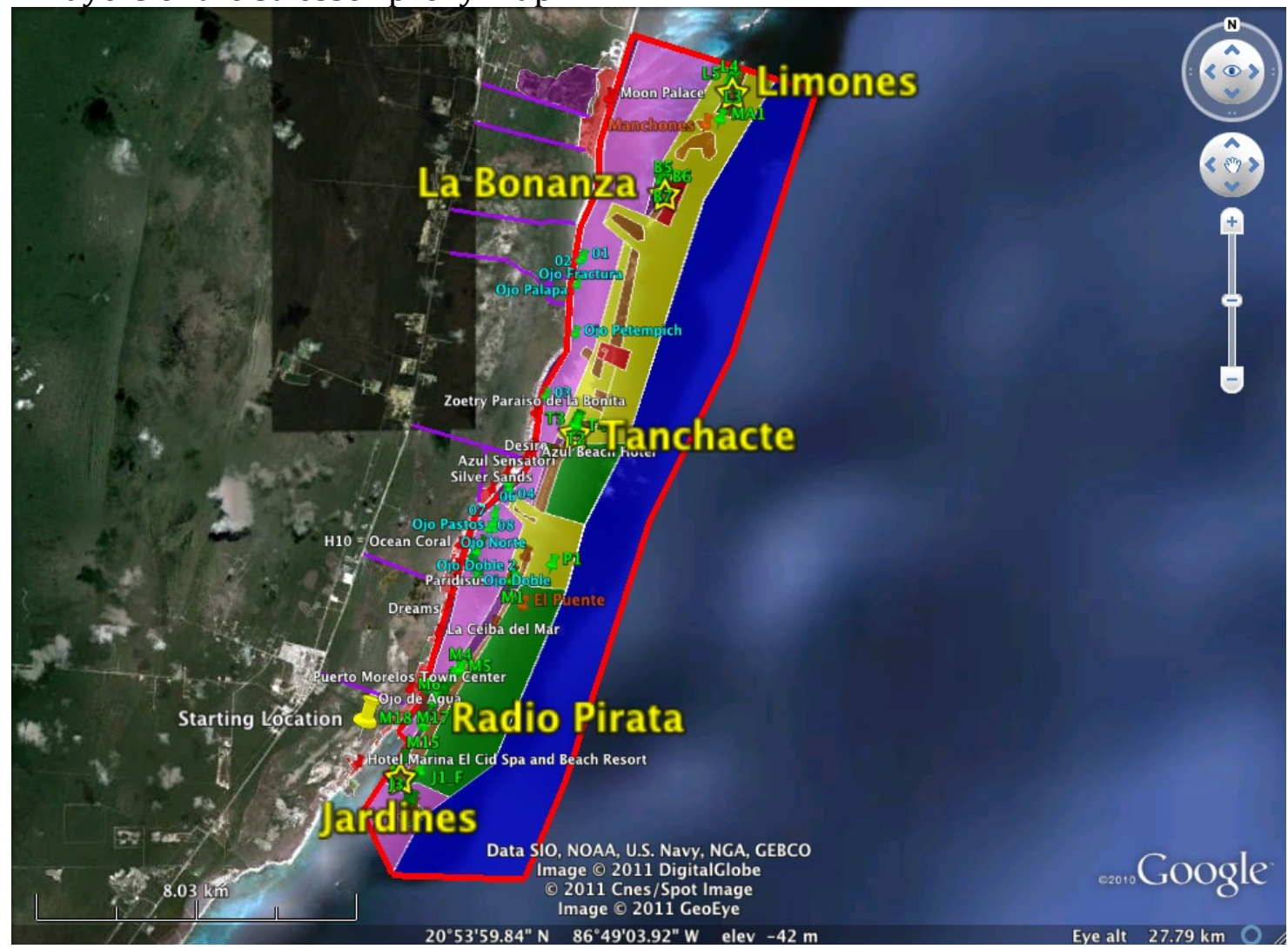


Close-up example of coastal development distribution in front of the Tanchacte study site.

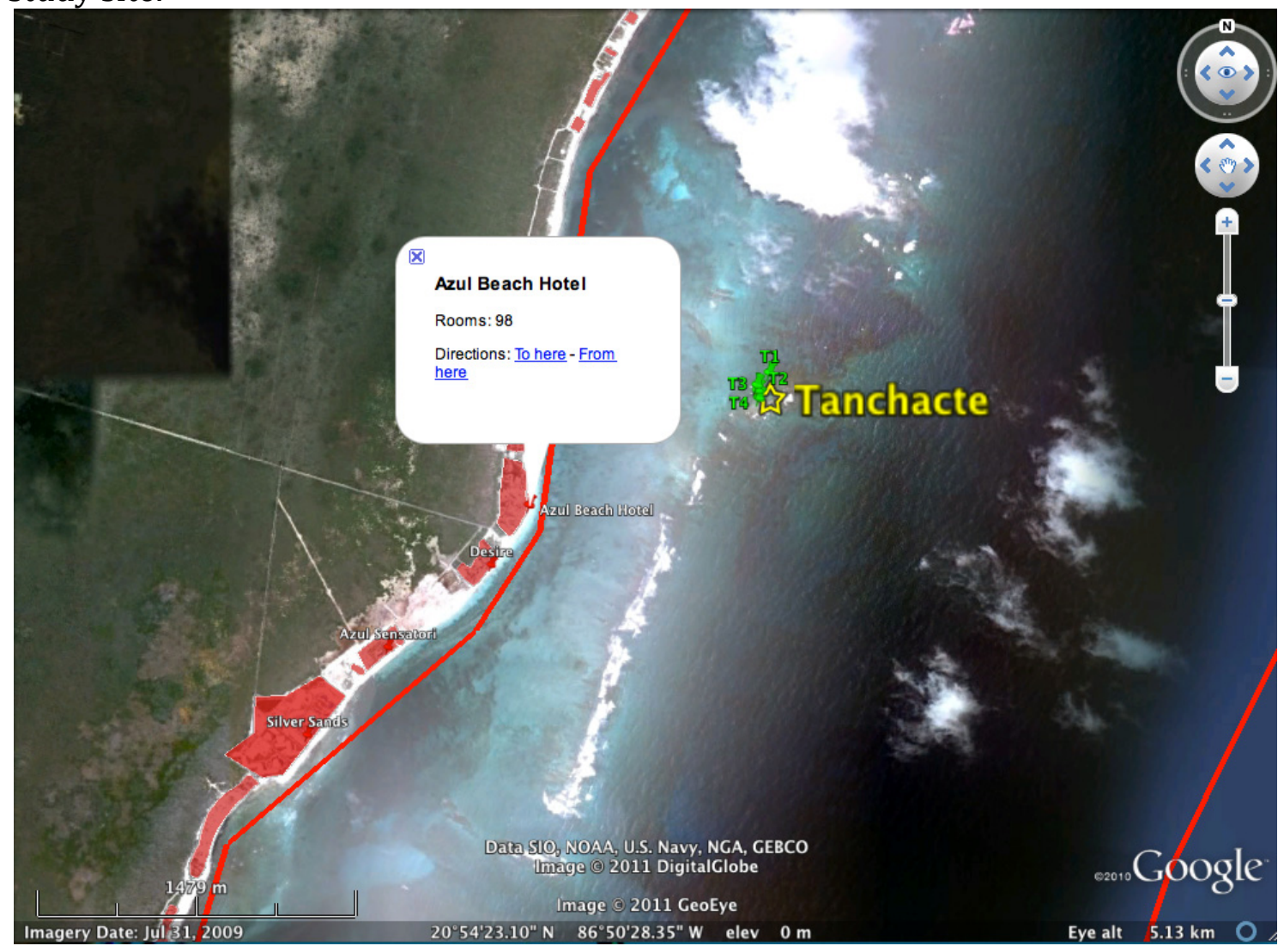

